\title{
IOT RECEIVER TECHNIQUES
}

On Filtering, Power Consumption and Phase Noise

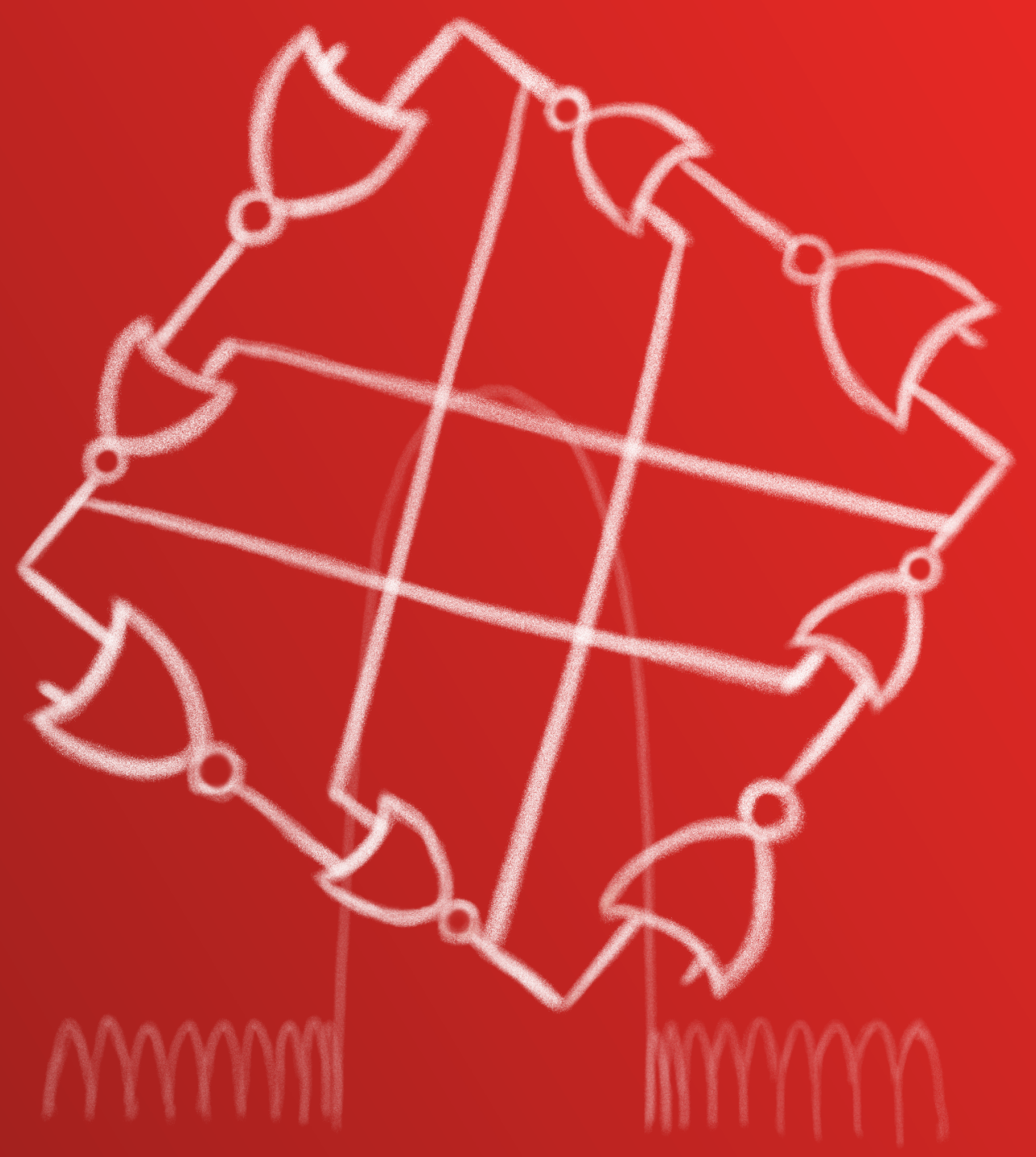

BART J. THIJSSEN 


\section{IoT Receiver Techniques}

On Filtering, Power Consumption

ANd Phase Noise

Bart J. Thijssen 
Samenstelling promotiecommissie:

Voorzitter en secretaris:

prof. dr. J.N. Kok

Universiteit Twente

Promotor:

prof. dr. ir. B. Nauta

Universiteit Twente

Co-promotor:

dr. ing. E.A.M. Klumperink

Universiteit Twente

Leden:

prof. dr. R.B. Staszewski

University College Dublin

prof. dr. ir. P.G.M. Baltus

Technische Universiteit Eindhoven

prof. dr. ir. F.E. van Vliet

Universiteit Twente

dr. ir. A.B.J. Kokkeler

Universiteit Twente

ISBN: $\quad$ 978-90-365-5122-9

DOI: $\quad$ https://doi.org/10.3990/1.9789036551229

Copyright (C) 2021 by Bart J. Thijssen, Enschede, The Netherlands.

All rights reserved.

Typeset with $\mathrm{LT}_{\mathrm{E}} \mathrm{X}$.

This dissertation was printed by Gildeprint, Enschede, The Netherlands. 


\title{
IoT ReceIVER TeChNiques
}

\author{
On Filtering, Power Consumption \\ ANd Phase Noise
}

\section{PROEFSCHRIFT}

ter verkrijging van

de graad van doctor aan de Universiteit Twente, op gezag van de rector magnificus,

prof. dr. ir. A. Veldkamp,

volgens besluit van het College voor Promoties

in het openbaar te verdedigen

op woensdag 7 april 2021 om 14:45 uur

door

Bartholomeus Jacobus Thijssen

geboren op 25 oktober 1992

te Ede 
Dit proefschrift is goedgekeurd door:

de promotor prof. dr. ir. B. Nauta

de co-promotor dr. ing. E.A.M. Klumperink 


\section{Abstract}

The wireless receiver has a significant impact on the connectivity performance and battery lifetime of Internet-of-Things (IoT) devices. High selectivity becomes increasingly important with an increasing number of devices that compete in the congested $2.4 \mathrm{GHz}$ industrial, scientific and medical (ISM) band. In addition, low power consumption is very important for IoT receivers as the burden of changing batteries increases proportionally with the number of the devices. Complementary metal-oxidesemiconductor (CMOS) technology allows for highly integrated IoT devices with small form factor, low digital processing power consumption and low costs. This dissertation presents circuit innovations for a CMOS wireless IoT receiver.

Chapter 2 introduces the concept of analog finite impulse-response (FIR) filtering as a low-power, highly-selective and highly flexible channel filter for IoT receivers. An extensive literature overview shows that analog FIR filters have been thoroughly researched for other applications, but these filters have a high power consumption of $>1 \mathrm{~mW}$.

Analog FIR filtering is proposed in Chapter 3 to realize low power channel selection filters for IoT receivers. High selectivity is achieved using an architecture based on only a single — time-varying — transconductance and integration capacitor. The transconductance is implemented as a digital-to-analog converter (DAC) and is programmable by an on-chip memory. The analog FIR operating principle is shown step-by-step, including its complete transfer function with aliasing. The filter bandwidth and transfer function are highly programmable through the transconductance coefficients and clock frequency. Moreover, the transconductance programmability allows an almost ideal filter response to be realized by careful analysis and compensation of the parasitic circuit impairments. The filter, manufactured in $22 \mathrm{~nm}$ fully-depleted silicon-on-insulator (FD-SOI), has an active area of $0.09 \mathrm{~mm}^{2}$. Its bandwidth can be accurately tuned from 0.06 to $3.4 \mathrm{MHz}$. The filter consumes $92 \mu \mathrm{W}$ from a $700 \mathrm{mV}$ supply. This low power consumption is combined with a high selectivity: $f_{-60 \mathrm{~dB}} / f_{-3 \mathrm{~dB}}=3.8$. The filter has $31.5 \mathrm{~dB}$ gain and $12 \mathrm{nV} / \sqrt{\mathrm{Hz}}$ input-referred noise

Parts from this abstract are published in the papers that are the basis of this dissertation. These papers are listed in the List of Publications on page 123 and cited in the corresponding chapters. 
for a $0.43 \mathrm{MHz}$ bandwidth. The output-referred third-order intercept point (OIP3) is $28 \mathrm{dBm}$, independent of the frequency offset. The output-referred 1dB-compression point is $3.7 \mathrm{dBm}$, and the in-band gain compresses by $1 \mathrm{~dB}$ for an $-3.7 \mathrm{dBm}$ out-of-band input signal, while still providing $>60 \mathrm{~dB}$ of filtering.

In Chapter 4 , a $2.4 \mathrm{GHz}$ zero-IF receiver front-end is proposed that reduces power consumption by $2 \times$ compared to state-of-the-art and improves selectivity by $>20 \mathrm{~dB}$ without compromising on other receiver metrics. To achieve this performance, the entire receive chain is optimized. The low-noise transconductance amplifier is optimized to combine low noise figure (NF) with low power consumption. State-of-the-art sub30nm CMOS processes have almost equal strength complementary transistors, which result in altered design trade-offs. A Windmill 25\%-duty cycle frequency divider architecture is proposed that uses only a single NOR-gate buffer per phase to minimize power consumption and phase noise. The proposed divider requires half the power consumption and has $2 \mathrm{~dB}$ or more reduced phase noise when benchmarked against state-of-the-art designs in simulation. An analog FIR filter is implemented to provide very high receiver selectivity with ultra low power consumption. The receiver frontend is fabricated in a $22 \mathrm{~nm}$ FD-SOI technology and has an active area of $0.5 \mathrm{~mm}^{2}$. It consumes $370 \mu \mathrm{W}$ from a $700 \mathrm{mV}$ supply voltage. This low power consumption is combined with $5.5 \mathrm{~dB} \mathrm{NF}$. The receiver has $-7.5 \mathrm{dBm}$ input-referred third-order intercept point (IIP3) and $1 \mathrm{~dB}$ gain compression for a $-22 \mathrm{dBm}$ blocker - both at maximum gain of $61 \mathrm{~dB}$. From three channels offset onward the adjacent-channel rejection is $\geq 63 \mathrm{~dB}$ for BLE, BT5.0 and IEEE802.15.4.

A feedforward phase noise cancellation technique to reduce phase noise of the output clock signal of a phase-locked loop (PLL) is presented in Chapter 5. It uses a sub-sampling phase detector (SSPD) to measure the phase noise and a variable time delay for cancellation. Both phase noise and spurs are reduced. Analytical expressions have been derived that characterize the performance of this technique and show its fundamental limitations. A sub-sampling phase-locked loop (SSPLL) with the cancellation technique as a built-in feature is described. The feedforward technique has no stability requirements in contrast to conventional PLL improvements. The phase noise reduction bandwidth is increased to almost a third of the reference frequency - $3 \times$ the maximal bandwidth for $3^{\text {rd }}$ order type-II PLLs. The proposed analytical model shows a phase noise reduction of $9 \mathrm{~dB}$ at a frequency offset of $f_{\text {ref }} / 10$. The total rms jitter is improved by $7.2 \mathrm{~dB}$. The analytical results are verified by simulations.

To summarize, this dissertation proposes system and CMOS circuit architectures that allow to improve the performance of an IoT receiver while reducing its power consumption. The analog FIR filter allows for a $>20 \mathrm{~dB}$ increased selectivity. Furthermore, the analog FIR techniques proposed in this dissertation have many other potential applications. The proposed Windmill divider architecture halves the power consumption while reducing the phase noise. The feedforward phase noise cancella- 
tion architecture reduces the PLL rms jitter by $7.2 \mathrm{~dB}$ without significantly increasing its power consumption. 


\section{Samenvatting}

De draadloze ontvanger heeft een aanzienlijke impact op de connectiviteit en de batterijlevensduur van een apparaat voor het Internet-der-Dingen (Internet-of-Things (IoT)). Hoge selectiviteit wordt alleen maar belangrijker, omdat er steeds meer apparaten concurreren in de al overvolle $2.4 \mathrm{GHz}$ industriële, wetenschappelijke en medische (ISM) frequentieband. Naast hoge selectiviteit is een laag energieverbruik zeer belangrijk voor IoT-ontvangers - de last van het vervangen van de batterijen stijgt evenredig met het aantal apparaten. Complementaire metaal-oxide-halfgeleider (CMOS) technologie maakt IoT apparaten mogelijk met een hoge vorm van integratie, een kleine vormfactor, lage kosten en een laag energieverbruik van de digitale signaalverwerking. Dit proefschrift presenteert circuit innovaties voor een CMOS draadloze IoT ontvanger.

Hoofdstuk 2 introduceert analoge eindige-impulsresponsie (FIR) filters als een zeer selectief, zeer flexibel en tevens laag vermogen oplossing voor kanaalfilters in IoT-ontvangers. Een uitgebreid literatuuronderzoek toont aan dat analoge FIR filters uitvoerig zijn onderzocht. Deze gepubliceerde analoge FIR filters hebben echter een hoog energieverbruik van $>1 \mathrm{~mW}$.

Analoge FIR filters worden geïntroduceerd in Hoofdstuk 3 om kanaalfilters met een laag energieverbruik te realiseren voor IoT-ontvangers. Hoge selectiviteit is bereikt door middel van een architectuur met slechts één enkele — tijdafhankelijke — transconductantie en integratie condensator. De transconductantie is geïmplementeerd als een digitaal-naar-analoog omzetter en is programmeerbaar door middel van een geheugen op de chip. Het analoge FIR werkingsprincipe is stap-voor-stap uitgelegd, inclusief de volledige overdracht en vouwvervorming (aliasing). De bandbreedte en overdracht van het filter zijn programmeerbaar via de transconductantiecoëfficiënten en klokfrequentie. Een bijna ideale filteroverdracht kan worden gerealiseerd, door de filter coëfficiënten zo te programmeren dat het effect van de parasitaire uitgangsweerstand van de transistor wordt gecompenseerd. Het filter, geproduceerd in $22 \mathrm{~nm}$ fully-

Onderdelen van deze samenvatting zijn een vertaling van de gepubliceerde artikelen die de basis vormen van dit proefschrift. Deze artikelen zijn opgesomd in de List of Publications op pagina 123 en geciteerd in de bijbehorende hoofdstukken. 
depleted silicon-on-insulator (FD-SOI), heeft een actieve oppervlakte van $0.09 \mathrm{~mm}^{2}$. De filter bandbreedte kan nauwkeurig worden ingesteld tussen 0.06 en $3.4 \mathrm{MHz}$. Het filter verbruikt $92 \mu \mathrm{W}$ van een $700 \mathrm{mV}$ voeding. Dit lage energieverbruik wordt gecombineerd met een hoge selectiviteit: $f_{-60 \mathrm{~dB}} / f_{-3 \mathrm{~dB}}=3.8$. Het filter heeft $31.5 \mathrm{~dB}$ versterking en $12 \mathrm{nV} / \sqrt{\mathrm{Hz}}$ ruis gerefereerd naar de ingang bij een $0.43 \mathrm{MHz}$ bandbreedte. Het uitgangsgerefereerde derde-orde snijpunt (OIP3) is $28 \mathrm{dBm}$, onafhankelijk van de frequentieafstand. De 1dB-compressie is $3.7 \mathrm{dBm}$ gerefereerd naar de uitgang. De versterking in de signaalband comprimeert met $1 \mathrm{~dB}$ bij een $3.7 \mathrm{dBm}$ ingangssignaal buiten de filterband, terwijl het signaal buiten de band nog steeds $>60 \mathrm{~dB}$ wordt verzwakt.

In Hoofdstuk 4 wordt een $2.4 \mathrm{GHz}$ ontvanger frontend gë̈ntroduceerd met $2 \times$ lager energieverbruik en verbeterde selectiviteit van $>20 \mathrm{~dB}$ ten opzichte van de meest recente publicaties zonder concessies te doen aan andere ontvangerseigenschappen. De volledige ontvangstketen is geoptimaliseerd om te komen tot deze prestaties. De lage ruis transconductantie versterker (LNTA) is geoptimaliseerd om een laag ruisgetal (NF) te combineren met een laag energieverbruik. Moderne sub-30nm CMOS processen hebben even sterke transistoren, wat resulteert in nieuwe ontwerpcompromissen. Een Windmolen 25\%-arbeidscyclus frequentiedeler architectuur wordt gepresenteerd met maar één NOF-poort buffer per uitgangsfase om het energieverbruik en de faseruis te minimaliseren. De frequentiedeler heeft een gehalveerd energieverbruik en heeft $\geq 2 \mathrm{~dB}$ minder faseruis in vergelijking - door middel van simulatie - met de meest recente publicaties. Een analoog FIR filter voorziet de ontvanger van een zeer hoge selectiviteit zonder het energieverbruik (significant) te verhogen. Het ontvanger frontend is geproduceerd in een 22nm FD-SOI technologie en heeft een actieve oppervlakte van $0.5 \mathrm{~mm}^{2}$. De ontvanger verbruikt $370 \mu \mathrm{W}$ van een $700 \mathrm{mV}$ voeding in combinatie met een 5.5dB NF. Het ingangsgerefereerde derde-orde snijpunt (IIP3) is $7.5 \mathrm{dBm}$ en er is $1 \mathrm{~dB}$ versterkingscompressie bij een $-22 \mathrm{dBm}$ verstoorder - beide voor de maximale versterking van $61 \mathrm{~dB}$. Vanaf 3 kanalen afstand is de naburig kanaalonderdrukking $(\mathrm{ACR}) \geq 63 \mathrm{~dB}$ voor de radiostandaarden BLE, BT5.0 en IEEE802.15.4.

Hoofdstuk 5 presenteert een vooruitgekoppelde faseruis annuleringstechniek om de faseruis te verminderen van het uitgangskloksignaal van een fase gekoppelde lus (PLL). Een sub-bemonstering (sub-sampling) fasedetector wordt gebruikt om de faseruis te meten en een varieerbare vertragingsbuffer voor annulering. Zowel de faseruis als andere onzuivere signalen worden gereduceerd. Analytische expressies zijn afgeleid om de prestatie van deze techniek te bepalen alsook de fundamentele limieten. Een sub-sampling PLL (SSPLL) met een ingebouwde faseruis annulering is beschreven. De vooruitgekoppelde techniek introduceert geen stabiliteitsproblemen in tegenstelling tot conventionele PLL technieken. De faseruisreductiebandbreedte is toegenomen tot bijna een derde van de referentiefrequentie $-3 \times$ de maximale bandbreedte van 3de orde type-II PLLs. Het analytische model toont een faseruisreductie van $9 \mathrm{~dB}$ 
voor een frequentieafstand van $f_{r e f} / 10$. De totale rms jitter is verbeterd met $7.2 \mathrm{~dB}$. De analytische resultaten zijn geverifieerd door middel van simulaties.

Dit proefschrift presenteert systeem en CMOS-schakeling architecturen die de prestaties van een IoT-ontvanger verbeteren voor een verminderd energieverbruik. Het analoog FIR filter zorgt voor een sterk verbeterde selectiviteit ( $>20 \mathrm{~dB}$ ). De analoge FIR technieken uit dit proefschrift zijn niet gelimiteerd tot zuinige ontvangers, maar kunnen worden gebruikt in vele toepassingen. De Windmolen frequentiedeler architectuur halveert het energieverbruik in combinatie met een gereduceerde faseruis. De faseruisannuleringsarchitectuur vermindert PLL rms jitter met $7.2 \mathrm{~dB}$ zonder het energieverbruik significant te verhogen. 


\section{Dankwoord}

It has been an interesting journey studying at and working for the Integrated Circuit Design (ICD) group. It all started in 2012 - the second year of my advanced technology (AT) bachelor - with Elbasfun and now comes to an end with this dissertation. The main thing I have learned from all of you is the ICD design approach: Finding simple solutions for the most difficult problems. We do this by fully understanding the challenges, including every important detail. I fully agree with and really enjoy this design philosophy.

Bram, je geeft als hoofd van de ICD-groep aan ons promovendi veel onderzoeksvrijheid. In onze hele opleiding en tijdens ons promotieonderzoek worden we gesteund om nieuwe, creatieve oplossingen te ontwikkelen en krijgen we de tijd om echte uitdagingen op te lossen. Deze vrijheid maakt het promotietraject een grote uitdaging, maar hierdoor heb ik ook ontzettend veel geleerd. Ik kan nu vol vertrouwen elke uitdaging aangaan. Heel veel dank.

Eric, je hebt een eindeloze interesse in onderzoek. Je stelt altijd vragen — bij alle onderzoeken binnen ICD, maar ook daarbuiten. Je enorme betrokkenheid bij het promotieonderzoek waardeer ik zeer. Je maakt altijd tijd: Bijvoorbeeld voor het bespreken van de nieuwste ideeën, het geven van paper commentaar, maar ook voor alle praktische zaken die horen bij een promotieonderzoek. Je werkt heel nauwgezet, immer op zoek naar betere argumenten voor onze innovaties in de artikelen. Je hebt mij voortreffelijk begeleid tijdens mijn masteropdracht en promotieonderzoek. Heel veel dank.

Philip, it has been a pleasure to collaborate with you on this project. I really enjoyed the collaboration with Analog Devices (ADI) and I learned a lot from the industry perspective. You have supported the research very effectively, whether it was arranging support for the memory of the filter or reviewing papers. I have very good memories of my visits to Cork, where I got to know you very well. I also have warm memories of all the ADI-colleagues you introduced me to in Ireland and at the ISSCC. We had some lovely meetings and dinners. Thank you very much.

Badhri and Yasaswini, you helped us out with the memory design of the analog FIR filter. It was a nice experience to collaborate with you. Thank you very much. 
Anne-Johan, als docent van Elbasfun heb je mijn interesse gewekt voor analoog circuit design. Als AT-student had ik altijd al een grote interesse in techniek, maar jij hebt mij duidelijk gemaakt hoe gaaf electronica is. Verder heb je mij voortreffelijk begeleid tijdens mijn bacheloropdracht en stage. Heel veel dank.

Frank, je adviezen over de on-chip spoelen hebben goed geholpen bij het ontwerp. Mark, Daniël en Sander, ik heb genoten van de samenwerking bij het onderwijs. Ronan, je hebt leuke vragen en een interessante insteek bij chiptalks. Harijot, you always keep us up-te-date with the latest publications. Gerard, ik heb genoten van de samenwerking en je hulp bij ICT-problemen en tape-outs. Gerdien, je staat altijd klaar om onze praktische zaken op te lossen. Henk en Arnoud, jullie zijn altijd behulpzaam bij metingen in het lab. Allemaal, heel veel dank.

Special thanks to my colleagues in CR2728: Alexander, Ali, Andreas, Anoop, Chris, Dirk-Jan, Erwin, Hugo, Inês, Labrinus, Nimit, Thomas, YC. I really enjoyed working with you. It was fun to come to work, because of the good atmosphere in our office. Thank you very much.

My other PhD-colleagues, Anton, Claudia, Dawei, Joep, Joeri, Maikel, Maryam, Roel, Sajad, Vijaya, Vishal, Zhiliang. I have always enjoyed talking to you and I have good memories of everyone of you. Thank you very much.

The PhD-colleagues that joined during the corona crisis. Unfortunately, we could not get to know each other.

Our pink coffee corner is the place where we have great conversations and discussions on all kinds of topics. Here, we found solutions for many engineering challenges, but also in many other fields such as social and political issues - making it a very special place. I got to know many next-door colleagues that are working on semiconductor components, in particular Bernhard, Dirk, Jurriaan, Kees, Kevin, Lis, Marthe, Maurits, Max, Ray, Remke, Rob, Tom and Tom. Thank you all for creating this nice place to meet.

Special thanks to everyone that joined our daily lunchwalks. It was a very nice distraction from our work - I have always greatly enjoyed it. It gives us all that extra energy to continue accomplishing great achievements every afternoon.

Tot slot wil ik mijn ouders, Rinie en Geert, bedanken voor de onvoorwaardelijke liefde en steun. Heel veel dank. 


\section{Contents}

Abstract $\quad$ i

Samenvatting $\quad$ v

Dankwoord $\quad$ ix

1 Introduction $\quad \mathbf{1}$

1.1 Wireless Connectivity Energy Consumption . . . . . . . . . . . 3

1.1.1 Power Consumption Wireless Link . . . . . . . . . . . . . 3

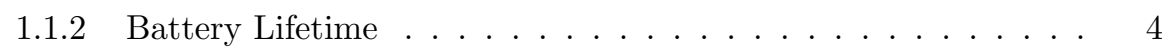

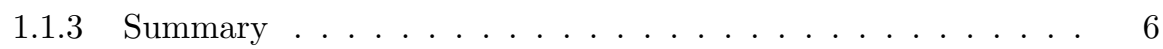

1.2 Wireless Receiver for IoT . . . . . . . . . . . . . . . 6

1.3 Motivation and Goal . . . . . . . . . . . . . . . . 7

1.4 Dissertation Outline . . . . . . . . . . . . . . . 7

2 Analog FIR Filtering $\quad 13$

2.1 Basic Concept . . . . . . . . . . . . . . . . . . 13

2.2 Transfer Function Analysis . . . . . . . . . . . . . . . . 15

2.2.1 Filter Alias Attenuation . . . . . . . . . . . . . . 18

2.2.2 Time-Interleaving and Output Sample Rate . . . . . . . . . . . 18

2.3 Analog FIR Filters Prior Art . . . . . . . . . . . . . . . . . . . . 19

2.3.1 History .......................... 20

2.3.2 Implementation Techniques . . . . . . . . . . . . . . 24

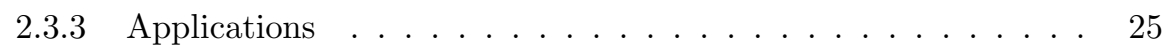

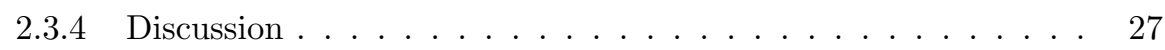

2.4 Analogous Filters . . . . . . . . . . . . . . . . . . . . 27

2.4.1 Phase-Array Antennas . . . . . . . . . . . . . . 27

2.4.2 Surface Acoustic Wave Filters . . . . . . . . . . . . . . 28

2.5 Summary . . . . . . . . . . . . . . . . . . . 29 
3 Analog-FIR Highly-Selective Low-Power Channel Filter 41

3.1 Introduction . . . . . . . . . . . . . . . . . 41

3.2 Analog FIR Filtering . . . . . . . . . . . . . . . . . . . 43

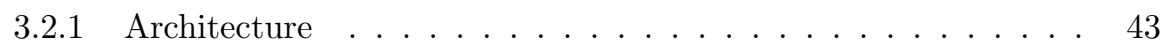

3.2.2 Time-Interleaving .................... . . 44

3.2.3 Filter Transfer Function . . . . . . . . . . . . . . . . . . . 44

3.2.4 Frequency Domain Example . . . . . . . . . . . . . . 46

3.2.5 Designing the Filter Bandwidth . . . . . . . . . . . . . . . 48

3.3 Circuit Implementation _. . . . . . . . . . . . . . . . . . 48

3.3.1 Digital Control and Memory .............. 49

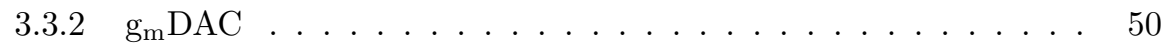

3.3.3 Common-Mode Feedback . . . . . . . . . . . . . . . . . 51

3.3.4 Practical Considerations . . . . . . . . . . . . . 51

3.4 Circuit Analysis and Solutions . . . . . . . . . . . . . . 52

3.4 .1 Output Impedance . . . . . . . . . . . . . . . . . . . . . . 52

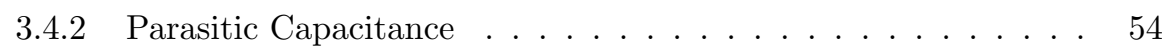

$3.4 .3 g_{m}$-cell Mismatch . . . . . . . . . . . . . . . . 55

3.4.4 $\mathrm{g}_{\mathrm{m}} \mathrm{DAC}$ Transient Behavior . . . . . . . . . . . . 56

3.4.5 Time-Interleaving Gain Mismatch . . . . . . . . . . . . 57

3.4.6 Timing Errors . . . . . . . . . . . . . . . . 57

3.5 Measurement Results . . . . . . . . . . . . . . . . . . 57

3.5.1 Measurement Setup . . . . . . . . . . . . . . . . . 58

3.5.2 Transfer Function . . . . . . . . . . . . . . . . . . 59

3.5.3 Noise and Distortion . . . . . . . . . . . . . . 61

3.5.4 Power Consumption .................. 63

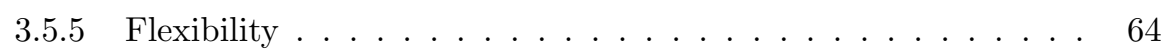

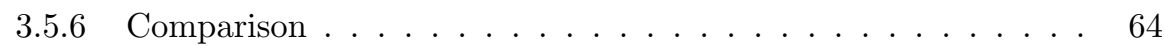

3.6 Conclusions . . . . . . . . . . . . . . . . . 66

4 Highly-Selective IoT Receiver Front-End with Power Optimization 71

4.1 Introduction . . . . . . . . . . . . . . . . . 71

4.2 Circuit Implementation _. . . . . . . . . . . . . . . . . 73

4.3 Low-Noise Transconductance Amplifier . . . . . . . . . . . . . . . . . . 73

4.3 .1 Ideal Inductors . . . . . . . . . . . . . . . . . . . . . . . . . . . . . . . 73

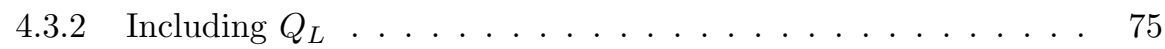

4.3.3 Brute-Force Search Model . . . . . . . . . . . . . . . . . 76

4.3.4 LNTA and Mixer Topology . . . . . . . . . . . . . . . . 77

4.4 Frequency Divider . . . . . . . . . . . . . . . . . . . 78

4.4.1 Minimum Logic Gate Design Strategy . . . . . . . . . . . . . . . 78

4.4.2 Windmill Frequency Divider .............. . 79 
4.4 .3 Divider Comparison . . . . . . . . . . . . . . 82

4.5 Baseband Analog FIR Filter . . . . . . . . . . . . . . . . . 85

4.6 Experimental Results . . . . . . . . . . . . . . . . . 86

4.6.1 Matching and Sensitivity . . . . . . . . . . . . . . 87

4.6 .2 Linearity . . . . . . . . . . . . . . . . . . . . . . 88

4.6.3 Adjacent Channel Rejection . . . . . . . . . . . . . . 89

4.6.4 Power Consumption . . . . . . . . . . . . . . . 91

4.6 .5 Comparison . . . . . . . . . . . . . . . 91

4.6.6 Full Receiver Discussion . . . . . . . . . . . . . . . . 94

4.7 Analog FIR Filter Discussion . . . . . . . . . . . . . . . . . 94

4.8 Conclusions . . . . . . . . . . . . . . . . . . . . 95

5 Phase Noise Cancellation Exploiting an SSPD 101

5.1 Introduction . . . . . . . . . . . . . . . . . 102

5.2 Phase-Locked Loops . . . . . . . . . . . . . . . . . . . 103

5.2 .1 PLL Phase Noise Spectrum . . . . . . . . . . . . . 103

5.2 .2 SSPD versus PFD . . . . . . . . . . . . . . . 104

5.2 .3 SSPD Hold Delay . . . . . . . . . . . . . . . . . . . . . . 104

5.3 Feedforward Phase Noise Cancellation . . . . . . . . . . . . . . . . 104

5.3 .1 SSPD Analysis . . . . . . . . . . . . . . . 105

5.3.2 Phase Noise Cancellation Output Spectrum . . . . . . . . . . . 107

5.3.3 Practical Implementation Limitations . . . . . . . . . . . . . . 109

5.3.4 Spur Cancellation ... . . . . . . . . . . . . . 109

5.4 Sub-Sampling Phase Noise Cancellation PLL . . . . . . . . . . . . . . 110

5.5 Simulation Results . . . . . . . . . . . . . . . . . . . . . . 110

5.6 IoT Receiver Context . . . . . . . . . . . . . . . . . . . . . . . . . . . . . . . . . . . . . . . . . . 113

5.7 Conclusions . . . . . . . . . . . . . . . . . . . 114

6 Conclusions $\quad 119$

6.1 Conclusions ............................ 119

6.2 Original Contributions . . . . . . . . . . . . . . . . 121

6.3 Recommendations ........................ 122

$\begin{array}{ll}\text { List of Publications } & 123\end{array}$

$\begin{array}{ll}\text { Acronyms } & 125\end{array}$

$\begin{array}{lr}\text { About the Author } & 129\end{array}$ 

There's a way to do it better -

find it.

Thomas A. Edison

\section{Introduction}

Wireless connectivity is one of the cornerstones that enable modern society. It allows people to keep in touch with their family and friends across the world. The possibility to access entertainment, but also knowledge and know-how anytime and anywhere. Businesses to operate globally.

Nowadays, there is a trend to connect more and more devices to the internet in the so-called Internet-of-Things (IoT), sometimes referred to as Internet-of-Everything (IoE). The connected devices allow for monitoring and optimization of all kinds of systems, e.g.:

- Health care, e.g., by monitoring heart beat and by making electrocardiograms (ECGs) using smartwatches;

- Entertainment, e.g., by wireless earbuds;

- Productivity, e.g.;

o in the office, smart pens, wireless mice and keyboards that connect to multiple computers;

○ in industry, smart tools in factories that automatically provide the correct torque to different bolts;

○ in agriculture, connected tractors that drive automatically between crops;

- Safety, e.g., wireless connected smoke detectors; 
- Home automation, e.g., smart thermostats that heat your house when you drive home; retractable awnings that open when its sunny and close during a storm by a wireless connected sun detector and wind detector, respectively.

Basically, the list of potential applications is endless.

Wireless connectivity is at the heart of the IoT trend. It is the essential building block in making devices smart: Connecting devices to a smartphone, the cloud or both. IoT devices often have a small form factor in the order of centimeters. Furthermore, many IoT devices are battery powered to remove the costs of installing cables, increase convenience and reduce the form factor.

The IoT scope is to connect literally everything. As a result, the wireless environment will become increasingly congested. Therefore, high selectivity and good linearity become increasingly important to allow proper operation of wireless links also for low power IoT devices. On the other hand, low costs are desired to enable the large increase of connected devices.

Both form factor and costs drive the trend to maximum integration - minimal off-chip components. Complementary metal-oxide-semiconductor (CMOS) technology enables these highly integrated devices as it allows for implementation of wireless connectivity, digital processing and sensor/actuator interfaces on a single chip. Considering the rapidly increasing number of IoT devices, the burden and costs of changing batteries increases proportionally. It is therefore paramount to minimize the energy consumption to increase lifetime.

The IoT devices are often not connected to the internet themselves, because a Wi-Fi or mobile connection entails to much power consumption. It would require a too large battery. Most often they are connected to a bridge device - that is connected to the internet — using a low power wireless standard such as Bluetooth Low Energy (BLE) [1] or IEEE802.15.4, e.g. music streaming to wireless earbuds via a smartphone using BLE.

The contradictory requirements necessitate innovations on the wireless connectivity. The main research subject of this dissertation is to improve the selectivity of a CMOS $2.4 \mathrm{GHz}$ IoT receiver while reducing its power consumption. This chapter introduces the context of this dissertation. High performance receivers, with high selectivity, have been published, but have off-chip components and/or high power consumption. Therefore, the chapter starts with providing a more general perspective on the energy consumption constraint and the related battery capacity. Maximum integration of the receiver is accomplished by having no off-chip components for matching or filtering. The next section describes the requirements on the other performance metrics of a wireless IoT receiver - in the context of the given power consumption - followed by a summary of the motivation and goal of this work. The last section provides the outline of this dissertation. 


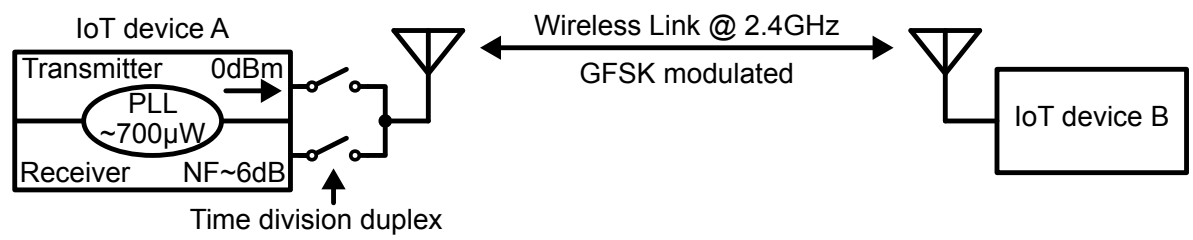

Figure 1.1: A BLE wireless link.

\subsection{Wireless Connectivity Energy Consumption}

As most IoT devices are battery powered, low energy consumption is perhaps the most important metric for IoT devices. The wireless communication is often the dominant contributor to the power consumption [2]. Therefore, the communication is heavily duty-cycled to increase battery lifetime. Although duty-cycled, the wireless communication is still a major contributor to the IoT device's energy consumption.

First, the power consumption in a wireless $2.4 \mathrm{GHz}$ IoT link is described to provide more context. Afterwards, a closer look on battery capacity is taken to reveal important insights in battery lifetime followed by a summary.

\subsubsection{Power Consumption Wireless Link}

Fig. 1.1 shows a typical wireless link for BLE. Wireless radio communication requires both transmission and reception. These functionalities are provided by the transmitter and receiver, respectively. Both functionalities are implemented together in a transceiver. From an electronics perspective these functionalities can generally be divided into separate architectures. Both transmitter and receiver require a phaselocked loop (PLL) clock for up-conversion and down-conversion, respectively. IoT standards most often use time-division duplexing, which allows a separate configuration of the matching network for transmission and reception and thereby a single antenna. Using multiple antennas or a circulator is too expensive.

Most IoT communication standards employ constant envelope modulation techniques based on phase or frequency modulation. This allows for highly non-linear power amplifiers on the transmit side, which are much more efficient than linear power amplifiers; as required for non-constant envelope modulation schemes. E.g. BLE employs Gaussian frequency-shift-keying (GFSK) [1].

A couple of specifications can already be estimated from the power consumption of the PLL. A state-of-the-art very low power all-digital phase-locked loop (ADPLL) for BLE consumes roughly $700 \mu \mathrm{W}[3]$. This is constrained by the limited $Q$-factor and inductance value of on-chip inductors. The voltage-controlled oscillator (VCO) voltage swing — which is part of a PLL — is directly related to its minimal power 
consumption to maintain oscillation [2]. A ring oscillator can be designed with a lower power consumption. However, it is not an option as it requires roughly $1000 \times$ more power consumption for the same phase noise compared to an $L C$-oscillator. The theoretical figure-of-merit $(\mathrm{FoM})^{1}$ of a ring oscillator is $-165 \mathrm{dBc} / \mathrm{Hz}$ [4], while a state-of-the-art $L C$-oscillator has a $\mathrm{FoM}$ of $-195 \mathrm{dBc} / \mathrm{Hz}$ [5]. If an $L C$-oscillator with a power consumption $10 \times$ below its practical limitation is desired, a ring oscillator alternative would require $100 \times$ more power than the $L C$-oscillator minimum. The $700 \mu \mathrm{W}$ PLL power consumption provides a lower limit on the power consumption for transmission and reception.

The transmitted power is often around 0dBm [1], so the total transmission power consumption is at least $1.7 \mathrm{~mW}$. Reducing the transmitted power further does not reduce the power consumption a lot, since the total power consumption is limited to $\sim 700 \mu \mathrm{W}$.

From the receiver perspective, it cannot be justified to compromise on the receiver front-end performance to reduce its power consumption far below the $700 \mu \mathrm{W}$ limit. Practically, the noise figure (NF) should be sub-6dB as this NF can be obtained in designs of around $1 \mathrm{~mW}[6-9]$. Furthermore, considering the link budget, it can be concluded that comprising on the $\mathrm{NF}$ is not desired. E.g. a $9 \mathrm{~dB} \mathrm{NF}$ transceiver with $3 \mathrm{dBm}$ transmit power would provide the same link budget, but would increase the transmission power consumption by at least $1 \mathrm{~mW}$, which is roughly equal to the entire power consumption of sub-6dB NF receiver front-end.

\subsubsection{Battery Lifetime}

Fig. 1.2 shows the capacity of the commonly used CR2032 coin cell battery [10]. The battery capacity is limited by the functional end point of the IoT device the minimum voltage at which the device can operate. Fig. 1.2a shows the CR2032 capacity for different load currents. By reducing the current from $3 \mathrm{~mA}$ to $0.5 \mathrm{~mA}$, the battery capacity increases by about $60 \%$. The lifetime is increased more than $9.5 \times$ instead of the $6 \times$ prediction based on current consumption alone.

Since the wireless communication is most often duty-cycled, the current that the battery has to provide is pulsed. The current consumption during communication is much larger than otherwise. Fig. $1.2 \mathrm{~b}$ compares the battery capacity of a $0.5 \mathrm{~mA}$ continuous load with a pulsed load. The pulsed load consists of a continuous $0.1 \mathrm{~mA}$ current plus a $10 \mathrm{~mA}, 1 \mathrm{~ms}$ current pulse every $25 \mathrm{~ms}$ to maintain the same average load current of $0.5 \mathrm{~mA}[10]$. Both the battery voltage when idle $\left(V_{\text {idle }}\right)$ and during a pulse $\left(V_{\text {load }}\right)$ are shown. The pulsed current battery capacity is reduced by roughly $20 \%$.

\footnotetext{
${ }^{1} \mathrm{FoM}=\mathcal{L}(\Delta f)-20 \log \left(f_{\text {osc }} / \Delta f\right)+10 \log (P / 1 \mathrm{~mW})$, where $\mathcal{L}(\Delta f)$ is the phase noise in $\mathrm{dBc} / \mathrm{Hz}$ at frequency offset $\Delta f, f_{\text {osc }}$ the oscillator frequency and $P$ the power consumption in $\mathrm{mW}$.
} 


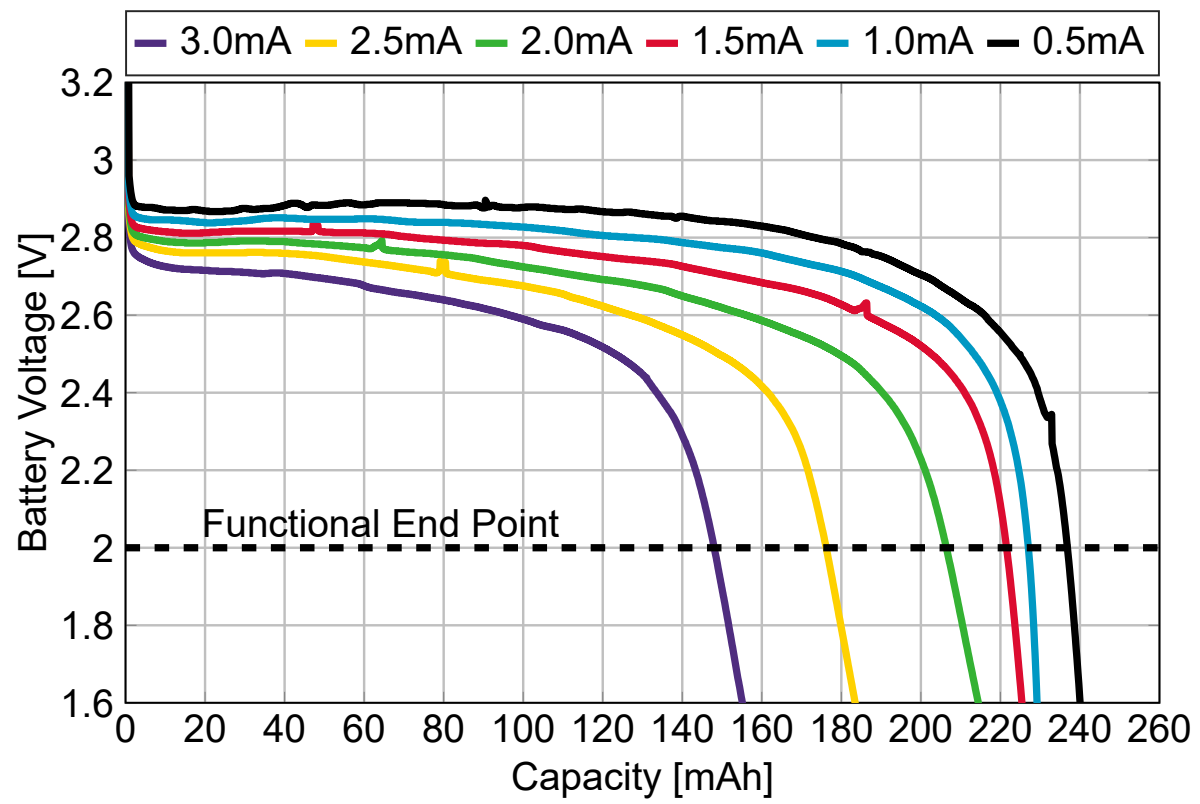

(a)

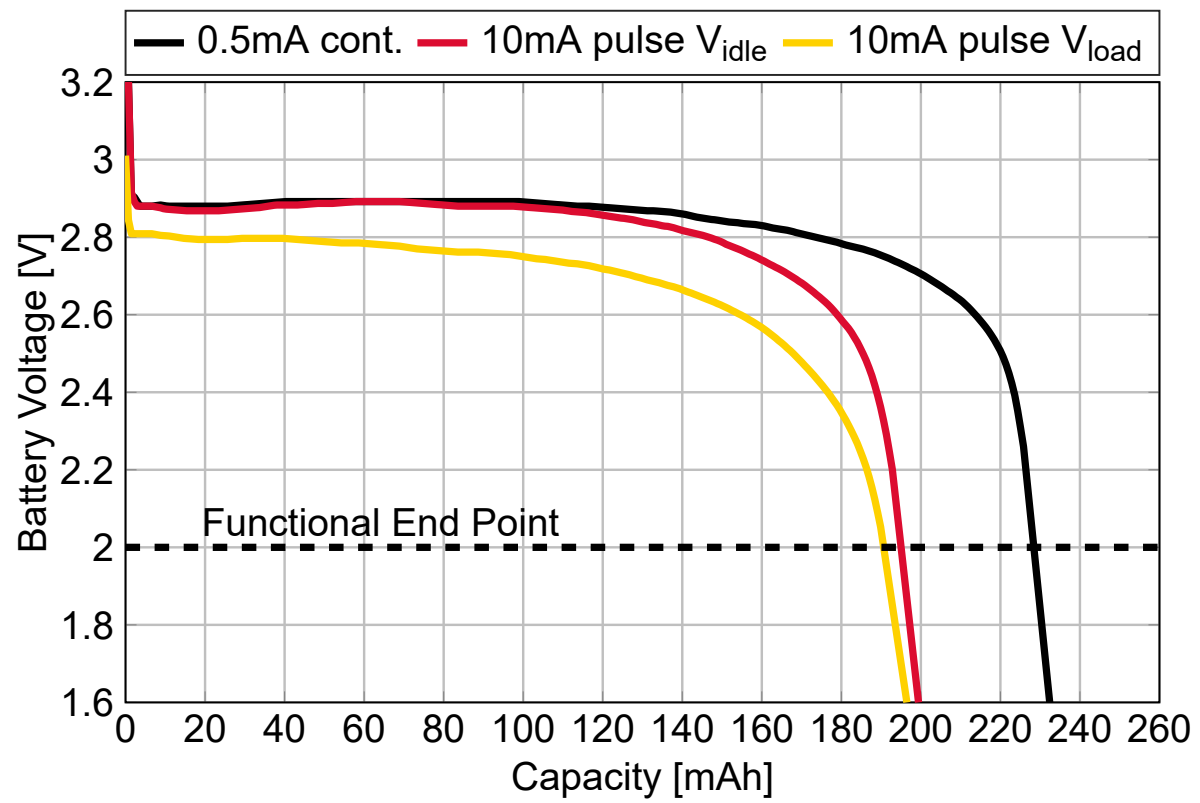

(b)

Figure 1.2: CR2032 coin cell battery voltage during discharging. (a) Continuous current [10]. (b) Continuous and pulsed current compared; $1 \mathrm{~ms}$ on, 24ms off [10]. 


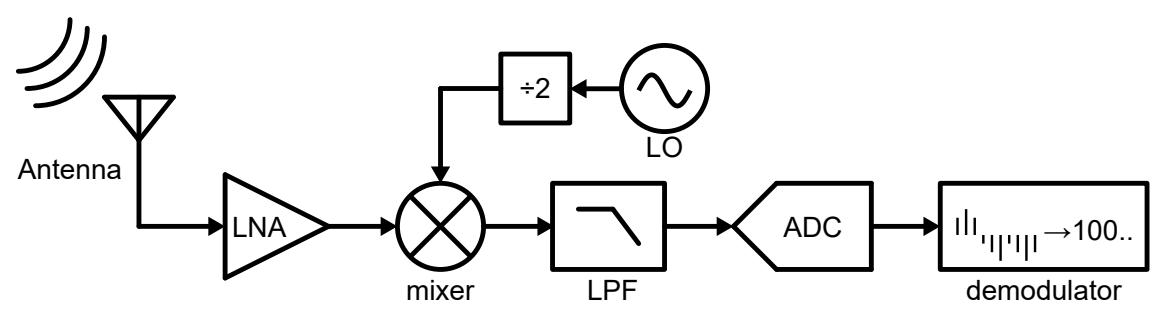

Figure 1.3: A typical wireless receiver architecture.

\subsubsection{Summary}

The scope of this work is the receiver including PLL. The receiver is important in terms of power consumption and wireless performance of IoT devices. Furthermore, it is clear that also the PLL is very important in terms of the total power consumption and provides a design constraint.

To increase battery life, low power consumption is important from multiple viewpoints. Low power consumption reduces the energy drawn per second and therefore the lifetime given a battery capacity. A larger current consumption reduces the battery capacity. Furthermore, when duty-cycling is employed to increase the lifetime, a high peak current reduces the battery capacity and thereby the lifetime.

\subsection{Wireless Receiver for IoT}

Fig. 1.3 shows a typical wireless receiver architecture, either with zero intermediate frequency (IF) or low-IF. A radio signal is detected by an antenna. This received signal is amplified by a low-noise amplifier (LNA). Afterwards the amplified signal is downconverted to baseband by means of a mixer. The mixer employs multiphase clocks that are provided by a frequency divider. The frequency divider has as input a clock signal that comes from a local oscillator (LO) - the PLL. Channel selection filtering is done in baseband by means of a low-pass filter (LPF). The filtered signal is fed to an analog-to-digital converter (ADC) to allow demodulation in the digital domain. The performance metrics are discussed in the context of a $2.4 \mathrm{GHz}$ IoT receiver.

Other architectures were proposed to reduce power consumption, e.g., slidingIF [11-15], phase domain [6-8, 16-18], a combination [19] or in-phase/quadraturephase (I/Q) generation in the radio frequency (RF) signal path [20]. However, these proposals do not obtain lower power consumption than the more conventional zero-IF $[9,21,22]$ or low-IF [23-36] architectures.

Power consumption is important, but other receiver metrics should also be ade- 
quate. The noise performance of a receiver is characterized by its NF or sensitivity. A state-of-the-art NF is roughly sub- $6 \mathrm{~dB}$, resulting in a sensitivity of around $-94 \mathrm{dBm}$ or lower $[6-9,11-15,21,22,25,26,28-33,36]$ - depending on the demodulation technique.

Other receiver metrics like filtering and linearity are also important to characterize its performance. Unfortunately, these are not always provided in publications, which makes fair comparison difficult. State-of-art adjacent-channel rejection (ACR) is roughly $40 \mathrm{~dB}$ at $3 \mathrm{MHz}$ offset for BLE $[7,8,14,22,33,35,36]$. The best published linearity in terms of input-referred third-order intercept point (IIP3) is around $-6 \mathrm{dBm}$ at maximum gain $[23,24]$. However, this receiver has an $8.5 \mathrm{~dB} \mathrm{NF}$ and two supply voltages.

\subsection{Motivation and Goal}

High selectivity will become increasingly important in the already congested $2.4 \mathrm{GHz}$ ISM-band. However, this should not come at the cost of other receiver metrics and, preferably, at minimal power consumption to improve battery lifetime. Furthermore, re-configurability of the receiver is increasingly important, because modern IoT receivers should cope with an increasing number of standards, that include more and more flexibility. To summarize, the goal of this work is to invent circuit techniques to obtain a receiver front-end that has:

- Improved selectivity, significantly above 40dB ACR;

- Sub-6dB NF;

- $>-10 \mathrm{dBm}$ IIP3;

- Minimal off-chip components, i.e. no off-chip matching or filtering;

- Reduced power consumption, significantly below $1 \mathrm{~mW}$;

- Flexibility/Programmability.

As the receiver selectivity increases, a low phase noise LO source becomes more important. Therefore, also techniques to reduce the LO phase noise for the same power consumption are researched.

\subsection{Dissertation Outline}

The dissertation is organized as follows. Chapter 2 gives is an overview of analog finite impulse-response (FIR) filters, discussing the concept and transfer function. This is 
followed by a literature overview that presents analog FIR filtering from a historical, implementation and application perspective. The prior art is discussed with respect to the IoT receiver application of this work. Furthermore, analog FIR circuits that are implemented in other domains are reviewed.

Chapter 3 presents a low power analog FIR filter architecture that is designed as a channel selection filter for an IoT receiver. The full transfer function is analytically derived - including all aliases. The filter architecture performance is determined by measurements on a prototype in 22nm fully-depleted silicon-on-insulator (FD-SOI) technology.

Chapter 4 presents a $2.4 \mathrm{GHz}$ highly selective IoT receiver front-end implemented in 22nm FD-SOI. This design incorporates the analog FIR filter of Chapter 3 as baseband channel selection filter. It combines the best selectivity and lowest power consumption to date, with good NF and linearity compared to state-of-the-art IoT receivers. The low power consumption is obtained by a zero-IF architecture with circuit optimizations across the entire receive chain, including a novel frequency divider architecture.

The improved ACR of the receiver front-end in Chapter 4 requires low LO phase noise. A phase noise cancellation PLL architecture that can accomplish this is described in Chapter 5. A theoretical analysis of the technique is provided. This architecture can be used to reduce the PLL phase noise without (significant) increase of its power consumption.

Chapter 6 presents the final conclusions of this dissertation, including the original contributions to the field and recommendations.

The published papers of this work are the foundation of this dissertation. These papers are listed in the List of Publications on page 123 and cited in the corresponding chapters. The author is aware that Chapters 3 to 5 partially overlap with other chapters. However, the author preferred minimal modification of the - already reviewed and accepted papers.

\section{References}

[1] Bluetooth Core Specification v5.2. Bluetooth SIG, 2019.

[2] A. Liscidini, "Ultra Low Power RF Circuits for IoT," 2017, as part of the MEAD course: "Wireless RF Front-End Design: from ULP to mmW".

[3] Y. He, Y.-H. Liu, T. Kuramochi, J. van den Heuvel, B. Busze, N. Markulic, C. Bachmann, and K. Philips, "A $673 \mu \mathrm{W}$ 1.8-to-2.5GHz Dividerless FractionalN Digital PLL with an Inherent Frequency-Capture Capability and a Phase- 
Dithering Spur Mitigation for IoT Applications," in IEEE Int. Solid-State Circuits Conf. Dig. Tech. Pap., Feb. 2017, pp. 420-421.

[4] A. Hajimiri, S. Limotyrakis, and T. H. Lee, "Jitter and Phase Noise in Ring Oscillators," IEEE J. Solid-State Circuits, vol. 34, no. 6, pp. 790-804, Jun. 1999.

[5] D. Murphy and H. Darabi, "A Complementary VCO for IoE that Achieves a $195 \mathrm{dBc} / \mathrm{Hz}$ FOM and Flicker Noise Corner of $200 \mathrm{kHz}$," in IEEE Int. Solid-State Circuits Conf. Dig. Tech. Pap., vol. 59, Jan. 2016, pp. 44-45.

[6] M. Ding, X. Wang, P. Zhang, Y. He, S. Traferro, K. Shibata, M. Song, H. Korpela, K. Ueda, Y.-H. Liu, C. Bachmann, and K. Philips, "A 0.8V 0.8mm² Bluetooth 5/BLE Digital-Intensive Transceiver with a $2.3 \mathrm{~mW}$ Phase-Tracking RX Utilizing a Hybrid Loop Filter for Interference Resilience in 40nm CMOS," in IEEE Int. Solid-State Circuits Conf. Dig. Tech. Pap., vol. 61, Feb. 2018, pp. $446-448$.

[7] H. Liu, Z. Sun, D. Tang, H. Huang, T. Kaneko, W. Deng, R. Wu, K. Okada, and A. Matsuzawa, "An ADPLL-Centric Bluetooth Low-Energy Transceiver with 2.3mW Interference-Tolerant Hybrid-Loop Receiver and 2.9mW Single-Point Polar Transmitter in 65nm CMOS," in IEEE Int. Solid-State Circuits Conf. Dig. Tech. Pap., 2018, pp. 444-445.

[8] H. Liu, Z. Sun, D. Tang, H. Huang, T. Kaneko, Z. Chen, W. Deng, R. Wu, and K. Okada, "A DPLL-Centric Bluetooth Low-Energy Transceiver With a 2.3-mW Interference-Tolerant Hybrid-Loop Receiver in 65-nm CMOS," IEEE J. Solid-State Circuits, vol. 53, no. 12, pp. 3672-3687, Dec. 2018.

[9] A. H. M. Shirazi, H. M. Lavasani, M. Sharifzadeh, Y. Rajavi, S. Mirabbasi, and M. Taghivand, "A $980 \mu \mathrm{W} 5.2 \mathrm{~dB}-\mathrm{NF}$ Current-Reused Direct-Conversion Bluetooth-Low-Energy Receiver in 40nm CMOS," in IEEE Cust. Integr. Circuits Conf., Apr. 2017.

[10] K. Furset and P. Hoffman, "High pulse drain impact on CR2032 coin cell battery capacity," Tech. Rep., 2011, accessed 25 June 2020. [Online]. Available: https://m.eet.com/media/1121454/c0924post.pdf

[11] A. C. W. Wong, M. Dawkins, G. Devita, N. Kasparidis, A. Katsiamis, O. King, F. Lauria, J. Schiff, and A. J. Burdett, "A 1V 5mA Multimode IEEE 802.15.6/Bluetooth Low-Energy WBAN Transceiver for Biotelemetry Applications," in IEEE Int. Solid-State Circuits Conf. Dig. Tech. Pap., vol. 48, Feb. 2012, pp. 300-302. 
[12] — " “A 1 V 5 mA Multimode IEEE 802.15.6/Bluetooth Low-Energy WBAN Transceiver for Biotelemetry Applications," IEEE J. Solid-State Circuits, vol. 48, no. 1, pp. 186-198, Jan. 2013.

[13] Y.-H. Liu, X. Huang, M. Vidojkovic, A. Ba, P. Harpe, G. Dolmans, and H. de Groot, "A 1.9nJ/b 2.4GHz Multistandard (Bluetooth Low Energy/Zigbee/IEEE802.15.6) Transceiver for Personal/Body-Area Networks," in EEE Int. Solid-State Circuits Conf. Dig. Tech. Pap., Feb. 2013, pp. 446-447.

[14] Y.-H. Liu, C. Bachmann, X. Wang, Y. Zhang, A. Ba, B. Busze, M. Ding, P. Harpe, G.-J. van Schaik, G. Selimis, H. Giesen, J. Gloudemans, A. Sbai, L. Huang, H. Kato, G. Dolmans, K. Philips, and H. de Groot, "A 3.7mW-RX 4.4mW-TX Fully Integrated Bluetooth Low-Energy/IEEE802.15.4/Proprietary SoC with an ADPLL-Based Fast Frequency Offset Compensation in 40nm CMOS," in IEEE Int. Solid-State Circuits Conf. Dig. Tech. Pap., Feb. 2015, pp. 236-237.

[15] T. Sano, M. Mizokami, H. Matsui, K. Ueda, K. Shibata, K. Toyota, T. Saitou, H. Sato, K. Yahagi, and Y. Hayashi, "A 6.3mW BLE Transceiver Embedded RX Image- Rejection Filter and TX Harmonic-Suppression Filter Reusing On-Chip Matching Network," in IEEE Int. Solid-State Circuits Conf. Dig. Tech. Pap., Feb. 2015, pp. 240-241.

[16] H. Okuni, A. Sai, T. T. Ta, S. Kondo, T. Tokairin, M. Furuta, and T. Itakura, "A 5.5mW ADPLL-Based Receiver with Hybrid-Loop Interference Rejection for BLE Application In 65nm CMOS," IEEE Int. Solid-State Circuits Conf. Dig. Tech. Pap., pp. 436-437, 2016.

[17] A. Sai, H. Okuni, T. T. Ta, S. Kondo, T. Tokairin, M. Furuta, and T. Itakura, "A $5.5 \mathrm{~mW}$ ADPLL-Based Receiver with a Hybrid Loop Interference Rejection for BLE Application in $65 \mathrm{~nm}$ CMOS," IEEE J. Solid-State Circuits, vol. 51, no. 12 , pp. 3125-3136, 2016.

[18] Y.-H. Liu, V. K. Purushothaman, C. Lu, J. Dijkhuis, R. B. Staszewski, C. Bachmann, and K. Philips, "A 770pJ/b 0.85V 0.3mm² DCO-Based Phase-Tracking RX Featuring Direct Demodulation and Data-Aided Carrier Tracking for IoT Applications," IEEE Int. Solid-State Circuits Conf. Dig. Tech. Pap., vol. 60, pp. 408-409, 2017.

[19] Y.-H. Liu, A. Ba, J. H. C. van den Heuvel, K. Philips, G. Dolmans, and H. de Groot, "A $1.2 \mathrm{~nJ} / \mathrm{b} 2.4 \mathrm{GHz}$ receiver with a sliding-IF phase-to-digital converter for wireless personal/body-area networks," in IEEE Int. Solid-State Circuits Conf. Dig. Tech. Pap., Feb. 2014, pp. 166-167. 
[20] W. H. Yu, H. Yi, P. I. Mak, J. Yin, and R. P. Martins, "A 0.18V 382 $\mu$ W bluetooth low-energy (BLE) receiver with $1.33 \mathrm{nW}$ sleep power for energy-harvesting applications in 28nm CMOS," IEEE Int. Solid-State Circuits Conf. Dig. Tech. Pap., pp. 414-415, 2017.

[21] S. Chakraborty, V. Parikh, S. Sankaran, T. Motos, O. Fikstvedt, J.-T. Marienborg, D. Griffith, I. Prathapan, K. Nagaraj, F. Zhang, R. Smith, W. Budziak, S. Sundar, and P. Cruise, "An ultra low power, reconfigurable, multi-standard transceiver using fully digital PLL," in IEEE Symp. VLSI Circuits, Dig. Tech. Pap., 2013, pp. C148-C149.

[22] E. Bechthum, J. Dijkhuis, M. Ding, Y. He, J. V. D. Heuvel, P. Mateman, G.-j. V. Schaik, K. Shibata, M. Song, E. Tiurin, S. Traferro, Y.-H. Liu, and C. Bachmann, "A Low-Power BLE Transceiver with Support for Phase-Based Ranging, Featuring $5 \mu$ s PL Locking Time and 5.3ms Ranging Time, Enabled by Staircase-Chirp PLL with Stick-Lock Channel-Switching," IEEE Int. Solid-State Circuits Conf. Dig. Tech. Pap., pp. 470-471, 2020.

[23] Z. Lin, P. I. Mak, and R. P. Martins, "A $1.7 \mathrm{~mW} 0.22 \mathrm{~mm}^{2} 2.4 \mathrm{GHz}$ ZigBee RX Exploiting a Current-Reuse Blixer + Hybrid Filter Topology in 65nm CMOS," IEEE Int. Solid-State Circuits Conf. Dig. Tech. Pap., pp. 448-449, 2013.

[24] —, "A $2.4 \mathrm{GHz}$ ZigBee receiver exploiting an RF-to-BB-current-reuse Blixer + hybrid filter topology in $65 \mathrm{~nm}$ CMOS," IEEE J. Solid-State Circuits, vol. 49, no. 6, pp. 1333-1344, 2014.

[25] F. Pengg, D. Barras, M. Kucera, N. Scolari, and A. Vouilloz, "A Low Power Miniaturized $1.95 \mathrm{~mm}^{2}$ Fully Integrated Transceiver with fastPLL Mode for IEEE 802.15.4 / Bluetooth Smart and Proprietary 2.4GHz Applications," in IEEE Radio Freq. Integr. Circuits Symp., Jun. 2013, pp. 71-74.

[26] F. Zhang, Y. Miyahara, and B. P. Otis, "Design of a 300-mV 2.4-GHz Receiver Using Transformer-Coupled Techniques," IEEE J. Solid-State Circuits, vol. 48, no. 12, pp. 3190-3205, 2013.

[27] Z. Lin, P.-I. Mak, and R. P. Martins, "A 0.14mm² 1.4-mW 59.4-dB-SFDR 2.4$\mathrm{GHz}$ ZigBee/WPAN Receiver Exploiting a Split-LNTA + 50\% LO Topology in 65-nm CMOS," IEEE Trans. Microw. Theory Tech., vol. 62, no. 7, pp. 1525-1534, Jul. 2014.

[28] J. Prummel, M. Papamichail, M. Ancis, J. Willms, R. Todi, W. Aartsen, W. Kruiskamp, J. Haanstra, E. Opbroek, S. Rievers, P. Seesink, H. Woering, and C. Smit, "A 10mW Bluetooth Low-Energy Transceiver with On-Chip Matching," in IEEE Int. Solid-State Circuits Conf. Dig. Tech. Pap., Feb. 2015, pp. 238-239. 
[29] J. Prummel, M. Papamichail, J. Willms, R. Todi, W. Aartsen, W. Kruiskamp, J. Haanstra, E. Opbroek, S. Rievers, P. Seesink, J. van Gorsel, H. Woering, and C. Smit, "A $10 \mathrm{~mW}$ Bluetooth Low-Energy Transceiver With On-Chip Matching," IEEE J. Solid-State Circuits, vol. 50, no. 12, pp. 3077-3088, Dec. 2015.

[30] F.-W. Kuo, S. B. Ferreira, M. Babaie, R. Chen, L.-C. Cho, C.-P. Jou, F.-L. Hsueh, G. Huang, I. Madadi, M. Tohidian, and R. B. Staszewski, "A Bluetooth Low-Energy (BLE) Transceiver with TX/RX Switchable On-Chip Matching Network, $2.75 \mathrm{~mW}$ High-IF Discrete-Time Receiver, and $3.6 \mathrm{~mW}$ All-Digital Transmitter," in IEEE Symp. VLSI Circuits, Dig. Tech. Pap., Jun. 2016.

[31] F.-W. Kuo, S. Binsfeld Ferreira, H.-N. R. Chen, L.-C. Cho, C.-P. Jou, F.-L. Hsueh, I. Madadi, M. Tohidian, M. Shahmohammadi, M. Babaie, and R. B. Staszewski, "A Bluetooth Low-Energy Transceiver With 3.7-mW All-Digital Transmitter, 2.75-mW High-IF Discrete-Time Receiver, and TX/RX Switchable On-Chip Matching Network," IEEE J. Solid-State Circuits, vol. 52, no. 4, pp. 1144-1162, Apr. 2017.

[32] S. Binsfeld Ferreira, F.-W. Kuo, M. Babaie, S. Bampi, and R. B. Staszewski, "System Design of a 2.75-mW Discrete-Time Superheterodyne Receiver for Bluetooth Low Energy," IEEE Trans. Microw. Theory Tech., vol. 65, no. 5, pp. 19041913, May 2017.

[33] W. Yang, D. Y. Hu, C. K. Lam, J. Q. Cui, L. K. Soh, D. C. Song, X. W. Zhong, H. C. Hor, and C. L. Heng, "A +8dBm BLE/BT Transceiver with Automatically Calibrated Integrated RF Bandpass Filter and $-58 \mathrm{dBc}$ TX HD2," in IEEE Int. Solid-State Circuits Conf. Dig. Tech. Pap., Feb. 2017, pp. 136-137.

[34] E. Kargaran, B. Guo, D. Manstretta, and R. Castello, "A Sub-1-V, 350- $\mu$ W, 6.5dB Integrated NF Low-IF Receiver Front-End for IoT in 28-nm CMOS," IEEE Solid-State Circuits Lett., vol. 2, no. 4, pp. 29-32, Apr. 2019.

[35] M. Silva-Pereira, J. T. de Sousa, J. Costa Freire, and J. Caldinhas Vaz, "A 1.7$\mathrm{mW}-92-\mathrm{dBm}$ Sensitivity Low-IF Receiver in 0.13- $\mu \mathrm{m}$ CMOS for Bluetooth LE Applications," IEEE Trans. Microw. Theory Tech., vol. 67, no. 1, pp. 332-346, Jan. 2019.

[36] M. Tamura, H. Takano, S. Shinke, H. Fujita, H. Nakahara, N. Suzuki, Y. Nakada, Y. Shinohe, S. Etou, T. Fujiwara, and Y. Katayama, "A 0.5V BLE Transceiver with a $1.9 \mathrm{~mW}$ RX Achieving -96.4dBm Sensitivity and 4.1dB Adjacent Channel Rejection at $1 \mathrm{MHz}$ Offset in 22nm FDSOI," in IEEE Int. Solid-State Circuits Conf. Dig. Tech. Pap., vol. 63, Feb. 2020, pp. 468-469. 
I have not failed. I've just found

10,000 ways that won't work.

Thomas A. Edison

\section{Analog FIR Filtering}

Highly selective receivers require channel selection filters with steep roll-off and strong attenuation. FIR filters have these properties and can be part of a low power receiver architecture when implemented in the analog domain.

This chapter provides an overview of analog FIR filters. First, the basics of analog FIR filtering is explained. This section was previously co-published in IEEE SolidState Circuits Letters [1] and at the European Solid-State Circuit Conference [2]. In the next section, the analog FIR transfer function properties are analyzed in detail. Section 2.3 describes the previously published work from a historical, implementation and application perspective. Furthermore, the prior art is discussed in the context of the IoT receiver application. Analog filters with a finite impulse-response that are not implemented on-chip are outlined in Section 2.4. The chapter finalizes with a summary.

\subsection{Basic Concept}

Fig. 2.1 illustrates the working principle of analog FIR filters by comparing it to its digital equivalent. A 6-tap digital FIR filter is shown in Fig. 2.1a. The input signal $x[n]$ is passed through a delay line with delays $z^{-1}$. The delayed samples of $x[n]$ are multiplied by an appropriate weight $w_{a}$ and summed providing the output $y[n]$. The weights $w_{a}$ represent the impulse response of the FIR filter. $y[n]$ can be downsampled resulting in output signal $y^{*}[k]$ without introducing significant aliases in-band, when 

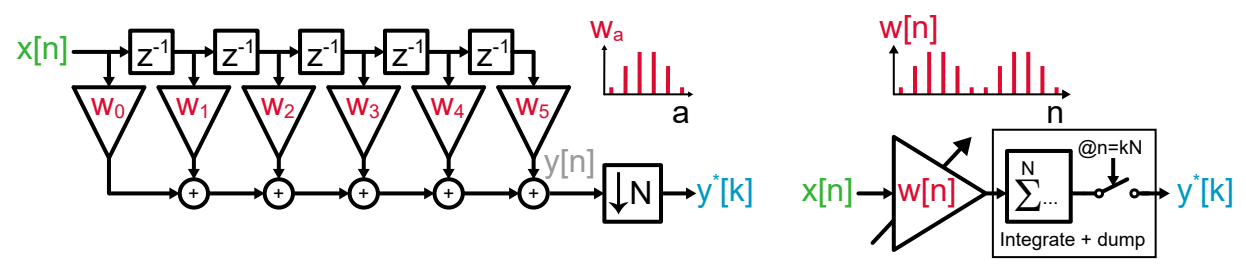

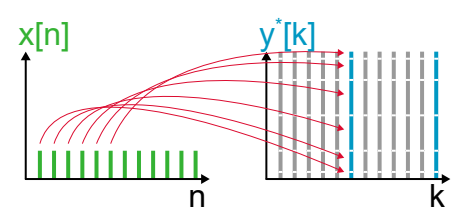

(a)

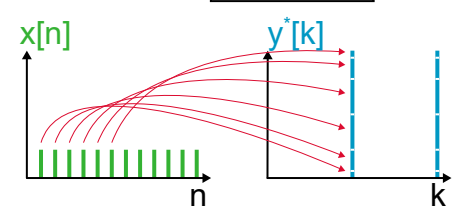

(b)

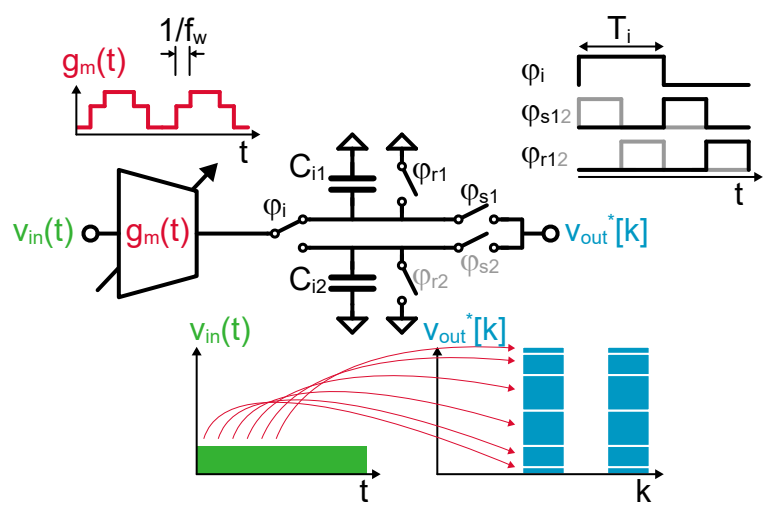

(c)

Figure 2.1: Comparison of different implementations of 6-tap digital and analog FIR filters. Input signals $x[n]$ and $v_{i n}(t)$ are assumed constant for simplicity. (a) Digital FIR with downsampling. (b) Digital FIR with accumulator. (c) Hardware efficient analog FIR.

the FIR filter rejection is sufficient. The corresponding timing diagram shows that an output sample of $y^{*}[k]$ consists of the weighted sum of different time instances of $x[n]$. The straightforward analog implementation is to store the input on multiple capacitors and sum the capacitor voltages while applying the appropriate weighting $[3,4]$. However, this becomes very hardware intensive when moving towards a high number of FIR taps.

Fig. 2.1b shows an alternative approach to implement the same filter. Instead of storing the previous input samples, $x[n]$ is multiplied by time-varying weighting coefficient $w[n]$ and accumulated in the integrate+dump block. The output signal 
$y^{*}[k]$ is constructed in the same way as in Fig. 2.1a and therefore the implementation of Fig. 2.1b has the same filter response.

The proposed analog FIR filter is shown in Fig. 2.1c. It performs a similar operation as its digital analogy (Fig. 2.1b). The input signal $v_{i n}(t)$ is converted to current via transconductance $g_{m}(t)$. The transconductance $g_{m}(t)$ varies in time at rate $f_{w}$ according to the FIR weighting coefficients $w_{a}$. The transconductor output current is integrated (summed) on integration capacitor $C_{i 1}$ during $\phi_{i}$. The output voltage sample $v_{\text {out }}^{*}[k]$ is sampled during $\phi_{s}$ and reset in during $\phi_{r}$. Meanwhile, the input signal is integrated on the other capacitor $C_{i 2}$; providing time for readout and reset. The output samples are thus determined by a weighted summation of previous input "samples" - similarly as in Fig. 2.1a and Fig. 2.1b. However, the windowed integration at $f_{w}$ introduces an extra sinc pre-filter.

The analog FIR transfer function neglecting aliasing is ${ }^{1}[5]$

$$
H(f) \approx \underbrace{\frac{\bar{g}_{m} T_{i}}{C_{i}}}_{\text {gain }} \underbrace{\operatorname{sinc}\left(\frac{f}{f_{w}}\right) e^{j \pi \frac{f}{f_{w}}}}_{\text {windowed } \int} \underbrace{\left.\sum_{a=0}^{N-1} w_{a} z^{-a}\right|_{z=e^{j 2 \pi} \frac{f}{f_{w}}}}_{\text {FIR }}
$$

where $\bar{g}_{m}$ is the average transconductance, $w_{a}$ the weighting coefficients normalized to $\sum w_{a}=1$ and $N$ the number of FIR coefficients. The transfer consists of three parts: gain, sinc windowed integration and the FIR filter. Note that the filter characteristic is determined by the weighting coefficients - only the gain is dependent on $\bar{g}_{m} / C_{i}$. The analog FIR input signal is time-continuous and the output signal time-discrete, so in addition to filtering also aliasing occurs. The output sample rate $f_{s}$ is significantly lower than the time-continuous input. Fortunately, the very strong filtering characteristic of the analog FIR provides sufficient pre-filtering by itself.

The filter bandwidth is inversely proportional — for a given set of FIR coefficients $w_{a}$ - to the filter delay $1 / f_{w}$ and integration time $T_{i}=N / f_{w}$. By doubling $T_{i}$, the filter bandwidth is halved. Fig. 2.1c describes a single path analog FIR design, which filter characteristic is limited by the fixed relationship between sample rate and bandwidth: $f_{s}=1 / T_{i}$. This constraint is broken by interleaving multiple paths. For $m$ paths, this results in an output sample rate

$$
f_{s}=\frac{m}{T_{i}} \quad m=1,2,3 \ldots
$$

\subsection{Transfer Function Analysis}

FIR filter theory can be used to design the analog FIR filter's coefficients. This section starts from the transfer function characteristics based on (2.1) and ends by including

\footnotetext{
${ }^{1}$ In this dissertation, sinc refers to the normalized function: $\operatorname{sinc}(x)=\frac{\sin \pi x}{\pi x}$
} 


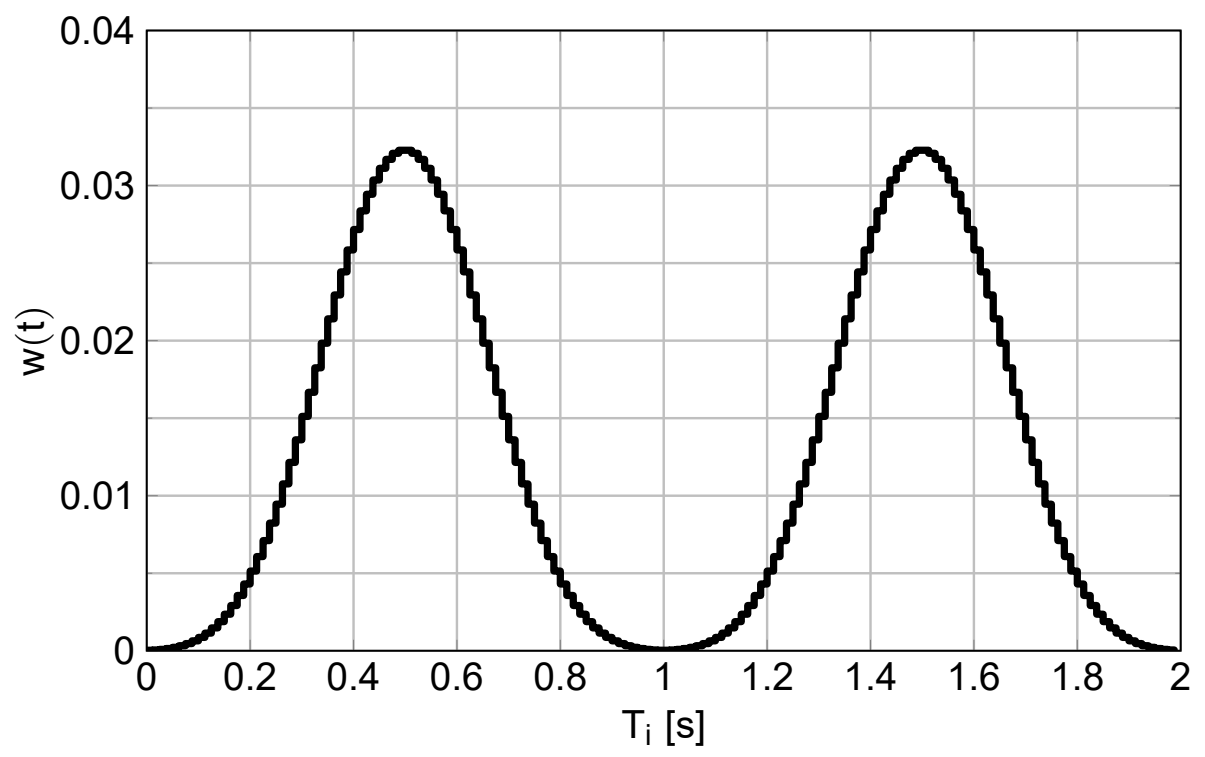

Figure 2.2: Normalized filter coefficients as function of $T_{i}$.

the aliasing due to the output sample rate to provide the complete aliasing picture. A more elaborate analytical derivation is provided in Section 3.2 on page 43, including a frequency domain example starting from several input signals.

The coefficients of a Chebyshev window with $-90 \mathrm{~dB}$ stopband depth are shown in Fig. 2.2. The time variant filter code $w(t)$ is periodic - one set of coefficients are provided each integration cycle. The coefficients are normalized to $\overline{w(t)}=1 / N$ as in (2.1). The number of coefficients is

$$
N=f_{w} T_{i}
$$

in this example 80 . The code is provided with a zero-order hold to the input, which results in the sinc filtering in (2.1).

Fig. 2.3 shows the corresponding analog FIR filter response as function of the integration frequency $\left(1 / T_{i}\right)$. The filter $-3 \mathrm{~dB}$-bandwidth $f_{-3 \mathrm{~dB}}$ is approximately $0.86 / T_{i}$. The gain shows a very steep roll-off (Fig. 2.3a). The stopband starts at $4.1 f_{B W}$ and has $-90 \mathrm{~dB}$ attenuation as designed. Filter aliases are located at multiples of $f_{w}$ and are filtered by the inherent sinc filter as expected. The FIR filter transfer is independent of the number of filter coefficients, only the filter aliases are. The phase response is shown in Fig. 2.3b. It has a linear phase response, because the filter coefficients are symmetric.

The number of time-interleaved paths determines the output sample rate and thereby the aliasing at the output. 


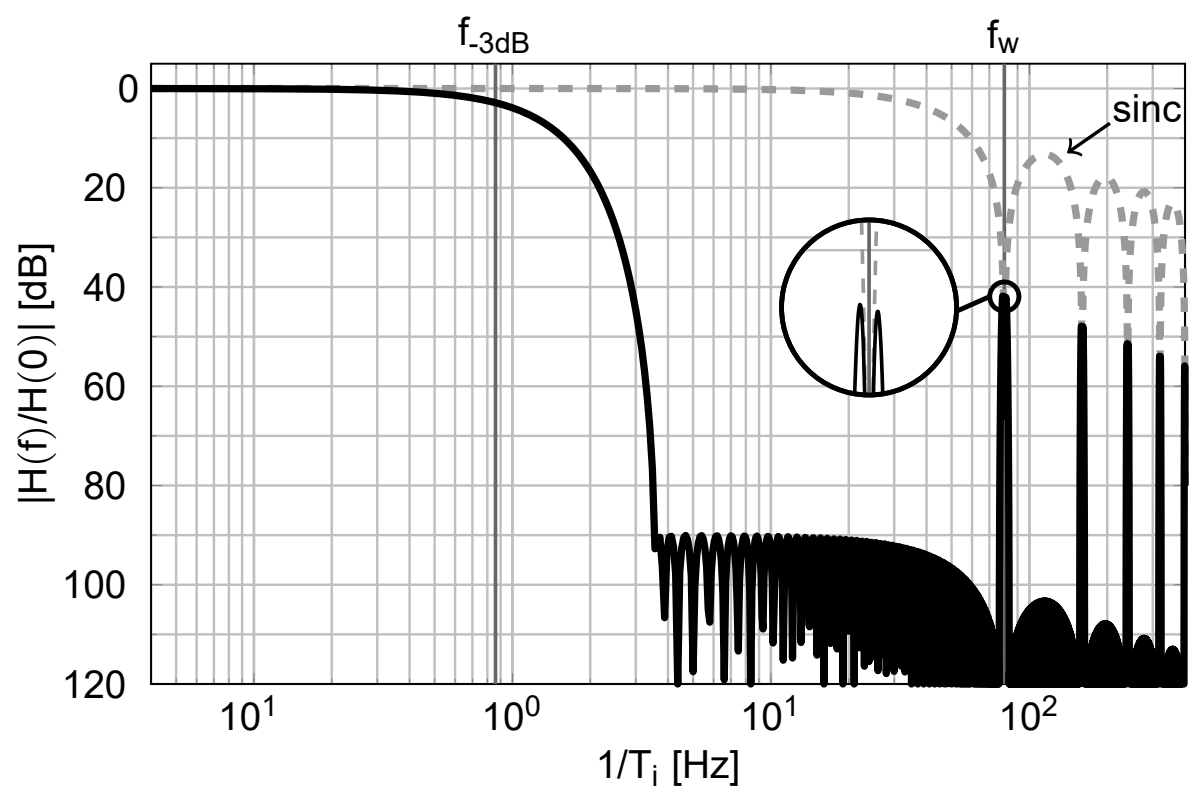

(a)

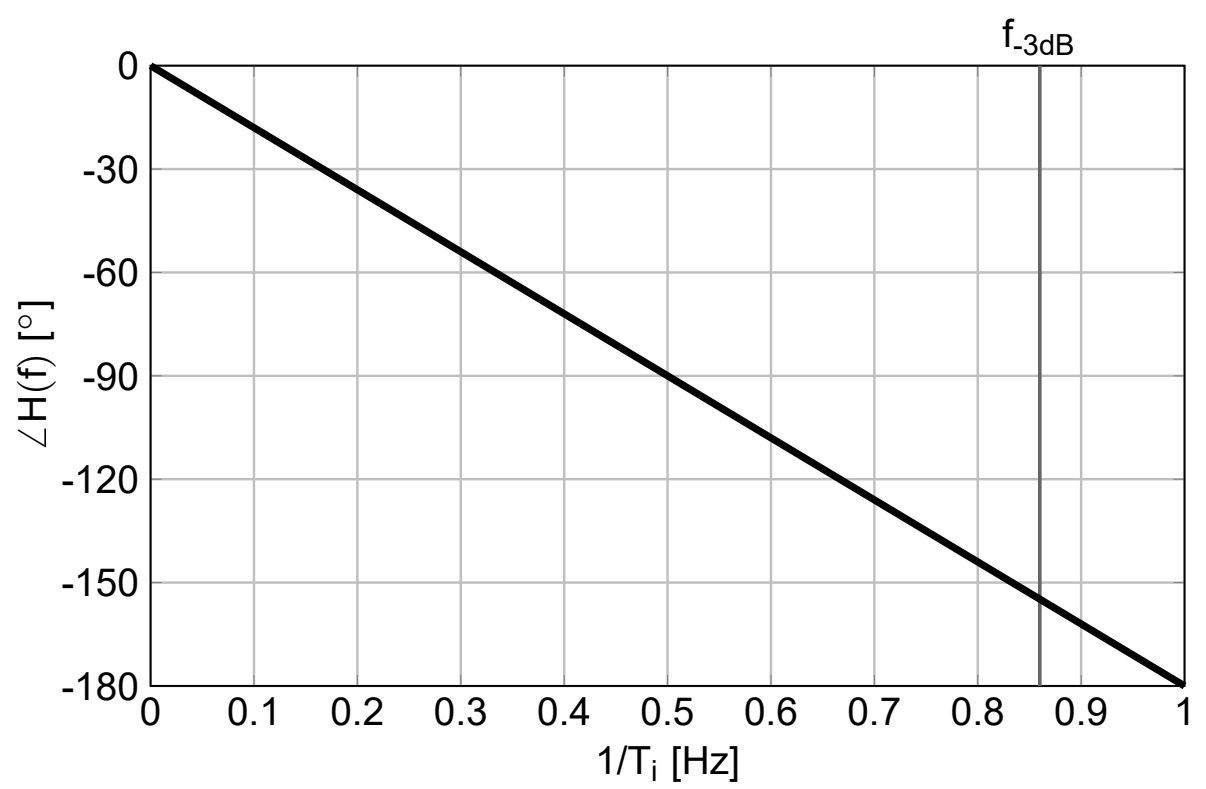

(b)

Figure 2.3: Analog FIR filter transfer as function of the integration frequency. (a) Normalized gain. (b) Phase. 


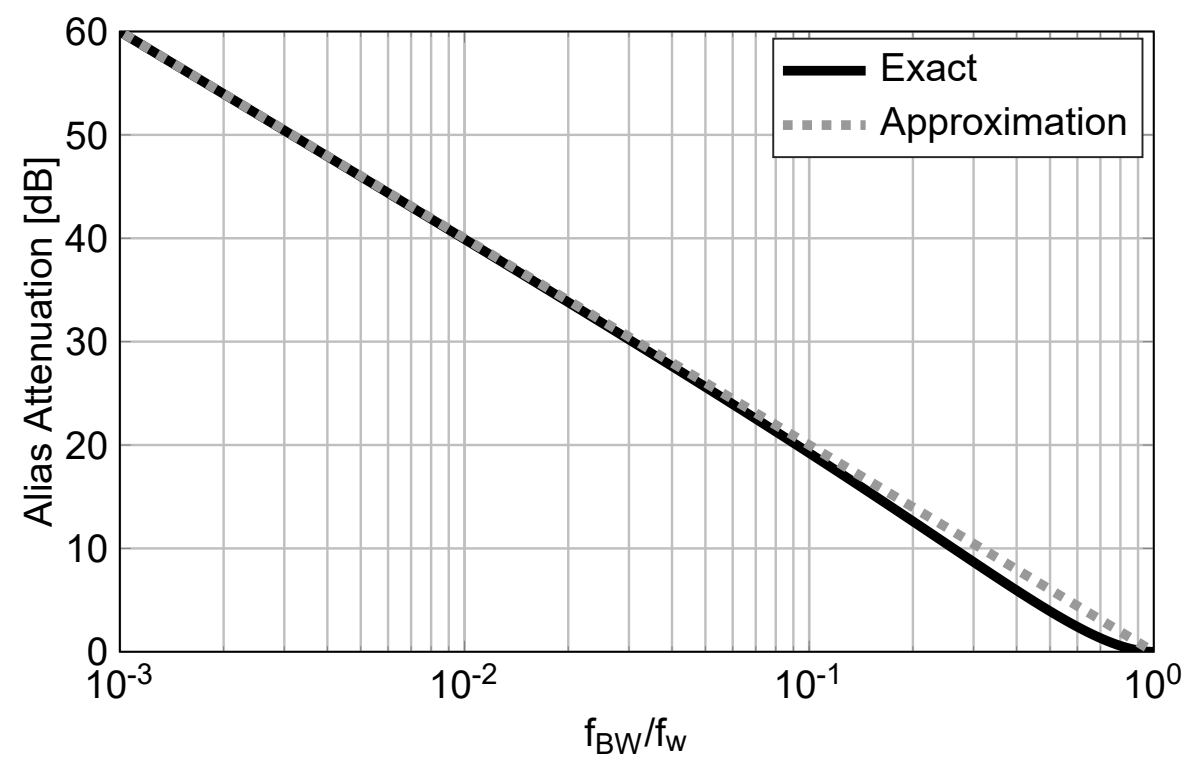

Figure 2.4: Attenuation of the first analog FIR filter alias as function of the normalized filter bandwidth.

\subsubsection{Filter Alias Attenuation}

Fig. 2.3a already indicates that the filter alias attenuation depends on the filter bandwidth $f_{B W}$ : A more narrowband filter will result in a smaller alias as it is more strongly suppressed by the sinc notches. The filter aliases occur on both sides of a notch, but the alias left of the notch is the largest. The sinc gain at the first alias is

$$
\begin{aligned}
\left|H_{\text {sinc }}\left(f_{w}-f_{B W}\right)\right| & =\left|\operatorname{sinc}\left(\frac{f_{w}-f_{B W}}{f_{w}}\right)\right| \\
& \approx f_{B W} / f_{w}
\end{aligned}
$$

assuming $f_{B W} \ll f_{w}$. (2.4) provides the filter alias gain for a brick-wall pass-band. The filter alias attenuation is shown in Fig. 2.4 as function of bandwidth ratio, the alias attenuation is approximately $3 \mathrm{~dB}$ more if the $-3 \mathrm{~dB}$ filter bandwidth is used. The alias at the left-hand side of the notches can be removed by using the quadrature signal path in a radio receiver. The approximation of (2.4) also holds for the right-hand side alias as long as $f_{B W} \ll f_{w}$.

\subsubsection{Time-Interleaving and Output Sample Rate}

The number of time-interleaved filter paths determines the output sample rate $f_{s}$ proportionally according to $(2.2)$. $f_{s}$ eventually determines the output Nyquist rate 


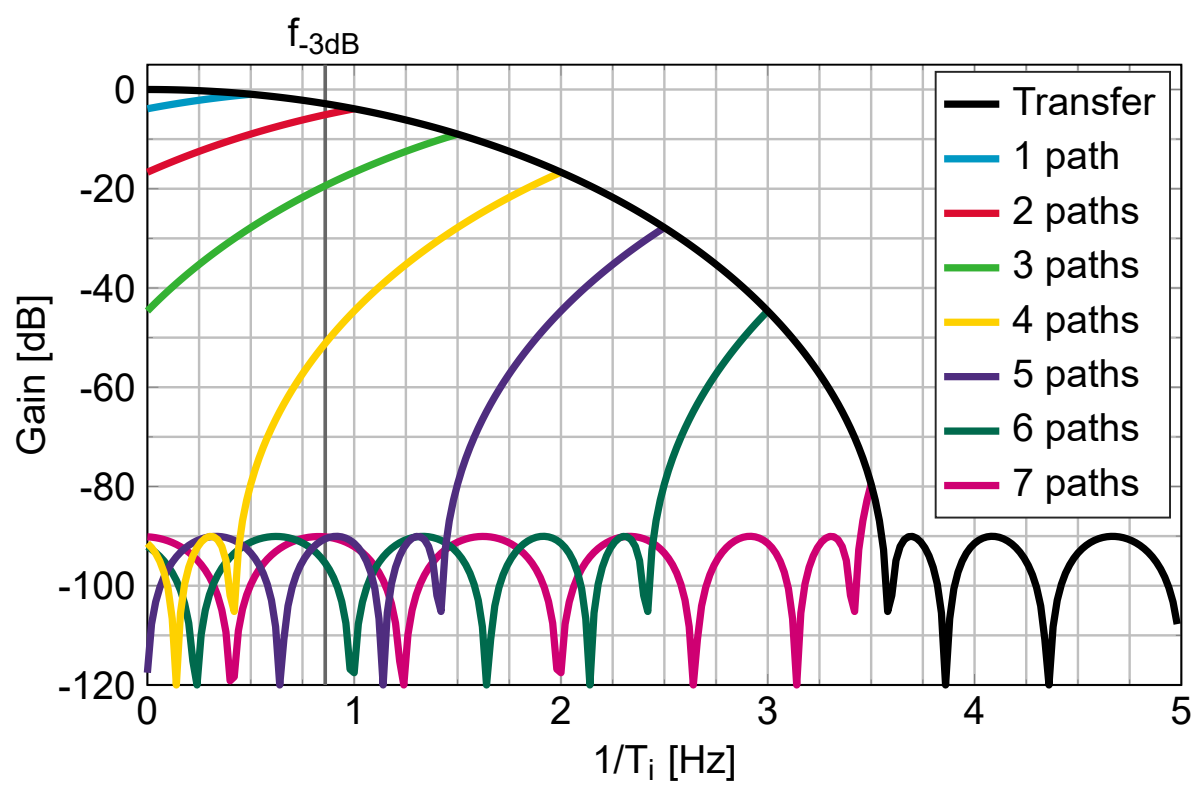

Figure 2.5: Analog FIR filter aliasing of the second Nyquist zone into the first Nyquist zone for different number of time-interleaved paths.

and hence the aliasing at the output. Fig. 2.5 shows the filter transfer as function of the integration time, including the alias of the second Nyquist zone folded into the first Nyquist zone for different number of time-interleaved paths. The first Nyquist zone ends at $f_{s} / 2$. An analog FIR filter with only a single path has $f_{s} / 2=0.5 / T_{i}$, almost half of the filter $f_{-3 d B}$ frequency. Therefore, close-in frequency components are hardly attenuated. The result is significant aliasing of unwanted close-in components, including noise. The strength of the close-in aliases falling into the first Nyquist zone reduces for increasing number paths. Starting from 5 time-interleaved paths, the in-band aliasing $\left(<f_{-3 d B}\right)$ is constrained to the stopband depth $-90 \mathrm{~dB}$ and does not reduce further. Beyond 7 paths the whole first Nyquist zone has only aliases of $-90 \mathrm{~dB}$ attenuation. The required number of paths depends on the application, but the maximum number of "useful" paths is somewhere between 4 to 7 , also depending the filter coefficient design. It is clearly not desirable to have $f_{w}=f_{s}$ - in other words, 80 paths in this example - for minimal hardware and power consumption.

\subsection{Analog FIR Filters Prior Art}

There are many analog FIR and related circuits published. Analog FIR techniques are sometimes also referred to as transversal filtering (before the year 2000) or Filtering- 


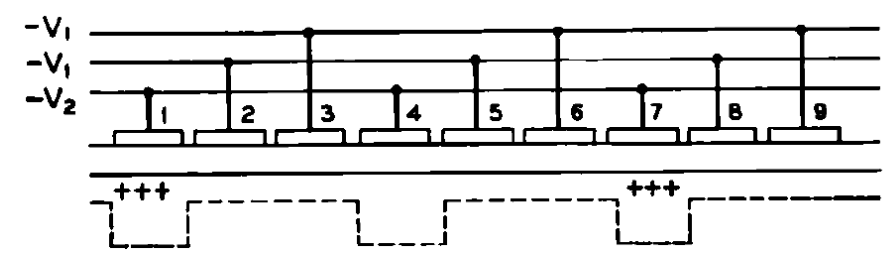

(a)

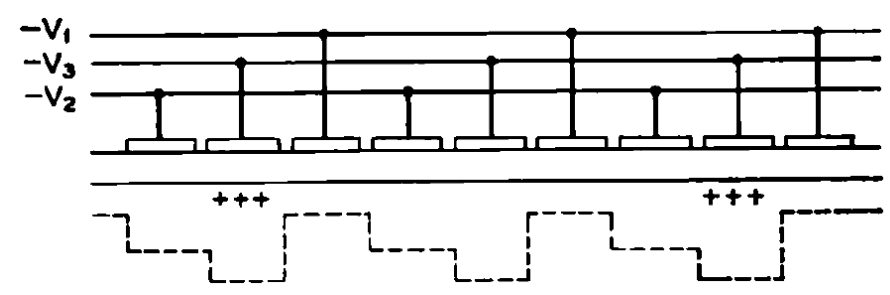

(b)

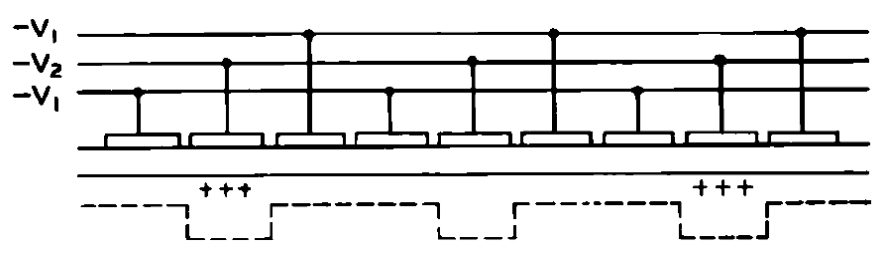

(c)

Figure 2.6: CCD delay line operation [6]. (a) Initial storage state. (b) Charge transfer to the next well. (c) Storage after shifting the charge one well.

by-Aliasing (recently by the University of California, Los Angeles).

First, the analog FIR prior art is described from a historical perspective. Second, the different implementation techniques are discussed. Third, the analog FIR prior art is reviewed in terms of their application. Finally, the prior art is discussed in the context of an IoT receiver.

\subsubsection{History}

Research on integrated analog FIR filters started since the development of charge transfer devices in the late 1960s, early 1970s [7, 8]. Various techniques of charge transfer devices were developed, including bucket-brigade devices (BBDs) [9-11], charge coupled devices (CCDs) [6], surface charge transistors (SCTs) [12], peristaltic charge coupled devices (PCCDs) [13], bulk channel charge coupled devices (BCCDs) [14, 15] and charge injection devices (CIDs) [16, 17]. The filter implementations follow the structure of Fig. 2.1a: A delay-line in which a discrete-time input signal (charge) is 


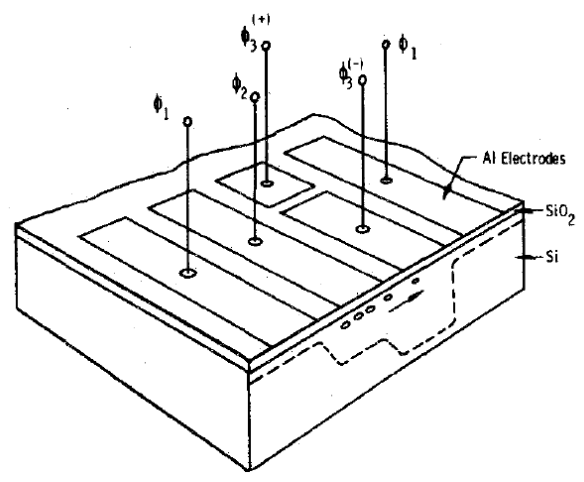

(a)

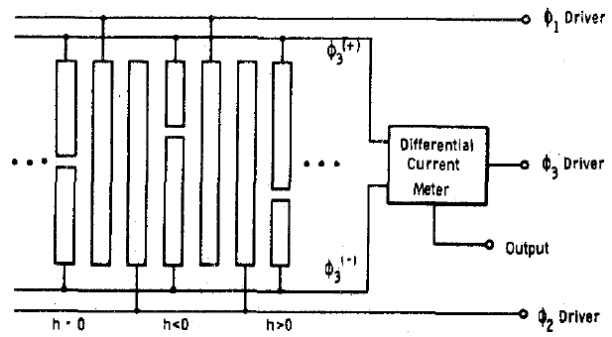

(b)

Figure 2.7: CCD based analog FIR filter [20]. (a) 3d impression. (b) Schematic.

transferred from one memory element (capacitor) to another [7, 8, 18-38].

The operating principle of these charge transfer analog FIR filters is explained on the basis of the CCD, because this one was the most popular. The CCD delay line operating principle is shown in Fig. 2.6 [6]. Below every electrode a potential well is placed where charge can be trapped. Every electrode above a well is connected through a metal line. The timing contains two phases: storage and transfer. Fig. 2.6a is in the storage phase. The storage wells are 1, 4, 7, and so on where charge is stored in wells 1 and 7 , well 4 is empty. Fig. 2.6b shows the transfer phase. The voltages to the electrodes are applied such that $-V_{3}<-V_{2}<-V_{1}$ and the charge transfers to the subsequent well. In Fig. 2.6c, the delay line is back in the storage phase. Except, the charge has moved one potential well. The third electrode, here 3, 6, 9 and so on blocks the charge from transferring backwards - ensuring unilateral operation.

This delay line structure allows to implement an analog FIR filter. Fig. 2.7 shows an implementation employing the CCD delay line [20]. The differential current when transferring the charge to the electrodes connected to $\phi_{3}$ is measured and summed to provide the filter weights and summation. The weights ( $h$ in Fig. $2.7 \mathrm{~b}$ ) are determined by the position where the electrode is split. The delayed inputs are weighted 


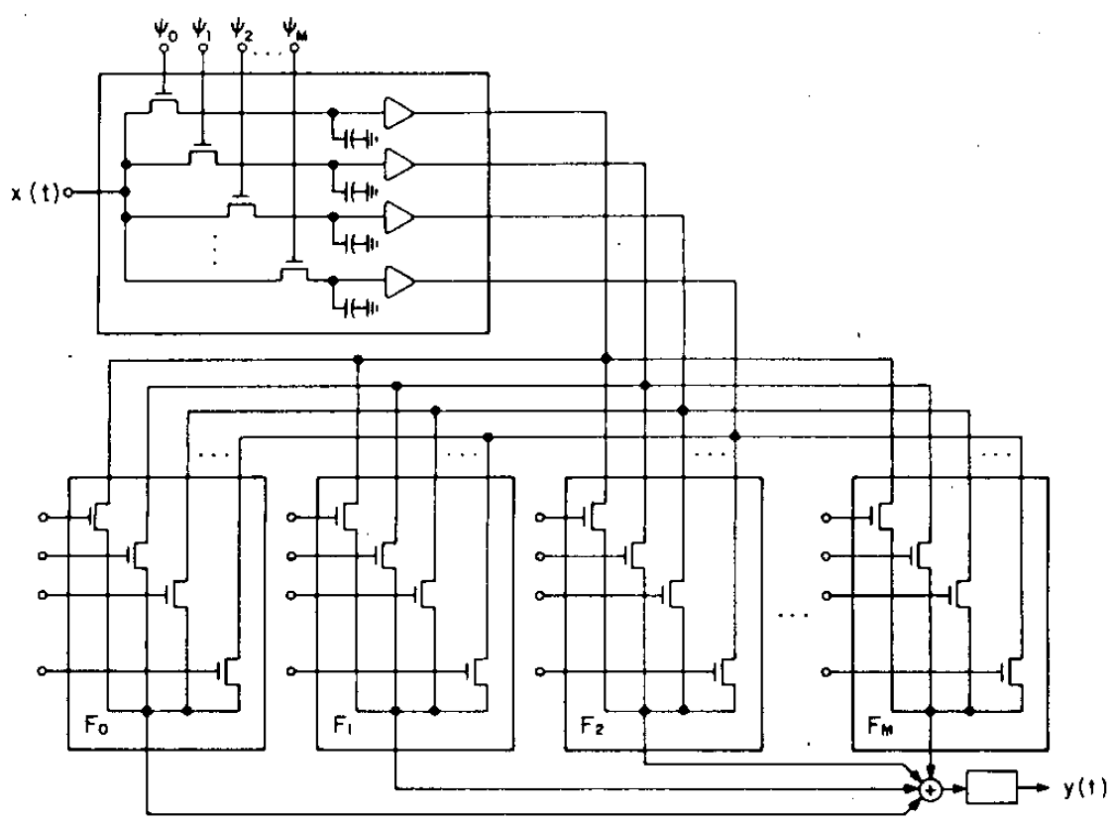

(a)

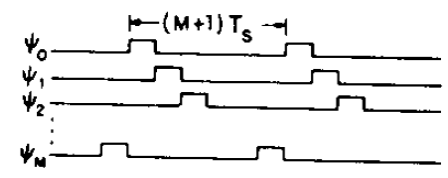

(b)

Figure 2.8: Analog FIR filter with rotating inputs and coefficients [39]. (a) Implementation. (b) Timing waveforms.

and summed to create an output sample. The input and output run at the same rate. The first proposals used only signed weights $(-1$ or +1$)$ for minimal complexity [18]. Shortly after more complicated weights were introduced to provide steeper filtering $[7,19,20,26,27]$, but all these implementations still have fixed weights and thereby a fixed filter shape. The analog FIR circuits are inherently programmable by changing the sampling clock frequency proportionally. More flexibility is obtained by programmable coefficients to allow for a flexible transfer function shape [8, 21, 23, 24, 28 $38]$.

CMOS technology became popular in the 1980s and thereby switch-capacitor implementations of analog FIR filters. Several approaches still used the direct implementation architecture (Fig. 2.1a) [40-51] — where the delay line is implemented using switch-capacitor amplifiers [52] — similar to the charge transfer device analog FIR 


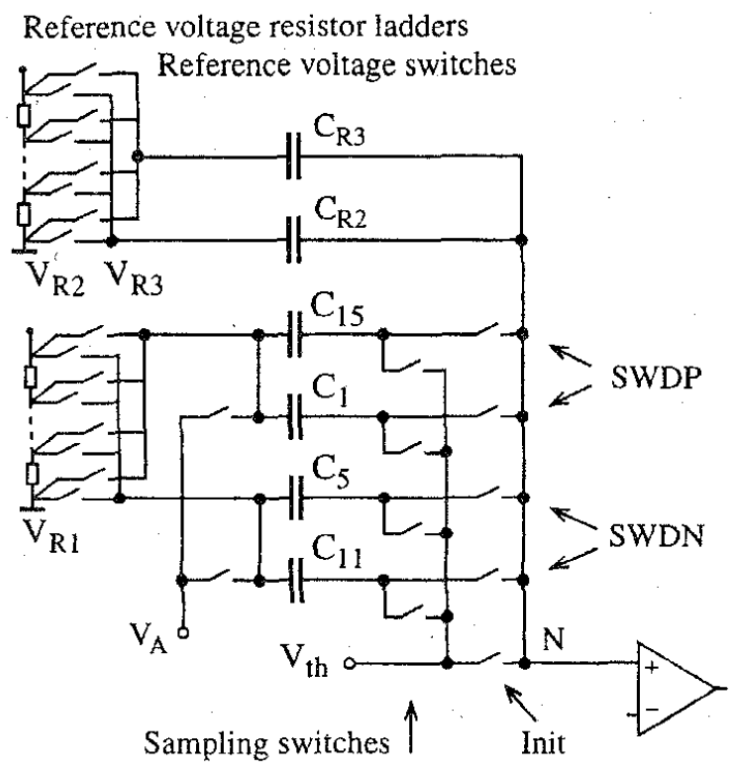

Figure 2.9: Analog FIR filter with sub-sampled output as pre-filter of a SAR ADC $[68]$.

architectures. An alternative circuit implementation removes the need to transfer the stored inputs [39, 44, 53-67] as shown in Fig. 2.8. Instead of transferring previous inputs from one storage element to another, the input is rotated among different storage capacitors. Also the coefficients rotate among the capacitors to create the desired filter response. The stored charge is not passed on. It is undisturbed, which removes the imperfect transfer issues of the direct implementation approach.

The next important step in analog FIR filter development is time-varying coefficients and sub-sampling at the output $[3-5,68-110]$ as — to the author's knowledge — first proposed by Eklund et al. in 1996 [68]. The filter is implemented as prefilter and IF downconverter of a successive-approximation register (SAR) ADC. Downconversion is accomplished by multiplying the filter coefficients with a triangle wave sequence of $1,0,-1,0$. Subsequent samples of the input are sampled on $C_{1}, C_{11}, C_{15}$ and $C_{5}$. The capacitor ratios create the filtering coefficients. Only four capacitors are required for the eight coefficient filter, because half of the coefficients are multiplied by a zero coefficient of the triangle wave. The ADC conversion is done separately for the positive and negative coefficients. The digital values are afterwards subtracted, which is equivalent to correlated double sampling to cancel comparator offset and $1 / f$-noise. However, it results in a constraint on the filter coefficients. The positive and negative coefficients have to add up equal to remove the DC input. The architec- 
ture with inherent sub-sampled output makes use one of the most common purposes of a filter: Allow sampling at a low(er) sample rate without significant aliasing.

The introduction of charge domain sampling [84, 111-113] in 1995 by Carley et al. [111] allows for a continuous-time input to the analog FIR filter. The charge domain analog FIR filter does not sample the input signal before providing the coefficients, but uses a continuous-time input signal as in Fig. 2.1c [3, 5, 65, 66, 69-73, 77-79, 8588, 90, 92, 93, 96-98]. This has an advantage of filtering the filter aliases by the inherent windowed integration sinc filter, instead of having unattenuated aliases when employing voltage sampling. However, it can result in sinc "distortion" [3, 93, 98] if the filter bandwidth is large compared to the coefficient update rate.

\subsubsection{Implementation Techniques}

A typical analog FIR circuit has a continuous-time voltage domain input and discretetime voltage domain output. To obtain an analog FIR filter four functions are required:

1. Coefficient multiplication;

2. Voltage-to-current $(\mathrm{V} \rightarrow \mathrm{I})$ conversion, or alternatively voltage-to-charge $(\mathrm{V} \rightarrow \mathrm{Q})$ conversion;

3. Integration or summation;

4. Sampling.

In CMOS processes, integration is typically implemented by a current or charge onto a capacitor. The $\mathrm{V} \rightarrow \mathrm{I}$ or $\mathrm{V} \rightarrow \mathrm{Q}$ conversion is directly related, since the input is typically voltage-domain and a current or charge is required for integration.

The coefficient multiplication can be implemented in various ways, resulting in different configurations of the analog FIR filters as shown in Fig. 2.10. Most analog FIR publications use charge based signal processing with coefficients based on capacitor ratios, which places the filter after either voltage-mode (Fig. 2.10a) [38, 40$42,44,45,47,49-51,53-56,67,68,74,76,82,89,94,95,107-109,114-118]$ or current-mode sampling (Fig. 2.10b) [3, 79, 81, 85, 86, 86, 88, 90-93, 96-98, 119] of the input signal. The weights can also be applied prior to sampling as illustrated in Fig. 2.10c. The $\mathrm{V} \rightarrow \mathrm{I}$ conversion can e.g. be implemented as a time-varying transconductor $[4,57,61,62,110]$. An alternative is to use resistors (conductors) to implement the coefficients in the $\mathrm{V} \rightarrow \mathrm{I}$ conversion process $[69,100-106,110,120]$. Prior to the $\mathrm{V} \rightarrow \mathrm{I}$ conversion, the weights can be applied in the voltage domain by voltage amplification or attenuation $[70,72,73]$ as shown in Fig. 2.10d. Fig. 2.10e shows the implementation where the weights are implemented in the current domain after the $\mathrm{V} \rightarrow \mathrm{I}$ conversion $[5,43,58-60,63-66,71,77,78]$. 


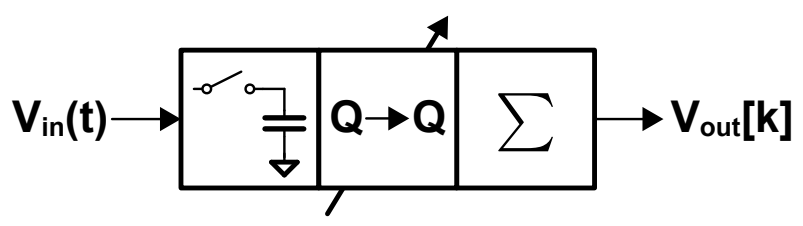

(a)

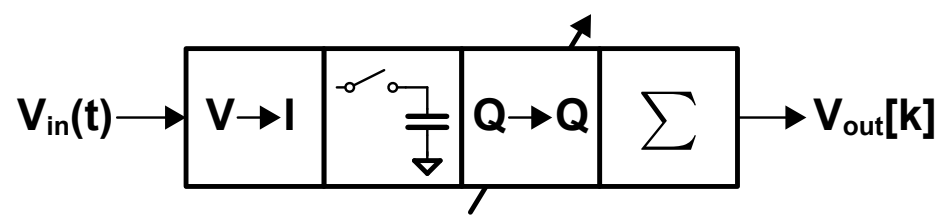

(b)

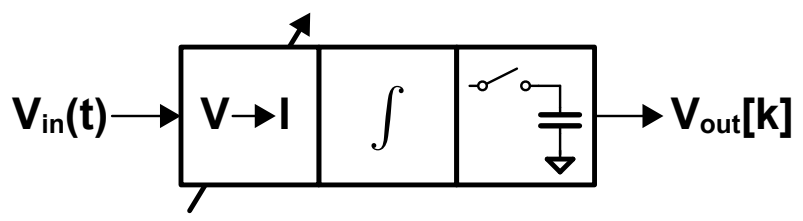

(c)

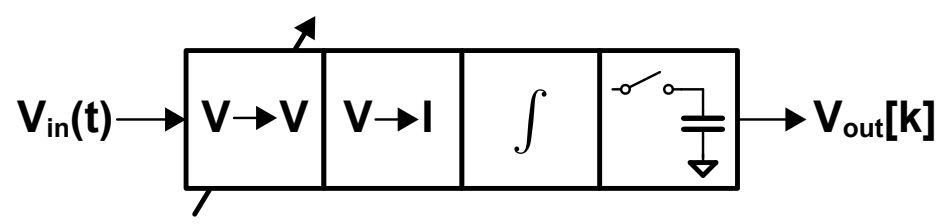

(d)

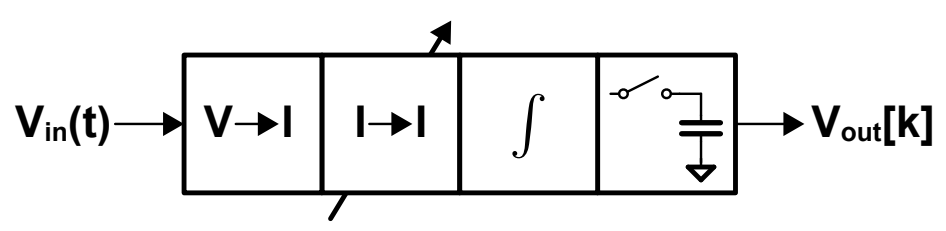

(e)

Figure 2.10: Different analog FIR filter configurations.

\subsubsection{Applications}

An analog FIR circuit is basically a signal processor that can implement any arbitrary finite impulse-response. Fig. 2.11 provides an analog FIR circuit overview categorized by the applications.

Analog FIR filters are most often applied as LPF [3-5, 22, 27, 31, 34-37, 39, 42, $43,51,53,54,58,63,64,67,70-77,79-83,85-97,100,114-116,119,121,122]$ as 


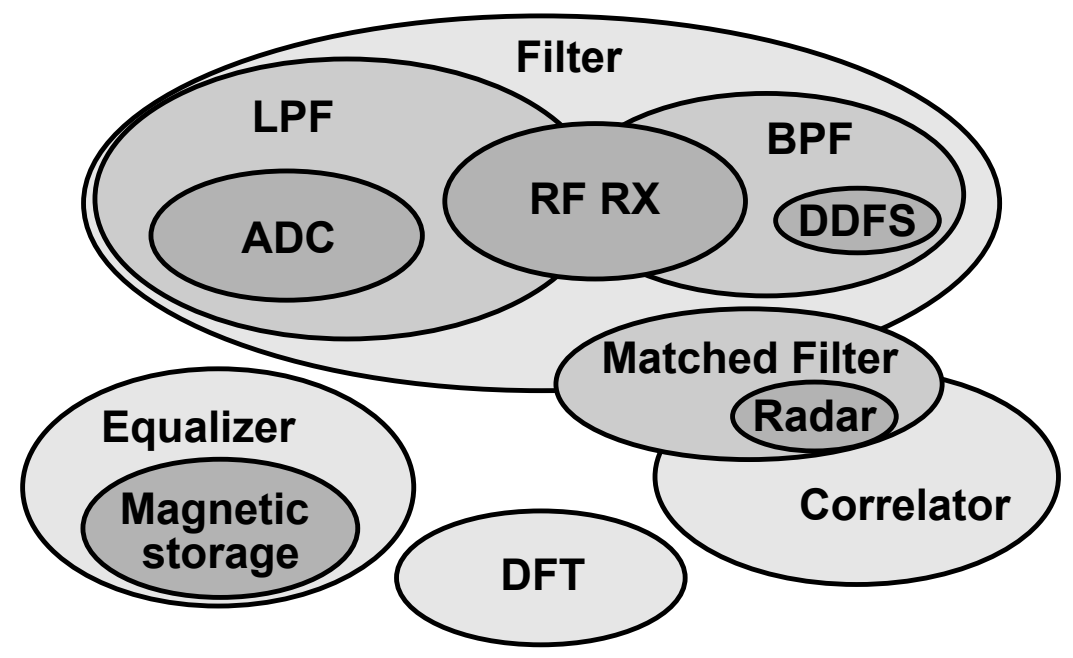

Figure 2.11: Analog FIR circuit applications.

they can provide (programmable) filters with steep roll-off and linear phase. The bandwidth is tunable by the FIR coefficient update rate. Bandpass filters (BPFs) can be implemented by multiplying the LPF FIR coefficients by the center frequency sine wave $[5,22,34,35,41,49,50,53,55,58,65,68,69,77,78,80,100-106,110]$.

Analog FIR filters are very suitable to implement anti-aliasing filtering of a subsequent (SAR) ADC to reduce the required sample rate and dynamic range of the $\mathrm{ADC}$ and thereby its power consumption $[4,5,51,67,68,75-77,79-82,91,94,95$, 108, 109, 115, 116, 119, 121, 123]. Analog FIR anti-alias filters can also be used to remove digital-to-analog converter (DAC) replicas e.g. for in direct-digital frequency systhesis (DDFS) systems [49, 50].

In $\mathrm{RF}$ receivers (RXs) analog FIR filters were first introduced as (higher order) sinc filters, which provide not much filtering [74, 79, 80, 116, 119, 121]. The selectivity demand is increasing with the increasing number of wireless devices. Instead of higher order sinc filters, FIR coefficient design can be used to increase the selectivity of the analog FIR filters in RF receivers $[51,67,75,76,81,83,91,94,95,101,102,102-$ 106, 110, 115, 122, 124].

In addition to filters, the analog FIR circuits are used as general purpose sampled analog signal processing. The first analog FIR circuits were applied as binary matched filters to pseudo-random noise signals [7, 18, 19, 29]. The analog FIR matched filters also have a potential application in radar receivers [125]. An alternative is to employ the analog FIR circuits implemented as analog-analog or analog-digital crosscorrelators $[21,23,24,28,30,33,38]$. It is an alternative to digital signal processing units and was also advocated as such in the first decade of analog FIR research. 
Analog FIR techniques can also be implemented as equalizers [45-48, 57, 59$62,117]$. In the 1990s, the analog FIR equalizer was a popular research topic for the read-out circuits of magnetic storage devices [45, 46, 48, 57-62].

The analog FIR circuits can be paralleled to implement a discrete Fourier transform (DFT), because each discrete Fourier coefficient is the sum of weighted delayed inputs $[21,25,26,40,107,118]$.

\subsubsection{Discussion}

Almost all prior art analog FIR filters have a high power consumption of $>1 \mathrm{~mW}$ and most of them much more, which is higher than the desired power consumption of the entire IoT receiver. To reduce power consumption, first of all, sub-sampling is important. The inherent anti-alias filtering of the analog FIR filter allows for a low sample rate at the output — in the order of twice the filter bandwidth — when the filter roll-off is steep.

A very steep filter roll-off can be obtained by properly designing the filter coefficients and having a sufficiently long integration time, which is not used by most prior art. The Filtering-by-Aliasing publications [99-106, 110] do have steep filtering. The FIR weights are applied at the input resistor of a mixer first receiver. Therefore the required update rate of the FIR coefficients is very high - much larger than the frequency of the RF wanted signal. The result is very high power consumption $(>60 \mathrm{~mW})$ at $500 \mathrm{MHz}$ RF input frequency - much lower than the $2.4 \mathrm{GHz}$ ISM band $[101,102,105,106,110]$.

The only $<1 \mathrm{~mW}$ work is by Harpe in 2018. The analog FIR anti-aliasing filter in the SAR ADC consumes only $15.2 \mu \mathrm{W}[108,109]$. However, the filter has limited stopband attenuation of $42 \mathrm{~dB}$ and has no suppression of the sinc aliases.

\subsection{Analogous Filters}

Analog finite impulse-responses are not only used in on-chip circuits, but are also employed in other application areas. Two examples are shortly discussed in this section: (spatial) filtering in phased-array antennas and surface acoustic wave (SAW) filters.

\subsubsection{Phase-Array Antennas}

A phased-array antenna with 6 radiating elements is shown in Fig. 2.12. At the farfield wavefront, the waves coming from different elements experience a different delay. 


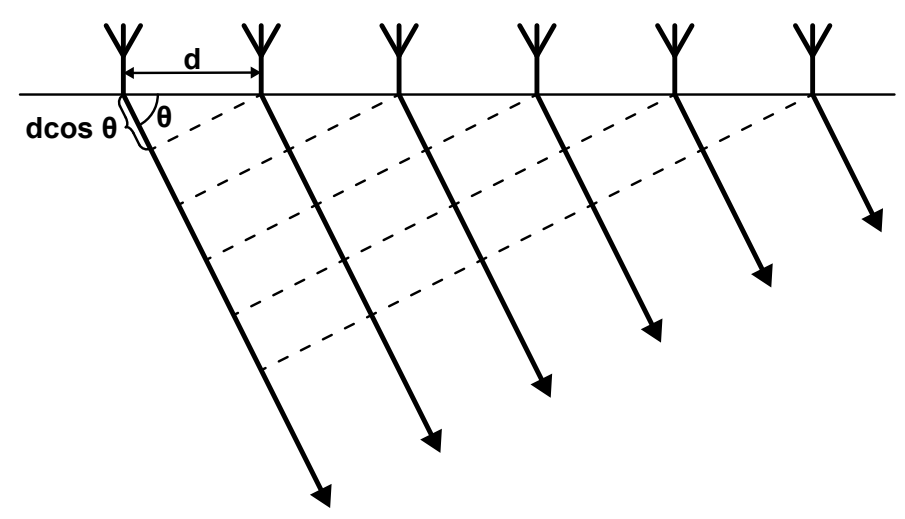

Figure 2.12: Linear phased-array antenna consisting of 6 radiating elements.

The delay between the waves of two neighboring antennas is [126]

$$
\Delta t=\frac{d \cos \theta}{c}
$$

where $c$ is the speed-of-light in air. FIR frequency filtering can be achieved by applying a different weight to each antenna element, e.g. at the amplifier before the antenna.

The result is an FIR filter frequency response in the far-field for a given angle $\theta$. The other way around, a single frequency will experience different delay per element in different directions. Therefore, the signal strength is different in different directions depending on the element weights (amplitude and phase). This results in spatial filtering, which is the main application of phased array antennas. It is very similar to the FIR frequency filtering, except that the spatial characteristics show up in the factor $\cos \theta$.

\subsubsection{Surface Acoustic Wave Filters}

A basic SAW filter schematic is shown in Fig. 2.13a [127, 128]. An input signal is connected to an interdigital transducer (IDT) that acts as the input - converting the electrical signal to an acoustic signal by means of piezoelectric material. The signal is transferred as a surface acoustic wave to the output IDT where the signal is converted back to the electrical domain. Absorbers are often used to suppress spurious SAW transmissions, because the IDTs are bidirectional [127, 128].

The operating principle of the filtering is as follows. The electrical signal arrives approximately instantaneous at all the fingers of the input IDT. The effective surface acoustic wave is the sum of the individual waves traveling from the fingers that all have a different distance to the wavefront. The acoustic wave velocity is much smaller than the electro-magnectic velocity. Therefore, the individual waves experience a different 


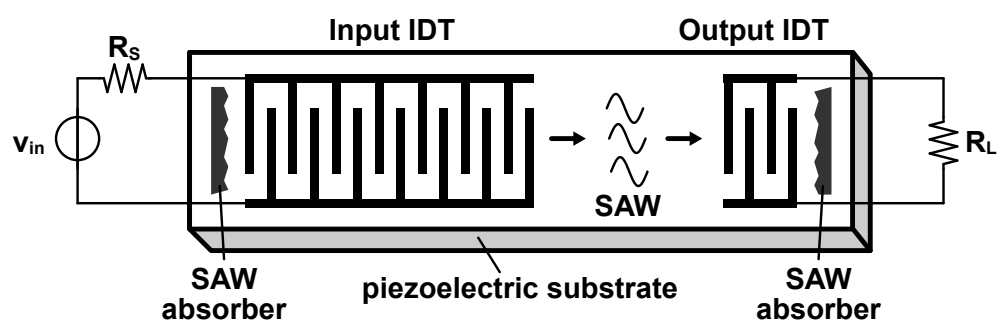

(a)

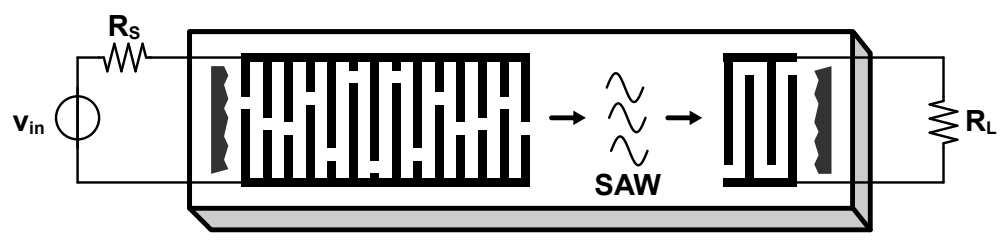

(b)

Figure 2.13: SAW filter. (a) Basic schematic. (b) Filter with one apodized IDT.

delay - similar to an end-fire $\left(\theta=0^{\circ}\right)$ array antenna. In Fig. 2.13a all fingers are the same length, which results in sinc filtering — FIR filtering with all equal weights - around the center frequency

$$
f_{0}=v / \lambda_{0}
$$

where $v$ is the SAW velocity and $\lambda_{0}$ the IDT finger spacing. By changing the finger size of one IDT, the strength of the corresponding individual waves is changed and therefore the transfer function's coefficients as shown Fig. 2.13. This apodizing of an IDT was first proposed by Hartemann and Dieulesaint in 1969 [129]. A sinc IDT finger profile will result in a "brick-wall" filter in the frequency domain as for an FIR filter with sinc coefficients.

\subsection{Summary}

Analog FIR filters employ the advantages of (digital) FIR filters in the analog domain. They have inherently stable steep filtering with linear phase response, for symmetric coefficients, and are programmable. However, analog FIR filters are not common practice in (IoT) receivers, because of their high power consumption or designs with only limited filtering. SAW filters, that exhibit a finite impulse-response, are employed in almost all smartphone and cellphone RF front-end modules units used today for the purpose of steep filtering a particular frequency band. Analog FIR filters could 
provide highly selective receiver front-ends for IoT applications as long as their power consumption is low.

Analog FIR circuits have many potential applications: e.g. as (channel) filter in $\mathrm{RF}$ receivers, anti-aliasing filters of ADCs, matched filters for radar, correlator or to perform discrete Fourier transforms. Circuit implementation improvements designed for the targeted IoT receiver application in this dissertation can be reused in other analog FIR applications.

\section{References}

[1] B. J. Thijssen, E. A. M. Klumperink, P. Quinlan, and B. Nauta, "A 0.06-3.4$\mathrm{MHz}$ 92- $\mu \mathrm{W}$ Analog FIR Channel Selection Filter With Very Sharp Transition Band for IoT Receivers," IEEE Solid-State Circuits Lett., vol. 2, no. 9, pp. $171-174,2019$.

[2] ——, "A 0.06-3.4-MHz 92- $\mu$ W Analog FIR Channel Selection Filter With Very Sharp Transition Band for IoT Receivers," in IEEE Eur. Solid State Circuits Conf., Sep. 2019.

[3] M.-F. Huang, M.-C. Kuo, T.-Y. Yang, and X.-L. Huang, "A 58.9-dB ACR, 85.5-dB SBA, 5-26-MHz Configurable-Bandwidth, Charge-Domain Filter in 65nm CMOS," IEEE J. Solid-State Circuits, vol. 48, no. 11, pp. 2827-2838, Nov. 2013.

[4] E. O'hAnnaidh, E. Rouat, S. Verhaeren, S. L. Tual, and C. Garnier, "A 3.2GHzSample-Rate $800 \mathrm{MHz}$ Bandwidth Highly Reconfigurable Analog FIR Filter in 45nm CMOS," in IEEE Int. Solid-State Circuits Conf. Dig. Tech. Pap., vol. 2, Feb. 2010, pp. 90-91.

[5] S. Karvonen, T. A. D. Riley, and J. Kostamovaara, "A CMOS Quadrature Charge-Domain Sampling Circuit with 66-dB SFDR up to $100 \mathrm{MHz}$," IEEE Trans. Circuits Syst. I Regul. Pap., vol. 52, no. 2, pp. 292-304, Feb. 2005.

[6] W. S. Boyle and G. E. Smith, "Charge Coupled Semiconductor Devices," Bell Syst. Tech. J., vol. 49, p. 587, 1970.

[7] D. Buss, C. Reeves, W. Bailey, and D. Collins, "Charge Transfer Devices in Frequency Filtering," in Symp. Freq. Control, 1972, pp. 171-179.

[8] R. D. Baertsch, "Transversal Filters with Charge Transfer Devices," IEEE Trans. Nucl. Sci., vol. 24, no. 1, pp. 312-316, 1977. 
[9] F. L. J. Sangster and K. Teer, "Bucket-Brigade Electronics: New Possibilities for Delay, Time-Axis Conversion, and Scanning," IEEE J. Solid-State Circuits, vol. 4, no. 3, pp. 131-136, Jun. 1969.

[10] F. L. J. Sangster, "Integrated MOS and Bipolar Analog Delay Lines Using Bucket-Brigade Capacitor Storage," in IEEE Int. Solid-State Circuits Conf. Dig. Tech. Pap., vol. XIII, 1970, pp. 74-75.

[11] —_, "The Bucket Brigade Delay Line, A Shift Register for Analog Signals," Philips Tech. Rev., vol. 31, pp. 99-110, 1970.

[12] W. Engeler, J. Tiemann, and R. Baertsch, "The Surface-Charge Transistor," IEEE Trans. Electron Devices, vol. 18, no. 12, pp. 1125-1136, Dec. 1971.

[13] M. J. J. Theunissen and L. J. M. Esser, "PCCD Technology and Performance," in Int. Conf. Tech. Appl. Charg. Coupled Devices, 1974, pp. 106-113.

[14] M. D. Jack and R. H. Dyck, "Charge Transfer Efficiency in a Buried-Channel Charge-Coupled Device at Very Low Signal Levels," IEEE J. Solid-State Circuits, vol. 11, no. 1, pp. 160-166, Feb. 1976.

[15] —-, "Charge-Transfer Efficiency in a Buried-Channel Charge-Coupled Device at Very Low Signal Levels," IEEE Trans. Electron Devices, vol. 23, no. 2, pp. 228-234, Feb. 1976.

[16] H. K. Burke and G. J. Michon, "Charge Injection Imaging: Operating Techniques and Performances Characteristics," IEEE J. Solid-State Circuits, vol. 11, no. 1, pp. 121-128, Feb. 1976.

[17] — , "Charge-Injection Imaging: Operating Techniques and Performances Characteristics," IEEE Trans. Electron Devices, vol. 23, no. 2, pp. 189-196, Feb. 1976.

[18] D. D. Buss, W. H. Bailey, and D. R. Collins, "Bucket-Brigade Analog Matched Filters," in IEEE Int. Solid-State Circuits Conf. Dig. Tech. Pap., vol. XV, 1972, pp. 250-251.

[19] D. R. Collins, W. H. Bailey, W. Gosney, and D. D. Buss, "Charge-CoupledDevice Analogue Matched Filters," Electron. Lett., vol. 8, no. 13, p. 328, 1972.

[20] D. D. Buss, D. R. Collins, W. H. Bailey, and C. R. Reeves, "Transversal Filtering Using Charge-Transfer Cevices," IEEE J. Solid-State Circuits, vol. 8, no. 2, pp. 138-146, Apr. 1973. 
[21] D. R. Lampe, M. H. White, J. L. Fagan, and J. H. Mims, "An ElectricallyReprogrammable Analog Transversal Filter," in IEEE Int. Solid-State Circuits Conf. Dig. Tech. Pap., Feb. 1974, pp. 156-157.

[22] C. M. Puckette, W. J. Butler, and D. A. Smith, "Bucket-Brigade Transversal Filters," IEEE Trans. Circuits Syst., vol. 21, no. 4, pp. 502-510, Jul. 1974.

[23] J. Tiemann, R. Baertsch, and W. Engeler, "A Surface-Charge Correlator," in IEEE Int. Solid-State Circuits Conf. Dig. Tech. Pap., Feb. 1974, pp. 154-155.

[24] J. Tiemann, W. Engeler, and R. Baertsch, "A Surface-Charge Correlator," IEEE J. Solid-State Circuits, vol. 9, no. 6, pp. 403-410, Dec. 1974.

[25] R. Brodersen, Horng-Sen Fu, R. Frye, and D. Buss, "A 500-Point Fourier Transform using Charge-Coupled Devices," in IEEE Int. Solid-State Circuits Conf. Dig. Tech. Pap., vol. XVIII, no. 9, 1975, pp. 144-145.

[26] R. Brodersen, C. Hewes, and D. Buss, "A 500-Stage CCD Transversal Filter for Spectral Analysis," IEEE J. Solid-State Circuits, vol. 11, no. 1, pp. 75-84, Feb. 1976.

[27] R. D. Baertsch, W. E. Engeler, H. S. Goldberg, C. M. Puckette, and J. J. Tiemann, "The Design and Operation of Practical Charge-Transfer Transversal Filters," IEEE J. Solid-State Circuits, vol. 11, no. 1, pp. 65-74, 1976.

[28] P. Bosshart, "An Integrated Analog Correlator Using Charge-Coupled Devices," in IEEE Int. Solid-State Circuits Conf. Dig. Tech. Pap., 1976, pp. 198-199.

[29] B. E. Burke and W. T. Lindley, "New C.C.D. Programmable Transversal Filter," Electron. Lett., vol. 13, no. 18, p. 521, 1977.

[30] Y. Haque and M. Copeland, "Design and Characterization of a Real-Time Correlator," IEEE J. Solid-State Circuits, vol. 12, no. 6, pp. 642-649, Dec. 1977.

[31] P. Denyer, J. Mavor, and J. Arthur, "Miniature Programmable Transversal Filter Using CCD/MOS Technology," Proc. IEEE, vol. 67, no. 1, pp. 42-50, 1979.

[32] Y. Haque and M. Copeland, "Distortion in Rotating Tap Weight Transversal Filters," IEEE J. Solid-State Circuits, vol. 14, no. 3, pp. 627-633, Jun. 1979.

[33] E. P. Herrmann and D. A. Gandolfo, "Programmable CCD Correlator," IEEE Trans. Electron Devices, vol. 26, no. 2, pp. 117-122, 1979. 
[34] R. A. Haken, R. C. Pettengill, and L. R. Hite, "A General Purpose 1024-stage Electronically Programmable Transversal Filter," IEEE J. Solid-State Circuits, vol. 15, no. 6, pp. 984-996, Dec. 1980.

[35] S. Tanaka and L. Lin, "An Integrated Real-Time Programmable Transversal Filter," IEEE J. Solid-State Circuits, vol. 15, no. 6, pp. 978-983, Dec. 1980.

[36] I. A. van Gelder, G. J. Declerck, and M. A. Copeland, "Programmable Transversal Filter," Electron. Lett., vol. 17, no. 17, p. 605, 1981.

[37] R. A. Haken, "An Electronically Programmable Transversal Input Filter," IEEE J. Solid-State Circuits, vol. 17, no. 1, pp. 34-39, 1982.

[38] A. Chiang and B. Burke, "A High-Speed Digitally Programmable CCD Transversal Filter," IEEE J. Solid-State Circuits, vol. 18, no. 6, pp. 745-753, 1983.

[39] Y. Tsividis, "Signal Processors with Transfer Function Coefficients Determined by Timing," IEEE Trans. Circuits Syst., vol. 29, no. 12, pp. 807-817, Dec. 1982.

[40] N. Reddy and M. Swamy, "Switched-Capacitor Realization of a Discrete Fourier Transformer," IEEE Trans. Circuits Syst., vol. 30, no. 4, pp. 254-255, Apr. 1983.

[41] K. Matsui, T. Matsuura, S. Fukasawa, Y. Izawa, Y. Toba, N. Miyake, and K. Nagasawa, "CMOS Video Filters Using Switched Capacitor 14-MHz Circuits," IEEE J. Solid-State Circuits, vol. 20, no. 6, pp. 1096-1102, Dec. 1985.

[42] J. E. Franca and S. Santos, "FIR Switched-Capacitor Decimators with ActiveDelayed Block Polyphase Structures," IEEE Trans. Circuits Syst., vol. 35, no. 8, pp. 1033-1037, 1988.

[43] G. Liang and D. Allstot, "FIR Filtering Using CMOS Switched-Current Techniques," in IEEE Int. Symp. Circuits Syst., vol. 3, 1990, pp. 2291-2293.

[44] J. E. Franca and V. F. Dias, "Systematic method for the design of multiamplifier switched-capacitor FIR decimator circuits," IEE Proceedings, Part G Circuits, Devices Syst., vol. 138, no. 3, pp. 307-314, 1991.

[45] R. Gomez, M. Rofougaran, and A. A. Abidi, "A Discrete-Time Analog Signal Processor for Disk Read Channels," in IEEE Int. Solid-State Circuits Conf. Dig. Tech. Pap., vol. 27, no. 2, 1993, pp. 212-213.

[46] R. G. Yamasaki, T. Pan, M. Palmer, and D. Browning, "A $72 \mathrm{Mb} / \mathrm{s}$ PRML Disk-Drive Channel Chip with an Analog Sampled-Data Signal Processor," in IEEE Int. Solid-State Circuits Conf. Dig. Tech. Pap., 1994, pp. 278-279. 
[47] B. C. Rothenberg, S. H. Lewis, and P. J. Hurst, "A 20MSamples WwitchedCapacitor Finite-Impulse-Response Filter in $2 \mu \mathrm{mCMOS}$," in IEEE Int. SolidState Circuits Conf. Dig. Tech. Pap., no. 92, 1995, pp. 210-211.

[48] J. Sonntag, O. Agazzi, P. Aziz, H. Burger, V. Comino, M. Heimann, T. Karanink, J. Khoury, G. Madine, K. Nagaraj, G. Offord, R. Peruzzi, J. Plany, N. Rao, N. Sayiner, P. Setty, and K. Threadgill, "A High Speed, Low Power PRML Read Channel Device," IEEE Trans. Magn., vol. 31, no. 2, pp. 1186$1195,1995$.

[49] S.-P. U, R. P. Martins, and J. E. Franca, "A 2.5V 57MHz 15-Tap SC Bandpass Interpolating Filter with $320 \mathrm{MHz}$ Output Sampling Rate in $0.35 \mu \mathrm{m}$ CMOS," in IEEE Int. Solid-State Circuits Conf. Dig. Tech. Pap., 2002, pp. 380-382.

[50] S.-P. U, R. Martins, and J. Franca, "A 2.5-V 57-MHz 15-Tap SC Bandpass In-

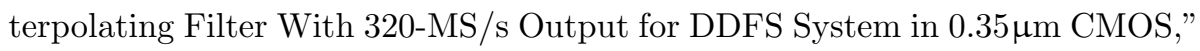
IEEE J. Solid-State Circuits, vol. 39, no. 1, pp. 87-99, Jan. 2004.

[51] A. Dabrowski, R. Dlugosz, P. Pawlowski, K. Iniewski, and V. Gaudet, "Analog Baseband Filtering Realized Using Switched Capacitor Finite Impulse Response Filter," in IEEE Int. Symp. VLSI Des. Autom. Test, 2005, pp. 108-111.

[52] T. Enomoto, T. Ishihara, and M.-A. Yasumoto, "Integrated Tapped MOS Analogue Delay Line Using Switched Capacitor Technique," Electron. Lett., vol. 18, no. 5, pp. 193-194, 1982.

[53] S. K. Sunter, E. F. Girczyc, and A. Chowaniec, "A Programmable Transversal Filter for Voice-Frequency Applications," IEEE J. Solid-State Circuits, vol. 16, no. 4, pp. 367-372, Aug. 1981.

[54] Y. A. Haque, "An Adaptive Transversal Filter," in IEEE Int. Conf. Acoust. Speech, Signal Process., 1983, pp. 1208-1211.

[55] Y.-S. Lee and K. Martin, "A Switched-Capacitor Realization of Multiple FIR Filters on a Single Chip," IEEE J. Solid-State Circuits, vol. 23, no. 2, pp. 536542, Apr. 1988.

[56] S. Lyle, G. Worstell, and R. Spencer, "An Analog Discrete-Time Transversal Filter in 2.0um CMOS," in IEEE Conf. Rec. Twenty-Sixth Asilomar Conf. Signals, Syst. Comput., 1992, pp. 970-974.

[57] D. Xu, Song Yonghua, and G. T. Uehara, "A 200MHz 9-Tap Analog Equalizer

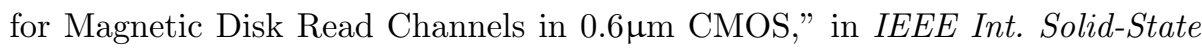
Circuits Conf. Dig. Tech. Pap., 1996, pp. 74-75. 
[58] Y. L. Cheung and A. Buchwald, "A Sampled-Data Switched-Current Analog 16tap FIR Filter with Digitally Programmable Coefficients in 0.8 $\mu \mathrm{m}$ CMOS," in IEEE Int. Solid-State Circuits Conf. Dig. Tech. Pap., vol. 27, 1997, pp. 54-55.

[59] S. Kiriaki, T. L. Viswanathan, G. Feygin, B. Staszewski, R. Pierson, B. Krenik, M. De Wit, and K. Nagaraj, "A $160 \mathrm{MHz}$ Analog Equalizer for Magnetic Disk Read Channels," in IEEE Int. Solid-State Circuits Conf. Dig. Tech. Pap., vol. 32 , no. 11, 1997, pp. 322-323.

[60] — , "A 160-MHz Analog Equalizer for Magnetic Disk Read Channels," IEEE J. Solid-State Circuits, vol. 32, no. 11, pp. 1839-1849, 1997.

[61] X. Wang and R. R. Spencer, "A Low Power 170 MHz Discrete-Time Analog FIR Filter," in Cust. Integr. Circuits Conf., 1997, pp. 13-16.

[62] —, "A Low-Power 170-MHz Discrete-Time Analog FIR Filter," IEEE J. Solid-State Circuits, vol. 33, no. 3, pp. 417-426, Mar. 1998.

[63] F. Farag, C. Galup-Montoro, and M. Schneider, "Digitally Programmable Switched-Current FIR Filter for Low-Voltage Applications," IEEE J. SolidState Circuits, vol. 35, no. 4, pp. 637-641, Apr. 2000.

[64] H. Jin and E. K. F. Lee, "A 350 MHz Programmable Analog FIR Filter Using Mixed-Signal Multiplier," Eur. Solid-State Circuits Conf., pp. 152-155, 2000.

[65] S. Karvonen, T. Riley, and J. Kostamovaara, "A Hilbert sampler/filter and complex bandpass SC Filter for I/Q demodulation," Eur. Solid-State Circuits Conf., pp. 1-4, 2000.

[66] — - "A Low Noise Quadrature Subsampling Mixer," in IEEE Int. Symp. Circuits Syst., vol. 4, 2001, pp. 790-793.

[67] D. Ahn and S. Hong, "A Low Cost Analog FIR Channel Select Filter for Wireless Receiver," in IEEE Radio Wirel. Symp., Jan. 2011, pp. 211-214.

[68] J.-E. Eklund and R. Arvidsson, "A Multiple Sampling, Single A/D Conversion Technique for I/Q Demodulation in CMOS," IEEE J. Solid-State Circuits, vol. 31, no. 12, pp. 1987-1994, 1996.

[69] J. Yuan, "A Charge Sampling Mixer with Embedded Filter Function for Wireless Applications," in Int. Conf. Microw. Millim. Wave Technol. Proc., 2000, pp. $315-318$.

[70] G. Xu and J. Yuan, "An Embedded Low Power FIR Filter," in IEEE Int. Symp. Circuits Syst., vol. 4, 2001, pp. 230-233. 
[71] S. Karvonen, T. Riley, and J. Kostamovaara, "Charge sampling mixer with $\Delta \Sigma$ quantized impulse response," in IEEE Int. Symp. Circuits Syst., vol. 1, 2002, pp. I-129-I-132.

[72] G. Xu and J. Yuan, "A CMOS Analog FIR Filter with Low Phase Distortion," in Eur. Solid-State Circuits Conf., no. 4, 2002, pp. 747-750.

[73] —_ "Charge sampling analogue FIR filter," Electron. Lett., vol. 39, no. 3, pp. 261-262, 2003.

[74] S. Lindfors, A. Parssinen, and K. A. I. Halonen, "A 3-V 230-MHz CMOS Decimation Subsampler," IEEE Trans. Circuits Syst. II Analog Digit. Signal Process., vol. 50, no. 3, pp. 105-117, 2003.

[75] Y. Poberezhskiy and G. Poberezhskiy, "Sampling and Signal Reconstruction Circuits Performing Internal Antialiasing Filtering and Their Influence on the Design of Digital Receivers and Transmitters," IEEE Trans. Circuits Syst. I Regul. Pap., vol. 51, no. 1, pp. 118-129, Jan. 2004.

[76] D. Jakonis, K. Folkesson, J. Dabrowski, P. Eriksson, and C. Svensson, "A 2.4-

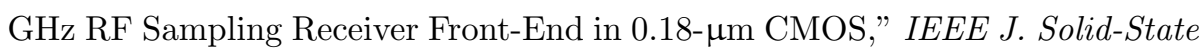
Circuits, vol. 40, no. 6, pp. 1265-1277, 2005.

[77] S. Karvonen, T. A. D. Riley, S. Kurtti, and J. Kostamovaara, "A Quadrature Charge-Domain Sampler With Embedded FIR and IIR Filtering Functions," IEEE J. Solid-State Circuits, vol. 41, no. 2, pp. 507-515, 2006.

[78] S. Karvonen, T. A. D. Riley, and J. Kostamovaara, "Charge-Domain FIR Sampler With Programmable Filtering Coefficients," IEEE Trans. Circuits Syst. II Express Briefs, vol. 53, no. 3, pp. 192-196, Mar. 2006.

[79] R. Bagheri, A. Mirzaei, S. Chehrazi, M. Heidari, M. Lee, M. Mikhemar, M. Tang, and A. Abidi, "An $800 \mathrm{MHz}$ to $5 \mathrm{GHz}$ Software-Defined Radio Receiver in 90nm CMOS," in IEEE Int. Solid-State Circuits Conf. Dig. Tech. Pap., 2006, pp. $1932-1941$.

[80] T. Sano, T. Maruyama, I. Yasui, H. Sato, and T. Shimizu, "A $1.8 \mathrm{~mm}^{2}, 11$ $\mathrm{mA}, 23.2 \mathrm{~dB}-\mathrm{NF}$, discrete-time filter for GSM/WCDMA/WLAN using retiming technique," in IEEE Cust. Integr. Circuits Conf., 2007, pp. 703-706.

[81] M.-F. Huang and L.-F. Chen, "A Programmable-Bandwidth Front-End with Clock- Interleaving Down-Conversion Filters," in IEEE Asian Solid-State Circuits Conf., no. 2, Nov. 2008, pp. 349-352. 
[82] J. Kang, D. T. Lin, L. Li, and M. P. Flynn, "A Reconfigurable FIR Filter Embedded in a 9b Successive Approximation ADC," IEEE Cust. Integr. Circuits Conf., pp. 711-714, 2008.

[83] M. Kitsunezuka, S. Hori, and T. Maeda, "A Widely-Tunable Reconfigurable CMOS Analog Baseband IC for Software-Defined Radio," in IEEE Int. SolidState Circuits Conf. Dig. Tech. Pap., Feb. 2008, pp. 66-595.

[84] A. Mirzaei, S. Chehrazi, R. Bagheri, and A. A. Abidi, "Analysis of First-Order Anti-Aliasing Integration Sampler," IEEE Trans. Circuits Syst. I Regul. Pap., vol. 55, no. 10, pp. 2994-3005, 2008.

[85] A. Yoshizawa and S. Iida, "A Gain-Boosted Discrete-Time Charge-Domain FIR LPF with Double-Complementary MOS Parametric Amplifiers," IEEE Int. Solid-State Circuits Conf. Dig. Tech. Pap., pp. 2008-2010, 2008.

[86] M.-F. Huang, S.-H. Wu, and T.-Y. Yang, "A Discrete-Time AAF with ClockEfficient Charge- Domain Filter for High Attenuation and Bandwidth," in IEEE Asian Solid-State Circuits Conf., Nov. 2009, pp. 41-44.

[87] M.-F. Huang, L.-F. Chen, and T.-L. Chiu, "A Quadrature Charge-Domain Filter with Frequency Down-Conversion and Filtering for RF Receivers," in IEEE Radio Freq. Integr. Circuits Symp., Jun. 2009, pp. 547-550.

[88] M.-F. Huang and T.-L. Chiu, "A Quadrature Charge-Domain Filter With Frequency Downconversion for RF Receivers," IEEE Trans. Microw. Theory Tech., vol. 58, no. 5, pp. 1323-1332, May 2010.

[89] C. Park, J. Yoon, and B. Kim, "Non-Decimation FIR Filter for Digital RF Sampling Receiver with Wideband Operation Capability," IEEE Radio Freq. Integr. Circuits Symp., vol. 1, pp. 487-490, 2009.

[90] A. Yoshizawa and S. Iida, "A 250-MHz Cutoff Charge-Domain Baseband Filter with Improved Stopband Attenuations," IEEE Radio Freq. Integr. Circuits Symp., pp. 491-494, 2009.

[91] A. Geis, J. Ryckaert, L. Bos, G. Vandersteen, Y. Rolain, and J. Craninckx, "A $0.5 \mathrm{~mm}^{2}$ Power-Scalable 0.5-3.8-GHz CMOS DT-SDR Receiver With SecondOrder RF Band-Pass Sample," IEEE J. Solid-State Circuits, vol. 45, no. 11, pp. 2375-2387, 2010.

[92] M.-F. Huang, "A Quadrature Charge-Domain Filter with an Extra In-Band Filtering for RF Receivers," in IEEE Radio Freq. Integr. Circuits Symp., 2010, pp. $31-34$. 
[93] M.-F. Huang and S.-H. Wu, "A Cascade Non-Decimation Charge-Domain Filter with Noise-Folding Reduction," in IEEE Asian Solid-State Circuits Conf., Nov. 2010 .

[94] D. T. Lin, L. Li, S. Farahani, and M. P. Flynn, "A Flexible 500MHz to $3.6 \mathrm{GHz}$ Wireless Receiver with Configurable DT FIR and IIR Filter Embedded in a 7b 21MS/s SAR ADC," in IEEE Cust. Integr. Circuits Conf., Sep. 2010.

[95] — , "A Flexible $500 \mathrm{MHz}$ to $3.6 \mathrm{GHz}$ Wireless Receiver with Configurable DT FIR and IIR Filter Embedded in a 7b $21 \mathrm{MS} / \mathrm{s}$ SAR ADC," IEEE Trans. Circuits Syst. I Regul. Pap., vol. 59, no. 12, pp. 2846-2857, 2012.

[96] A. Yoshizawa and S. Iida, "Parasitic Discrete-Time-Pole cancelling techniques for Ultra-Wideband Discrete-Time Charge-Domain Baseband Filters Atsushi," in IEEE Asian Solid-State Circuits Conf., Nov. 2010.

[97] M.-F. Huang, "Discrete-time charge-domain filter with charge buffer for flexible design of FIR filter," Electron. Lett., vol. 47, no. 24, 2011.

[98] — - "A Discrete-Time Charge-Domain Filter with Bandwidth Calibration for LTE Application," in IEEE Cust. Integr. Circuits Conf., Sep. 2011.

[99] M. Rachid, S. Pamarti, and B. Daneshrad, "Filtering by Aliasing," IEEE Trans. Signal Process., vol. 61, no. 9, pp. 2319-2327, May 2013.

[100] N. Sinha, M. Rachid, and S. Pamarti, "A Sharp Programmable Passive Filter based on Filtering by Aliasing," IEEE Symp. VLSI Circuits, Dig. Tech. Pap., pp. C58-C59, 2015.

[101] S. Hameed, N. Sinha, M. Rachid, and S. Pamarti, "A Programmable Receiver Front-End Achieving $>17 \mathrm{dBm}$ IIP3 at $<1.25 x$ BW Frequency Offset," in 2016 IEEE Int. Solid-State Circuits Conf., vol. 59, Jan. 2016, pp. 446-447.

[102] S. Hameed and S. Pamarti, "Design and Analysis of a Programmable Receiver Front End Based on Baseband Analog-FIR Filtering Using an LPTV Resistor," IEEE J. Solid-State Circuits, vol. 53, no. 6, pp. 1592-1606, 2018.

[103] N. Sinha, M. Rachid, and S. Pamarti, "An 8mW, 1GHz Span, Passive Spectrum Scanner with $>+31 \mathrm{dBm}$ Out-of-Band IIP3," in IEEE Radio Freq. Integr. Circuits Symp., May 2016, pp. 278-281.

[104] N. Sinha, M. Rachid, S. Pavan, and S. Pamarti, "Design and Analysis of an 8 mW, 1 GHz Span, Passive Spectrum Scanner With >+31 dBm Out-of-Band IIP3 Using Periodically Time-Varying Circuit Components," IEEE J. SolidState Circuits, vol. 52, no. 8, pp. 2009-2025, Aug. 2017. 
[105] S. Hameed and S. Pamarti, "A Time-Interleaved Filtering-by-Aliasing Receiver Front-End with $>70 \mathrm{~dB}$ Suppression at $<4 \mathrm{x}$ Bandwidth Frequency Offset," IEEE Int. Solid-State Circuits Conf. Dig. Tech. Pap., vol. 60, pp. 418-419, 2017.

[106] —, "Design and Analysis of a Programmable Receiver Front End With Time-Interleaved Baseband Analog-FIR Filtering," IEEE J. Solid-State Circuits, vol. 53, no. 11, pp. 3197-3207, Nov. 2018.

[107] H. Shin and R. Harjani, "Low-Power Wideband Analog Channelization Filter Bank Using Passive Polyphase-FFT Techniques," IEEE J. Solid-State Circuits, vol. 52, no. 7, pp. 1753-1767, 2017.

[108] P. Harpe, "A $0.0013 \mathrm{~mm}^{2}$ 10b $10 \mathrm{MS} / \mathrm{s}$ SAR ADC with a $0.0048 \mathrm{~mm}^{2} 42 \mathrm{~dB}-$ Rejection Passive FIR Filter," in IEEE Cust. Integr. Circuits Conf., Apr. 2018.

[109] — - "A Compact 10-b SAR ADC With Unit-Length Capacitors and a Passive FIR Filter," IEEE J. Solid-State Circuits, vol. 54, no. 3, pp. 636-645, Mar. 2019 .

[110] S. Bu, S. Hameed, and S. Pamarti, "An LPTV Noise Cancellation Technique for a $0.9-\mathrm{V}$ Filtering-by-Aliasing Receiver Front-End with >67-dB Stopband Rejection," in IEEE Cust. Integr. Circuits Conf., Apr. 2019.

[111] L. Carley and T. Mukherjee, "High-Speed Low-Power Integrating CMOS Sample-and-Hold Amplifier Architecture," in IEEE Cust. Integr. Circuits Conf., 1995 , pp. 543-546.

[112] G. Xu and J. Yuan, "Comparison of Charge Sampling and Voltage Sampling," in IEEE Midwest Symp. Circuits Syst., vol. 1, 2000, pp. 440-443.

[113] — - "Performance Analysis of General Charge Sampling," IEEE Trans. Circuits Syst. II Express Briefs, vol. 52, no. 2, pp. 107-111, 2005.

[114] J. E. da Franca, "Nonrecursive Polyphase Switched-Capacitor Decimators and Interpolators," IEEE Trans. Circuits Syst., vol. 32, no. 9, pp. 877-887, Sep. 1985.

[115] H. Repo and T. Rahkonen, "Programmable switched capacitor 4-tap FIR filter," in IEEE Eur. Solid State Circuits Conf., 2003, pp. 445-448.

[116] K. Muhammad, D. Leipold, B. Staszewski, Y. Ho, C. M. Hung, K. Maggio, C. Fernando, T. Jung, J. Wallberg, J. Koh, S. John, I. Deng, O. Moreira, R. Staszewski, R. Katz, and O. Friedman, "A Discrete-Time Bluetooth Receiver 
in a $0.13 \mu \mathrm{m}$ Digital CMOS Process," IEEE Int. Solid-State Circuits Conf. Dig. Tech. Pap., pp. 196-197, 2004.

[117] N. J. Guilar, P.-K. Lau, P. J. Hurst, and S. H. Lewis, "A 200 MS/s Passive Switched-Capacitor FIR Equalizer using a Time-Interleaved Topology," in IEEE Cust. Integr. Circuits Conf., 2005, pp. 628-631.

[118] B. Sadhu, M. Sturm, B. M. Sadler, and R. Harjani, "Analysis and Design of a 5 GS/s Analog Charge-Domain FFT for an SDR Front-End in 65 nm CMOS," IEEE J. Solid-State Circuits, vol. 48, no. 5, pp. 1199-1211, May 2013.

[119] J. Koh, K. Muhammad, B. Staszewski, G. Gomez, and B. Horoun, "A SigmaDelta ADC with a built-in Anti-aliasing filter for Bluetooth receiver in $130 \mathrm{~nm}$ digital process," in IEEE Cust. Integr. Circuits Conf., 2004, pp. 535-538.

[120] S. Hameed and S. Pamarti, "Impedance Matching and Reradiation in LPTV Receiver Front-Ends: An Analysis Using Conversion Matrices," IEEE Trans. Circuits Syst. I Regul. Pap., vol. 65, no. 9, pp. 2842-2855, Sep. 2018.

[121] A. Mirzaei, R. Bagheri, S. Chehrazi, and A. Abidi, "A Second-Order AntiAliasing prefilter for an SDR receiver," in IEEE Cust. Integr. Circuits Conf., no. 2, 2005, pp. 624-627.

[122] M. Kitsunezuka, S. Hori, and T. Maeda, "A Widely-Tunable, Reconfigurable CMOS Analog Baseband IC for Software-Defined Radio," IEEE J. Solid-State Circuits, vol. 44, no. 9, pp. 2496-2502, Sep. 2009.

[123] Y. Poberezhskiy and G. Poberezhskiy, "Sampling technique allowing exclusion of antialiasing filter," Electron. Lett., vol. 36, no. 4, p. 297, 2000.

[124] A. A. Abidi, "The Path to the Software-Defined Radio Receiver," IEEE J. Solid-State Circuits, vol. 42, no. 5, pp. 954-966, May 2007.

[125] J. S. Mincey, E. C. Su, J. Silva-Martinez, and C. T. Rodenbeck, "A 128-Tap Highly Tunable CMOS IF Finite Impulse Response Filter for Pulsed Radar Applications," IEEE Trans. Very Large Scale Integr. Syst., vol. 26, no. 6, pp. 1192-1203, 2018.

[126] C. A. Balanis, Antenna Theory, 3rd ed. John Wiley \& Sons, 2005.

[127] C. Campbell, Surface Acoustic Wave Devices and Their Signal Processing Applications. San Diego: Academic Press, 1989.

[128] D. Morgan, Surface Acoustic Wave Filters, 2nd ed. Elsevier Ltd., 2007.

[129] P. Hartemann and E. Dieulesaint, "Acoustic-Surface-Wave Filters," Electron. Lett., vol. 5, no. 25, p. 657, 1969. 
Success is the ability to go from one

failure to another without loss of

enthusiasm.

Winston Churchill

\section{3}

\section{Analog-FIR Highly-Selective Low-Power Channel Filter}

The contents of the chapter are published in IEEE Journal of Solid-State Circuits [1] except for Section 3.5.1 which was published in IEEE Solid-State Circuit Letters [2]. In addition, Section 3.4.6 is included. The patent application related to this work is allowed [3].

\subsection{Introduction}

Low power highly selective channel filters become increasingly important. The trend to connect everyone and everything creates a need for highly selective wireless receivers, since the radio environment becomes increasingly crowded. Additionally, when targeting IoT applications minimal power consumption is desired to increase battery life.

A typical zero-IF receiver is shown in Fig. 3.1. It consists of a LNA, mixer, local oscillator, LPF and ADC. In this chapter, we target a highly-selective integrated LPF with minimal power consumption, which is implemented employing an analog FIR (AFIR) architecture.

The author is aware that the content of this chapter partially overlaps with Chapters 1 and 2 . However, the author preferred minimal modification of the already reviewed and accepted papers. 


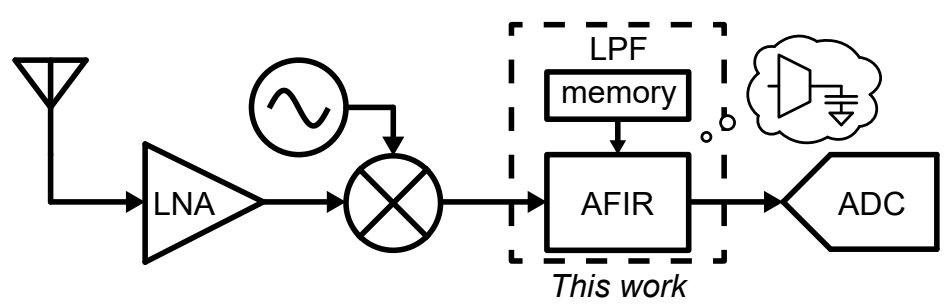

Figure 3.1: This work in a receiver.

Conventionally, these LPFs have $\mathrm{g}_{\mathrm{m}} \mathrm{C}[4,5]$ or opamp $\mathrm{R}-\mathrm{C}[6]$ implementations. Both require multiple transconductors to create higher order filters. These transconductors introduce noise which limits the signal-to-noise ratio (SNR) for a given power consumption and filter characteristic. Alternatives are the time-discrete analog infinite-impulse response (IIR) filters of [7-9], but they do not achieve a sharp filter transition.

Analog FIR filters [10-14], some of which referred to as Filtering-by-Aliasing [1517], have a very sharp filter transition and good out-of-band (OOB) rejection. The most straightforward analog FIR filter implementation stores samples of the input signal, provides a weighting coefficient for every time step and delivers an output sample at the input sampling rate $[11,13]$. This requires a lot of storage capacitors for a high filter order. The analog FIR filter can be implemented more efficiently by realizing that the output sample rate does not need to equal the input sample rate $[10,14-18]$. As the filter removes the unwanted signal components (outside the filter bandwidth), the filtered signal can be downsampled without corrupting it by aliasing.

Previous analog FIR implementations use a high FIR update rate [15-17], cascaded FIR stages [12] or a power hungry transconductor [18] and have therefore high power consumption. [14] shows a low power implementation, but has limited OOB rejection and an unattenuated filter alias.

This chapter is an extension on [2] where we proposed a low power analog FIR filter implementation as a channel selection filter. It contains a single inverter based $\mathrm{g}_{\mathrm{m}}-\mathrm{C}$ integrator for maximal SNR per power [19]. The transconductor is implemented as a digital-to-analog converter: $g_{m}$ DAC. In the nominal operation mode, the filter bandwidth is $0.43 \mathrm{MHz}$, which roughly resembles the I/Q baseband bandwidth of a $1 \mathrm{Mbps}$ IoT-standard, e.g. BLE. The filter programmability allows for a tunable bandwidth from 0.06 to $3.4 \mathrm{MHz}$. The power consumption is only $92 \mu \mathrm{W}$, because of a low FIR update rate, power efficient transconductor and partially thermometer design. The filter's power consumption is an acceptable fraction of the total power consumption of state-of-the-art IoT receivers [20-23].

In this chapter, a detailed derivation of the analog FIR transfer function - including all aliases — is provided. The proposed circuit is analyzed in detail; showing its 

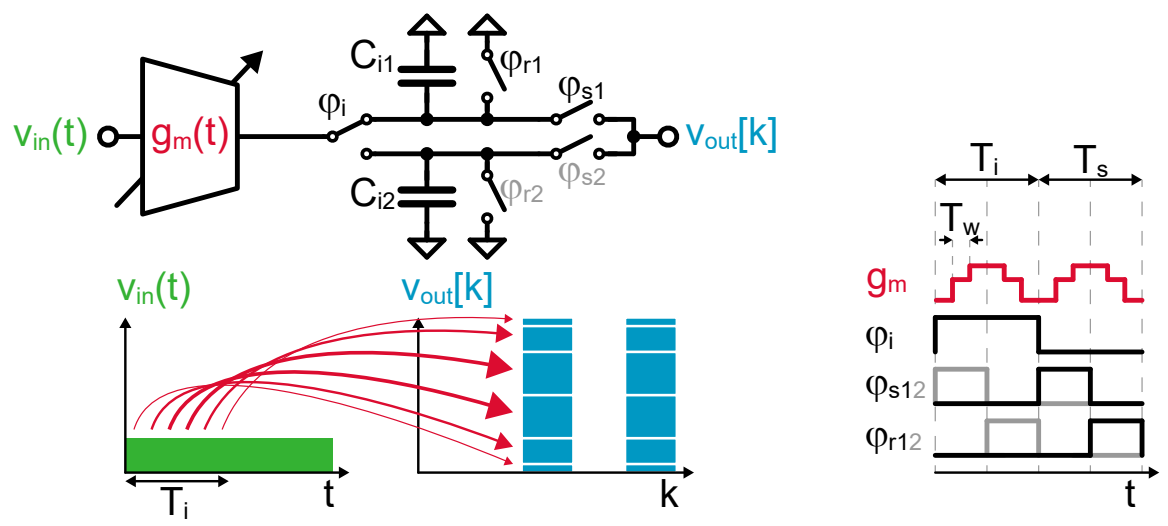

Figure 3.2: Analog FIR filter with 6 filter coefficients.

parasitic impairments, but also providing solutions to mitigate these. Furthermore, additional measurements of the transfer function and distortion give a more complete picture of the filter's performance.

The structure of the chapter is as follows. In Section 3.2, the analog FIR filtering approach is analyzed in detail. Section 3.3 discusses the low power analog FIR implementation. A comprehensive analysis of the device impairments due to mismatch and parasitics is described in Section 3.4. Section 3.5 discusses the measurement results and the conclusions are provided in Section 3.6.

\subsection{Analog FIR Filtering}

In this section, the analog FIR filter theory is discussed. First, the architecture is introduced, followed by a detailed analysis of its transfer function and a simple mathematical model, a frequency domain example and a summary of how to tune the filter bandwidth.

\subsubsection{Architecture}

Fig. 3.2 shows a 6-tap analog FIR filter architecture. In Section 2.1 [2], a step-by-step explanation is provided starting from a conventional digital FIR filter to the analog FIR filter of Fig. 3.2. Here, the working principle is just briefly summarized. For simplicity, the input signal is assumed constant. The input signal $v_{i n}(t)$ is converted to current by a transconductance $g_{m}(t)$, which varies in time and provides the FIR weights at rate $f_{w}=1 / T_{w}$. Different time instances of $v_{i n}(t)$ are weighted differently as in a textbook FIR filter [24]. Starting on an empty capacitor $C_{i 1}$, the weighted current is summed on $C_{i 1}$ during integration phase $\phi_{i}$ for integration time $T_{i}$. The output is sampled during $\phi_{s}$ creating an FIR filtered output voltage $v_{\text {out }}[k]$ sample. 

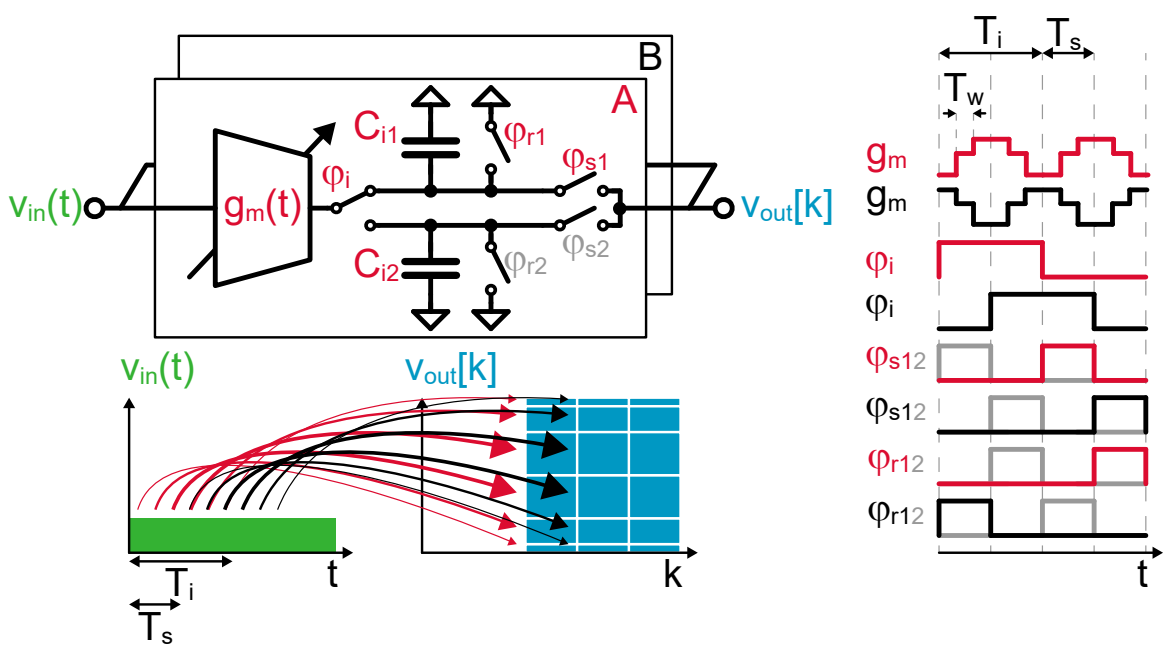

Figure 3.3: Two-path time-interleaved analog FIR filter with 6 filter coefficients $(m=2)$.

Afterwards, the voltage on $C_{i 1}$ is reset during $\phi_{r}$. Two integration capacitors are used to allow for simultaneous integration of the input and read-out at the output. Fig. 3.2 illustrates the concept using a 6-tap analog FIR architecture, where the 6 coefficients are processed in one integration cycle.

\subsubsection{Time-Interleaving}

In Fig. 3.2, the output sample rate $f_{s}=1 / T_{s}=1 / T_{i}$ and is thus limited to the integration time. This constraint is broken by time-interleaving multiple paths: the output sample rate can be increased for the same filter shape and bandwidth. For $m$ paths, this results in an output sample rate

$$
f_{s}=\frac{m}{T_{i}}, \quad m=1,2,3, \ldots
$$

Fig. 3.3 shows a two-path $(m=2)$ 6-tap time-interleaved analog FIR filter. The output sample rate is doubled for the same filter transfer function (and FIR coefficients).

\subsubsection{Filter Transfer Function}

The filter transfer function is determined using the time-domain representation of Fig. 3.3. As illustrated by the different blocks in $v_{\text {out }}[k]$, an output voltage sample consists of $N$ charge contributions. $N$ is the number of filter taps and related to the integration time and weights update time according to $N=T_{i} / T_{w}$. The individual 
charge contributions $q[n]$ become available at

$$
t=n T_{w}, \quad n=\ldots,-1,0,1, \ldots
$$

The output charge is

$$
q[n]=\overline{g_{m}} w[n] \int_{(n-1) T_{w}}^{n T_{w}} v_{i n}(t) \mathrm{d} t
$$

where $w[n]=g_{m}\left(n T_{w}\right) / \overline{g_{m}}$ is the time-dependent FIR coefficient and $\overline{g_{m}}$ the average transconductance. The output voltage samples are available at

$$
t=k T_{s}=k \frac{N T_{w}}{m}, \quad k=\ldots,-1,0,1, \ldots
$$

The output voltage samples consist of the sum of $N$ charge contributions during a single integration period

$$
v_{\text {out }}[k]=\frac{1}{C_{i}} \sum_{a=0}^{N-1} q[k N-a]
$$

The input is thus integrated over time $T_{w}$, sampled at $n T_{w}$, weighted by an FIR coefficient, summed and sampled at $k T_{s}$. The reset is implicitly present in (3.5); output number $k$ contains only charge contributions of one integration cycle.

Since, $f_{w}$ and $f_{s}$ have an integer relationship and $f_{w} \geq f_{s}$, the two sampling actions can be seen as a single sampling action at the lower rate $f_{s}$ — the first "sampling" by the weighting coefficients does not place the signal in a different position in the $f_{s}$ Nyquist zones. The output spectrum $S_{\text {out }}(f)$ is derived from the input spectrum $S_{i n}(f)$ by taking the Fourier Transform of (3.3) and (3.5)

$$
S_{\text {out }}(f)=\sum_{k=-\infty}^{\infty} H\left(f-k f_{s}\right) S_{\text {in }}\left(f-k f_{s}\right)
$$

where the harmonic transfer function $H(f)$ is

$$
H(f)=\underbrace{\frac{\overline{g_{m}} T_{i}}{C_{i}}}_{\text {gain }} \underbrace{\operatorname{sinc}\left(\frac{f}{f_{w}}\right) e^{-j \pi \frac{f}{f_{w}}}}_{\text {windowed } \int} \underbrace{\left.\sum_{a=0}^{N-1} w_{a} z^{-a}\right|_{z=e^{j 2 \pi \frac{f}{f_{w}}}}}_{\text {FIR }}
$$

where

$$
w_{a}=w[N-a], \quad a=0,1, \ldots, N-1
$$

are the FIR weighting coefficients, normalized to $\sum w_{a}=\sum^{N} w[n]=1$. (3.7) was derived in [18] as the ideal FIR transfer function with windowed integration prefiltering. Note, that the time varying code $w[n]$ resembles the time-inverse FIR impulseresponse $w_{a}[15,16]$. 


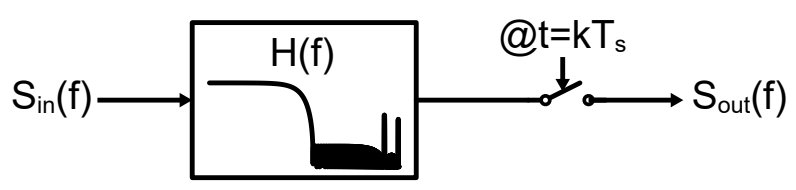

Figure 3.4: Analog FIR filter model.

Three components can be distinguished in (3.7): gain, sinc windowed integration and the FIR filter. The FIR filter provides very selective filtering with a sharp filter transition and can be designed to have linear phase. The windowed integration acts as a prefilter, attenuating the FIR filter aliases at integer multiples of $f_{w}$. The gain is determined by $\overline{g_{m}} / C_{i}$, which is PVT sensitive. The normalized analog FIR filter transfer function is only dependent on $g_{m}$-ratios and clock frequencies, which is PVT independent (apart from mismatch).

The analog FIR filter characteristics can be modeled as shown in Fig. 3.4. The input spectrum is filtered by $H(f)$ and sampled afterwards at $t=k T_{s}$.

\subsubsection{Frequency Domain Example}

In this section, we give an example to provide more intuition of the analog FIR filtering function. Fig. 3.5 shows the step-by-step analog FIR filtering operation as indicated by the arrows. Consider an input spectrum $S_{i n}(f)$ consisting of four equal power signals: a wanted signal A and three unwanted signals B, C and D. The harmonic transfer function $H(f)$ shows the final gain of the input signals. All inputs have a non-zero bandwidth to ensure that they are not completely canceled by a spectral null. The analog FIR filters as follows:

1. The signal is sinc filtered. Mainly $\mathrm{C}$ is attenuated.

2. The signal is sampled at $f_{w}$ resulting in aliasing of $\mathrm{C}$ and D. Hereafter, we only consider the signal in the first Nyquist zone: $\left[0 f_{w} / 2\right]$. C and D are grayed out at their original positions.

3. The signal is FIR filtered; attenuating B and D considerably.

4. The signal is sampled at $f_{s}$ resulting in aliasing of $\mathrm{B}$ and $\mathrm{D}$ to $\left[0 f_{s} / 2\right]$.

In $S_{\text {out }}(f)$, all signals are in the frequency band $\left[0 f_{s} / 2\right]$ and fall (almost) on top of each other. However, the previous filtering reduces the signal-to-interference ratio sufficiently not to corrupt the wanted signal $\mathrm{A}$. $\mathrm{C}$ is filtered by the windowed integration sinc, but is filtered less than B and D. Additional prefiltering is needed, but a first-order low-pass prefilter can significantly reduce this alias if $f_{w}$ is sufficiently 

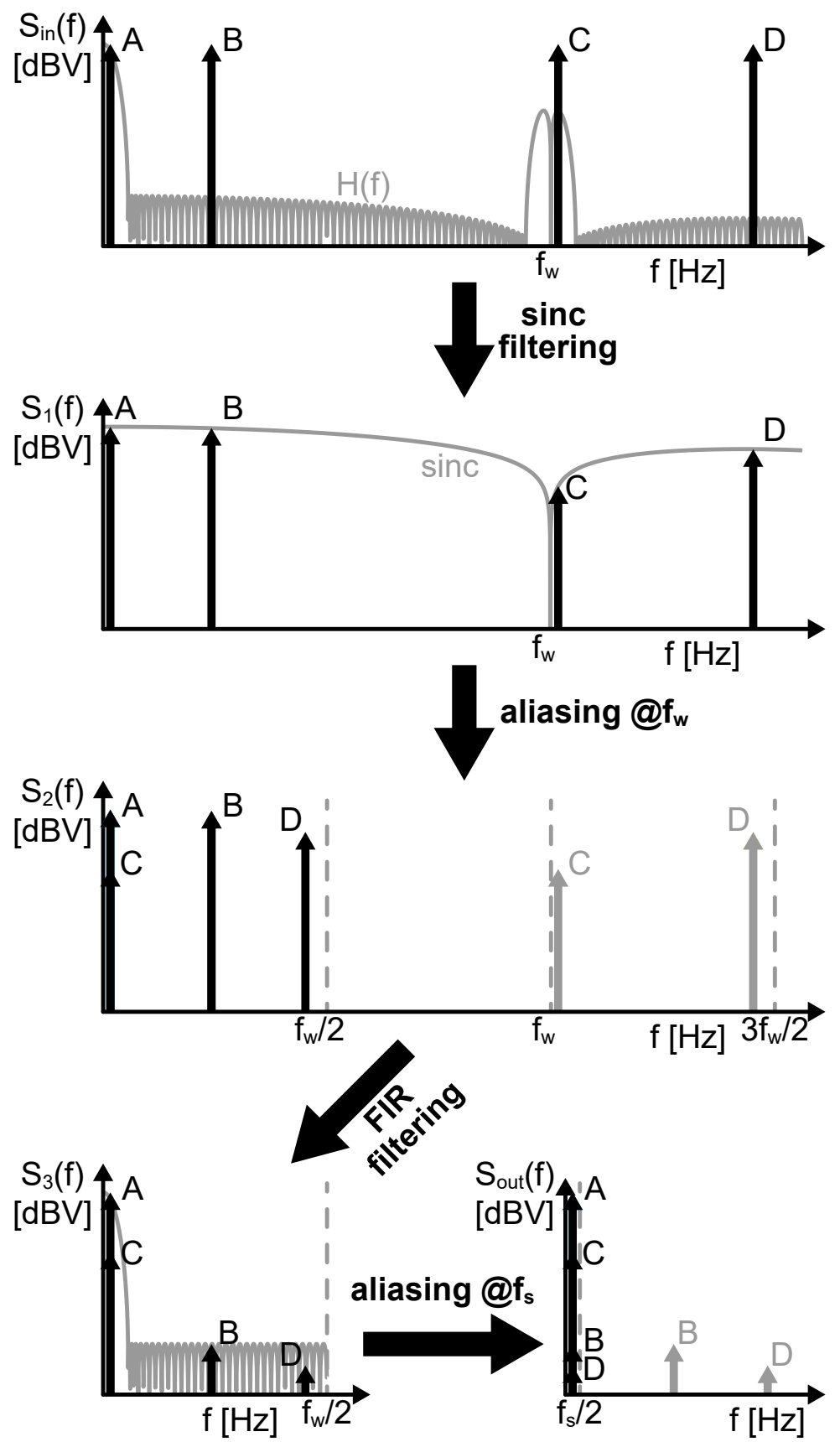

Figure 3.5: Analog FIR filter frequency response example. The filter has four equal power input signals: A, B, C and D. 
higher than $f_{s}$. The same output spectrum can directly be obtained by applying the model of Fig. 3.4, where the intermediate sampling at $f_{w}$ is neglected.

\subsubsection{Designing the Filter Bandwidth}

The filter bandwidth and roll-off is determined by the shape of its coefficients and $T_{i}$. The filter coefficients can be designed using standard digital FIR filter theory. The number of time-interleaved paths is then determined by the desired $f_{s}$. The filter aliases are at integer multiples of $f_{w}$. Increasing $f_{w}$, increases the number of coefficients for the same FIR filter.

The filter bandwidth can be tuned by changing $1 / T_{i}$ proportionally. E.g. the bandwidth is doubled by halving $T_{i}$, the other parameters can change in two ways:

1. Double $f_{w}$, constant $N$. The frequency offset of the filter aliases, relative to the filter bandwidth, remains constant and thereby the sinc suppression of the aliases.

2. Constant $f_{w}$, half $N$. The frequency offset of the filter aliases, relative to the filter bandwidth, reduces and thereby the sinc suppression of the aliases.

Most often, it is desirable to keep the sample-rate to bandwidth ratio constant, so that the close-in aliasing at $f_{s}$ is not changed.

\subsection{Circuit Implementation}

Fig. 3.6 shows the proposed circuit implementation. Two time-interleaved paths (A and $\mathrm{B})$ are implemented to double the output sample rate $(1 \mathrm{MHz})$ for a $2 \mu$ s integration time. The nominal filter bandwidth is $0.43 \mathrm{MHz}$. The variable transconductance is implemented as a pseudo-differential 10bit transconductance digital-to-analog converter $\left(\mathrm{g}_{\mathrm{m}} \mathrm{DAC}\right)$. The $10 \mathrm{bit} g_{m}$ tunability is determined from the mismatch analysis including the number of bits (Section 3.4.3). The analog FIR $g_{m}$ DAC code and control logic is reclocked by a differential clock at $64 \mathrm{MHz}$. The maximum integration time of $2 \mu \mathrm{s}$ for a $64 \mathrm{MHz} \mathrm{g}_{\mathrm{m}} \mathrm{DAC}$ update rate requires 128 filter coefficients (FIR taps) - which are provided by an on-chip memory for each time-interleaved path. The sample and reset phases partially overlap to ensure that the parasitic capacitances of the $\mathrm{PCB}$ and measurement probe are also reset.

The implemented integration capacitor is $20 \mathrm{pF}$. In this prototype, the capacitor value can be increased $4 \times$ by differentially implemented capacitors (not shown) to (partially) compensate for gain variation when changing the bandwidth. The integration capacitors could be reused as a sampling capacitor of a SAR ADC, removing the need of an intermediate buffer. The circuit implementation is described block-byblock below. 


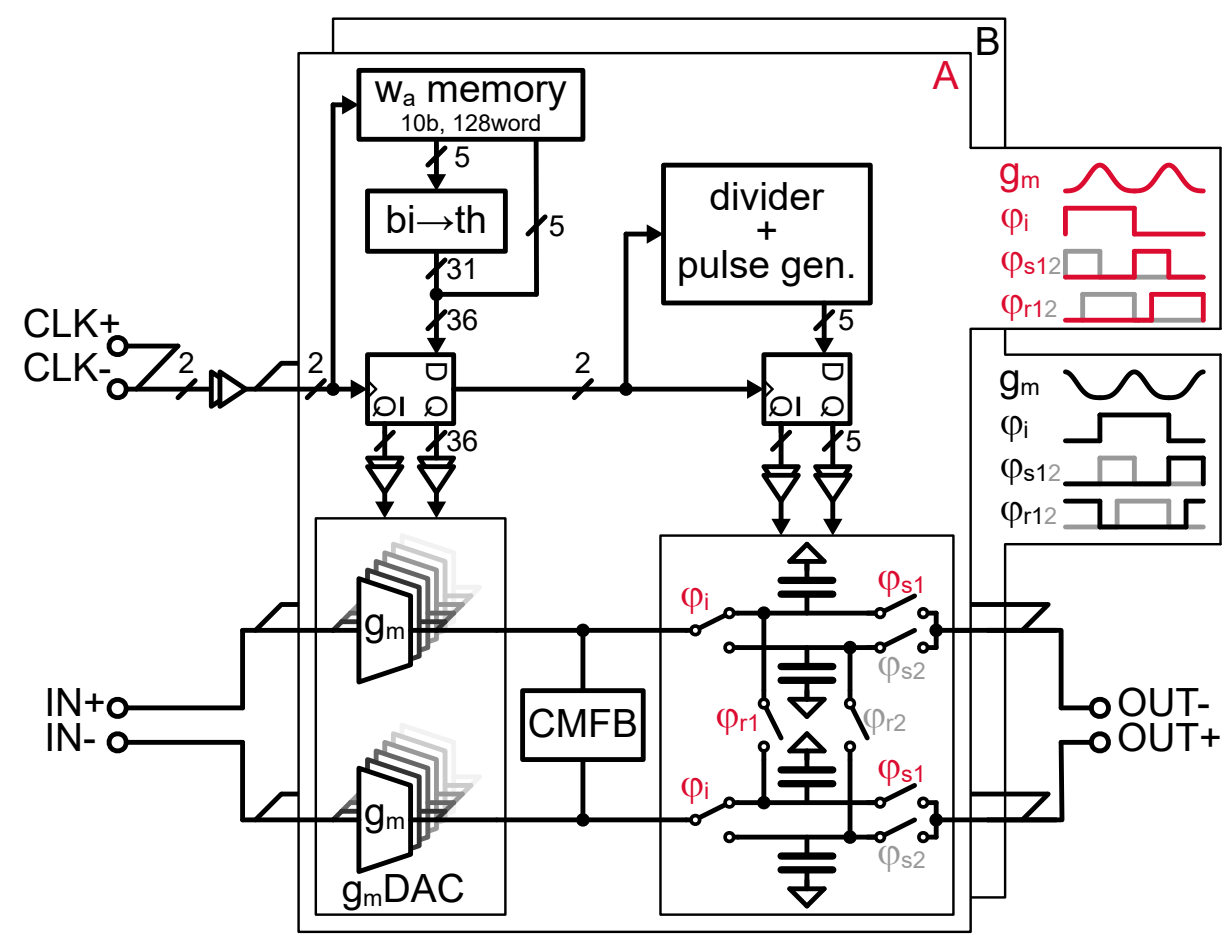

Figure 3.6: Analog FIR circuit implementation.

\subsubsection{Digital Control and Memory}

The $g_{m}$-code and integration capacitor control signals are reclocked in D-flipflops by a pseudo-differential clock at $64 \mathrm{MHz}$. The digital power consumption is significantly reduced due to this relatively low update rate compared to previous analog FIR designs $[11,12,17,18]$. However, the filter has aliases around integer multiples of this $64 \mathrm{MHz}$ as illustrated in Fig. 3.5. By careful design, we choose to allow these aliases, as they are severely suppressed by the sinc notches. Furthermore, a simple first-order prefilter can sufficiently attenuate these aliases for the $0.43 \mathrm{MHz}$ bandwidth.

When observing a single integration phase, the $g_{m}$-value monotonically increases to the $g_{m} \mathrm{DAC}$ maximum and afterwards it monotonically decreases to the minimum value - the $g_{m}$ DAC is effectively only turned on/off once during a single integration phase. Therefore, the power consumption of the buffers driving the $g_{m} \mathrm{DAC}$ enable switches can be significantly reduced by implementing the $\mathrm{g}_{\mathrm{m}} \mathrm{DAC}$ (partially) thermometer coded. Fig. 3.7a shows the number of code transitions versus the number of MSB thermometer bits for a 10bit $g_{m}$ DAC; a fully binary coded DAC contains 1 thermometer bit. A 5 bit thermometer coded $g_{m}$ DAC reduces the number of transitions and thus the buffer power consumption — by $2.7 \times$ compared to a fully binary design. 


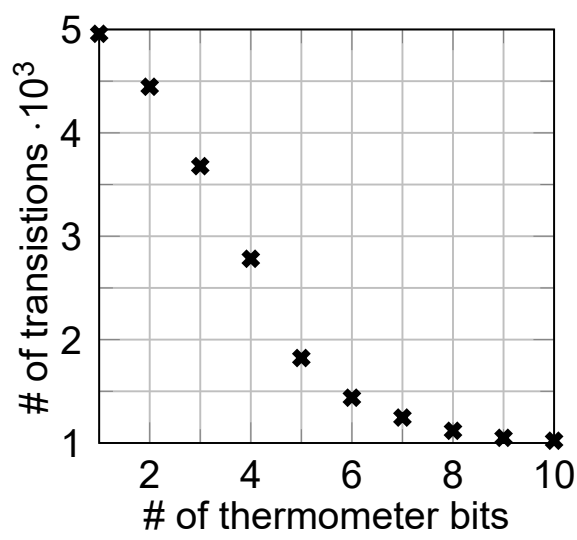

(a)

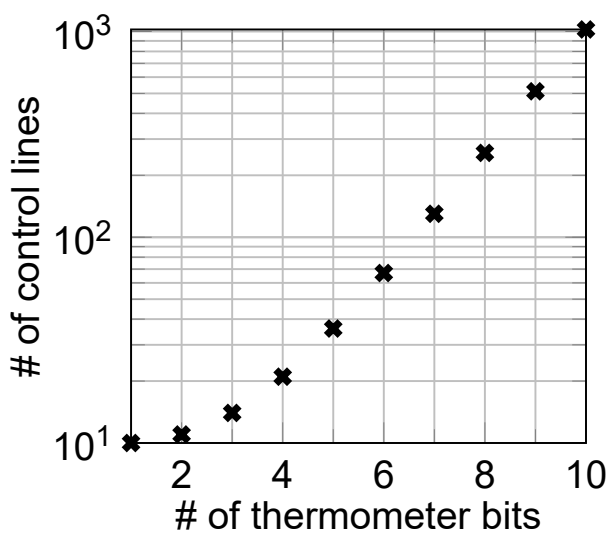

(b)

Figure 3.7: Partially thermometer implementation of a 10bit DAC. (a) Number of transitions per output sample. (b) Number of control lines.

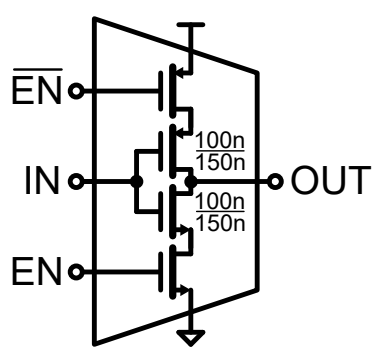

(a)

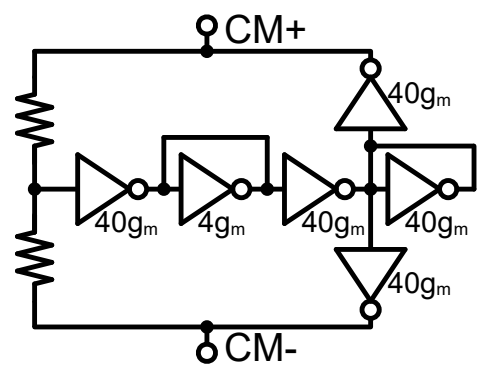

(b)

Figure 3.8: Circuit implementations. (a) Unit $g_{m}$-cell. (b) Common-mode feedback.

Furthermore, Fig. 3.7b shows that the complexity of a 5 bit thermometer design is manageable.

Each $\mathrm{g}_{\mathrm{m}} \mathrm{DAC}$ is controlled by a $10 \mathrm{bit} 128$ word memory, making the filter code highly reconfigurable.

\subsection{2 $\mathrm{g}_{\mathrm{m}} \mathrm{DAC}$}

The $g_{m}$ DAC is split: 5bit thermometer and 5bit binary weighted as determined from the digital control power consumption and $g_{m}$-cell mismatch analysis (Section 3.4.3). It is constructed from unary $g_{m}$-cells of $1.3 \mu \mathrm{S}$, which are implemented as shown in Fig. 3.8a. The $g_{m}$-cell is turned on/off by the enable signal $E N$. The $g_{m}$-cells have 
a push-pull architecture to double the supply current efficiency. In addition, the $\mathrm{g}_{\mathrm{m}} \mathrm{DAC}$ current consumption is proportional to the FIR code - resulting in higher SNR per power consumption than for the current steering design of [18]. The inverter transconductor architecture is very suitable for modern CMOS processes with a low supply voltage.

\subsubsection{Common-Mode Feedback}

The common-mode feedback (CMFB) circuit is shown in Fig. 3.8b. The $\mathrm{g}_{\mathrm{m}} \mathrm{DAC}$ output common-mode is set to the voltage of a self-biased inverter, roughly $V_{D D} / 2$. The switching of the $g_{m} \mathrm{DAC}$ results in common-mode charge injection to the output, which is suppressed by the CMFB. The dominant pole of the CMFB loop is placed at $\mathrm{CM}+$ and $\mathrm{CM}-$, because the parasitic output capacitance of the $\mathrm{g}_{\mathrm{m}} \mathrm{DAC}$ is ill-defined. Therefore $C_{i}$ is implemented single-ended, although a differential implementation would save area. The CMFB circuit has three non-dominant poles. Two non-dominant poles are at $f_{t} / 2$ and $f_{t} / 10$, which can be very high in a state-of-theart CMOS process ${ }^{1}$. The third is determined by the CM sensing resistors and the inverter parasitic input capacitance. High common-mode sensing resistors are chosen, for which the CMFB-loop is stable across PVT in extracted simulations, to minimize charge loss during integration. The power penalty is small: only $20 \%$ of the total $\mathrm{g}_{\mathrm{m}} \mathrm{DAC}$ power consumption. The noise of the center transconductors is commonmode and has no effect on the differential output signal. The noise contribution of the last transconductors is small; since $g_{m}$ is only 40 unit $g_{m}$ 's, 10 times smaller than the average $g_{m}$ DAC code of roughly 400.

\subsubsection{Practical Considerations}

In this work, the analog FIR filter is designed with a BLE IoT receiver in mind, although the analog FIR concept is not limited to this application. In this section, we show that the proposed implementation fits within a BLE receiver design.

The noise factor of the receiver in Fig. 3.1 is

$$
F=1+\Delta F_{\mathrm{LNA}}+\Delta F_{\text {Mixer }}+\frac{{\overline{v_{i n, n}}}^{2}}{A_{v}^{2} k T R_{a n t}}<4
$$

where $\Delta F$ is the respective noise factor contribution, $\overline{v_{i n, n}}$ the input-referred noise voltage of the analog FIR filter, $A_{v}$ the voltage gain from the antenna to the analog

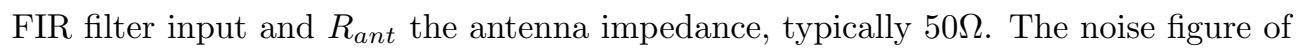
the state-of-the-art BLE receivers is sub-6dB $(F<4)[20-23]$.

\footnotetext{
${ }^{1}$ In this chapter, $f_{t}$ is defined as the unity-gain frequency of an inverter with a self-biased inverter load.
} 
An estimate of the filter's input-referred noise voltage is

$$
\begin{aligned}
{\overline{v_{i n, n}}}^{2} & \approx \frac{\left.{\overline{i_{n}}}^{2}\right|_{\mathrm{g}_{\mathrm{m}} \mathrm{DAC}}+\left.{\overline{i_{n}}}^{2}\right|_{\mathrm{g}_{\mathrm{m}} \mathrm{CMFB}}}{\left.{\overline{g_{m}}}^{2}\right|_{\mathrm{g}_{\mathrm{m}} \mathrm{DAC}}} \cdot 2 \cdot \frac{1}{m} \\
& \approx \frac{4 k T \gamma \cdot(400+40) g_{m}}{\left(400 g_{m}\right)^{2}}
\end{aligned}
$$

where $k$ is the Boltzmann constant, $T$ the absolute temperature, $\gamma$ the noise excess coefficient and $\overline{i_{n}}$ the respective average single-ended output noise current from the $\mathrm{g}_{\mathrm{m}} \mathrm{DAC}$ and CMFB. When assuming $\gamma \approx 2$, the analog FIR filter noise factor contribution is about 0.34 for $30 \mathrm{~dB} \mathrm{LNA}+$ mixer gain and $1.3 \mu \mathrm{S} g_{m}$-cells, which is reasonable for $F<4$.

The analog FIR filter gain can be estimated from (3.7) as $34 \mathrm{~dB}$ for $20 \mathrm{pF}$ integration capacitors. The $34 \mathrm{~dB}$ gain is well below the intrinsic gain $\left(g_{m} r_{o}=162\right.$ in simulation) of the $g_{m}$ DAC. Therefore, the $g_{m}$ DAC output impedance has limited effect on the filter's transfer function.

\subsection{Circuit Analysis and Solutions}

The circuit implementation has several practical impairments compared to the theoretical model of Section 3.2. This section analyzes these impairments and provides practical solutions.

\subsubsection{Output Impedance}

A limited output impedance of the $g_{m}$ DAC results in charge loss during the integration phase. This effect is illustrated in Fig. 3.9. During integration, previously integrated charge leaks away through parasitic resistance $r_{o}(t)$. Hence, the effective charge $q_{a}$ (FIR coefficient) is smaller than the programmed charge $q_{g_{m}}$ of the $g_{m}$ DAC; more so, for earlier applied coefficients. Although, the effect on the filter transfer function is limited in this design, because the DC gain is lower than the $g_{m} \mathrm{DAC}$ intrinsic gain, it is still desirable to compensate for it. The net charge contributions with and without a limited output impedance are shown in Fig. 3.9b. The effective FIR code is skewed. The charge contribution $q_{a}$ to the total charge at the end of integration is

$$
q_{a}=w_{a} \overline{g_{m}} r_{o, a} \overline{v_{i n}} C_{i}\left(1-e^{\frac{-T_{w}}{r_{o}, a C_{i}}}\right) \prod_{b=0}^{a} e^{\frac{-T_{w}}{r_{o, b} C_{i}}}
$$

where $w_{a}$ is the coefficient number $(a=0,1, . ., N-1)$ of the $\mathrm{g}_{\mathrm{m}} \mathrm{DAC}$ and $\overline{v_{i n}}$ the average input voltage during $T_{w}$. The corresponding output resistance $r_{o, a}$ is

$$
r_{o, a}=R_{\text {fixed }} \| \frac{\mu}{w_{a} \overline{g_{m}}}
$$




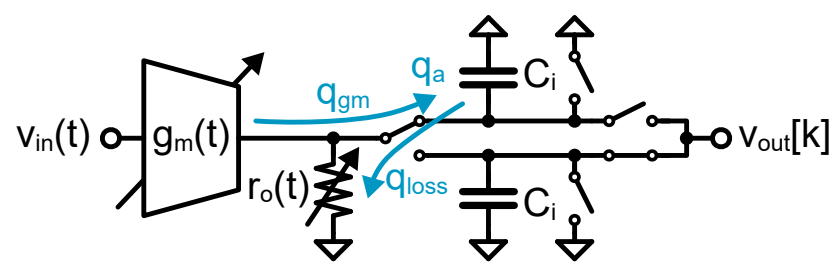

(a)

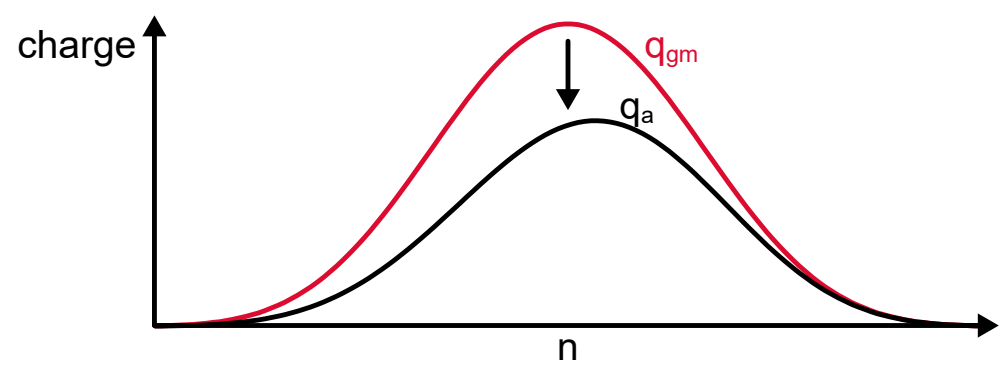

(b)

Figure 3.9: Effect of limited output impedance. (a) Schematic. (b) Ideal charge $q_{g_{m}}$ and actual integrated charge $q_{a}$ at the end of $T_{i}$.

where $\mu$ is the transconductor intrinsic voltage gain and $\|$ denotes the parallel configuration of the impedances. It contains a fixed component $R_{\text {fixed }}$, from the CMFB sensing resistors, and the $g_{m}$ DAC output impedance which varies in accordance with the transconductance value. When high CMFB resistor values are chosen, the fixed term can be neglected.

Fortunately, the filter shape is determined by the relative size of the coefficients. Therefore, a precorrected code can be determined, that takes into account the charge loss and can be applied to the analog FIR memory to closely match the effective charge profile with the ideal profile.

The algorithm to calculate the precorrected code $\vec{c}$, with coefficients $c_{a}$, is shown in Fig. 3.10. First, the ideal weights are scaled by $\alpha$. This scaling factor ensures that $\vec{c}$ matches the $\mathrm{g}_{\mathrm{m}} \mathrm{DAC}$ full-scale (normalized to 1 ), to minimize the quantization error. Therefore, $\alpha$ starts from $1 / \max \left(w_{a}\right)$. Starting from $a=0$ (the last code in time, first of the impulse-response), code $c_{a}$ is precorrected for all future charge loss. In addition, the instantaneous charge loss during its own integration period has to be corrected. The required coefficient can be derived as

$$
c_{a}=-\frac{\mu C_{i}}{g_{m}^{\dagger} T_{w}} \ln (1-\alpha w_{a} \frac{g_{m}^{\dagger} T_{w}}{\mu C_{i}} \underbrace{\prod_{b=0}^{a} e^{\frac{T_{w}}{r_{o, b} C_{i}}}}_{\text {future loss }})
$$




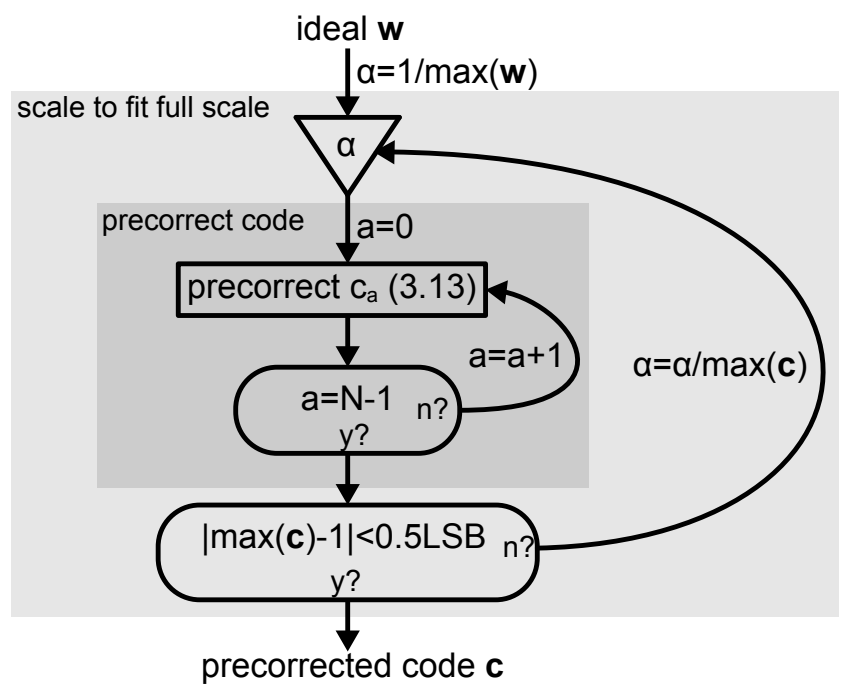

Figure 3.10: Algorithm to calculate $r_{o}$-precorrected code.

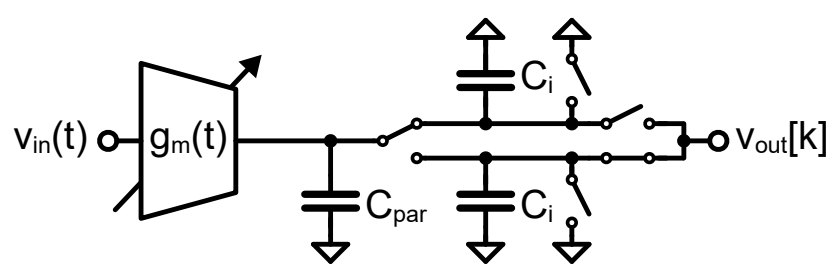

Figure 3.11: Parasitic capacitance at $g_{m}$ output.

where $g_{m}^{\dagger}$ is the maximum transconductance. The future loss is corrected by the product of exponentials and the rest compensates for the loss during its own integration period, neglecting $R_{\text {fixed }}$ only for its own period. $c_{a}$ is calculated for all $N$ coefficients. Afterwards, $\vec{c}$ is compared to the $\mathrm{g}_{\mathrm{m}} \mathrm{DAC}$ full scale and $\alpha$ is varied until the precorrected code exactly fits within. The correction can even be applied to a purely resistive transconductor with $\mu=1$. A similar code precorrection approach, for a purely resistive transconductor with source resistance, is provided in [16].

\subsubsection{Parasitic Capacitance}

The filter transfer function can be affected by the $g_{m}$ DAC parasitic output capacitance $C_{\text {par }}$ as shown in Fig. 3.11. The charge of subsequent output samples are shared though $C_{\text {par }}$, because this charge is not reset. This results in an additional IIR 


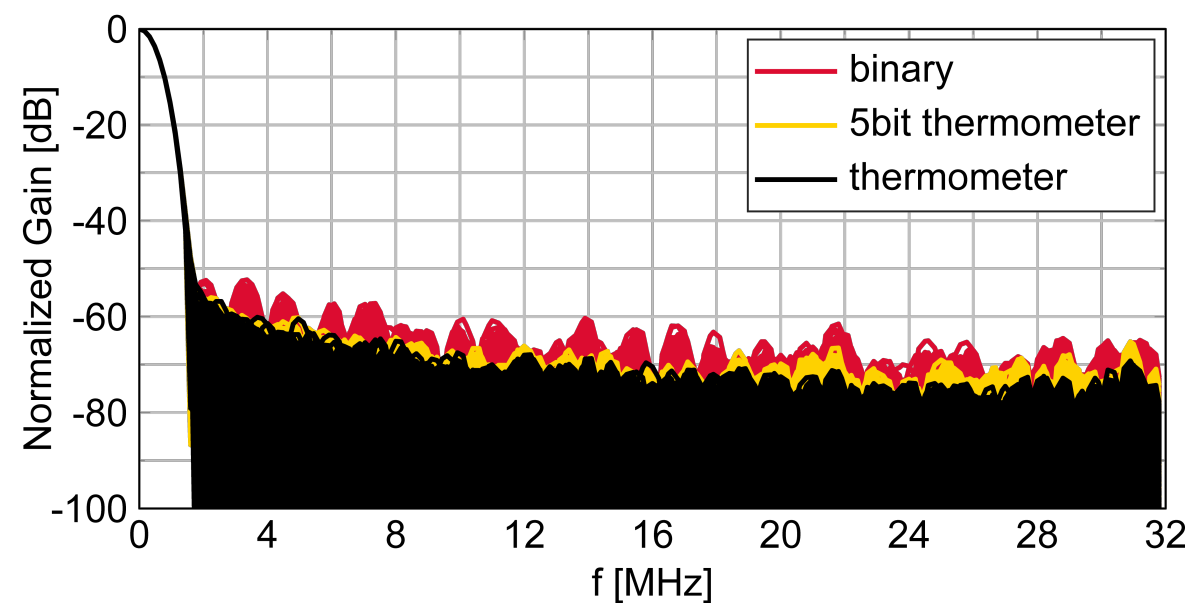

Figure 3.12: Transfer function of $500 \mathrm{~g}_{\mathrm{m}} \mathrm{DAC}$ mismatch realizations for different $g_{m^{-}}$ code control.

filtering according to

$$
H_{C_{\text {par }}}(f)=\left.\frac{1}{1-\frac{C_{\text {par }}}{C_{\text {par }}+C_{i}} z^{-1}}\right|_{z=e^{j 2 \pi f T_{i}}}
$$

The extra filtering is at the output of the model in Fig. 3.4. If significant, this effect can be easily mitigated by resetting the parasitic capacitance during the first $T_{w}$ integration period, at the loss of only a single filter coefficient.

\subsection{3 $g_{m}$-cell Mismatch}

The filter stopband attenuation is limited by the $g_{m}$-cell mismatch of the $g_{m}$ DAC. Given the simulated mismatch of a single unary $g_{m}$-cell $\left(\sigma_{g_{m}} / g_{m}=10.7 \%\right)$, the transfer function is determined for numerous $\mathrm{g}_{\mathrm{m}} \mathrm{DAC}$ mismatch realizations; neglecting sinc filtering and aliasing. The aggregation of these transfer functions provides an estimate of the worst-case filter transfer function, which is shown in Fig. 3.12 for 500 realizations and different $\mathrm{g}_{\mathrm{m}} \mathrm{DAC}$ control. The filter bandwidth and roll-off is unaffected by the mismatch - only the stopband floor level is impacted. The binary controlled transfer functions show spurious responses, which are reduced by $>8 \mathrm{~dB}$ in the (5bit) thermometer controlled $\mathrm{g}_{\mathrm{m}} \mathrm{DAC}$ realizations.

The mismatch realizations of Fig. 3.12 allow for a more detailed analysis of the implications on the filter transfer function. Fig. 3.13 shows the cumulative distribution of the $g_{m}$ DACs that have a certain $f_{-60 d B}$; for frequencies $f \geq f_{-60 d B}$ the attenuation is $\geq 60 \mathrm{~dB}$. The binary coded $\mathrm{g}_{\mathrm{m}} \mathrm{DACs}$ have unwanted filter spurs as can 


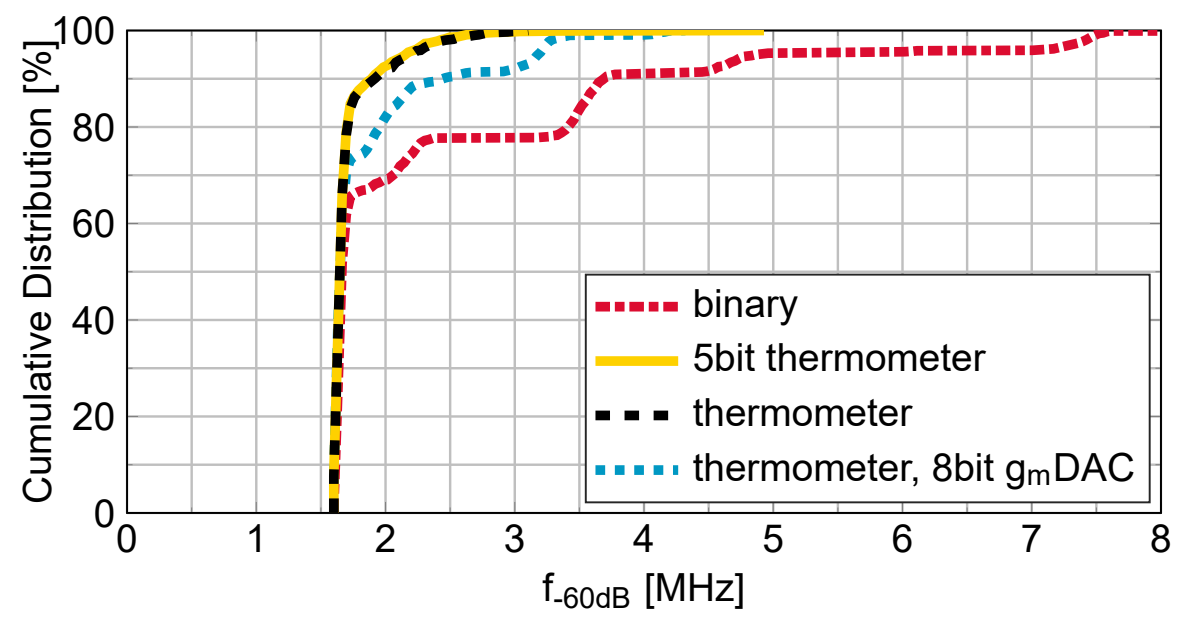

Figure 3.13: Cumulative distribution of the $10 \mathrm{bit} \mathrm{g}_{\mathrm{m}} \mathrm{DACs}$ versus $f_{-60 \mathrm{~dB}}$.

be recognized from the steps in Fig. 3.13. The performance is significantly improved when implemented as a thermometer-coded $\mathrm{g}_{\mathrm{m}} \mathrm{DAC}$. 5bit thermometer coding has similar performance as a fully thermometer coded $\mathrm{g}_{\mathrm{m}} \mathrm{DAC}$, but adds significantly less complexity. The stopband attenuation can further be improved by mismatch calibration as done in $[15,16]$.

Fig. 3.13 also shows the cumulative distribution for an 8bit fully thermometer coded $g_{m}$ DAC with the same MSB $g_{m}$ size. The performance is clearly reduced compared to a 10bit design. 9bit and 10bit designs have similar filter suppression, including mismatch. A 10bit design is chosen to ensure that the filter performance is not limited by the number of bits.

\subsection{4 $\mathrm{g}_{\mathrm{m}} \mathrm{DAC}$ Transient Behavior}

The dynamic switching of the $g_{m}$-cells in the $g_{m}$ DAC has an effect on the analog FIR filter's performance in terms of circuit and system level. The transient switching behavior has three contributing error sources; charge injection to the input (driving stage) of the filter, settling behavior of the $g_{m}$-value and charge injection to the output. All three effects are common-mode, since the $g_{m}$ for the pseudo-differential paths is identical. The injected charge does not, to first order, disturb the differential wanted signal.

The charge injection to the input, or kickback, is of little concern in the receiver application. The simulated peak-to-peak and rms common-mode voltage variations are $<1 \mathrm{mV}$ and $<0.1 \mathrm{mV}$, respectively; when assuming a parallel output impedance of 
about $24 \mathrm{k} \Omega$ and $2 \mathrm{pF}$ of the previous stage ${ }^{2}$.

The settling behavior of a switching $g_{m}$-cell changes its effective $g_{m}$-value. This effect can be compensated by taking into account the error in $g_{m}$-value in a transition and compensating for this in the code. Simulations showed that for the proposed design, this was not required.

The effect of charge injection to the output is alleviated by the time-continuous common-mode feedback circuit and by placing the integration capacitors to ground - providing a low-impedance for the high frequency common-mode switching signals - as verified by simulations.

Partially thermometer coding of the $\mathrm{g}_{\mathrm{m}} \mathrm{DAC}$ reduces all three effects by reducing the number of transitions as discussed in Section 3.3.1.

\subsubsection{Time-Interleaving Gain Mismatch}

The output sample rate is increased by time-interleaving two paths for the same filter shape, which allows for a flexible analog FIR design. $g_{m}$ DAC mismatch in the two paths, results in a gain mismatch - effectively multiplying the input signal with a square wave with frequency $0.5 f_{s}$. The result is spurs at

$$
f_{\text {spur }}=f_{\text {in }} \pm n \cdot 0.5 f_{s}, \quad n=1,2,3, . .
$$

For in-band signals this creates unwanted distortion components. In an IoT receiver, this is of minor concern. Typically, only low SNR (10-20dB) is required for demodulation, yet strong suppression of (much larger) interferers is desired - which is realized by the strong filter suppression of $>60 \mathrm{~dB}$.

\subsubsection{Timing Errors}

The filter code accuracy is affected by the timing of the reclocking D-flipflops. A timing error results in different weighting coefficient time $T_{w}$ and therefore an error in the FIR coefficient $w_{a}$. The simulated timing mismatch $\sigma_{T_{w}}$ is $20 \mathrm{ps}$. Due to the 5bit binary design the largest code transition controlled at a clock edge is 32LSBs. For this design $T_{w}$ is $16 \mathrm{~ns}$, resulting in a $\sigma_{w_{a}}$ due to timing of about $0.04 \mathrm{LSB}$. Indicating that the implemented filter performance is not constrained by timing errors.

\subsection{Measurement Results}

The analog FIR filter was designed and fabricated in a 22nm FD-SOI process. The chip operates at a $700 \mathrm{mV}$ supply voltage and has an active area of $0.09 \mathrm{~mm}^{2}$. Fig. 3.14

\footnotetext{
${ }^{2} 12 \mathrm{k} \Omega$ is the input impedance of the self-biased $g_{m}$-cells that provide the input bias.
} 

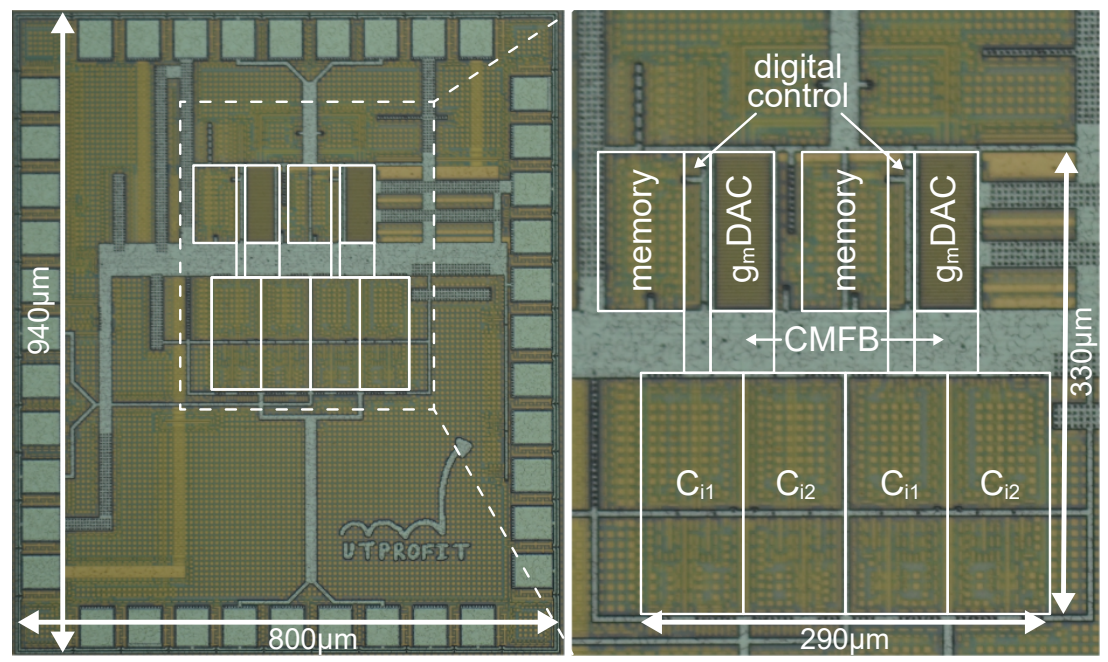

Figure 3.14: Chip photo indicating filter blocks.

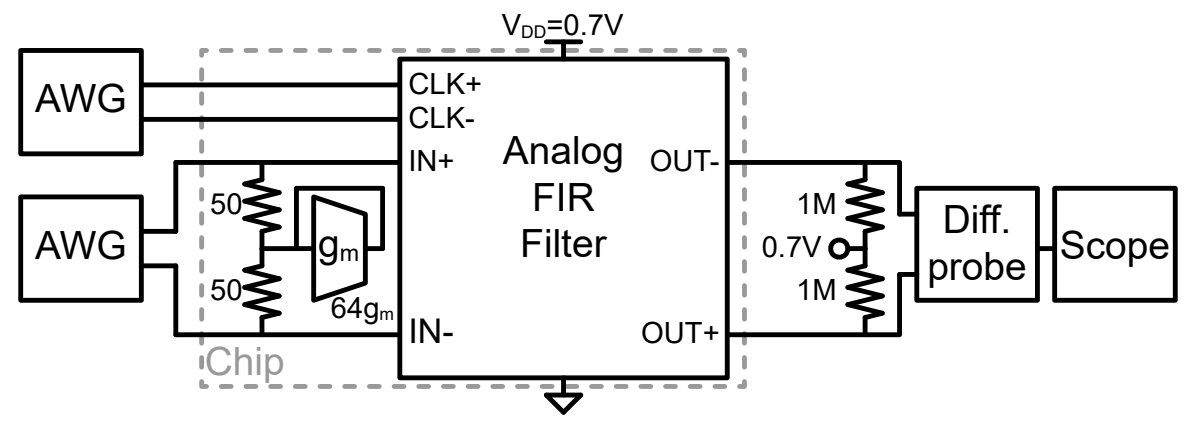

Figure 3.15: Analog FIR measurement setup.

shows the chip micrograph, indicating its major blocks. The FIR code is a Chebyshev window with $r_{o}$-precorrection, where $r_{o}$ is estimated from simulation.

\subsubsection{Measurement Setup}

Fig. 3.15 shows the measurement setup. The input voltage and the $64 \mathrm{MHz}$ clock are provided by arbitrary waveform generators (AWGs) with a differential output. The input common-mode voltage is set by on-chip self-biased $\mathrm{g}_{\mathrm{m}}$-cells. A differential $50 \Omega$ input match is provided to allow characterization of the analog FIR up to RF frequencies. The output samples are only available half of the time, because $\phi_{s}$ and $\phi_{r}$ partially overlap. In this way, the capacitances of the measurement probe and $\mathrm{PCB}$ are also reset to avoid an extra undesired IIR filtering by averaging subsequent output 


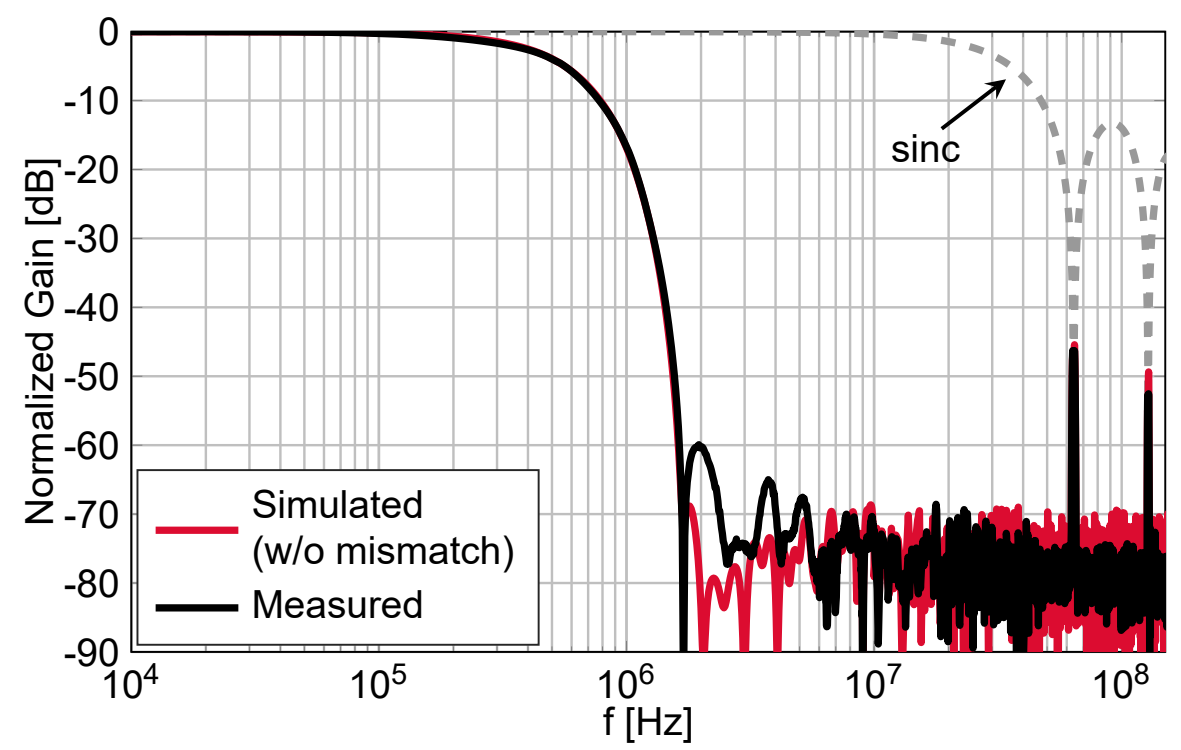

Figure 3.16: Measured normalized transfer function at a bandwidth of $0.43 \mathrm{MHz}$ (without calibration).

samples. The charge sharing between the integration capacitors and the measurement probe (and PCB) capacitors results in a gain reduction, which is de-embedded. The gain reduction was estimated as $3.1 \mathrm{~dB}$ from the capacitances of extracted simulations and the Teledyne LeCroy AP033 datasheet. The output bias network compensates for the resistive common-mode loss of the probe. The bandwidth is set at $0.43 \mathrm{MHz}$, unless specified otherwise.

\subsubsection{Transfer Function}

The filter has a DC gain of $31.5 \mathrm{~dB}$. Fig. 3.16 shows the simulated and measured normalized filter transfer function without $g_{m}$-cell mismatch calibration. The measured transfer function is very close to the simulation result including the very steep transition: the ratio between the 60 and $3 \mathrm{~dB}$ attenuation frequencies is only 3.8 . The stopband attenuation is limited to about $60 \mathrm{~dB}$ at $2 \mathrm{MHz}$ which can be expected from the mismatch analysis of Section 3.4.3. The filter aliases at 64 and $128 \mathrm{MHz}$ are suppressed by $>45 \mathrm{~dB}$ - as expected from the windowed integration sinc filter (3.7).

The effect of $r_{o}$-precorrection is shown in the measurement of Fig. 3.17a. The transfer function error is mainly in the transition band. Here, the input varies slowly in comparison to the integration time, requiring "long-term" accuracy of the coefficients. High offset frequencies are locally canceled during integration and are thus affected 


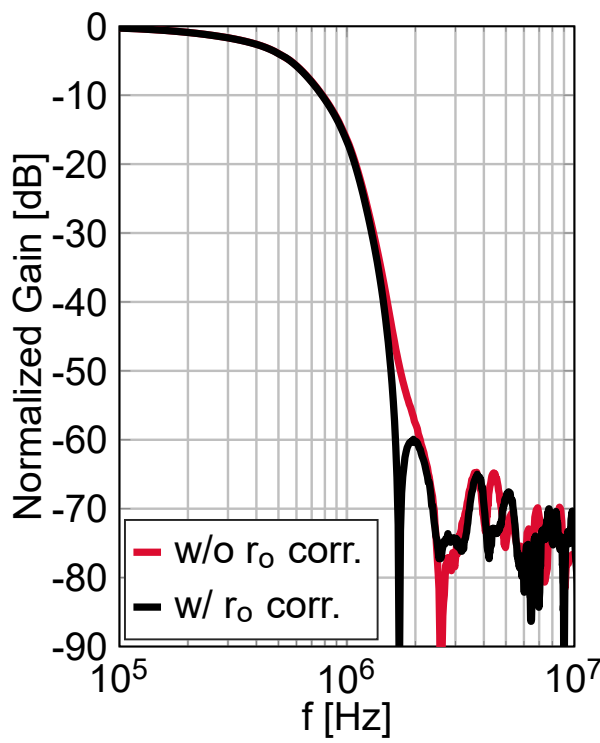

(a)

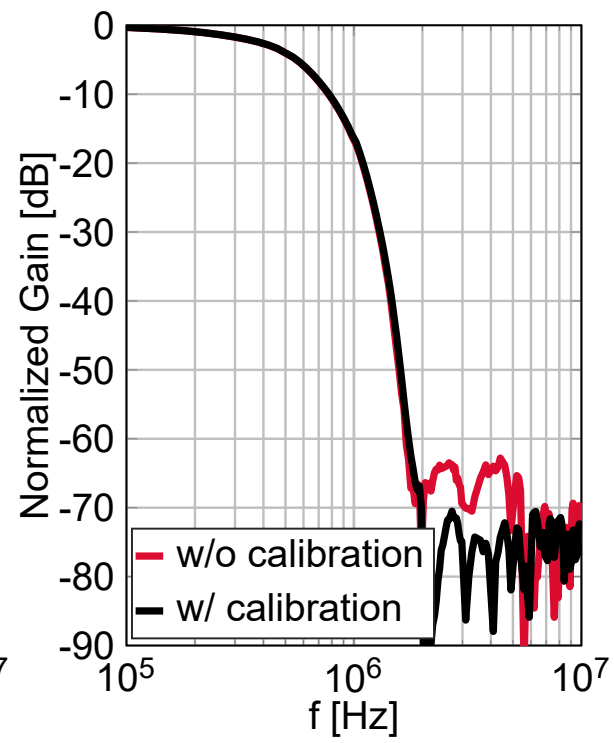

(b)

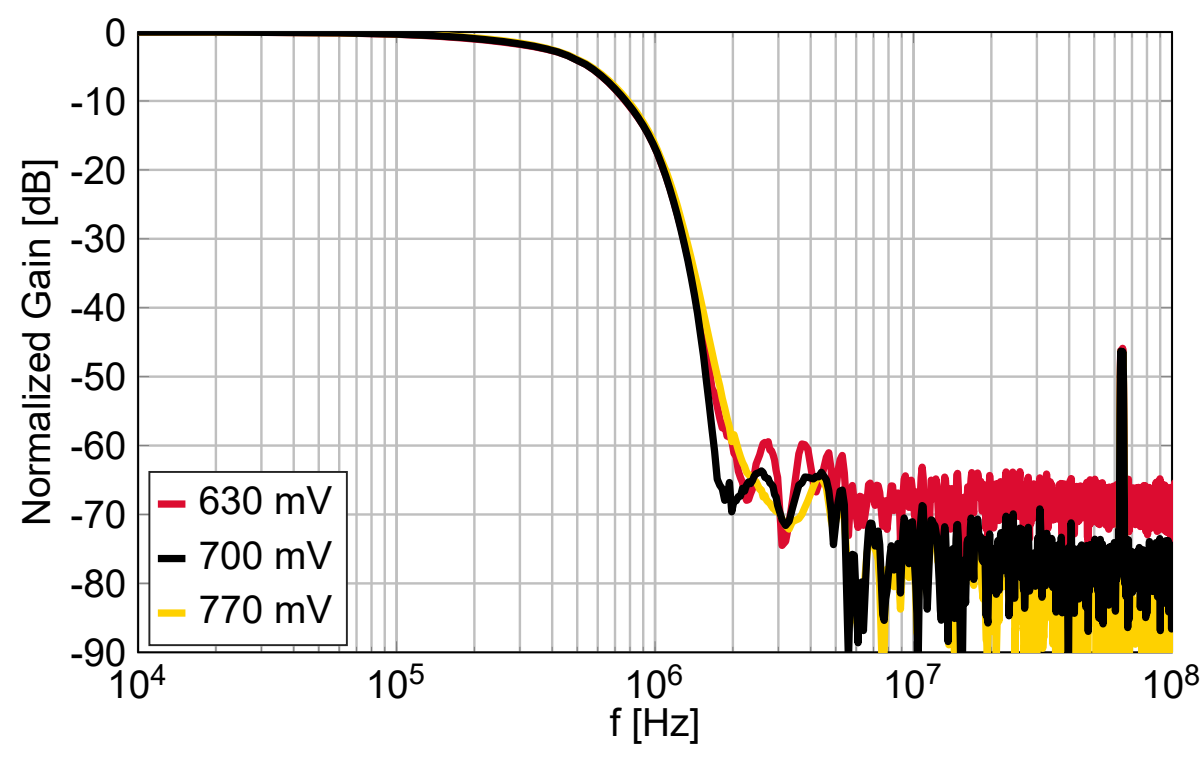

(c)

Figure 3.17: Measured filter transfer function for $0.43 \mathrm{MHz}$ bandwidth. (a) $r_{o^{-}}$ precorrection (b) $g_{m}$-cell mismatch calibration. (c) Different supply voltages. 
less by the skewed effective impulse-response. $r_{o}$-precorrection clearly improves the filter transition.

The parasitic output capacitance of the $g_{m} D A C$ was minimized in the design. The measured in-band attenuation is only $0.3 \mathrm{~dB}$ compared to the ideal transfer function (3.7), which is not a significant error in the targeted application.

Fig. 3.17b shows the measured transfer function with and without mismatch calibration of the $g_{m}$ coefficients after characterizing the $g_{m}$ DAC. $g_{m}$-cell mismatch has little effect on the transfer function roll-off. The stopband depth is improved by $8 \mathrm{~dB}$, indicating that the stopband suppression is indeed limited by the $\mathrm{g}_{\mathrm{m}} \mathrm{DAC}$ mismatch.

Fig. 3.17c shows the filter transfer function for different supply voltages; $700 \mathrm{mV}$ $\pm 10 \%$. The filter bandwidth is independent of the supply voltage as expected from (3.7). The transfer functions have only small deviations in the transition and stopband - especially, considering the gain variation of $-9 \mathrm{~dB}(630 \mathrm{mV})$ and $+7 \mathrm{~dB}(770 \mathrm{mV})$. All supplies use the same $r_{o}$-compensation code, which explains the reduced roll-off for the non-nominal cases. The stop-band attenuation is limited for the $630 \mathrm{mV}$ case by the error caused by $g_{m}$-cell transitions, while the relative mismatch improves for a larger overdrive voltage. Process and temperature variations will have similar effect on the filter transfer function. In a practical application, it could be desirable to have some coarse trimming settings to reduce gain and supply current variations.

\subsubsection{Noise and Distortion}

In this section, the analog FIR filter is characterized for several performance metrics. The measured input-referred noise (IRN) is $12 \mathrm{nV} / \sqrt{\mathrm{Hz}}$; averaged across 0.01$0.43 \mathrm{MHz}$.

The in-band compression is characterized by the in-band gain shown in Fig. 3.18a. The output-referred $1 \mathrm{~dB}$ compression point $\left(\mathrm{OP}_{1 \mathrm{~dB}}\right)$ is $3.7 \mathrm{dBm}$, which corresponds to almost $1 \mathrm{~V}_{\mathrm{pp}}-70 \%$ of the $1.4 \mathrm{~V}$ differential voltage range.

The small signal nonlinearity is characterized by the output-referred third-order intercept point (OIP3). The third-order modulation (IM3) is measured by placing two tones at $\Delta f$ and $2 \Delta f$. In Fig. 3.18a, the IM3 is shown for 5.01 and $9.98 \mathrm{MHz}$ signals. The IM3-tone is at $40 \mathrm{kHz}$, which does not coincide with the aliases of the two input tones. Fig. $3.18 \mathrm{~b}$ shows the OIP3 for various frequency offsets $\Delta f$. The measured OIP3 is $28 \mathrm{dBm}$ and constant for different offset frequencies, which implies that the $3^{\text {rd }}$-order nonlinearity is dominated by the transconductance rather than the output resistance.

Large OOB signals can degrade the filter performance. $60 \mathrm{~dB}$ of filtering is only useful when this dynamic range can also be handled for large blockers. Fig. 3.19a shows the measured in-band gain for a blocker at $5.14 \mathrm{MHz}$, where the blocker input power is swept. The $B_{1 \mathrm{~dB}}$ is $-3.6 \mathrm{dBm}$; the blocker input power for which the in- 


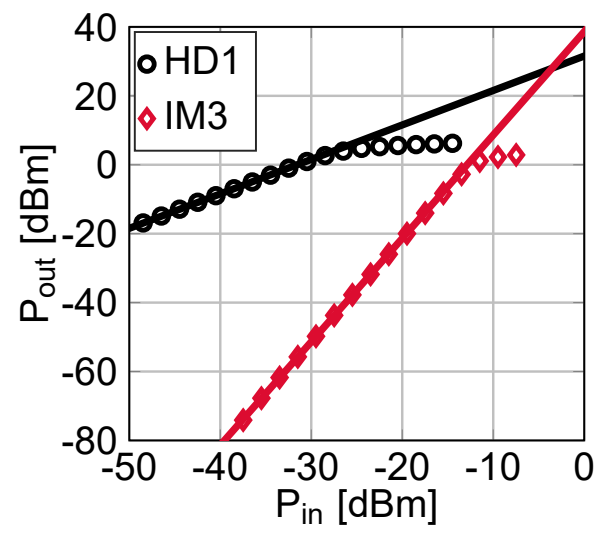

(a)

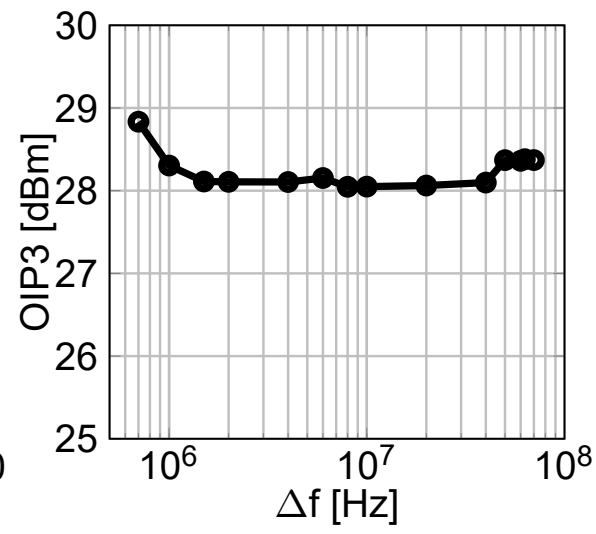

(b)

Figure 3.18: Measured linearity. (a) In-band gain and out-of-band OIP3. (b) OIP3.

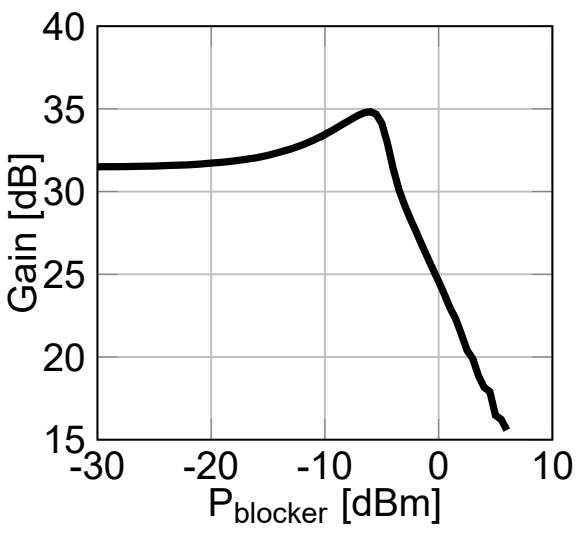

(a)

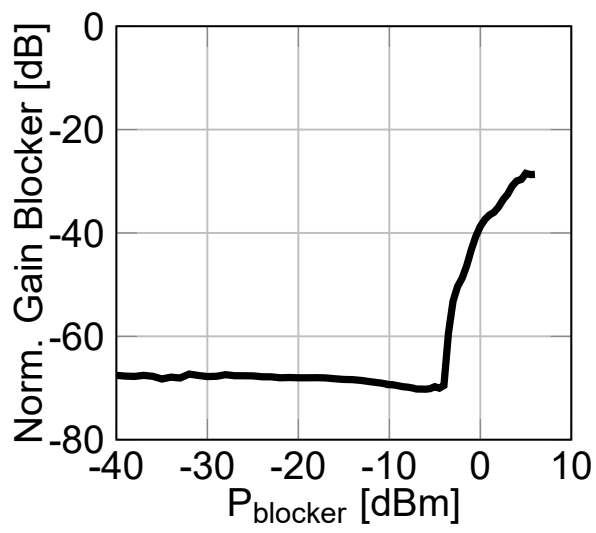

(b)

Figure 3.19: Measured filter characteristics for a blocker at $5.14 \mathrm{MHz}$. (a) In-band gain. (b) Normalized gain blocker.

band gain is $1 \mathrm{~dB}$ compressed. Fig. 3.19a shows a gain increase just before the $\mathrm{B}_{1 \mathrm{~dB}}$. The class-AB biasing of the $g_{m}$ DAC increases the gain when a large (OOB) signal is applied.

Fig. 3.19b shows the gain of an OOB blocker at $5.14 \mathrm{MHz}$ versus its input power; where the gain is normalized to the DC gain. The blocker remains attenuated by almost $70 \mathrm{~dB}$ up to an input power of $-4 \mathrm{dBm}$, after that the filtering sharply degrades. The input range for OOB blockers is about $400 \mathrm{mV}_{\mathrm{pp}}$ differentially, concluding from 


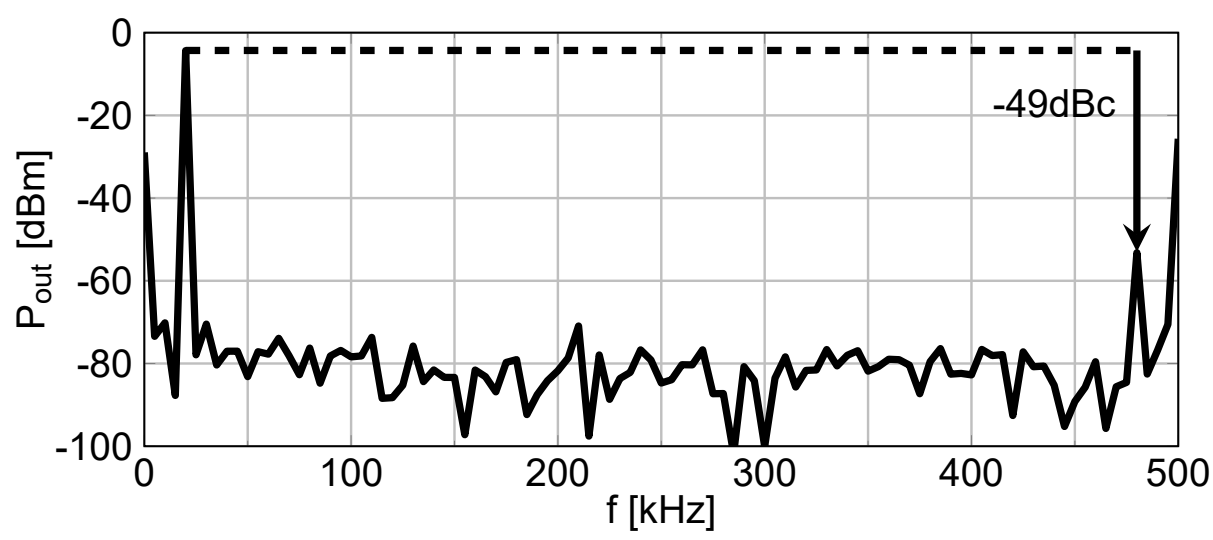

Figure 3.20: Measured output spectrum for a $20 \mathrm{kHz}$ input frequency.

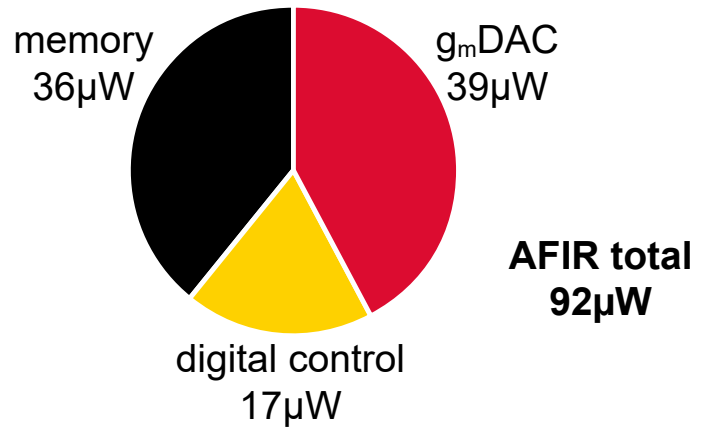

Figure 3.21: Power consumption breakdown.

the in-band gain and large signal filtering in Fig. 3.19.

Time-interleaving two paths doubles the output sample rate. However, a spur is expected due to the gain mismatch of the paths (Section 3.4.5), which is a consequence of the $g_{m}$-cell mismatch. The output spectrum for a $20 \mathrm{kHz}$ input signal is shown in Fig. 3.20. The time-interleaving spur at $-49 \mathrm{dBc}$ is in accordance with the simulated $\mathrm{g}_{\mathrm{m}} \mathrm{DAC}$ mismatch of about $0.33 \%$. Calibration of the $\mathrm{g}_{\mathrm{m}} \mathrm{DAC}$ coefficients can reduce this spur. Underestimation, of the CMFB inverter mismatch manifests itself as a DC offset and a tone at $500 \mathrm{kHz}$ of about $30 \mathrm{mV}_{\mathrm{pp}}$ differentially, which can be removed by calibration.

\subsubsection{Power Consumption}

Fig. 3.21 shows the power consumption breakdown. The total power consumption is $92 \mu \mathrm{W}$. The power consumption of the digital and analog ( $\mathrm{g}_{\mathrm{m}} \mathrm{DACs}$, including CMFB) 


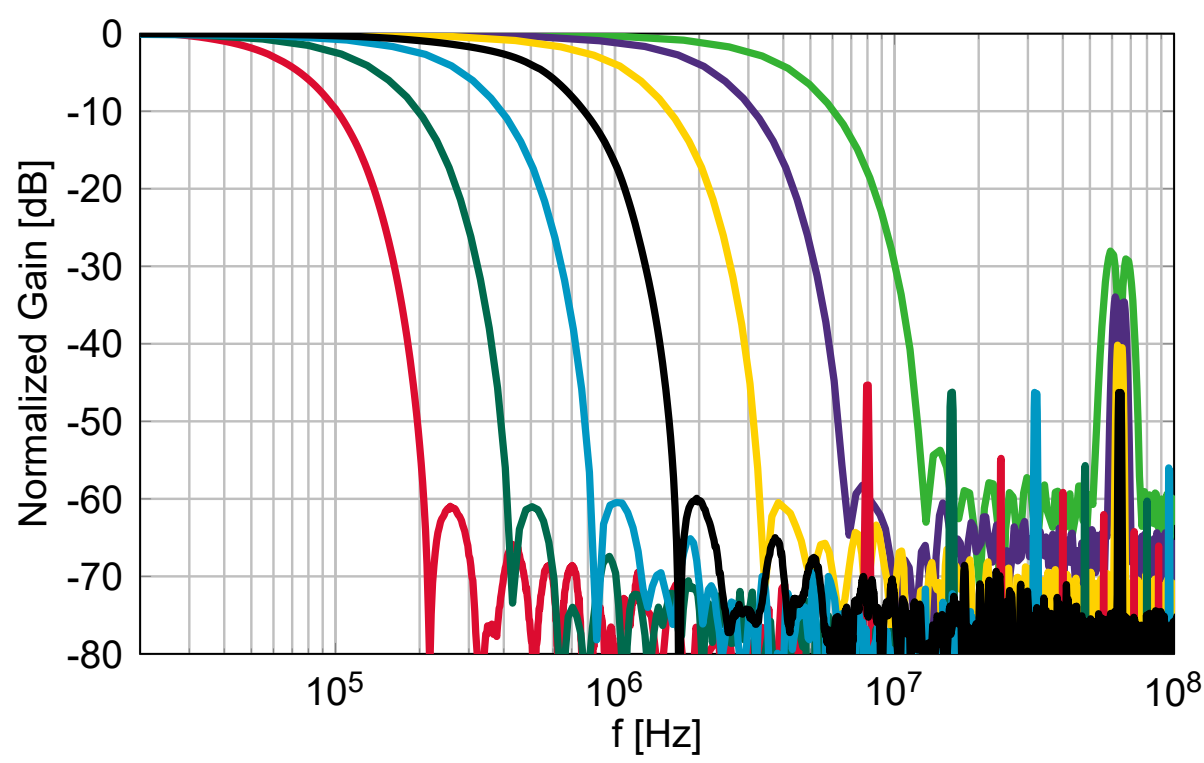

Figure 3.22: Measured filter transfer function for different bandwidth settings.

blocks is about equal. The memory is not specially designed for this application, allowing of further power reduction.

\subsubsection{Flexibility}

The filter is highly reconfigurable. In this section, the flexibility is demonstrated without (significantly) increasing the power consumption. Fig. 3.22 shows the filter transfer function for bandwidths from 0.06 to $3.4 \mathrm{MHz}$.

The bandwidth is reduced by decreasing the $\mathrm{g}_{\mathrm{m}} \mathrm{DAC}$ update rate and $\mathrm{g}_{\mathrm{m}} \mathrm{DAC}$ output sample rate proportionally. This is accomplished by reducing the input clock frequency (Section 3.2.5, option 1). The filter aliases are at lower frequencies, because the $\mathrm{g}_{\mathrm{m}} \mathrm{DAC}$ update frequency is reduced.

The bandwidth is increased by reducing the number of coefficients, while maintaining the same clock frequency (Section 3.2.5, option 2). The filter alias remains at $64 \mathrm{MHz}$; the number of filter coefficients are reduced. The filter alias is attenuated less, because it has a larger bandwidth for the same sinc windowed-integration filter. The power consumption is only increased by $10 \%$ for a filter bandwidth of $3.4 \mathrm{MHz}$.

\subsubsection{Comparison}

The proposed filter performance summary and a comparison to state-of-the-art powerefficient filters is shown in Table 3.1. This work achieves the lowest power consumption 


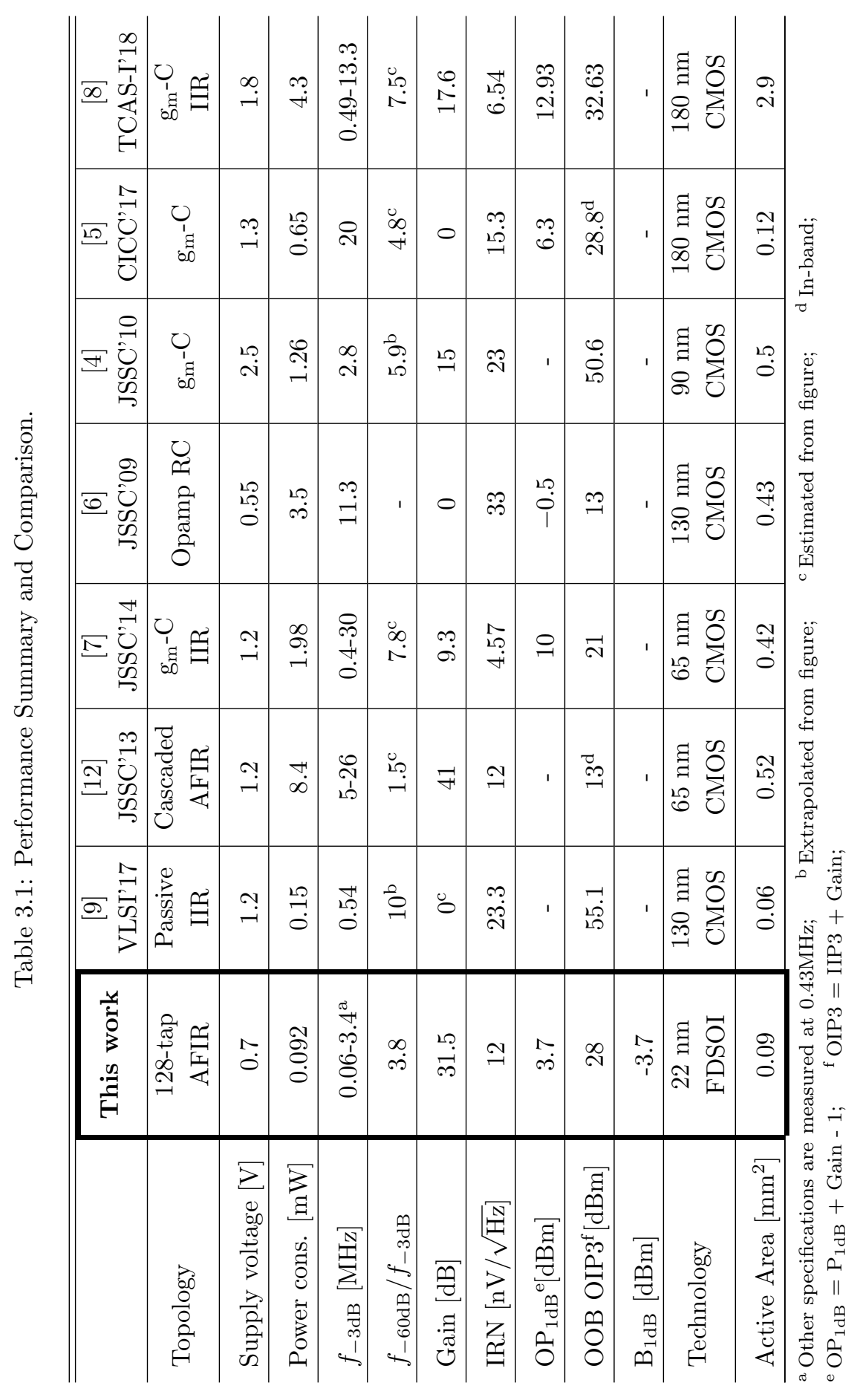


in combination with a very sharp transition band. [12] has a sharper filter transition, but at $>90 \times$ more power consumption. The filter IRN is low and the linearity is competitive. The active chip area is relatively small.

When comparing the classical opamp $\mathrm{R}-\mathrm{C}$ and $\mathrm{g}_{\mathrm{m}}-\mathrm{C}$ filters with the recent digitally controlled analog FIR and IIR filters, the FIR and IIR analog filters show very strong potential in modern CMOS processes. Digital control is attractive as it only consumes dynamic power, while its power consumption scales down with technology and low supply voltages. The proposed analog FIR approach allows for a very steep filter with a single transconductor to maximize the SNR for a given power consumption. The programmability of the proposed analog FIR implementation, not only allows for a flexible filter shape and bandwidth, but it can also be deployed to reduce the effect of circuit impairments e.g. the limited output impedance of a transconductor.

\subsection{Conclusions}

An analog FIR filter architecture is proposed, to serve as a channel selection filter for low power receivers. It employs a hardware efficient implementation that requires only two 10bit pseudo-differential transconductor DACs $\left(\mathrm{g}_{\mathrm{m}} \mathrm{DACs}\right)$ and four integration capacitors to obtain a 128-tap FIR filter.

The bandwidth is accurately tunable from 0.06 to $3.4 \mathrm{MHz}$. Very sharp filtering is obtained, the stopband attenuation at small frequency offsets $-3.8 \times$ the $-3 \mathrm{~dB}$ bandwidth - is $60 \mathrm{~dB}$, without $g_{m}$-cell mismatch calibration. A low power consumption $(92 \mu \mathrm{W})$ is achieved by: the single transconductor $\left(\mathrm{g}_{\mathrm{m}} \mathrm{DAC}\right)$ design with a low update-rate and 5bit thermometer coding. The filter shows constant in-band gain and filtering for blockers with an input power of up to $-4 \mathrm{dBm}$.

The analog FIR filter low power consumption and high selectivity enable future IoT receivers in an increasingly crowded wireless environment. Furthermore, the programmability supports software defined IoT receivers.

\section{References}

[1] B. J. Thijssen, E. A. Klumperink, P. Quinlan, and B. Nauta, "Low-Power Highly Selective Channel Filtering Using a Transconductor-Capacitor Analog FIR," IEEE J. Solid-State Circuits, vol. 55, no. 7, pp. 1785-1795, 2020.

[2] B. J. Thijssen, E. A. M. Klumperink, P. Quinlan, and B. Nauta, "A 0.06-3.4-MHz 92- $\mathrm{WW}$ Analog FIR Channel Selection Filter With Very Sharp Transition Band for IoT Receivers," IEEE Solid-State Circuits Lett., vol. 2, no. 9, pp. 171-174, 2019. 
[3] B. J. Thijssen, E. A. M. Klumperink, P. E. Quinlan, and B. Nauta, "Systems and Methods for Analog Finite Impulse Response Filters," United States Patent US20200321943 A1, October 8, 2020.

[4] A. Pirola, A. Liscidini, and R. Castello, "Current-Mode, WCDMA Channel Filter With In-Band Noise Shaping," IEEE J. Solid-State Circuits, vol. 45, no. 9, pp. 1770-1780, Sep. 2010.

[5] Y. Xu, J. Muhlestein, and U.-K. Moon, "A 0.65mW 20MHz 5 ${ }^{\text {th }}$-Order Low-pass Filter with $+28.8 \mathrm{dBm}$ IIP3 Using Source Follower Coupling," in IEEE Cust. Integr. Circuits Conf., vol. 2017-April, no. 1, Apr. 2017, pp. 1-4.

[6] M. De Matteis, S. D'Amico, and A. Baschirotto, "A 0.55 V 60 dB-DR FourthOrder Analog Baseband Filter," IEEE J. Solid-State Circuits, vol. 44, no. 9, pp. 2525-2534, Sep. 2009.

[7] M. Tohidian, I. Madadi, and R. B. Staszewski, "Analysis and Design of a HighOrder Discrete-Time Passive IIR Low-Pass Filter," IEEE J. Solid-State Circuits, vol. 49, no. 11, pp. 2575-2587, Nov. 2014.

[8] P. Payandehnia, H. Maghami, H. Mirzaie, M. Kareppagoudr, S. Dey, M. Tohidian, and G. C. Temes, "A 0.49-13.3 MHz Tunable Fourth-Order LPF with Complex Poles Achieving 28.7 dBm OIP3," IEEE Trans. Circuits Syst. I Regul. Pap., vol. 65, no. 8, pp. 1-12, 2018.

[9] S. Z. Lulec, D. A. Johns, and A. Liscidini, "A 150- $\mu \mathrm{W} 3^{\text {rd }}$-order Butterworth Passive-Switched-Capacitor Filter with 92 dB SFDR," in IEEE Symp. VLSI Circuits, Jun. 2017, pp. C142-C143.

[10] J.-E. Eklund and R. Arvidsson, "A Multiple Sampling, Single A/D Conversion Technique for I/Q Demodulation in CMOS," IEEE J. Solid-State Circuits, vol. 31, no. 12, pp. 1987-1994, 1996.

[11] E. O'hAnnaidh, E. Rouat, S. Verhaeren, S. L. Tual, and C. Garnier, "A 3.2GHzSample-Rate $800 \mathrm{MHz}$ Bandwidth Highly Reconfigurable Analog FIR Filter in 45nm CMOS," in IEEE Int. Solid-State Circuits Conf. Dig. Tech. Pap., vol. 2, Feb. 2010, pp. 90-91.

[12] M.-F. Huang, M.-C. Kuo, T.-Y. Yang, and X.-L. Huang, “A 58.9-dB ACR, 85.5dB SBA, 5-26-MHz Configurable-Bandwidth, Charge-Domain Filter in 65-nm CMOS," IEEE J. Solid-State Circuits, vol. 48, no. 11, pp. 2827-2838, Nov. 2013. 
[13] J. S. Mincey, E. C. Su, J. Silva-Martinez, and C. T. Rodenbeck, "A 128-Tap Highly Tunable CMOS IF Finite Impulse Response Filter for Pulsed Radar Applications," IEEE Trans. Very Large Scale Integr. Syst., vol. 26, no. 6, pp. 11921203, 2018.

[14] P. Harpe, "A Compact 10-b SAR ADC With Unit-Length Capacitors and a Passive FIR Filter," IEEE J. Solid-State Circuits, vol. 54, no. 3, pp. 636-645, Mar. 2019.

[15] S. Hameed and S. Pamarti, "A Time-Interleaved Filtering-by-Aliasing Receiver Front-End with $>70 \mathrm{~dB}$ Suppression at $<4 \mathrm{x}$ Bandwidth Frequency Offset," IEEE Int. Solid-State Circuits Conf. Dig. Tech. Pap., vol. 60, pp. 418-419, 2017.

[16] N. Sinha, M. Rachid, S. Pavan, and S. Pamarti, "Design and Analysis of an $8 \mathrm{~mW}, 1 \mathrm{GHz}$ Span, Passive Spectrum Scanner With $>+31 \mathrm{dBm}$ Out-of-Band IIP3 Using Periodically Time-Varying Circuit Components," IEEE J. Solid-State Circuits, vol. 52, no. 8, pp. 2009-2025, Aug. 2017.

[17] N. Sinha, M. Rachid, and S. Pamarti, "A Sharp Programmable Passive Filter based on Filtering by Aliasing," IEEE Symp. VLSI Circuits, Dig. Tech. Pap., pp. C58-C59, 2015.

[18] S. Karvonen, T. A. D. Riley, and J. Kostamovaara, "A CMOS Quadrature Charge-Domain Sampling Circuit with 66-dB SFDR up to $100 \mathrm{MHz}$," IEEE Trans. Circuits Syst. I Regul. Pap., vol. 52, no. 2, pp. 292-304, Feb. 2005.

[19] E. Klumperink and B. Nauta, "Systematic Comparison of HF CMOS Transconductors," IEEE Trans. Circuits Syst. II Analog Digit. Signal Process., vol. 50, no. 10, pp. 728-741, Oct. 2003.

[20] M. Ding, X. Wang, P. Zhang, Y. He, S. Traferro, K. Shibata, M. Song, H. Korpela, K. Ueda, Y.-H. Liu, C. Bachmann, and K. Philips, "A 0.8V 0.8 $\mathrm{mm}^{2}$ Bluetooth 5/BLE Digital-Intensive Transceiver with a $2.3 \mathrm{~mW}$ Phase-Tracking RX Utilizing a Hybrid Loop Filter for Interference Resilience in 40nm CMOS," in IEEE Int. Solid-State Circuits Conf. Dig. Tech. Pap., vol. 61, Feb. 2018, pp. $446-448$.

[21] H. Liu, Z. Sun, D. Tang, H. Huang, T. Kaneko, W. Deng, R. Wu, K. Okada, and A. Matsuzawa, "An ADPLL-Centric Bluetooth Low-Energy Transceiver with 2.3mW Interference-Tolerant Hybrid-Loop Receiver and 2.9mW Single-Point Polar Transmitter in 65nm CMOS," in IEEE Int. Solid-State Circuits Conf. Dig. Tech. Pap., 2018, pp. 444-445. 
[22] B. J. Thijssen, E. A. M. Klumperink, P. Quinlan, and B. Nauta, "A 370 $\mathrm{W}$ 5.5dB-NF BLE/BT5.0/IEEE 802.15.4-Compliant Receiver with >63dB Adjacent Channel Rejection at $>2$ Channels Offset in 22nm FDSOI," in IEEE Int. SolidState Circuits Conf. Dig. Tech. Pap., Feb. 2020, pp. 467-468.

[23] A. H. M. Shirazi, H. M. Lavasani, M. Sharifzadeh, Y. Rajavi, S. Mirabbasi, and M. Taghivand, "A $980 \mu \mathrm{W} 5.2 \mathrm{~dB}-\mathrm{NF}$ Current-Reused Direct-Conversion Bluetooth-Low-Energy Receiver in 40nm CMOS," in IEEE Cust. Integr. Circuits Conf., Apr. 2017.

[24] J. G. Proakis and D. G. Manolakis, Digital Signal Processing. Pearson Prentice Hall, 2007. 


\section{4}

\section{Highly-Selective IoT Receiver Front-End with Power Optimization}

The contents of this chapter are published in the IEEE Journal of Solid-State Circuits [1]. Fig. 4.12 is published at the IEEE International Solid-State Circuits Conference [2]. In addition, Section 4.7 is included. The analog FIR filter and receiver front-end are patented in [3].

\subsection{Introduction}

Low power receivers with very high selectivity are a prerequisite for the next generation IoT applications. It is expected that the number of wireless devices will increase rapidly. Battery life-time becomes increasingly important because the burden of charging or changing batteries directly increases with the number of devices. An increasing number of devices compete in the already crowded low-GHz spectrum, thereby increasing the receiver's interference rejection requirements; especially, in the popular $2.4 \mathrm{GHz}$ industrial, scientific and medical (ISM)-band.

The author is aware that the content of this chapter partially overlaps with Chapters 1 to 3 . However, the author preferred minimal modification of the already reviewed and accepted papers. 


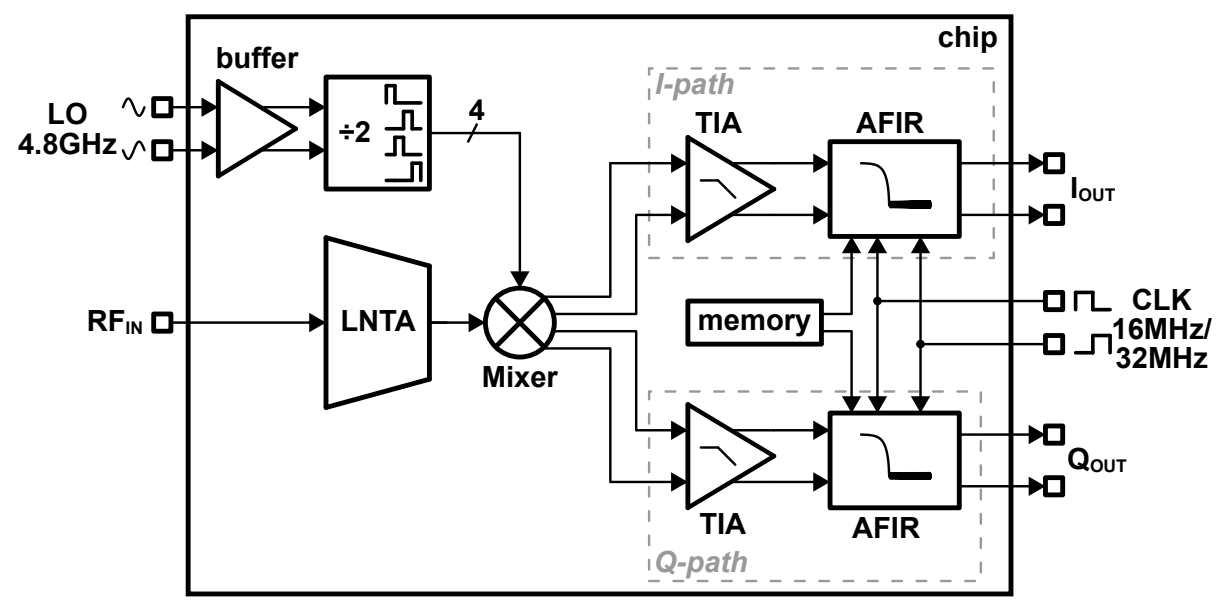

Figure 4.1: Proposed receiver front-end architecture.

Reduced power consumption and improved selectivity should be achieved without compromising on NF. A good NF for state-of-the-art IoT receivers is 5-6dB [4-9]. In IoT receivers all blocks tend to contribute to the total power consumption [4-13]. Therefore, a fully optimized (system) design is required to obtain minimal power consumption.

This chapter is an extension on [2], where we proposed an IoT receiver front-end that combines reduced power consumption with improved selectivity and without compromising on NF or linearity. Power optimization is applied across the entire receive chain: the low-noise transconductance amplifier (LNTA), frequency divider with mixer and baseband filter. The baseband filter is implemented as analog FIR filter to improve selectivity without increasing the power consumption. The receiver frontend is designed for BLE, BT5.0 and IEEE802.15.4 and contains on-chip impedance matching. In this chapter, we provide an extensive analysis of the optimizations in the LNTA, frequency divider and baseband filtering architectures. Furthermore, the measurement results are extended, including additional linearity measurements and discussion on the obtained performance.

The structure of the chapter is as follows. First, the receiver front-end overview is provided in Section 4.2. Followed by a detailed description of the optimizations in the LNTA (Section 4.3) and frequency divider (Section 4.4), including a comparison to other divider approaches. The baseband filter architecture, including an analog FIR filter is described in Section 4.5. Section 4.6 discusses the measurement results and the conclusions are provided in Section 4.8 . 


\subsection{Circuit Implementation}

Fig. 4.1 shows the proposed receiver front-end with zero-IF architecture [2]. A singleended RF input is converted to current by an LNTA. This current is passed through a four-phase passive mixer to create differential I/Q baseband signals. The current is converted to voltage and low-pass filtered by a transimpedance amplifier (TIA). The channel selection is performed by an analog FIR (AFIR) filter, clocked at $16 \mathrm{MHz}$ and $32 \mathrm{MHz}$ for a $1 \mathrm{Mbps}$ and $2 \mathrm{Mbps}$ data-rate, respectively. The four-phase clock signals are provided by the divide-by-two frequency divider. For this prototype, the $16 \mathrm{MHz} / 32 \mathrm{MHz}$ and $4.8 \mathrm{GHz} \mathrm{LO}$ clocks are provided externally, but multiphase clock generation and clock distribution is on-chip.

\subsection{Low-Noise Transconductance Amplifier}

An inductive degenerated LNTA combines a low NF with low power consumption [14]. However, for very low power consumption the design trade-offs change. In the $2.4 \mathrm{GHz}$ IoT receiver application targeted in this work, our design goal is minimum power consumption at a reasonable NF.

\subsubsection{Ideal Inductors}

Fig. $4.2 \mathrm{a}$ shows the inductive degenerated topology. The input impedance is

$$
Z_{i n}=j \omega\left(L_{s}+L_{g}\right)+\frac{1}{j \omega C_{g s}}+\frac{g_{m}}{C_{g s}} L_{s}
$$

where $g_{m}$ is the transistor's transconductance. Matching is accomplished at the resonance frequency

$$
w_{c}^{2}=\frac{1}{\left(L_{s}+L_{g}\right) C_{g s}}
$$

for which $\operatorname{Im}\left(Z_{\text {in }}\right)=0$ and

$$
Z_{i n}=\frac{g_{m}}{C_{g s}} L_{s}=Z_{0}=50 \Omega
$$

where $Z_{0}$ is the source (antenna) impedance, here $50 \Omega$. The noise performance of the LNTA can be described by its noise factor: the SNR degradation from input to output. Including only the thermal noise of the transistor transconductance, the noise factor is $[14,15]$

$$
F=1+\gamma Z_{0} \frac{\omega_{c}^{2} C_{g s}^{2}}{g_{m}}
$$




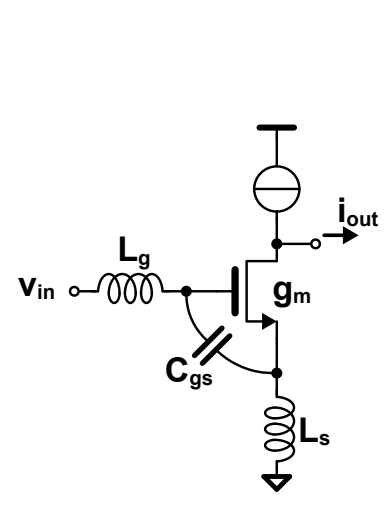

(a)

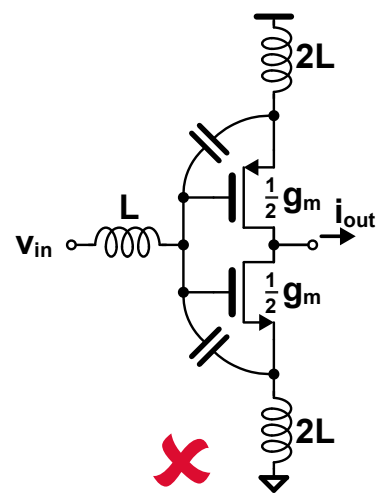

(b)

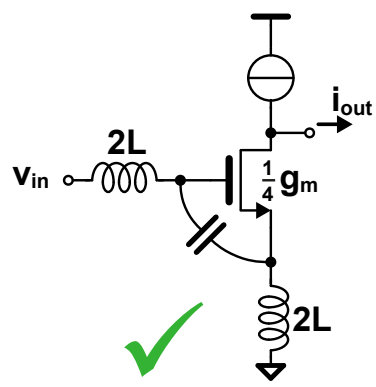

(c)

Figure 4.2: Inductive degenerated LNTA design. (a) Architecture. (b) Push-pull implementation. (c) $2 L$ implementation.

where $\gamma$ is the transistor's noise excess factor. The noise factor can be rewritten using (4.2) and the matching condition (4.3) as

$$
F=1+\gamma \frac{1}{1+\alpha}
$$

with $L_{g}=\alpha L_{s}$. The corresponding required transconductance is

$$
g_{m}=\frac{1}{F-1} \cdot \frac{\gamma Z_{0}}{w_{c}^{2} L_{t o t}^{2}}
$$

where $L_{t o t}=L_{s}+L_{g}$. (4.5) provides a possibly somewhat non-intuitive result: $F$ is independent on $g_{m}$. It is solely determined by the inductor ratio $\alpha$ for a given $\gamma$, assuming impedance matching and ideal inductors. According to (4.6), the minimal $g_{m}$ is obtained for a maximum $F$ and maximum $L_{t o t}$. The maximum allowed $F$ is often specified. The maximum inductor value is generally constrained by its selfresonance frequency or chip area requirements. In IoT applications, it is not desirable to have a very high inductor ratio $\alpha$ - often applied in ultra-low NF-designs to obtain minimal NF - but high $L_{t o t}$ should be pursued to minimize $g_{m}$ and hence lower power consumption. The $L_{g}$ and $L_{s}$ values are in the same order of magnitude, given the maximum inductor value constraint.

Fig. 4.2 shows a thought experiment regarding the LNTA design; assuming $\alpha=1$ provides a sufficiently low NF and for simplicity the current source is ideal. Starting from $L_{g}=L_{s}=L$ one could propose a push-pull design (Fig. 4.2b), since it provides double the $g_{m}$ for the same bias current [16]. At first sight, this seems favorable only half the bias current is required. However, two $2 L$-sized inductors are required to 


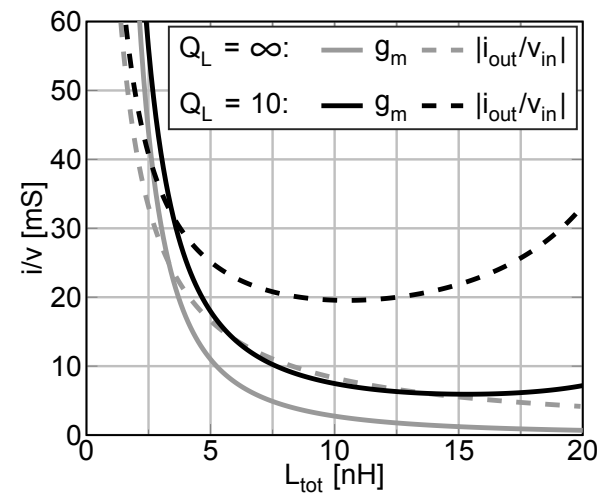

(a)

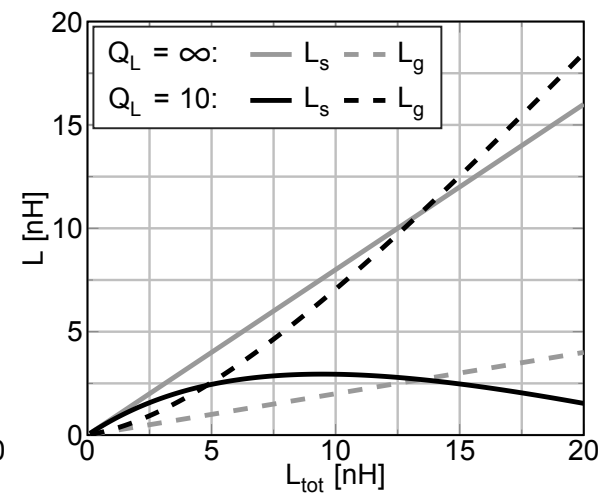

(b)

Figure 4.3: LNTA parameters of Fig. 4.2a for different $Q_{L}$ with $F=1.8$. (a) Required transconductance and transconductance gain. (b) Inductance.

provide an effective $L_{s}=L$. When a maximum inductance value of $2 L$ is available, the circuit of Fig. 4.2c can also be implemented. This configuration requires only $\frac{1}{4} g_{m}$ - in other words, half the bias current of the push-pull architecture - because $g_{m} \propto 1 / L_{\text {tot }}^{2}$. It also requires a smaller area than Fig. $4.2 \mathrm{~b}$. This is a non-intuitive result and would mean that the push-pull architectures of [2, 16-18] are unfavorable.

\subsubsection{Including $Q_{L}$}

Detailed analysis shows that the circuits in Fig. 4.2 are oversimplified. Integrated inductors are far from ideal and have a typical quality factor $Q_{L}$ of 10 in the $\mathrm{GHz}$ frequency range. Including the limited $Q_{L}$, the noise factor becomes

$$
F=1+\frac{r_{g}}{Z_{0}}+\frac{r_{s}}{Z_{0}}+\gamma \frac{1}{1+\alpha}\left(\frac{Z_{0}+r_{g}+r_{s}}{Z_{0}}\right)^{2}
$$

where $r_{g}$ and $r_{s}$ are the resistance of $L_{g}$ and $L_{s}$, respectively. Not only the two resistive noise terms are added, but also the $i_{\text {out }} / v_{\text {in }}$ and $i_{\text {out }} / i_{n, g_{m}}$ transfers change and thereby the $\gamma$ term, which was neglected in [14]. The $\gamma$ term increases for higher $r_{g}$ and $r_{s}$ (lower $Q_{L}$ ). The $Q_{L}$ limitation affects the circuit matching only little, but it has a significant effect on the noise factor and thus the required $g_{m}$. Using (4.7), the required $g_{m}$ is

$$
g_{m}=\frac{1}{F-\left(1+\frac{\omega_{c} L_{t o t}}{Q_{L} Z_{0}}\right)} \cdot \frac{\gamma Z_{0}}{\omega_{c}^{2} L_{t o t}^{2}}\left(1+\frac{\omega_{c} L_{t o t}}{Q_{L} Z_{0}}\right)^{2}
$$

which simplifies to (4.6) for no inductor losses $\left(Q_{L} \rightarrow \infty\right)$. 
Fig. 4.3 shows the required $g_{m}$ and inductances for $Q_{L}=\infty$ and $Q_{L}=10$ as function of $L_{t o t}$, assuming a desired noise factor of 1.8 and $\gamma \approx 1$. The required $g_{m}$ is higher for $Q_{L}=10$ as expected. Some interesting observations can be made: For $L_{t o t} \geq 10 \mathrm{nH}$, the required $g_{m}$ is roughly constant; higher inductance hardly reduces the required $g_{m}$. Even when neglecting that high valued on-chip inductors typically have lower $Q_{L}$. The result is that chip area can be saved. Furthermore, the required $L_{s}$ does not increase above $2.9 \mathrm{nH}$ (Fig. $4.3 \mathrm{~b}$ ). $g_{m}$ is no longer proportional to $1 / L_{s}^{2}$. The push-pull configuration is favorable when the maximum attainable inductor value is $\geq 2 L_{s}$ (here $\geq 5.8 \mathrm{nH}$ ).

Fig. 4.3a also shows the LNTA transconductance "gain" $\left|i_{\text {out }} / v_{i n}\right|$. A higher $\left|i_{\text {out }} / v_{\text {in }}\right|$ will result in smaller noise contribution of subsequent stages. At minimum $g_{m},\left|i_{\text {out }} / v_{\text {in }}\right|$ is also at its minimum. However, it cannot be changed much by changing $L_{t o t}$. By decreasing $L_{t o t},\left|i_{\text {out }} / v_{\text {in }}\right|$ increases, but the required $g_{m}$ increases more rapidly and thus the LNTA current consumption; when taking into account that $\left|i_{\text {out }} / v_{\text {in }}\right|$ is squared regarding the noise contribution for subsequent stages. $\left|i_{\text {out }} / v_{\text {in }}\right|$ increases slightly for high inductor values, but the $Q_{L}$ and self resonance frequency will decrease significantly for very large inductors $(L>8 \mathrm{nH})$.

The above analysis provides insight in the design complexity of the inductive degenerated LNTA. It concludes that $L_{g}$ and $L_{s}$ should be in the same order of magnitude and a push-pull architecture can become favorable when including $Q_{L}=10$ in the analysis. The LNTA transconductance gain cannot be increased much to reduce the noise contribution of subsequent stages, because this would result in a large increase in power consumption or impractically large inductors.

\subsubsection{Brute-Force Search Model}

Including the limited $Q_{L}$ is insufficient to fully optimize the LNTA design. This requires the more complex circuit of Fig. 4.4 to model the LNTA's small-signal behavior. Parasitic capacitors are included: $C_{p c b}$ the PCB parasitic, $C_{E S D}$ the ESD diodes' capacitance including pad parasitics, and $C_{g}$ the parasitic to ground at the gate. $L_{b}$ is the bondwire inductance, which has an estimated $Q$-factor of $35 . L_{s}$ is modeled with $Q_{L}=10 . L_{g}$ is not connected to ground and requires the more extensive $\Pi$-model. The $L_{g} \Pi$-models are derived from the $S$-parameters at $2.44 \mathrm{GHz}$, which is sufficient to optimize for our target application. A design space for $L_{s}, C_{g s}, g_{m}$ is estimated from the results of the simplified analysis. About 20 different $L_{g}$ designs were characterized using Momentum simulations. All resistors and the $g_{m}$ have an associated noise source.

Based on this design space, brute-force search is applied to find the minimal required $g_{m}$ for the NF and $S_{11}<-15 \mathrm{~dB}$ in the $2.4 \mathrm{GHz}$ ISM-band requirements optimizing the design. A push-pull architecture is selected, because the required $L_{s}$ 


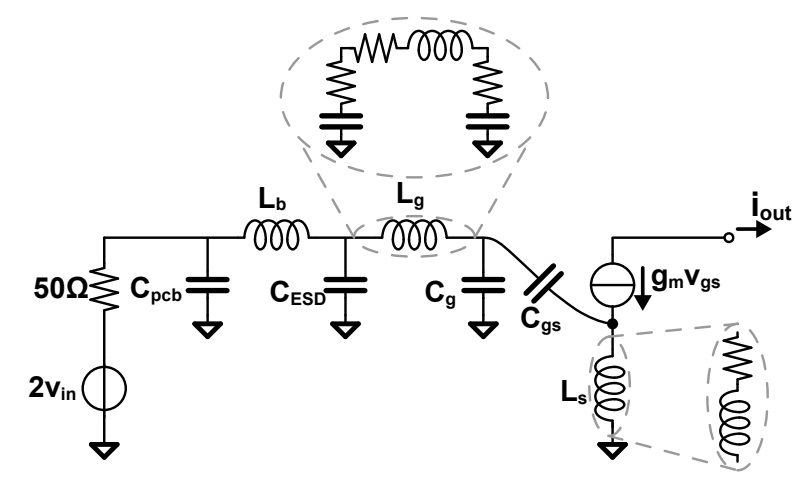

Figure 4.4: Small-signal model for brute-force optimization of the LNTA.

is sufficiently low at $3.6 \mathrm{nH}$. $L_{g}$ is $4.3 \mathrm{nH}$, the inductors are approximately equal as expected to minimize $g_{m}$.

In addition to minimum $g_{m}$ for a given $\mathrm{NF}$, the linearity requirement has to be satisfied. The main non-linearity sources are the transistor transconductance and output impedance. The output impedance non-linearity contribution depends on mixer/TIA design. Typically, the TIA input impedance is limiting in-band while OOB the mixer switch on-resistance. The transconductance non-linearity can be changed by the biasing conditions. A larger overdrive voltage improves the linearity at the cost of transconductance efficiency $g_{m} / I_{D C}$ and hence power consumption. An alternative measure would be to increase $L_{s}$ (the transconductance feedback), but the desired $L_{s}$ is already high.

\subsubsection{LNTA and Mixer Topology}

Fig. 4.5 shows the proposed LNTA including the passive mixer switches. In this design, both FETs are nominally biased at roughly half supply to allow for maximum voltage swing and to minimize large signal clipping given the supply headroom. The OOB IIP3 is slightly limited by drain voltage swing induced non-linearity in the LNTA due to the large mixer switch resistance values, which have been optimized to save power. The OOB IIP3 could be improved by $4 \mathrm{~dB}$, according to simulation, by reducing the mixer switch resistance. The simulated output impedance magnitude of the LNTA is $3.3 \mathrm{k} \Omega$. The linearity is state-of-the-art for a BLE receiver (IIP3 $>-10 \mathrm{dBm}$ ) combined with a low mixer load to the frequency divider. Constant $g_{m}$-biasing is employed to maintain the LNTA NF, matching and IIP3 specifications across PVT variations. 


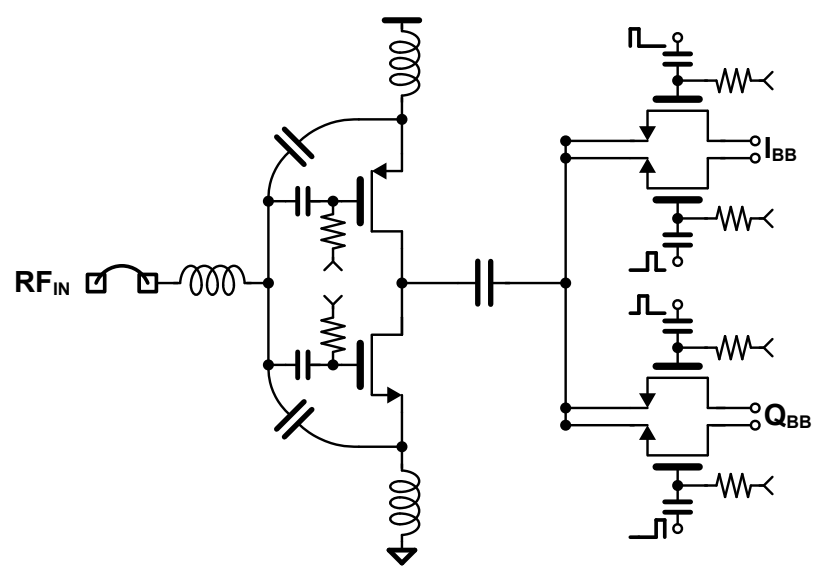

Figure 4.5: Proposed LNTA including mixer.

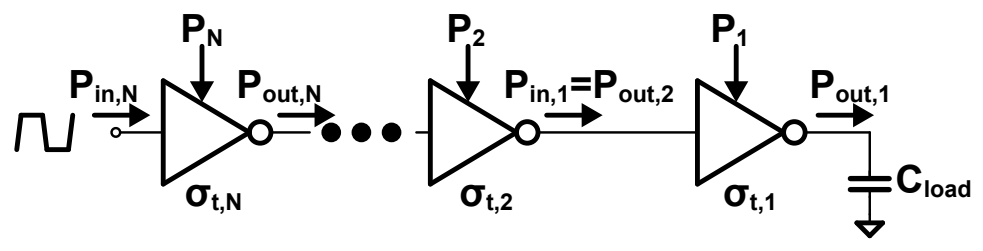

Figure 4.6: Power consumption of multiple buffers driving a capacitive load.

\subsection{Frequency Divider}

A significant part of the power consumption is consumed by the frequency divider and mixer clock buffers in an IoT receiver, e.g. one third in [8]. The proposed receiver front-end employs $25 \%$ duty-cycle clocks to downconvert the single-ended LNTA output RF current to differential I/Q baseband currents. In this section, a minimum logic gate design strategy to minimize power consumption is explained, followed by a novel "Windmill" frequency divider architecture to achieve very low power consumption [2]. Finally, the Windmill divider performance is evaluated by a comparison to multiple prior art designs.

\subsubsection{Minimum Logic Gate Design Strategy}

Fig. 4.6 shows a chain of multiple (inverter) buffers; $P_{n}$ is the power provided by the supply and $P_{i n, n}=P_{o u t, n+1}$ is the power required to drive stage $n$. The fundamental required power to drive the (mixer) load is

$$
P_{\text {load }}=f_{m} C_{\text {load }} V_{D D}^{2}=P_{\text {out }, 1}
$$


where $f_{m}$ is the mixer clock frequency and $V_{D D}$ the supply voltage. All other power is "lost" - in the output parasitics of the buffer, as crowbar current or in driving the buffer. Therefore, the power dissipation of a single buffer stage is

$$
P_{\text {diss }, n}=P_{n}-P_{\text {out }, n}+P_{\text {in }, n}
$$

and the total dissipated power of an $N$ stage buffer is

$$
P_{\text {diss }}=\sum_{n=1}^{N} P_{n}-P_{\text {out }, 1}+P_{\text {in }, N}=\sum_{n=1}^{N} P_{d i s s, n}
$$

The total random time deviation $\sigma_{t}$, either by phase noise and/or mismatch, is the sum of the variances

$$
\sigma_{t}^{2}=\sum_{n=1}^{N} \sigma_{t, n}^{2}
$$

assuming that the individual random timing deviations are uncorrelated. and (4.12) show that minimum $P_{\text {diss }}$ and $\sigma_{t}^{2}$ is obtained when the most efficient buffers - in terms of minimum $P_{d i s s}$ and $\sigma_{t}^{2}$ - are used with a minimal number of stages. Therefore, a minimum number of efficient gates - e.g. CMOS logic gates is a strong starting point to optimize the frequency divider.

\subsubsection{Windmill Frequency Divider}

Fig. 4.7 illustrates the design procedure of the $25 \%$ duty-cycle frequency divider starting from the minimum — single — gate design strategy. Typically, differential $50 \%$ duty-cycle $L O$ signals are available at $2 f_{m}$ or $4 f_{m}$ to generate the mixer clocks [8$12,19,20]$. At minimum one selective gate is required to create the $25 \%$ duty-cycle mixer phases. Here, we start with $2 f_{m}$ clocks. This results in less power consumption in the buffers that create the square wave $L O$ from the sinusoidal VCO signals.

The available signals of the design are the input signals $\mathrm{LO}+$ and $\mathrm{LO}-, 50 \%$ dutycycle at $2 f_{m}$, and the output signals $Q_{x}(x=1 . .4), 25 \%$ duty-cycle at $f_{m}$, as shown in Fig. 4.7 (top left). The second illustration shows the single gate implementation using a NOR-gate. A NOR-gate is chosen, because it provides selectivity on high pulses as required. NOR-gates are very efficient in modern CMOS technologies where NFETs and PFETs are approximately equal strength. $L O-$ is inverted through the NOR-gate to create $Q_{1}$. Every other $L O$ - low should be passed to $Q_{1}$ which requires a memory element to count the $L O$ - lows. The memory element is implemented as shown in Fig. 4.7 (bottom left) by a NOR SR-latch. Signals $Q_{2}$ and $Q_{4}$ create an enable signal $E_{1}$, which is low for every other $L O-$ low. This structure is repeated in the last illustration for every output, to create the "Windmill" divider — indicating 


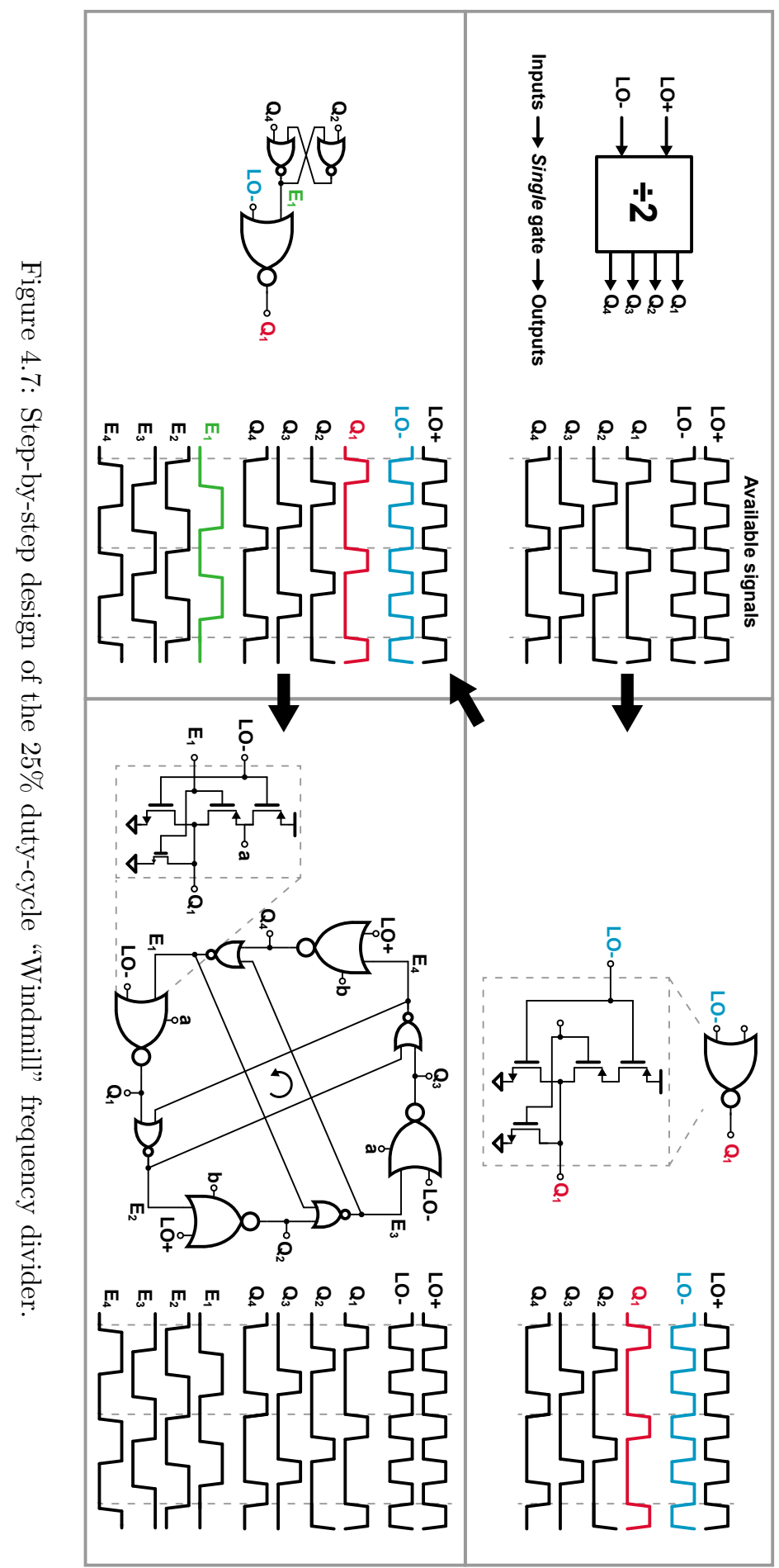




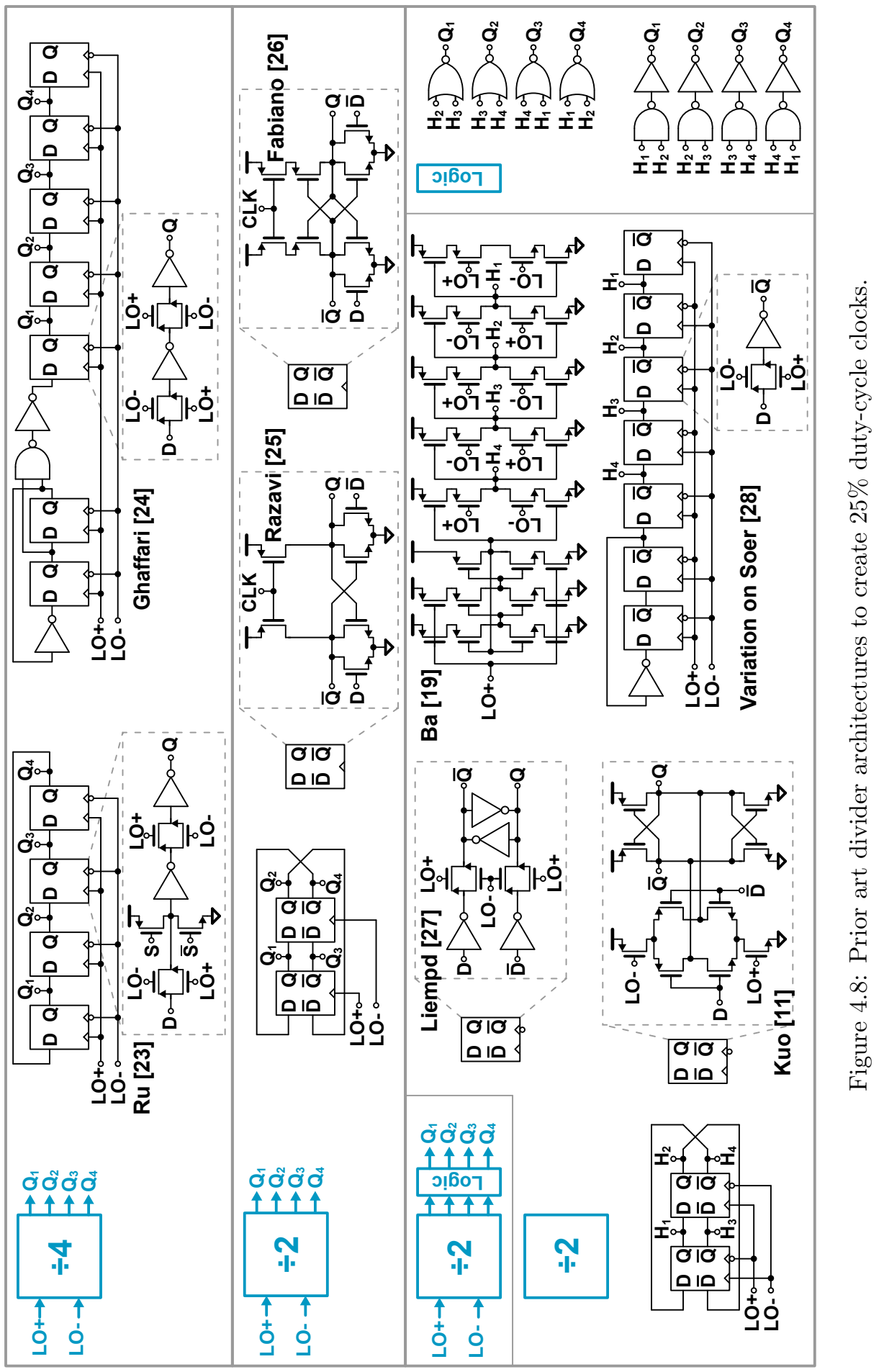



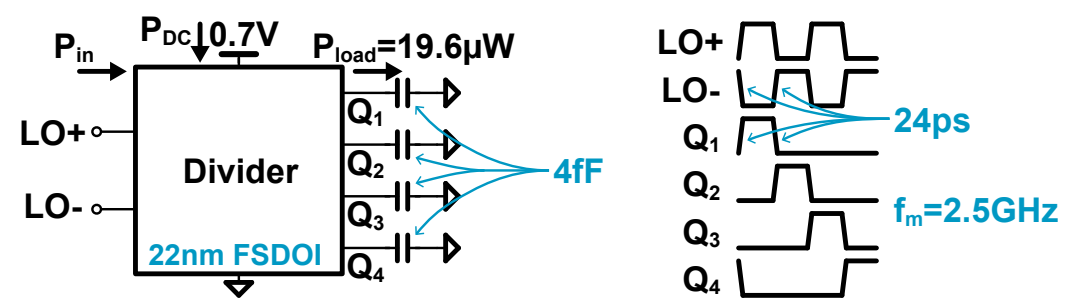

Figure 4.9: Assumptions (highlighted) for simulation based 25\% duty-cycle divider comparison. The LO signals are shown for the divide-by-2 case.

the rotating nature of the gate enable signals $E_{x}$ and outputs $Q_{x}$. The latches toggle the $L O-, L O+$ to $Q_{1} / Q_{3}, Q_{2} / Q_{4}$, respectively.

Only the large transistors in the large NOR gates contribute to the output edges and have to be scaled to the drive mixer load. All other transistors can be minimal size as long as the divider meets the speed requirement. Furthermore, only those large transistors contribute to the phase noise and mismatch. In this way, very low power consumption is achieved while also realizing good phase noise and mismatch as only a single gate propagation delay contributes to timing uncertainty. The top PFET of the opposite large NOR gates is shared, via nodes $a$ and $b$, to reduce the uncorrelated phase noise contributions that degrade the receiver's NF [21, 22]. In addition, since the PFET is shared, a single PFET is used to create two rising edges; reducing the power consumption of the preceding buffers. The phase relation of the outputs is independent on the start-up condition as verified by the I/Q mismatch simulations.

\subsubsection{Divider Comparison}

In this section, we provide a comparison between published divider architectures that create $25 \%$ duty-cycle clock signals. Three approaches can be distinguished as illustrated in Fig. 4.8:

- Direct divide-by-4; divide a differential $L O$ at $4 f_{m}$ by four to create $25 \%$ dutycycle clock signals; [23, 24].

- Direct divide-by-2; divide a differential $L O$ at $2 f_{m}$ by two to create $25 \%$ dutycycle clock signals; the Windmill divider (Fig. 4.7) and [25, 26].

- Divide-by-2 with logic; divide a differential $L O$ at $2 f_{m}$ by two to create $50 \%$ duty-cycle clock signals at $f_{m}$ and use subsequent logic to create $25 \%$ dutycycle outputs; [11, 19, 27] and a variation on [28] without the extra intermediate inverters to reduce its power consumption.

The dividers, all designed in 22nm FDSOI, are compared by simulation with the assumptions as summarized in Fig. 4.9. $C_{\text {load }}$ is $4 \mathrm{fF}$ for each $Q_{x}$-output - equal 
to the mixer switch that is optimized by using $3 \times$ the minimal finger gate pitch to reduce its parasitic capacitance and contact resistance by increasing the number of source and drain contacts. The output frequency is $2.5 \mathrm{GHz}$, which means an input frequency of $10 \mathrm{GHz}$ and $5 \mathrm{GHz}$ for the divide-by- 4 and divide-by- 2 cases, respectively. The required power to drive the mixer load is $19.6 \mu \mathrm{W}$ for a $700 \mathrm{mV}$ supply. The $L O$ rise- $(5 \% \rightarrow 95 \%)$ and fall-times $(95 \% \rightarrow 5 \%)$ are $24 \mathrm{ps.} \mathrm{The} \mathrm{transistors} \mathrm{are} \mathrm{sized} \mathrm{such}$ that the outputs $Q_{x}$ have equal rise- and fall-times as the inputs: $24 \pm 0.3 p s$. All designs are optimized in terms of scaling, e.g. in [24] the first divider is minimal size as these transistors do not contribute to the phase noise or mismatch. The dividers of $[19,24,28]$ contain a dummy device to avoid I/Q-offsets.

The schematic simulation results are summarized in Table 4.1, where the best performance per specification is highlighted by bold text. The dividers are compared on power dissipation $\left(P_{\text {diss }}\right)$ as defined in $(4.10)$, phase noise in the white and $1 / \mathrm{f}$ regions and I/Q-mismatch $\left(\sigma_{I Q}\right)$. I/Q mismatch is of little concern in the proposed zero-IF architecture, but is included for a complete comparison of the dividers. The divider DC power consumption $\left(P_{D C}\right)$ is also included for completeness.

The power dissipation of the Windmill divider is $42 \%$ reduced or more compared to the other architectures. The Windmill divider has the lowest phase noise by $2 \mathrm{~dB}$ or more in the white noise region. The $1 / \mathrm{f}$-noise is less dominant, because the noise corner is at a low offset frequency of about $2 \mathrm{MHz}$. Only [26] has a slightly better I/Qmismatch than the Windmill divider at a significantly higher power dissipation. For [11], the two different logic architectures are compared. The NOR-based design has lower phase noise and I/Q-mismatch at a similar power dissipation. The NOR-gate benefits from the equal NFET-PFET strength in modern CMOS processes.

Some remarks: [23] requires start-up circuitry, controlled by $S$ and $\bar{S}$, which can introduce possible start-up issues. [25, 26] have clock overlap, because the rising edge of $Q_{x+1}$ triggers the falling edge of $Q_{x}$. [19] has an additional static 1.2\% I/Q-offset, because the rising edge of $H_{4}$ is relatively slow. During $H_{4}$ 's rising edge, the input of the tri-state inverter is not at ground, because of charge injection of the previous stage while the input node is floating. Furthermore, [19] has a significantly asymmetric load to the driver of the divider.

All in all, the Windmill divider consumes almost half the power and has $2 \mathrm{~dB}$ less phase noise. The Windmill divider is the only design with only a single gate involved in creating both rising and falling output edges and has outstanding performance. Moreover, it does not have any of the (potential) issues mentioned above. These results are not IoT application specific - all designs can be scaled for more drive power or to reduce phase noise and/or I/Q-mismatch. 


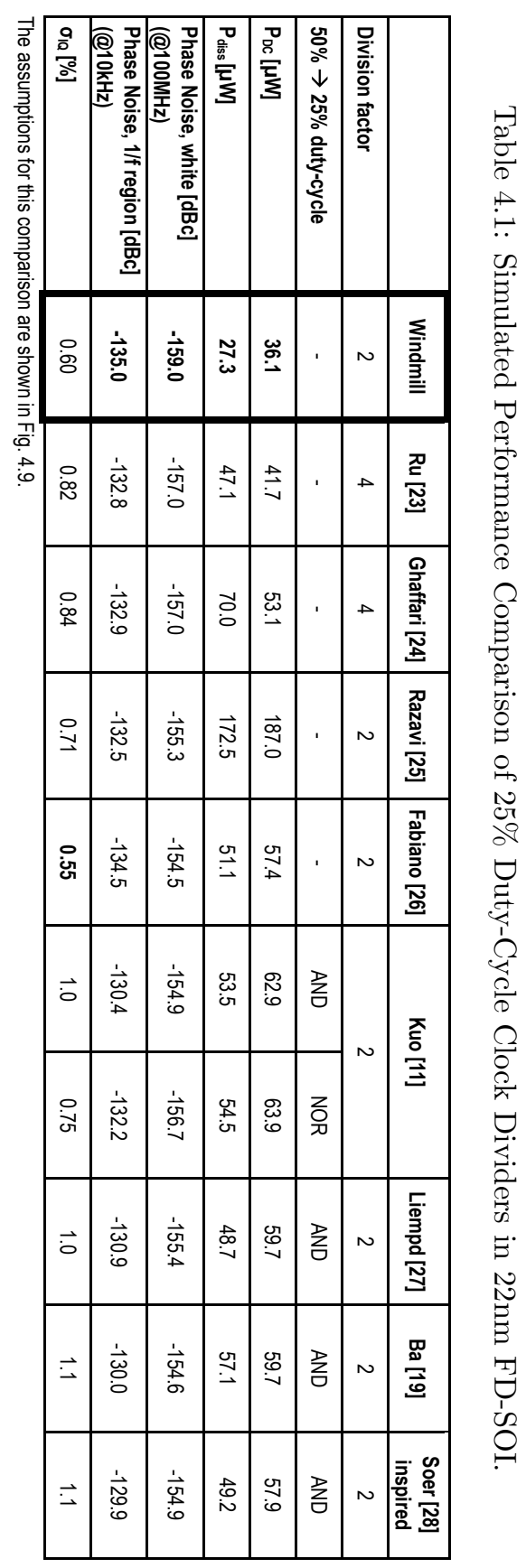




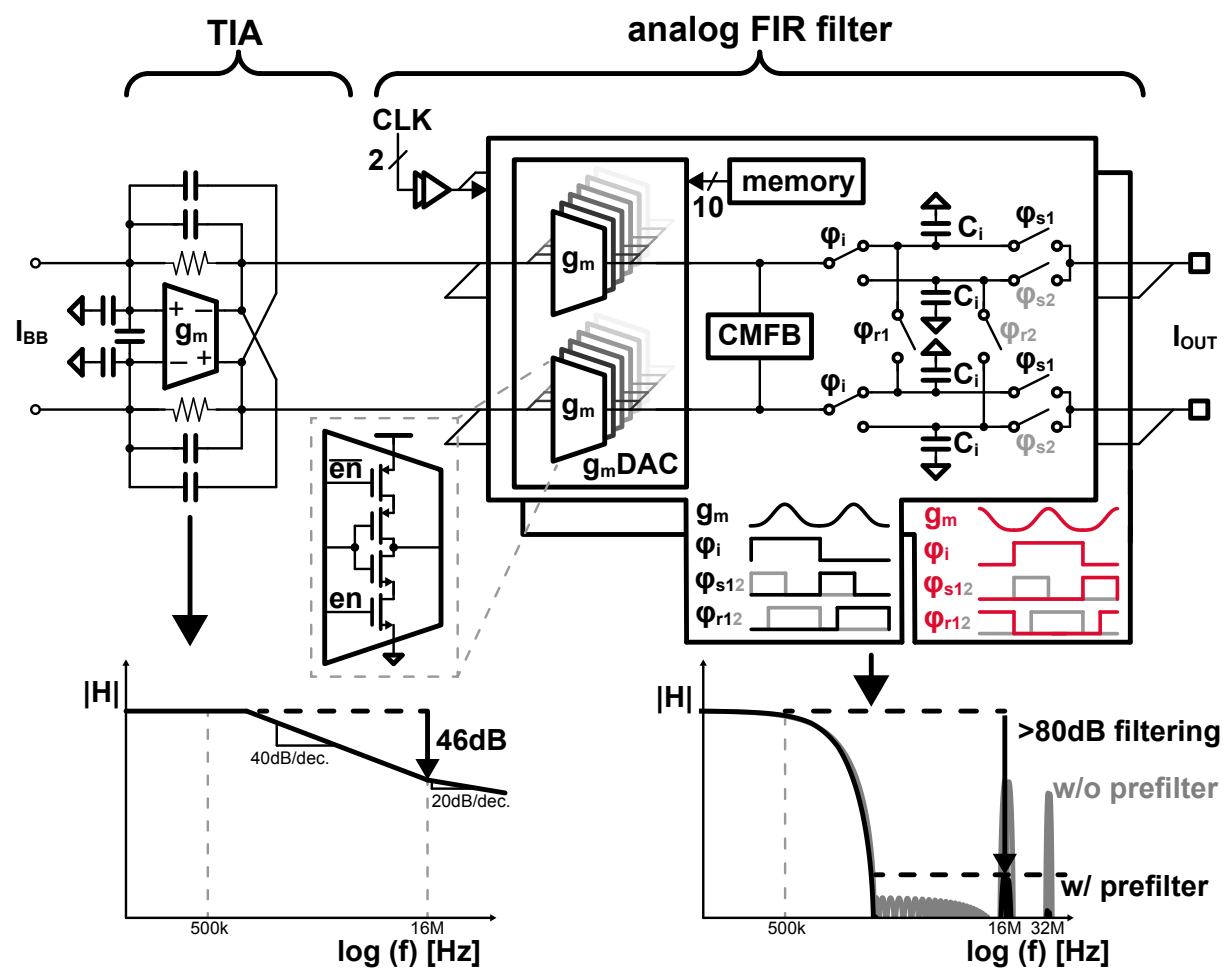

Figure 4.10: Baseband filter consisting of TIA and analog FIR filter.

\subsection{Baseband Analog FIR Filter}

High selectivity is achieved by the baseband analog FIR filter as shown in Fig. 4.10. It contains two time-interleaved paths to double the sample-rate for the same filter bandwidth $[29,30]$. The transconductor is implemented as a 10bit pseudo-differential $\mathrm{g}_{\mathrm{m}}$ DAC. A detailed explanation of the analog FIR filtering operation is described in Chapters 2 and 3. Low power consumption is obtained by push-pull transconductors, 5bit thermometer coding of the $g_{m} \mathrm{DAC}$ and a low update rate of the $\mathrm{g}_{\mathrm{m}} \mathrm{DAC}$. The push-pull transconductors have low input referred noise for a given supply current. 5bit thermometer coding of the $g_{m} D A C$ reduces the number of transitions in the $\mathrm{g}_{\mathrm{m}} \mathrm{DAC}$, because the filter code turns fully on/off only once per integration cycle, much slower than the $g_{m} \mathrm{DAC}$ update frequency. Furthermore, the partially thermometer coding of the $\mathrm{g}_{\mathrm{m}} \mathrm{DAC}$ reduces the effect of transconductor mismatch on the filter stopband - in this design limited to $-60 \mathrm{~dB}[30]$.

The $g_{m}$ DAC update-rate is $16 \mathrm{MHz}$ instead of $64 \mathrm{MHz}[29,30]$ to further reduce the power consumption [2]. This comes at the cost of a closer filter alias and proportion- 


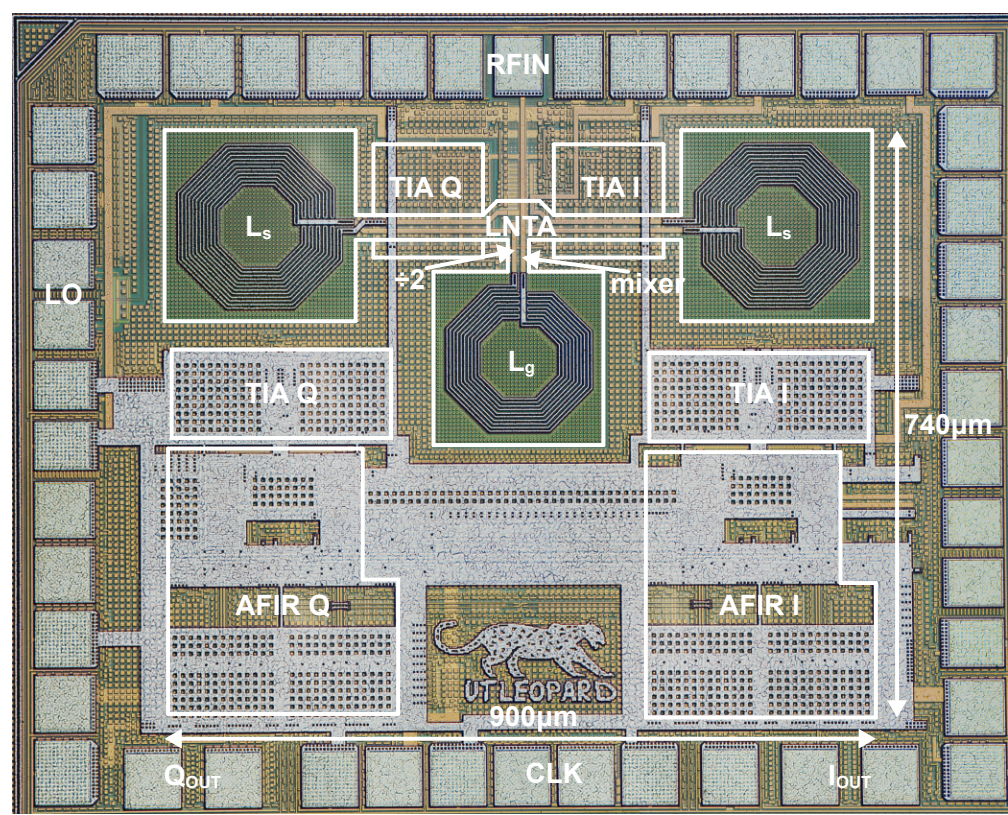

Figure 4.11: Die micrograph indicating the major blocks.

ally reduced attenuation of the filter alias. The inherent sinc windowed integration provides now only $34 \mathrm{~dB}$ of attenuation of this alias. The TIA is employed to provide a prefilter that mitigates the remaining alias. The TIA provides $2^{\text {nd }}$-order filtering by feedforward capacitors for about one decade [31]. In this way, $46 \mathrm{~dB}$ of filtering is achieved at the alias frequency. Resulting in $80 \mathrm{~dB}$ of total attenuation of the analog FIR alias. The exact cut-off frequency of the TIA is relatively relaxed, because it only has to provide prefiltering of the alias. Furthermore, the filtering characteristic is determined by the $g_{m}$ DAC-code and clock signals - making the baseband filtering PVT insensitive [30]. Back-biasing is employed to compensate for the differential DC-offset in the TIAs. In this way, the DC-offset can be compensated without a significant increase in power consumption or noise - in contrast to current injection. The differential DC-offset of the $\mathrm{g}_{\mathrm{m}} \mathrm{DACs}$ is very small, well below $1 \mathrm{mV}$ referred at the output.

\subsection{Experimental Results}

The receiver front-end was designed and fabricated in a 22nm FD-SOI process and wire-bonded in a $40 \times 40$ pin QFN package. The die has an active area of $0.5 \mathrm{~mm}^{2}$ and the supply voltage is $700 \mathrm{mV}$. Fig. 4.11 shows the die micrograph.

The measurement setup is shown in Fig. 4.12. The package is placed in a ZIF 


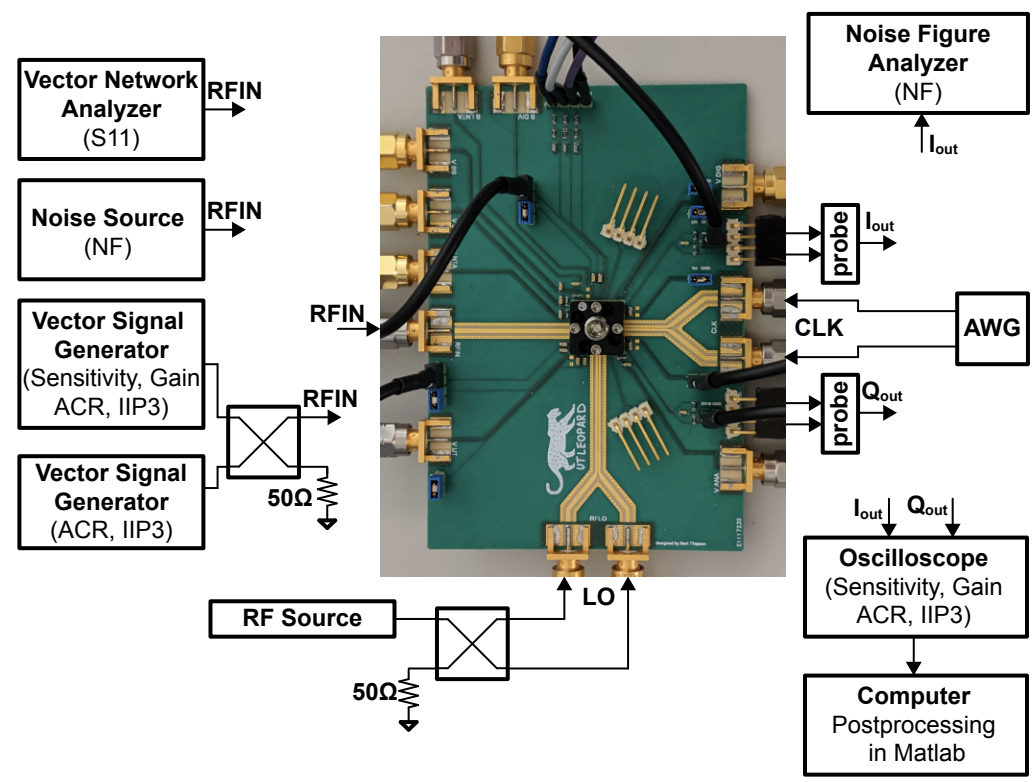

Figure 4.12: Measurement setup.

socket (Ironwood SG-MLF). Impedance matching is realized on chip - no external matching components are used. The capacitor output voltage is measured using an active probe (Teledyne LeCroy AP033) and the charge sharing loss is de-embedded as in Chapter 3 [30]. The measurements are performed in BLE (1Mbps) mode unless stated otherwise.

\subsubsection{Matching and Sensitivity}

The measured $S_{11}$ is shown in Fig. 4.13a. Good matching $\left(S_{11}<-10 \mathrm{~dB}\right)$ is achieved between 2.2 and $2.9 \mathrm{GHz}$. The receiver's $S_{11}$ is below $-15 \mathrm{~dB}$ in the ISM-band which is used in the targeted applications.

The measured noise figure is $5.5 \mathrm{~dB}$. The measured sensitivity for $<0.1 \%$ bit-errorrate (BER) is shown in Fig. 4.13b for each channel. The transmitted signal is a PRBS-9 sequence. The received signal is demodulated using Matlab CPM demodulator (BLE, BT5.0) and MSK demodulator (802.15.4). For BLE, the Matlab CPM demodulator requires roughly $8 \mathrm{~dB}$ SNR to achieve $0.1 \% \mathrm{BER}$, which is about $2 \mathrm{~dB}$ less than a coherent receiver with threshold detection. The sensitivity is flat across the measured band. The 802.15.4 standard is characterized at 2Mbps HS-OQPSK raw data rate without despreading as in $[6,7]$. 


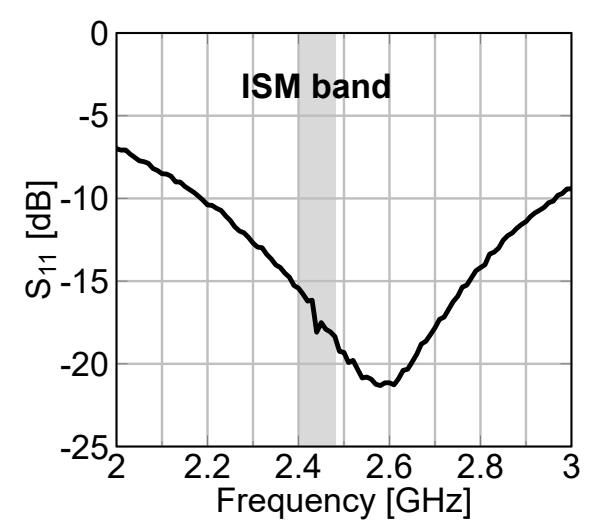

(a)

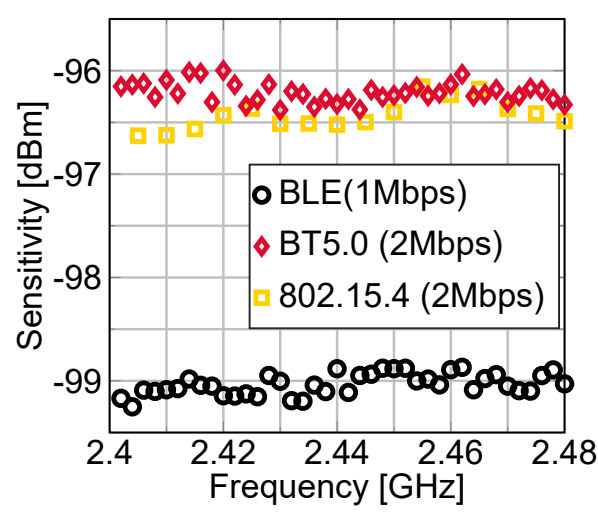

(b)

Figure 4.13: Measured receiver front-end performance. (a) $\mathrm{S}_{11}$. (b) Sensitivity.

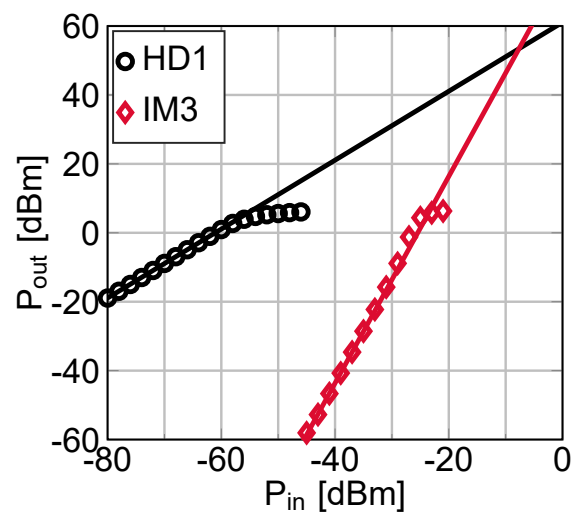

(a)

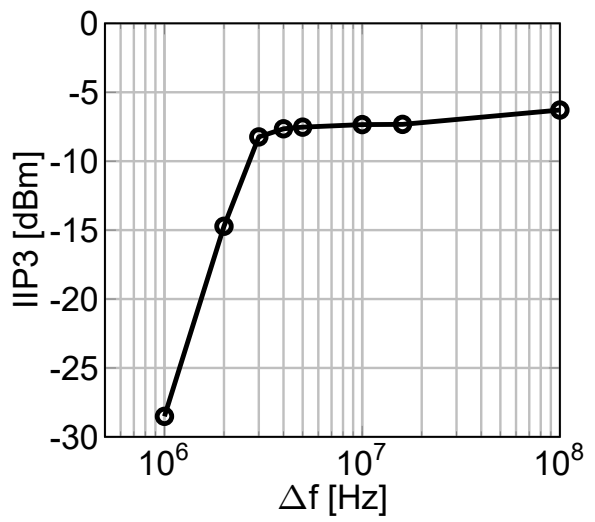

(b)

Figure 4.14: Measured linearity. (a) In-band gain and out-of-band IM3 (for $\Delta f=$ $4.01 \mathrm{MHz}$ and $2 \Delta f=7.98 \mathrm{MHz}$ input tones). (b) IIP3 versus frequency offset.

\subsubsection{Linearity}

The large signal in-band linearity is characterized by the compression point. The in-band gain is shown in Fig. 4.14a. The maximum gain is $61 \mathrm{~dB}$, roughly $30 \mathrm{~dB}$ in both the front-end up to the TIA and analog FIR filter. The $\mathrm{OP}_{1 \mathrm{~dB}}$ is $5.0 \mathrm{dBm}$, corresponding to a $1.1 \mathrm{~V}_{\mathrm{pp}}$ differential output voltage.

The small-signal nonlinearity is characterized by the IM3 product as shown in Fig. 4.14. The IIP3 is $-7.5 \mathrm{dBm}$ for a $4.01 \mathrm{MHz}$ offset at maximum gain of $61 \mathrm{~dB}$. The IIP3 is approximately flat from a $3 \mathrm{MHz}$ offset frequency. Simulation shows that this 


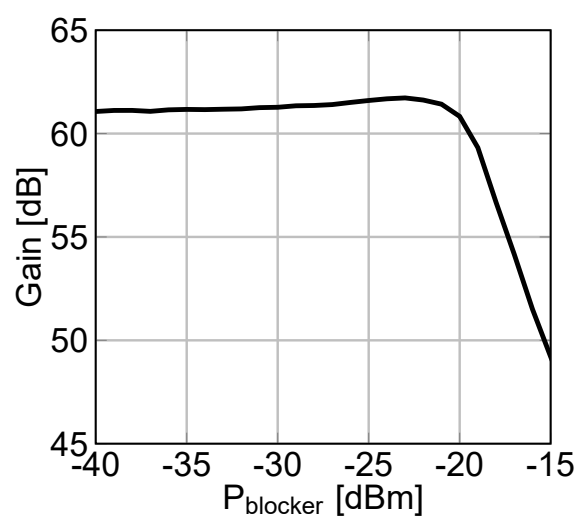

(a)

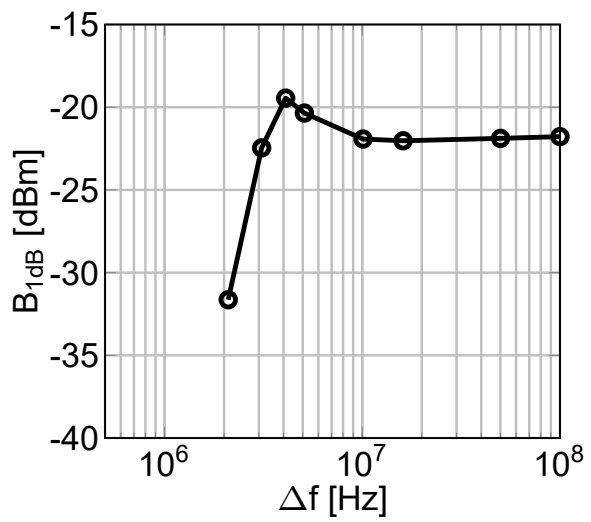

(b)

Figure 4.15: Measured receiver front-end performance in presence of a blocker. (a) Gain for a blocker at $4.1 \mathrm{MHz}$ offset. (b) $\mathrm{B}_{1 \mathrm{~dB}}$ versus frequency offset.

is limited by the LNTA.

Fig. 4.15 shows the measured $\mathrm{B}_{1 \mathrm{~dB}}$, the blocker input power for which the in-band gain is $1 \mathrm{~dB}$ compressed. The $\mathrm{B}_{1 \mathrm{~dB}}$ is approximately $-22 \mathrm{dBm}$ for a frequency offset $\geq 3 \mathrm{MHz}$.

\subsubsection{Adjacent Channel Rejection}

The receiver's performance in presence of a blocker is characterized by the ACR. The $\mathrm{ACR}$ is measured with the desired signal strength at sensitivity $+3 \mathrm{~dB}$ and a blocker signal, modulated using the same standard with PRBS-15 sequence, at various offset frequencies. The wanted signal and blocker are generated with an R\&S SMW200A and R\&S SMBV100A, respectively. Fig. 4.16 shows the measured ACR.

The ACR is $\geq 63 \mathrm{~dB}$ for BLE (1Mbps) at a frequency offset $\geq 3 \mathrm{MHz}$. BT5.0 with double the data-rate has double the filter bandwidth. This shows in the ACR as $\geq 65 \mathrm{~dB}$ ACR at $\geq 6 \mathrm{MHz}$; double the frequency offset of BLE. The 802.15.4 ACR is $\geq 67 \mathrm{~dB}$ for frequency offsets of $\geq 15 \mathrm{MHz}$. 802.15 .4 does not use Gaussian filtering of the transmitted signals and has therefore more transmitted spectral leakage in neighboring channels, which limits the maximal achievable ACR as confirmed here by the measurements. The filter alias at $16 \mathrm{MHz} / 32 \mathrm{MHz}$ for $1 \mathrm{Mbps} / 2 \mathrm{Mbps}$ is just visible by a small perturbation in the ACR rejection profile - indicating that the prefilter operates as desired.

In the following, we provide a short discussion regarding the ACR. From Fig. 4.16, we conclude that the ACR for BLE is limited to about 70dB. Various sources can 


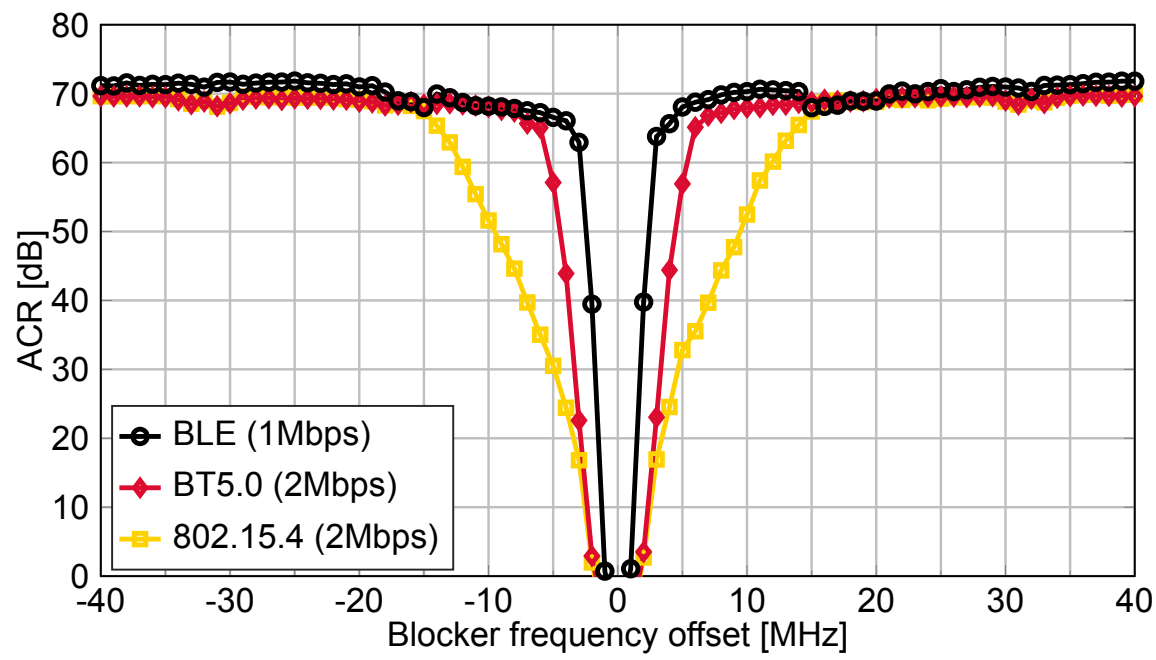

Figure 4.16: Measured adjacent channel rejection for different standards.

constrain the ACR performance:

- Limited blocker attenuation; the (small-signal) filtering.

- Reciprocal mixing; because of LO phase noise.

- Blocker gain compression; related to $\mathrm{B}_{1 \mathrm{~dB}}$.

The demodulation algorithm requires an SNR as derived from

$$
\begin{aligned}
\mathrm{SNR}_{\min } & \approx 174+\text { Sensitiviy }-\mathrm{NF}-10 \log (\mathrm{BW}) \\
& \approx 10 \mathrm{~dB}
\end{aligned}
$$

where NF is measured noise figure and BW the bandwidth. Therefore, $70 \mathrm{~dB}$ of ACR requires about $80 \mathrm{~dB}$ of attenuation to still demodulate the wanted signal. The phase noise of the mixer clock will result in an in-band reciprocal mixing product. The receiver's blocker noise figure (BNF) can be estimated as [32]

$$
\mathrm{BNF} \approx-174+P_{b}+\mathcal{L}(\Delta f)
$$

where $P_{b}$ is the blocker input power, which is

$$
P_{b}=\text { Sensitivity }+3+\mathrm{ACR}
$$

at a given ACR level. From (4.13) to (4.15) the maximum allowed phase noise to achieve $70 \mathrm{~dB}$ ACR is derived as

$$
\begin{aligned}
\mathcal{L}_{\max }(\Delta f) & \approx-\mathrm{SNR}_{\min }-10 \log (\mathrm{BW})-\mathrm{ACR} \\
& \approx-140 \mathrm{dBc} / \mathrm{Hz}
\end{aligned}
$$


neglecting the circuit induced noise, i.e. $\mathrm{BNF}=\mathrm{NF}+3 \mathrm{~dB}$, as in [32]. The minimal required $B_{1 \mathrm{~dB}}$ for $70 \mathrm{~dB} A C R$ is

$$
\begin{aligned}
\mathrm{B}_{1 \mathrm{~dB}, \mathrm{~min}} & \approx \text { Sensitivity }+3+\mathrm{ACR} \\
& \approx-26 \mathrm{dBm}
\end{aligned}
$$

From a frequency offset of $5 \mathrm{MHz}$ onward, the BLE ACR is roughly constant at 70dB. Although, the analog FIR filter has constant rejection, the prefilter has more attenuation for larger frequency offsets. Hence, the ACR is not limited by the filter attenuation in this region. The simulated phase noise of the Windmill divider is $-153.6 \mathrm{dBc} / \mathrm{Hz}$ at $1 \mathrm{MHz}$ offset, which means that also the phase noise is not limiting. The ACR is most likely limited by blocker gain compression of $-22 \mathrm{dBm}$, which is somewhat more severe for a modulated blocker. This also explains that the $2 \mathrm{Mbps}$ ACR is slightly worse, because these standards have $3 \mathrm{~dB}$ higher sensitivity and thus less "headroom" towards blocker gain compression.

At $2 \mathrm{MHz}$ offset, the $\mathrm{ACR}$ is $39 \mathrm{~dB}$ - requiring a $\mathrm{B}_{1 \mathrm{~dB}}$ of approximately $-57 \mathrm{dBm}$, which is much less than the measured $-31 \mathrm{dBm}$. The required filtering is roughly $49 \mathrm{~dB}$. The expected attenuation at $2 \mathrm{MHz}$ is about $70 \mathrm{~dB}(10 \mathrm{~dB}$ TIA $+60 \mathrm{~dB}$ analog FIR $[29,30])$. However, the blocker is modulated with $1 \mathrm{Mbps}$ covering a bandwidth of $1 \mathrm{MHz}$, so that the filter attenuation from 1.5 to $2.5 \mathrm{MHz}$ offset is relevant. The worst case attenuation at $1.5 \mathrm{MHz}$ is only $46 \mathrm{~dB}(6 \mathrm{~dB}$ TIA $+40 \mathrm{~dB}$ analog FIR [29, $30]$ ), because of the steep FIR filter profile. At $3 \mathrm{MHz}$ offset the expected filtering is $76 \mathrm{~dB}(16 \mathrm{~dB}$ TIA $+60 \mathrm{~dB}$ analog FIR $[29,30])$. Therefore, the measured ACR of $39 \mathrm{~dB} / 63 \mathrm{~dB}$ for $2 \mathrm{MHz} / 3 \mathrm{MHz}$ offset can be explained by taking into account the blocker bandwidth. Consequently, the filter profile limits the ACR performance below approximately $5 \mathrm{MHz}$ offset when also taking into account the divider phase noise above.

The receivers frequency response was not measured here, as it is constrained by compression above $5 \mathrm{MHz}$. Instead we report ACR performance, because this is what ultimately matters. The analog FIR filter response can be found in Chapter 3 .

\subsubsection{Power Consumption}

The total power consumption is $370 \mu \mathrm{W}$ as shown in Fig. 4.17. The frequency divider power consumption is only $41 \mu \mathrm{W}$, excluding the preceding buffer.

\subsubsection{Comparison}

The ACR in BLE-mode is compared to state-of-the-art IoT receivers in Fig. 4.18. The proposed receiver front-end has $>20 \mathrm{~dB}$ improved ACR for frequency offsets $>2 \mathrm{MHz}$. The prior art is measured with the wanted signal at $-67 \mathrm{dBm}$, which is similar to 


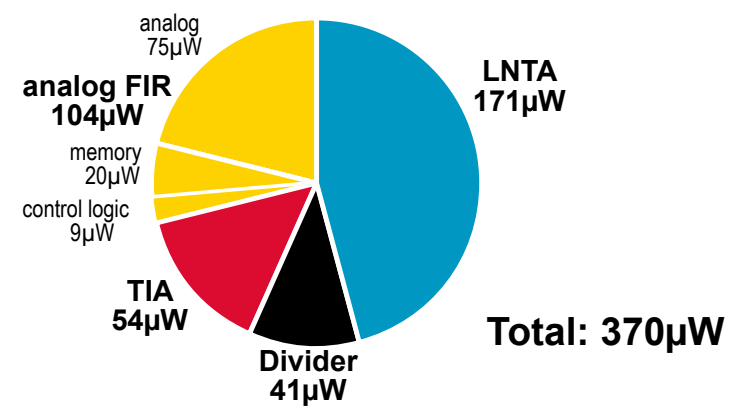

Figure 4.17: Power consumption breakdown.

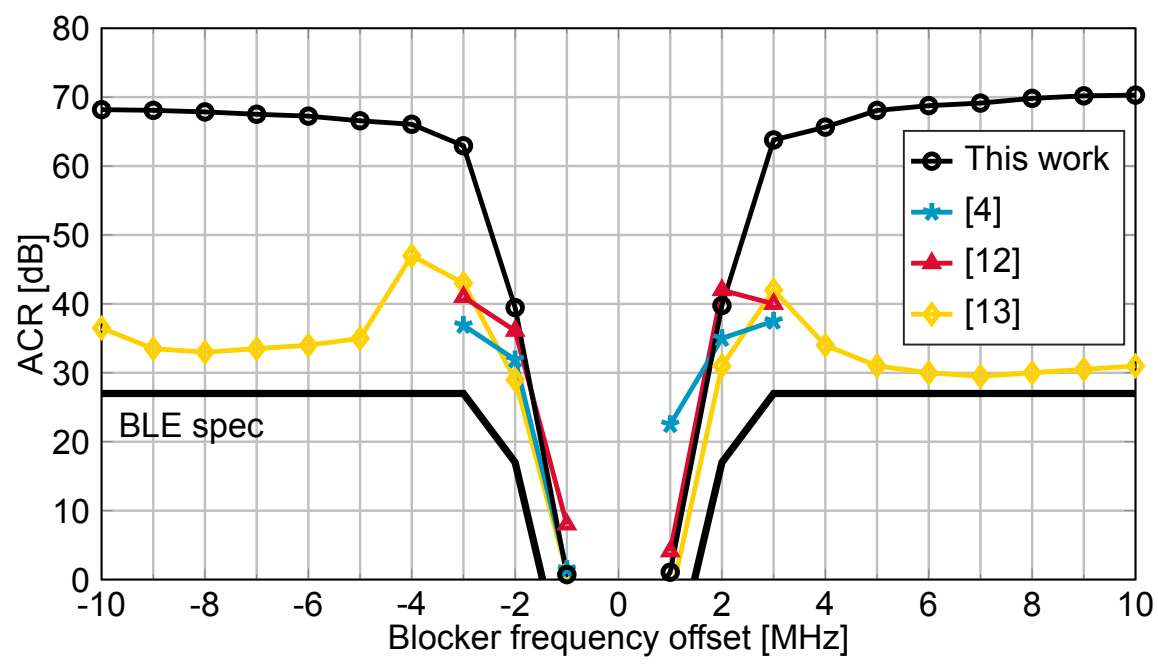

Figure 4.18: Comparison of the measured ACR for BLE (1Mbps).

placing a $29 \mathrm{~dB}$ attenuator in front of the proposed receiver front-end. Alternatively, the feedback resistor can be reduced to avoid gain compression. The TIA feedback resistor is tunable in this design - allowing a $20 \mathrm{~dB}$ gain reduction. Note that this is not an industrial product design, but rather an academic research work that has a broader scope: software defined ultra-low-power radio front-ends. Rather than choosing a standard specific sensitivity, we instead use a more general standard independent criterion: (actual NF based) sensitivity $+3 \mathrm{~dB}$.

Table 4.2 summarizes the proposed receiver's performance and compares it to state-the-of-art $2.4 \mathrm{GHz}$ IoT receivers — only comparing the front-end. The power consumption of the receive chain is reduced by $2 \times$ or more, while achieving similar noise figure. The ACR is improved by more than $20 \mathrm{~dB}$ at the $3^{\text {rd }}$ channel offset. The IIP3 linearity is similar or higher than the prior art. 


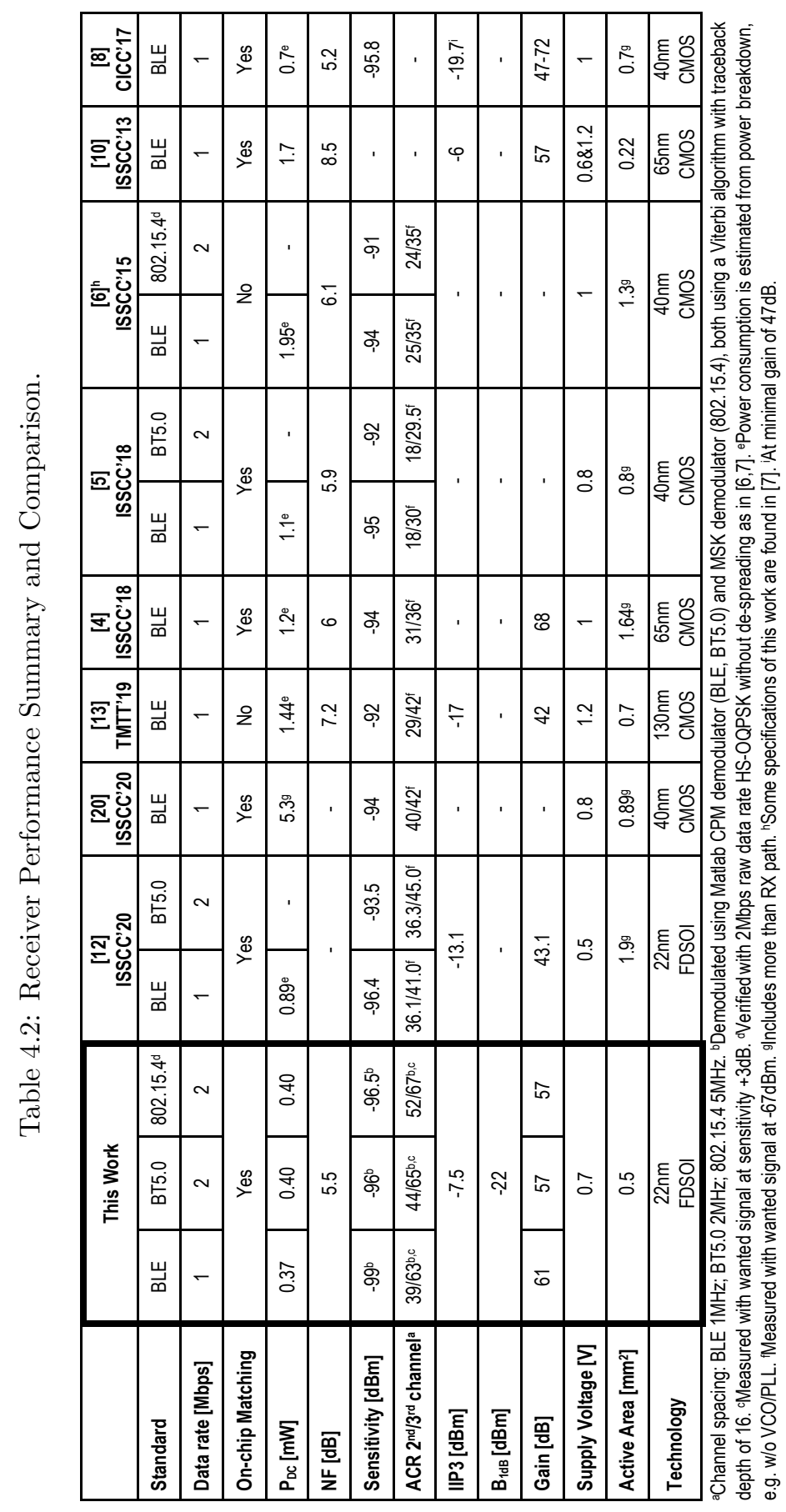




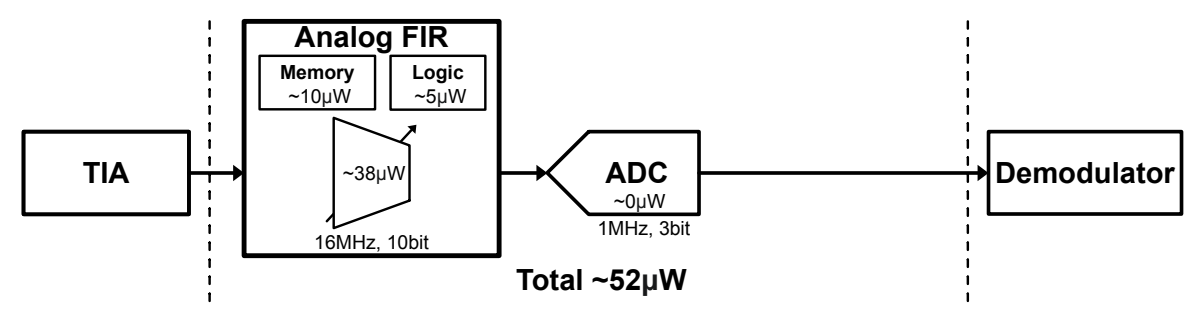

Figure 4.19: Overview of analog FIR baseband power consumption for BLE.

\subsubsection{Full Receiver Discussion}

In this section, the proposed design's performance is placed in the perspective of a full receiver design - including PLL and ADC.

In this design, all the channel filtering requirements are achieved by placing the high-order analog FIR filter after the TIA. This architecture choice significantly relaxes the dynamic range, sample rate and power consumption requirements of the $\mathrm{ADC}$ and down-stream digital signal processing functions, which only has to support demodulation and symbol detection.

In an application, the LO comes from an on-chip PLL with VCO and its phase noise could result in significant blocker induced noise which cannot be filtered constraining the ACR. The phase noise of a state-of-the-art $0.5 \mathrm{~mW} 5 \mathrm{GHz} \mathrm{VCO}$ is $-140 \mathrm{dBc} / \mathrm{Hz}$ at $10 \mathrm{MHz}$ offset [33]. This corresponds to $-140 \mathrm{dBc} / \mathrm{Hz}$ at $5 \mathrm{MHz}$ offset when divided down to $2.5 \mathrm{GHz}$ using the frequency divider, which is sufficiently low for the achieved ACR.

It is useful to estimate the total power consumption of the entire receiver. A state-of-the art ADPLL consumes $673 \mu \mathrm{W}$ [34] and will consume roughly $910 \mu \mathrm{W}$ when implementing the low phase noise VCO design of [33] to obtain the ACR performance. The sampled output of the analog FIR filter, at 1Msample/s, can be used for ADC conversion. The ADC power consumption will be negligible if a SAR ADC is used. E.g., the $1 \mathrm{Msample/s} 10 \mathrm{bit} \mathrm{SAR}$ ADC in [35] consumes only $3.2 \mu \mathrm{W}$, more than sufficient for demodulation. Hence, the total power consumption excluding demodulation is estimated as $0.91+0.37=1.3 \mathrm{~mW}$.

\subsection{Analog FIR Filter Discussion}

Chapter 3 already showed that the proposed analog FIR has significant improved selectivity and power consumption compared to prior art continuous-time filters and discrete-time IIR filters. However, the requirements on the subsequent ADC are very low. The required sample rate is only $1 \mathrm{Msample/s}$ and roughly 3 to 4 bits are required for demodulation - resulting in negligible power consumption. This could give the 
impression that a more digital approach can be beneficial. This section provides a discussion based on rough estimates. Architectural and technology improvements could significantly change the comparison results.

A single (I/Q) baseband path of the analog FIR approach is shown in Fig. 4.19. The total power consumption is about $52 \mu \mathrm{W}$. An alternative is placing the FIR filter in digital and increasing the dynamic range and sample rate of the ADC. A 16Msam$\mathrm{ple} / \mathrm{s} \mathrm{ADC}$ is required to apply the FIR filter in digital. The state-of-the-art $12 \mathrm{bit}$ $12 \mathrm{Msample} / \mathrm{s}$ ADC of [36] consumes $472 \mu \mathrm{W}$ and has $75.1 \mathrm{~dB}$ spurious-free dynamic range (SFDR). These specifications are almost sufficient to allow $60 \mathrm{~dB}$ of filtering in a subsequent digital FIR filter - and demodulation. However, this approach still requires an amplifier upfront. Actually the charge domain sampler of the analog FIR approach would be good candidate as it uses efficient inverter-based transconductors, has low IRN and provides sinc filtering of sampling aliases. It would consume roughly $38 \mu \mathrm{W}$. The digital FIR filter would also require the memory to provide the FIR coefficients $(10 \mu \mathrm{W})$. The digital FIR filter can be implemented using two time interleaved multiply-accumulate paths (Fig. 2.1b) - similar to the analog FIR approach. The multiplier FoM of 22nm FD-SOI is $4.6 \mathrm{fJ} / \mathrm{bit}^{2}$ [37]. Hence, the two multipliers combined would consume roughly $18 \mu \mathrm{W}$ for $12 \mathrm{x} 10 \mathrm{bit}$ multiplication at $16 \mathrm{MHz}$.

All in all, a digital approach will consume significantly more power consumption than the proposed analog FIR filter. Mainly, because the additional power of the analog FIR filter is only $5 \mu \mathrm{W}$ - from the logic buffers that drive the $\mathrm{g}_{\mathrm{m}} \mathrm{DAC}$. The other blocks are also required when choosing a digital approach. Furthermore, switching to $2 \mathrm{Mbps}$ BT5.0 will double the power consumption of the digital circuitry. In case of the proposed analog FIR approach this means $15 \mu \mathrm{W}$ additional power for the memory + logic - as confirmed by the measurement results in Table 4.2. The digital approach will also roughly double the power consumption of the (already high power) ADC and digital FIR filter.

\subsection{Conclusions}

A $2.4 \mathrm{GHz}$ IoT receiver front-end is proposed and characterized for BLE, BT5.0 and IEEE802.15.4. The entire receive chain is optimized to minimize power consumption and improve selectivity.

Several techniques are proposed that achieve a $370 \mu \mathrm{W}$ power consumption - almost $2 \times$ lower than the state-of-the-art - in combination with a competitive $5.5 \mathrm{~dB}$ NF. The LNTA has a push-pull inductive degenerated common-source architecture and is optimized using brute-force search on a simplified, though accurate, model. A single gate Windmill frequency divider has almost half the power dissipation concurrent with a phase noise improvement of $2 \mathrm{~dB}$ or more compared to prior art. An 
analog FIR filter is implemented with prefilter. Its 10bit transconductor DAC contains push-pull transconductors, 5bit thermometer coding and a low (16MHz for BLE) FIR-coefficient update-rate to optimize its power consumption while also achieving very sharp transition band. The receiver has $\geq 63 \mathrm{~dB}$ ACR at $\geq 3$ channels offset improving the state-of-the-art by $>20 \mathrm{~dB}$. The analog FIR filter incorporates high selective filtering in a receiver baseband amplifier with negligible additional power consumption.

The proposed architecture and implementation techniques result in very low power consumption combined with outstanding selectivity, which makes the receiver frontend design ready for future IoT standards.

\section{References}

[1] B. J. Thijssen, E. A. M. Klumperink, P. Quinlan, and B. Nauta, "2.4-GHz Highly Selective IoT Receiver Front End With Power Optimized LNTA, Frequency Divider, and Baseband Analog FIR Filter," IEEE J. Solid-State Circuits, 2020.

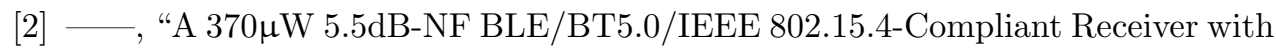
$>63 \mathrm{~dB}$ Adjacent Channel Rejection at $>2$ Channels Offset in 22nm FDSOI," in IEEE Int. Solid-State Circuits Conf. Dig. Tech. Pap., Feb. 2020, pp. 467-468.

[3] B. J. Thijssen, E. A. M. Klumperink, P. E. Quinlan, and B. Nauta, "Systems and Methods for Analog Finite Impulse Response Filters," United States Patent US20200321943 A1, October 8, 2020.

[4] H. Liu, Z. Sun, D. Tang, H. Huang, T. Kaneko, W. Deng, R. Wu, K. Okada, and A. Matsuzawa, "An ADPLL-Centric Bluetooth Low-Energy Transceiver with 2.3mW Interference-Tolerant Hybrid-Loop Receiver and 2.9mW Single-Point Polar Transmitter in 65nm CMOS," in IEEE Int. Solid-State Circuits Conf. Dig. Tech. Pap., 2018, pp. 444-445.

[5] M. Ding, X. Wang, P. Zhang, Y. He, S. Traferro, K. Shibata, M. Song, H. Korpela, K. Ueda, Y.-H. Liu, C. Bachmann, and K. Philips, "A 0.8V 0.8 $\mathrm{mm}^{2}$ Bluetooth 5/BLE Digital-Intensive Transceiver with a $2.3 \mathrm{~mW}$ Phase-Tracking RX Utilizing a Hybrid Loop Filter for Interference Resilience in 40nm CMOS," in IEEE Int. Solid-State Circuits Conf. Dig. Tech. Pap., vol. 61, Feb. 2018, pp. $446-448$.

[6] Y.-H. Liu, C. Bachmann, X. Wang, Y. Zhang, A. Ba, B. Busze, M. Ding, P. Harpe, G.-J. van Schaik, G. Selimis, H. Giesen, J. Gloudemans, A. Sbai, L. Huang, H. Kato, G. Dolmans, K. Philips, and H. de Groot, "A 3.7mW-RX 4.4mW-TX Fully Integrated Bluetooth Low-Energy/IEEE802.15.4/Proprietary 
SoC with an ADPLL-Based Fast Frequency Offset Compensation in 40nm CMOS," in IEEE Int. Solid-State Circuits Conf. Dig. Tech. Pap., Feb. 2015, pp. 236-237.

[7] Y.-H. Liu, V. K. Purushothaman, C. Lu, J. Dijkhuis, R. B. Staszewski, C. Bachmann, and K. Philips, "A 770pJ/b 0.85V 0.3mm² DCO-Based Phase-Tracking RX Featuring Direct Demodulation and Data-Aided Carrier Tracking for IoT Applications," IEEE Int. Solid-State Circuits Conf. Dig. Tech. Pap., vol. 60, pp. 408-409, 2017.

[8] A. H. M. Shirazi, H. M. Lavasani, M. Sharifzadeh, Y. Rajavi, S. Mirabbasi, and M. Taghivand, "A $980 \mu \mathrm{W} 5.2 \mathrm{~dB}-\mathrm{NF}$ Current-Reused Direct-Conversion Bluetooth-Low-Energy Receiver in 40nm CMOS," in IEEE Cust. Integr. Circuits Conf., Apr. 2017.

[9] Y.-H. Liu, X. Huang, M. Vidojkovic, A. Ba, P. Harpe, G. Dolmans, and H. de Groot, "A 1.9nJ/b 2.4GHz Multistandard (Bluetooth Low Energy/Zigbee/IEEE802.15.6) Transceiver for Personal/Body-Area Networks," in EEE Int. Solid-State Circuits Conf. Dig. Tech. Pap., Feb. 2013, pp. 446-447.

[10] Z. Lin, P. I. Mak, and R. P. Martins, "A $1.7 \mathrm{~mW} 0.22 \mathrm{~mm}^{2} 2.4 \mathrm{GHz}$ ZigBee RX Exploiting a Current-Reuse Blixer + Hybrid Filter Topology in 65nm CMOS," IEEE Int. Solid-State Circuits Conf. Dig. Tech. Pap., pp. 448-449, 2013.

[11] F.-W. Kuo, S. Binsfeld Ferreira, H.-N. R. Chen, L.-C. Cho, C.-P. Jou, F.-L. Hsueh, I. Madadi, M. Tohidian, M. Shahmohammadi, M. Babaie, and R. B. Staszewski, "A Bluetooth Low-Energy Transceiver With 3.7-mW All-Digital Transmitter, 2.75-mW High-IF Discrete-Time Receiver, and TX/RX Switchable On-Chip Matching Network," IEEE J. Solid-State Circuits, vol. 52, no. 4, pp. 1144-1162, Apr. 2017.

[12] M. Tamura, H. Takano, S. Shinke, H. Fujita, H. Nakahara, N. Suzuki, Y. Nakada, Y. Shinohe, S. Etou, T. Fujiwara, and Y. Katayama, "A 0.5V BLE Transceiver with a $1.9 \mathrm{~mW}$ RX Achieving -96.4dBm Sensitivity and 4.1dB Adjacent Channel Rejection at $1 \mathrm{MHz}$ Offset in 22nm FDSOI," in IEEE Int. Solid-State Circuits Conf. Dig. Tech. Pap., vol. 63, Feb. 2020, pp. 468-469.

[13] M. Silva-Pereira, J. T. de Sousa, J. Costa Freire, and J. Caldinhas Vaz, "A 1.7$\mathrm{mW}$-92-dBm Sensitivity Low-IF Receiver in 0.13- $\mu \mathrm{m}$ CMOS for Bluetooth LE Applications," IEEE Trans. Microw. Theory Tech., vol. 67, no. 1, pp. 332-346, Jan. 2019.

[14] D. Shaeffer and T. Lee, "A 1.5-V, 1.5-GHz CMOS Low Noise Amplifier," IEEE J. Solid-State Circuits, vol. 32, no. 5, pp. 745-759, May 1997. 
[15] B. Razavi, RF Microelectronics, 2nd ed. Pearson Eductation, 2013.

[16] F. Gatta, E. Sacchi, F. Svelto, P. Vilmercati, and R. Castello, "A 2-dB Noise Figure 900-MHz Differential CMOS LNA," IEEE J. Solid-State Circuits, vol. 36, no. 10, pp. $1444-1452,2001$.

[17] Z. Jiang, D. A. Johns, and A. Liscidini, "A Low-Power sub-GHz RF Receiver Front-End with Enhanced Blocker Tolerance," in IEEE Cust. Integr. Circuits Conf., Apr. 2018, pp. 1-4.

[18] K. Xu, J. Yin, P.-I. Mak, R. B. Staszewski, and R. P. Martins, "A Single-Pin Antenna Interface RF Front End Using a Single-MOS DCO-PA and a Push-Pull LNA," IEEE J. Solid-State Circuits, vol. 55, no. 8, pp. 2055-2068, 2020.

[19] A. Ba, K. Salimi, P. Mateman, P. Boer, J. van den Heuvel, J. Gloudemans, J. Dijkhuis, M. Ding, Y.-h. Liu, C. Bachmann, G. Dolmans, and K. Philips, "A 4mW-RX 7mW-TX IEEE 802.11ah Fully-Integrated RF Transceiver," in IEEE Radio Freq. Integr. Circuits Symp., Jun. 2017, pp. 232-235.

[20] E. Bechthum, J. Dijkhuis, M. Ding, Y. He, J. V. D. Heuvel, P. Mateman, G.-j. V. Schaik, K. Shibata, M. Song, E. Tiurin, S. Traferro, Y.-H. Liu, and C. Bachmann, "A Low-Power BLE Transceiver with Support for Phase-Based Ranging, Featuring 5 $\mu$ s PLL Locking Time and 5.3ms Ranging Time, Enabled by Staircase-Chirp PLL with Stick-Lock Channel-Switching," IEEE Int. Solid-State Circuits Conf. Dig. Tech. Pap., pp. 470-471, 2020.

[21] D. Murphy, A. Hafez, A. Mirzaei, M. Mikhemar, H. Darabi, M. C. F. Chang, and A. Abidi, "A Blocker-Tolerant Wideband Noise-Cancelling Receiver with a $2 \mathrm{~dB}$ Noise Figure," IEEE Int. Solid-State Circuits Conf. Dig. Tech. Pap., vol. 55, pp. $74-75,2012$.

[22] D. Murphy, H. Darabi, A. Abidi, A. A. Hafez, A. Mirzaei, M. Mikhemar, and M.-C. F. Chang, "A Blocker-Tolerant, Noise-Cancelling Receiver Suitable for Wideband Wireless Applications," IEEE J. Solid-State Circuits, vol. 47, no. 12, pp. 2943-2963, Dec. 2012.

[23] Z. Ru, N. Moseley, E. A. Klumperink, and B. Nauta, "Digitally Enhanced Software-Defined Radio Receiver Robust to Out-of-Band Interference," IEEE J. Solid-State Circuits, vol. 44, no. 12, pp. 3359-3375, Dec. 2009.

[24] A. Ghaffari, E. A. M. Klumperink, M. C. M. Soer, and B. Nauta, "Tunable HighQ N-Path Band-Pass Filters: Modeling and Verification," IEEE J. Solid-State Circuits, vol. 46, no. 5, pp. 998-1010, May 2011. 
[25] B. Razavi, K. F. Lee, and R. H. Yan, "Design of High-Speed, Low-Power Frequency Dividers and Phase-Locked Loops in Deep Submicron CMOS," IEEE J. Solid-State Circuits, vol. 30, no. 2, pp. 101-109, 1995.

[26] I. Fabiano, M. Sosio, A. Liscidini, and R. Castello, "SAW-Less Analog Front-End Receivers for TDD and FDD," IEEE J. Solid-State Circuits, vol. 48, no. 12, pp. 3067-3079, Dec. 2013.

[27] B. van Liempd, J. Borremans, E. Martens, S. Cha, H. Suys, B. Verbruggen, and J. Craninckx, "A 0.9 V 0.4-6 GHz Harmonic Recombination SDR Receiver in 28 nm CMOS With HR3/HR5 and IIP2 Calibration," IEEE J. Solid-State Circuits, vol. 49, no. 8, pp. 1815-1826, Aug. 2014.

[28] M. C. M. Soer, E. A. M. Klumperink, D.-J. van den Broek, B. Nauta, and F. E. van Vliet, "Beamformer With Constant-Gm Vector Modulators and Its Spatial Intermodulation Distortion," IEEE J. Solid-State Circuits, vol. 52, no. 3, pp. 735-746, Mar. 2017.

[29] B. J. Thijssen, E. A. M. Klumperink, P. Quinlan, and B. Nauta, "A 0.06-3.4-MHz 92- $\mathrm{WW}$ Analog FIR Channel Selection Filter With Very Sharp Transition Band for IoT Receivers," IEEE Solid-State Circuits Lett., vol. 2, no. 9, pp. 171-174, 2019 .

[30] — - "Low-Power Highly-Selective Channel Filtering Using a TransconductorCapacitor Analog FIR," IEEE J. Solid-State Circuits, vol. 55, no. 7, pp. 17851795, 2020.

[31] Y. C. Lien, E. A. Klumperink, B. Tenbroek, J. Strange, and B. Nauta, "Enhanced-Selectivity High-Linearity Low-Noise Mixer-First Receiver with Complex Pole Pair Due to Capacitive Positive Feedback," IEEE J. Solid-State Circuits, vol. 53, no. 5, pp. 1348-1360, 2018.

[32] H. Wu, M. Mikhemar, D. Murphy, H. Darabi, and M.-C. F. Chang, "A BlockerTolerant Inductor-Less Wideband Receiver With Phase and Thermal Noise Cancellation," IEEE J. Solid-State Circuits, vol. 50, no. 12, pp. 2948-2964, Dec. 2015 .

[33] D. Murphy and H. Darabi, "A Complementary VCO for IoE that Achieves a $195 \mathrm{dBc} / \mathrm{Hz}$ FOM and Flicker Noise Corner of $200 \mathrm{kHz}$," in IEEE Int. Solid-State Circuits Conf. Dig. Tech. Pap., vol. 59, Jan. 2016, pp. 44-45.

[34] Y. He, Y.-H. Liu, T. Kuramochi, J. van den Heuvel, B. Busze, N. Markulic, C. Bachmann, and K. Philips, "A $673 \mu \mathrm{W}$ 1.8-to-2.5GHz Dividerless FractionalN Digital PLL with an Inherent Frequency-Capture Capability and a Phase- 
Dithering Spur Mitigation for IoT Applications," in IEEE Int. Solid-State Circuits Conf. Dig. Tech. Pap., Feb. 2017, pp. 420-421.

[35] H. S. Bindra, A.-J. Annema, S. M. Louwsma, E. J. M. van Tuijl, and B. Nauta, "An energy reduced sampling technique applied to a 10b 1MS/s SAR ADC," in IEEE Eur. Solid State Circuits Conf., Sep. 2017, pp. 235-238.

[36] Z. Li, A. Dutta, A. Mukherjee, X. Tang, L. Shen, L. He, and N. Sun, "A SAR ADC with Reduced kT/C Noise by Decoupling Noise PSD and BW," in IEEE Symp. VLSI Circuits, Dig. Tech. Pap., Jun. 2020.

[37] J. Zanen, E. Klumperink, and B. Nauta, "Power Efficiency Model for MIMO Transmitters Including Memory Polynomial Digital Predistortion," IEEE Trans. Circuits Syst. II Express Briefs, 2020. 
Insanity: doing the same thing over

and over again and expecting

different results.

Albert Einstein

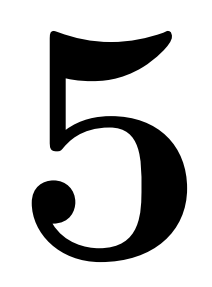

\section{Phase Noise Cancellation} Exploiting a Sub-Sampling Phase Detector

Clocks with low phase noise are a prerequisite for highly selective receivers. The $>20 \mathrm{~dB}$ improvement in selectivity of the receiver in Chapter 4 makes the phase noise requirement more stringent, as IoT receivers preferably do not use RF filters to reduce the cost. This chapter proposes a technique to reduce the phase noise by feedforward cancellation. The proposed technique reduces the phase noise of an integer-N PLL as verified by simulations. However, it can also be employed in fractional-N PLLs when a digital-to-time converter (DTC) is used in the reference path to align the edges at the phase detector - a common technique for fractional-N sub-sampling phaselocked loops (SSPLLs) [1, 2]. The contents of this chapter were previously published in the IEEE Transactions on Circuits and Systems II: Express Briefs [3], which is an extension on [4]. The proposed phase noise cancellation concept is patented in [5]. Section 5.6 and the last paragraph of Section 5.7 are added to discuss the phase noise cancellation technique in the context of the IoT receiver.

The author is aware that the content of this chapter partially overlaps with Chapter 1 . However, the author preferred minimal modification of the already reviewed and accepted papers. 


\subsection{Introduction}

Clocks with low phase noise and jitter are required in many applications - e.g. analog-to-digital converters, optical data communication and RF front-ends. SSPLLs $[2,6-8]$ have superior phase noise performance compared to conventional phasefrequency detector (PFD) PLLs. However, SSPLLs only reduce the close-in phase noise. The overall phase noise reduction is still limited to the maximal stable bandwidth of the PLL. For $3^{\text {rd }}$ order type-II PLLs this is around the so-called Gardner's limit $f_{\text {ref }} / 10[9]$.

A different method to reduce phase noise is by cancellation. This is a feedforward method and has therefore no stability limitations. Recently, several phase noise cancellation approaches have been published [10-14]. In [11], the delay in a ring oscillator is exploited for a delay-discriminator phase noise detection. The cancellation is performed by a variable delay block. Although showing $12.5 \mathrm{~dB}$ phase noise improvement at $0.1 f_{\text {ref }}$, the detection gain is constrained by limited inverter delay and the jitter performance is not state-of-the-art. [12] is also delay-line discriminator based and uses expensive off-chip components. The work in $[13,14]$ does not affect the clock phase noise, but the result of phase noise. In [13], the reciprocal mixing product as a result of phase noise is canceled and [14] cancels the phase noise in the digital domain — which does not improve the blocker noise figure.

Injection-locked PLLs [15-17] and PLLs with cascaded sub-sampling delay-locked loops (SSDLLs) [18] are also promising techniques to improve clock phase noise. In injection-locked PLLs the VCO edge is aligned to the reference clock edge by injection. In the PLL with cascaded SSDLL, the phase error of a PLL is measured by a sub-sampling phase detector (SSPD) and corrected in a DLL; a feedback method. Recently, a feedforward phase noise cancellation architecture was proposed that also exploits an SSPD [19]. All these techniques have ring oscillator implementations with state-of-the-art performance - a PLL FoM [6] around -235dB.

In this chapter, we analyze the fundamental limitations of a sub-sampling phase noise cancellation PLL (SSPNC-PLL) that we developed simultaneously but independently of [19]. Our analysis shows that the phase noise improvement is limited by aliasing and the SSPD hold operation. The SSPNC-PLL can achieve significantly lower root mean square (rms) jitter than an SSPLL alone.

The structure of this chapter is as follows. First, in Section 5.2, the PLL transfer characteristics are introduced. In Section 5.3, the fundamental limitations of the feedforward phase noise cancellation system exploiting an SSPD are analyzed. Section 5.4 introduces the SSPNC-PLL. The theoretical results are verified by simulation in Section 5.5 and conclusions are presented in Section 5.7. 


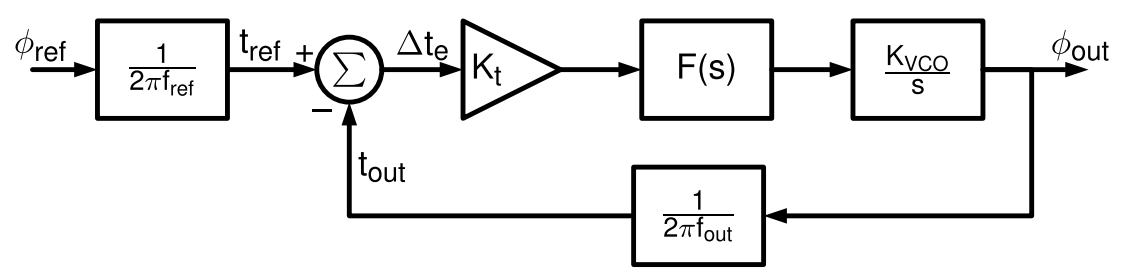

Figure 5.1: Unified linear PLL model for timing error based phase detectors.

\subsection{Phase-Locked Loops}

PFDs and SSPDs both measure the timing difference of two incoming clock signals. The linear model of Fig. 5.1 allows for a unified analysis of PLLs with timing error detectors. It models the phase detector with jitter detection gain $K_{t}$, the loop filter with transfer function $F(s)$ and the $\mathrm{VCO}$ with transfer function $K_{V C O} / s$. The phase detector is often implemented including a charge pump $[2,6-9,11]$. The relation between output frequency $f_{\text {out }}$ and reference frequency $f_{\text {ref }}$ is

$$
N \equiv \frac{f_{\text {out }}}{f_{\text {ref }}}
$$

Note that we explicitly model the phase detector as a timing error detector, in contrast to the conventional approach of a phase detector $[6,9]$. A divide-by- $N$ - and multiply-by- $N$ in case of an SSPLL [6] - are not explicitly present in the model, because a frequency divider does not alter the timing instance of the clock signal zero crossings. Only the frequency of zero crossings is changed. In this chapter, we use the following transfer functions of the PLL:

$$
\begin{aligned}
G(s) & \equiv \frac{t_{\text {out }}(s)}{\Delta t_{e}(s)}=K_{t} F(s) \frac{K_{V C O}}{s} \cdot \frac{1}{2 \pi f_{\text {out }}} \\
H(s) & \equiv \frac{\phi_{\text {out }}(s)}{\phi_{\text {ref }}(s)}=\frac{1}{2 \pi f_{\text {ref }}} \cdot \frac{K_{t} F(s) \frac{K_{V C O}}{s}}{1+G(s)} \\
E(s) & \equiv \frac{\Delta t_{e}(s)}{t_{\text {ref }}(s)}=\frac{1}{1+G(s)}
\end{aligned}
$$

\subsubsection{PLL Phase Noise Spectrum}

The output phase noise spectrum of the PLL can be derived given the additive noise at the different nodes in the model. Suppose, the charge pump noise $S_{i, C P}(f)$ and VCO phase noise $S_{\phi, V C O}(f)$ are the dominating components in the PLL output noise. 
The output phase noise spectrum can be determined as

$$
S_{\phi, \text { out }}(f)=\left|\frac{2 \pi f_{r e f}}{K_{t}}\right|^{2}|H(f)|^{2} S_{i, C P}(f)+|E(f)|^{2} S_{\phi, V C O}(f)
$$

\subsubsection{SSPD versus PFD}

The linear model of Fig. 5.1 can directly be applied to both SSPD and PFD based PLLs. Both phase detectors measure the timing difference of the two input clocks. The key distinction is in the timing detector gain [8]

$$
\begin{aligned}
K_{t, P F D} & \propto f_{\text {ref }} \\
K_{t, S S P D} & \left.\propto \frac{\mathrm{d} v(t)}{\mathrm{d} t}\right|_{t=t_{\text {ref }}} \approx 2 \pi f_{\text {out }} \hat{v}
\end{aligned}
$$

assuming a sinusoidal VCO output $v(t)$. In (5.7), $\hat{v}$ is the amplitude of $v(t)$ and $t_{r e f}$ the sampling instant. The slope of $v(t)$ is finite and known - e.g. provided by a constant slope generator [1]. The SSPD gain is approximately $N$ times higher than of the PFD. Therefore, the charge pump's phase noise contribution is reduced by $N^{2}$. The result is superior jitter performance of SSPLLs compared with PFD PLLs - e.g. [1] demonstrated $0.16 \mathrm{ps}$ rms jitter while consuming only $8.2 \mathrm{~mW}$.

\subsubsection{SSPD Hold Delay}

The SSPD introduces a delay of $0.5 T_{\text {ref }}$ when it is implemented using an ideal sampleand-hold circuit. The result is $18^{\circ}$ less phase margin for an SSPLL with bandwidth $f_{\text {ref }} / 10$ - considerably reducing the loop stability. SSPLLs are often implemented with a pulser to reduce the SSPD gain and thereby reducing the required capacitor size for stable operation [6]. An added bonus is the reduced hold delay of the pulser implementation. This increases the phase margin and improves the SSPLL stability. The SSPD characteristics are further analyzed in Section 5.3.1.

\subsection{Feedforward Phase Noise Cancellation}

Feedforward phase noise cancellation relies on the principle shown in Fig. 5.2a [10-12]. The phase noise of the input clock is detected in the auxiliary path and subtracted from the phase noise of the clock in the main path by a phase modulator. Ideally, the result is a clock without phase noise.

[19] proposed the implementation of Fig. 5.2b. It consists of an SSPD as phase detector, variable delay $\tau$ and an appropriate gain $A$. The SSPD bandwidth is constrained by the Nyquist limit $f_{\text {ref }} / 2$. This potentially allows for phase noise reduction 


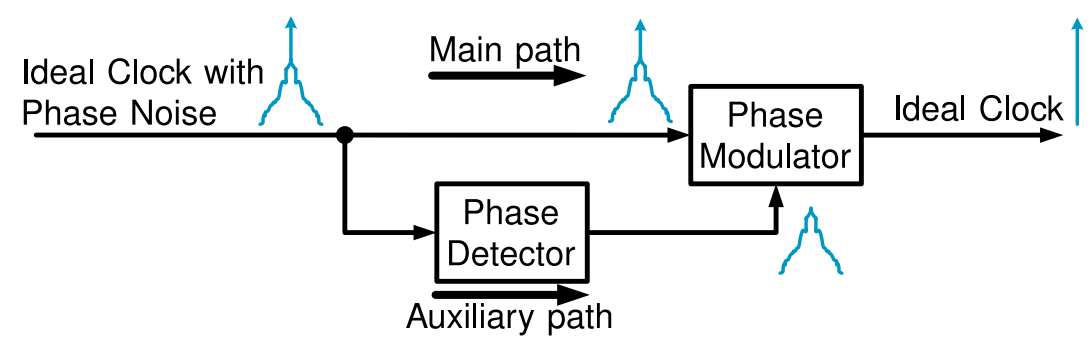

(a)

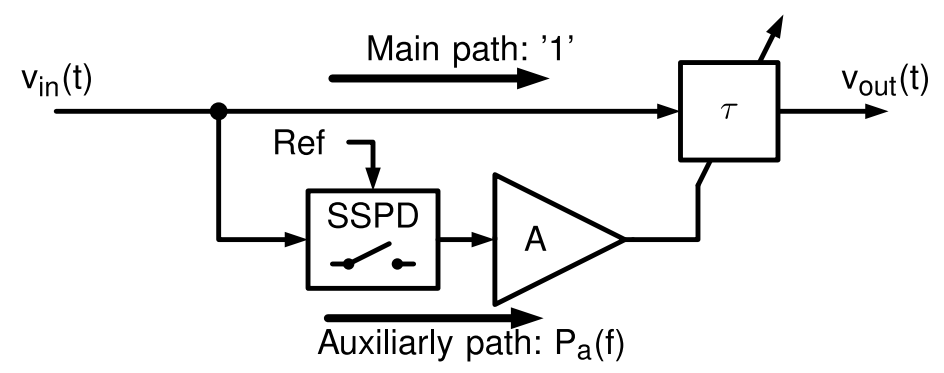

(b)

Figure 5.2: Feedforward phase noise cancellation. (a) Basic principle [10-12]. (b) Block implementation [19].

up to 5 times the maximal PLL bandwidth. We refer to frequencies up to $f_{\text {ref }} / 2$ as in-band and outside this range as out-of-band. Sub-sampling phase noise cancellation can be cascaded to any generated clock signal as long as the reference and input clocks are aligned - e.g. realized by an SSPLL (Section 5.4).

In this section, we discuss the fundamental limitations of feedforward phase noise cancellation employing an SSPD. The variable delay and gain are assumed ideal. A possible implementation of the variable delay is e.g. with a current-starved inverter $[19]$.

\subsubsection{SSPD Analysis}

An SSPD converts the timing error of input clock signal $v_{i n}(t)$ into a sampled voltage, according to

$$
v_{s a m}\left(t_{r e f}\right)=\left.\Delta t_{e} \cdot \frac{\mathrm{d} v_{i n}(t)}{\mathrm{d} t}\right|_{t=t_{r e f}}
$$




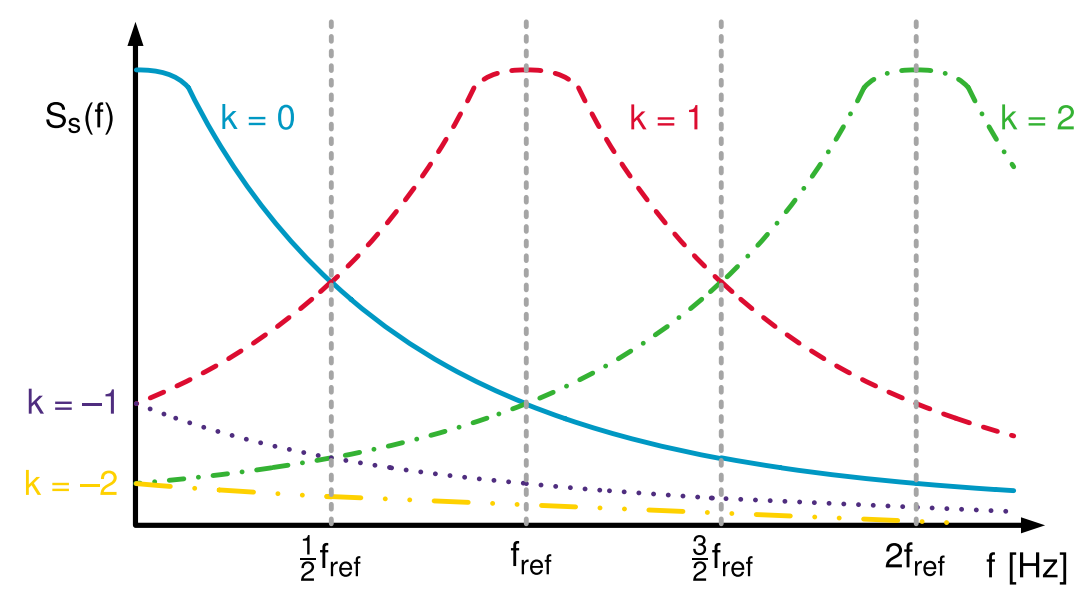

(a)

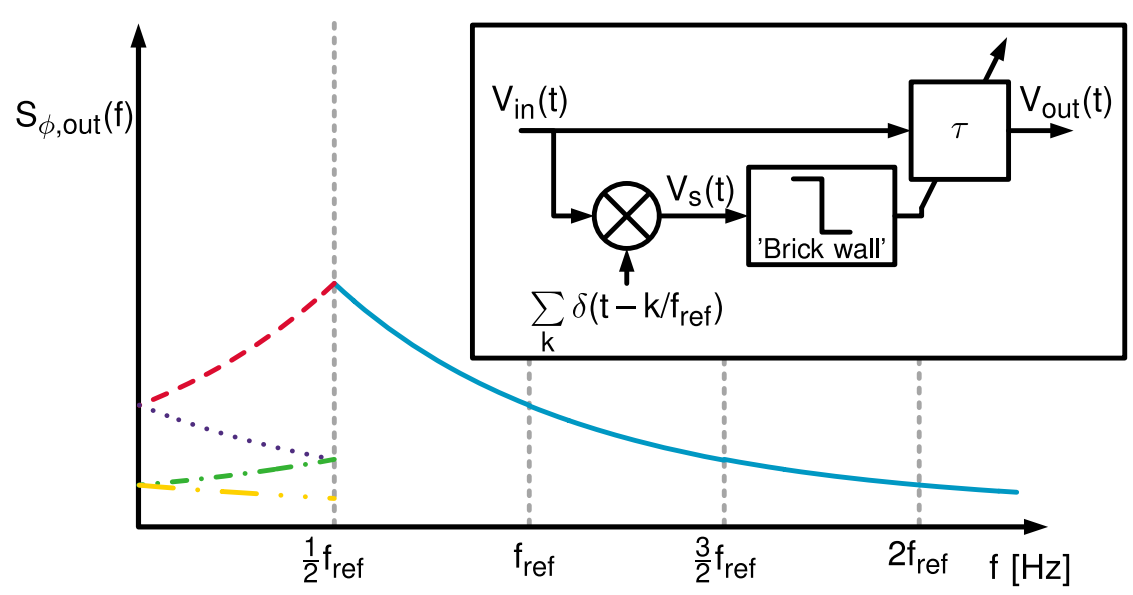

(b)

Figure 5.3: Phase noise spectral components up to $k= \pm 2$. (a) After sub-sampling detection. (b) After cancellation with ideal reconstruction filtering.

where $t_{r e f}$ is the sampling instant. The timing error is

$$
\Delta t_{e}=t_{r e f}-t_{i n}
$$

where $t_{\text {in }}$ and $t_{\text {ref }}$ are the time instances corresponding to the zero crossings of the input clock and reference signal, respectively. The derivative of $v_{i n}(t)$ is approximated as constant within time interval $\Delta t_{e}$.

Two mechanisms impair the phase noise detection performance: Aliasing during phase detection and the filtering of the hold function. During detection the clock 
phase noise aliases around every $f_{\text {ref }} / 2$. The detected - sub-sampled - spectrum is

$$
S_{s}(f)=f_{\text {ref }} \sum_{k=-\infty}^{\infty} S_{\phi, i n}\left(f-k f_{\text {ref }}\right)
$$

This spectrum is illustrated in Fig. 5.3a. We assume a stationary input phase noise spectrum with bounded total rms jitter; e.g. the output of a PLL. The aliased spectral components are illustrated by color. The sum of these components is the actual detected spectrum. In addition to the wanted solid $(k=0)$ spectral component, several other spectral components alias towards the $\left[0, f_{\text {ref }} / 2\right]$ band. Suppose an ideal brick-wall filter with cut-off at $f_{r e f} / 2$ is applied as reconstruction filter. As the filter comes after the sampler, the unwanted aliased components remain present in-band and are uncorrelated with the solid $(k=0)$ component that we wish to cancel. The resulting output phase noise spectrum $S_{\phi, \text { out }}(f)$ after cancellation is shown in Fig. 5.3b and can be approximated by

$$
S_{\phi, \text { out }}(f) \approx \begin{cases}S_{\phi, \text { in }}\left(f_{\text {ref }}-f\right) & 0 \leq f<f_{\text {ref }} / 2 \\ S_{\phi, \text { in }}(f) & f \geq f_{\text {ref }} / 2\end{cases}
$$

The aliased components up to $f_{r e f} / 2$ fundamentally limit the cancellation performance. Fortunately, the VCO phase noise shows a $1 / f^{2}$ roll-off. This colored spectrum allows for phase noise detection even after aliasing, because in-band the non-aliased phase noise dominates the output of the SSPD.

In practical systems, a zero-order hold is applied to the sampled signal. The hold operation transfer function $H_{h}(f)$ is

$$
H_{h}(f)=T_{h} \operatorname{sinc}\left(f T_{h}\right) e^{-j \pi f T_{h}}
$$

Several limitations arise due to the hold filter function:

- The hold attenuation limits the in-band cancellation.

- The delay of the zero-order hold impairs the cancellation performance, especially at high frequency offsets.

- The out-of-band aliases are only moderately filtered.

\subsubsection{Phase Noise Cancellation Output Spectrum}

Suppose, that the gain $A$ and delay sensitivity $K_{\tau}$ are ideal, linear and with bandwidth $\gg f_{r e f} / 2$. The cancellation condition is

$$
P_{a}(f)=f_{r e f} T_{h} \operatorname{sinc}\left(f T_{h}\right) e^{-j \pi f T_{h}} A K_{\tau}=1
$$




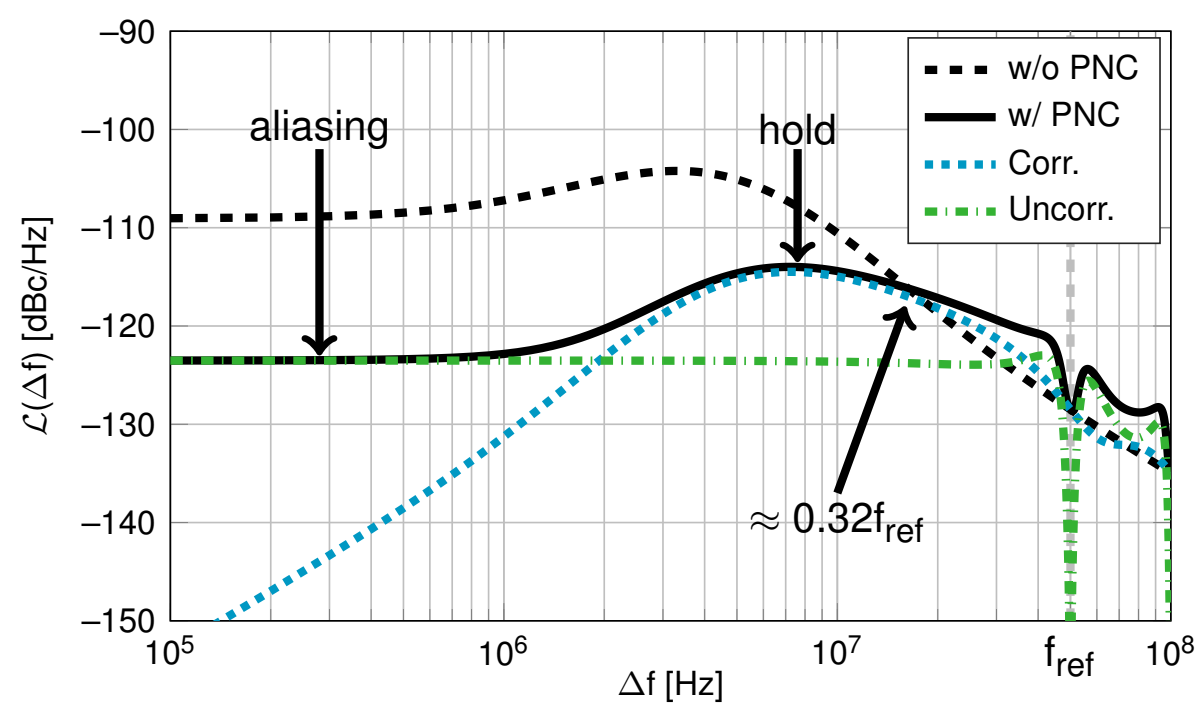

Figure 5.4: Modeled phase noise cancellation (PNC) output spectrum.

where $P_{a}(f)$ is the transfer function of the auxiliary path. $P_{a}(f)$ is frequency dependent, which means it is practically impossible to cancel at every frequency. The output spectrum of the phase noise cancellation system $S_{\phi, o u t}(f)$ using (5.10) and (5.13) is

$$
S_{\phi, \text { out }}(f)=\underbrace{\left|1-P_{a}(f)\right|^{2} S_{\phi, \text { in }}(f)}_{\text {correlated PN }}+\underbrace{\left|P_{a}(f)\right|^{2} \sum_{\substack{k=-\infty \\ k \neq 0}}^{\infty} S_{\phi, \text { in }}\left(f-k f_{\text {ref }}\right)}_{\text {uncorrelated PN }}
$$

In (5.14), we recognize two terms: The correlated phase noise $(k=0)$ and uncorrelated phase noise that is introduced by aliasing $(k \neq 0)$. An equation with similar structure was also found for a feedback system analyzing sampling effects in a PFD PLLs [20].

Fig. 5.4 illustrates the phase noise cancellation performance for a clock with the phase noise spectrum of the Section 5.5 SSPLL; assuming $T_{h}=1 / f_{\text {ref }}$. The phase noise is canceled up to $0.32 f_{\text {ref }}$, more than $3 \times$ Gardner's limit. The reduction is limited by: aliasing at low frequency offsets, the hold operation at intermediate offsets and both correlated and uncorrelated phase noise contributions outside the cancellation bandwidth. (5.14) explains also the phase noise increase above roughly $10 \mathrm{MHz}$ in [18]. Since, a wide bandwidth SSDLL does not provide filtering of aliased phase noise nor delayed phase noise that is introduced by the SSPD. 


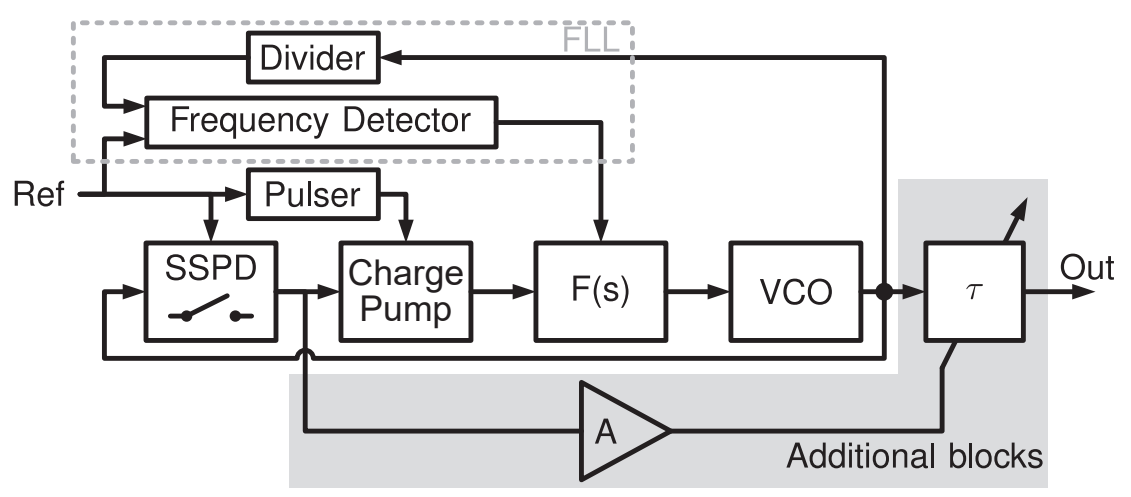

Figure 5.5: Sub-sampling phase noise cancellation PLL [19].

\subsubsection{Practical Implementation Limitations}

The total gain of the auxiliary path $G_{a}$ should be 1 . Mismatch between the main and auxiliary paths results in imperfect cancellation, as expressed by

$$
\text { Cancellation Limit }=20 \log \left|1-G_{a}\right|
$$

The required specification for maximal cancellation can be obtained from the fundamental limits. $90 \%$ accuracy limits the reduction to $20 \mathrm{~dB}$, sufficient for the spectrum of Fig. 5.4. This also imposes the required linearity in the auxiliary path.

The phase noise cancellation performance is in-band ultimately limited by the reference phase noise, which is directly present at the output. The noise contribution of $A$ is small, because of the high SSPD detector gain; typically $>1 \mathrm{GV} / \mathrm{s}$. An SSPD phase offset introduces a delay offset in the variable delay. However, a fixed delay offset has no influence on the output phase noise - it just introduces clock skew. The input clock jitter should be constraint to avoid saturation of the variable delay. The variable delay $\tau$ can be part of an existing buffer [11], because the required delay is small; in the order of picoseconds, much smaller than the buffer rise/fall time. Therefore, the added jitter of the variable delay is marginal, since this is proportional to the delay [21].

\subsubsection{Spur Cancellation}

In addition to phase noise, other spurs introduced in the PLL loop are canceled as well. E.g. supply variations might introduce spurs at the VCO. In [19] it is shown that a spur at $100 \mathrm{kHz}$ offset can be reduced by $19.5 \mathrm{~dB}$. 


\subsection{Sub-Sampling Phase Noise Cancellation PLL}

The phase noise cancellation system of Section 5.3 requires aligned zero-crossings of the reference and input clock. This is accomplished by cascading a PLL with phase noise cancellation. In this way, the PLL aligns the clocks. The PLL is implemented by an SSPLL for minimal jitter. The SSPD error signal in the SSPLL can be reused for phase noise cancellation, because both signals are the same - the SSPLL output phase error. The schematic of this sub-sampling phase noise cancellation PLL (SSPNC-PLL) is shown in Fig. 5.5 [19]. It consists of a regular SSPLL with VCO, SSPD, charge pump, pulser and loop filter with transfer $F(s)$. The frequency-locked loop (FLL) is required to frequency lock the SSPLL [6]. Additionally, an appropriate gain and variable delay element for phase noise cancellation are implemented. The SSPD is part of the SSPLL and reused for phase noise cancellation.

The large detection gain of the SSPD results in only little required gain $A$ in the auxiliary path, typically in the order of 1 . Furthermore, the required bandwidth of $A$ is small - approximately $5 f_{\text {ref }}$ - and an existing buffer can be reused as variable delay. Therefore, we expect little additional power consumption compared with a conventional SSPLL.

To verify the derivations of Section 5.3 , the widely used $3^{\text {rd }}$ order type-II PLL is applied, with loop filter [9]

$$
F(s)=\frac{s \tau_{2}+1}{s \tau_{1}\left(s \tau_{3}+1\right)}
$$

The bandwidth of the SSPLL can be estimated by [9]

$$
K=K_{t} K_{V C O} \frac{\tau_{2}}{\tau_{1}} \cdot \frac{1}{2 \pi f_{\text {out }}} \quad[\mathrm{rad} / \mathrm{s}]
$$

From (5.5) and (5.14), the output phase noise spectrum of the SSPNC-PLL can be determined as

$$
S_{\phi, \text { out }}(f)=\left|1-P_{a}(f)\right|^{2} S_{\phi, S S P L L}(f)+\left|P_{a}(f)\right|^{2} \sum_{\substack{k=-\infty \\ k \neq 0}}^{\infty} S_{\phi, S S P L L}\left(f-k f_{s}\right)
$$

\subsection{Simulation Results}

The theory of Sections 5.3 and 5.4 is verified in simulation. The assumptions of the simulations are listed below

1. The output frequency of the PLL is $2.5 \mathrm{GHz}$ with a $50 \mathrm{MHz}$ reference, $(N=50)$ and pulser on time of 1 ns. 
2. The PLL is locked. The steady-state is achieved.

3. The charge pump noise and VCO phase noise are dominant. The VCO phase noise is purely $1 / f^{2}$ and is modeled as additive white noise on the VCO input. The loop noise is modeled as additive white noise to the charge pump current. $1 / f$ noise is neglected.

4. The reference is assumed clean; without phase noise.

5. The SSPLL is a $3^{\text {rd }}$ order type-II PLL with loop parameters $K \tau_{2}=3$ and $\tau_{2} / \tau_{3}=9$. These normalization parameters fully characterize the PLL steadystate behavior and are identified as nearly optimum [9] when maximum bandwidth, good damping and as much filtering of the $3^{\text {rd }}$ pole as possible is required.

6. The VCO phase noise is based on a $1 \mathrm{~mW},-163 \mathrm{dBc} / \mathrm{Hz}$ FoM oscillator - close to the theoretical limit of $-165 \mathrm{dBc} / \mathrm{Hz}$ for ring oscillators [22].

7. The loop noise power is chosen such that the loop noise and VCO phase noise equally contribute to the total rms jitter; i.e. the bandwidth is chosen as the optimum bandwidth given the loop noise and VCO phase noise power [23].

8. Both the gain $A$ and variable delay $\tau$ are ideal.

9. The noise spectra are obtained by averaging 200 (transient noise) simulations in Matlab Simulink.

Fig. 5.6 shows the output phase noise with and without phase noise cancellation for both a PLL bandwidth of $f_{\text {ref }} / 10$ and $f_{\text {ref }} / 50$. We first discuss $f_{\text {ref }} / 10$. The phase noise is reduced at low frequency offsets up to $15 \mathrm{~dB}$. At $5 \mathrm{MHz}$ offset $\left(f_{\text {ref }} / 10\right)$, the phase noise reduction is $8 \mathrm{~dB}$. The phase noise reduction bandwidth is $14 \mathrm{MHz}$ $\left(f_{\text {ref }} / 3.6\right)$. Outside the reduction bandwidth the phase noise is slightly increased as expected. The model of (5.14) is in accordance with the simulated phase noise spectrum. We define the cumulative rms jitter $\sigma_{t}\left(f_{u}\right)$ as

$$
\sigma_{t}^{2}\left(f_{u}\right)=\frac{1}{\left(2 \pi f_{\text {out }}\right)^{2}} \int_{0}^{f_{u}} 2 \mathcal{L}(\Delta f) \mathrm{d} \Delta f
$$

The total rms jitter $\sigma_{t}(\infty)$ is improved by $3.2 \mathrm{~dB}$.

The phase noise cancellation system allows for novel loop filter designs to improve the jitter even further. Most of the jitter contribution is around the PLL bandwidth. Reducing the PLL bandwidth re-positions the phase noise bump to lower offset frequencies.

This is illustrated by the $f_{\text {ref }} / 50$ plots in Fig. 5.6. At low offset frequencies the SSPLL phase noise slope is $+20 \mathrm{~dB} /$ decade, so the VCO phase noise contribution is 


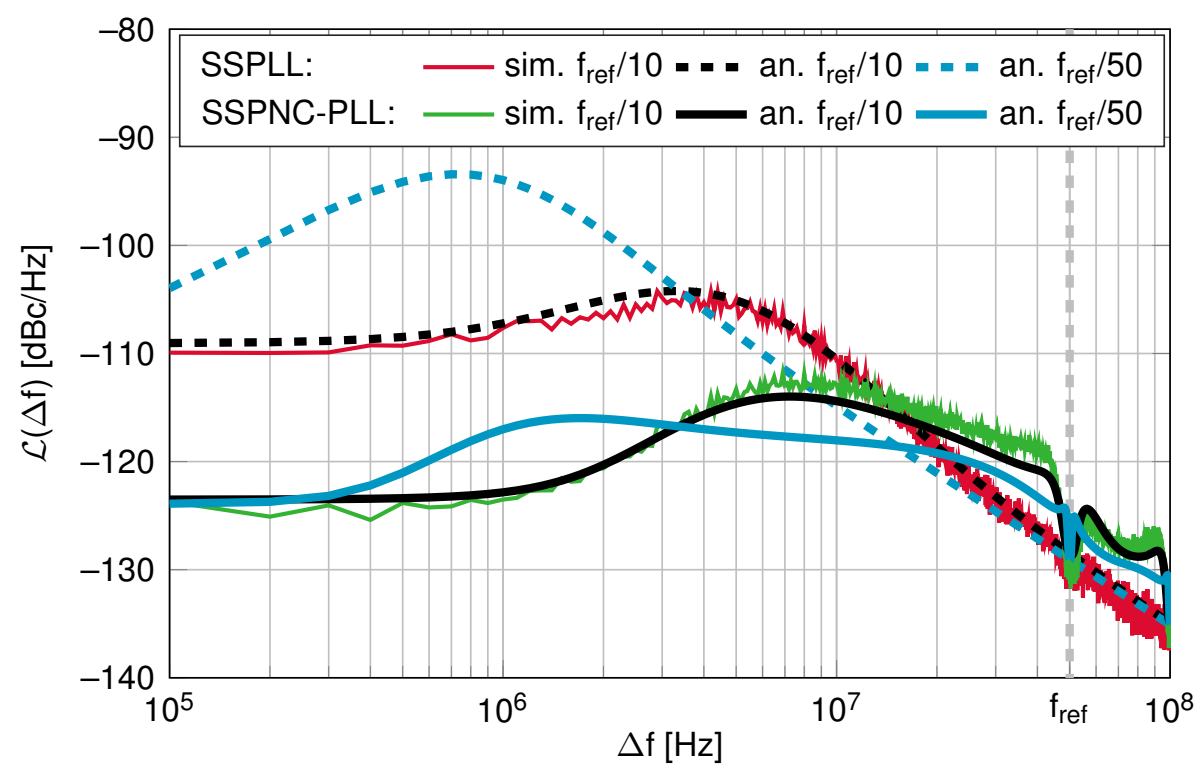

Figure 5.6: Simulated (sim.) and analytical (an.) phase noise w/ (SSPNC-PLL) and w/o (SSPLL) phase noise cancellation for different PLL bandwidths using (5.5) and (5.18).

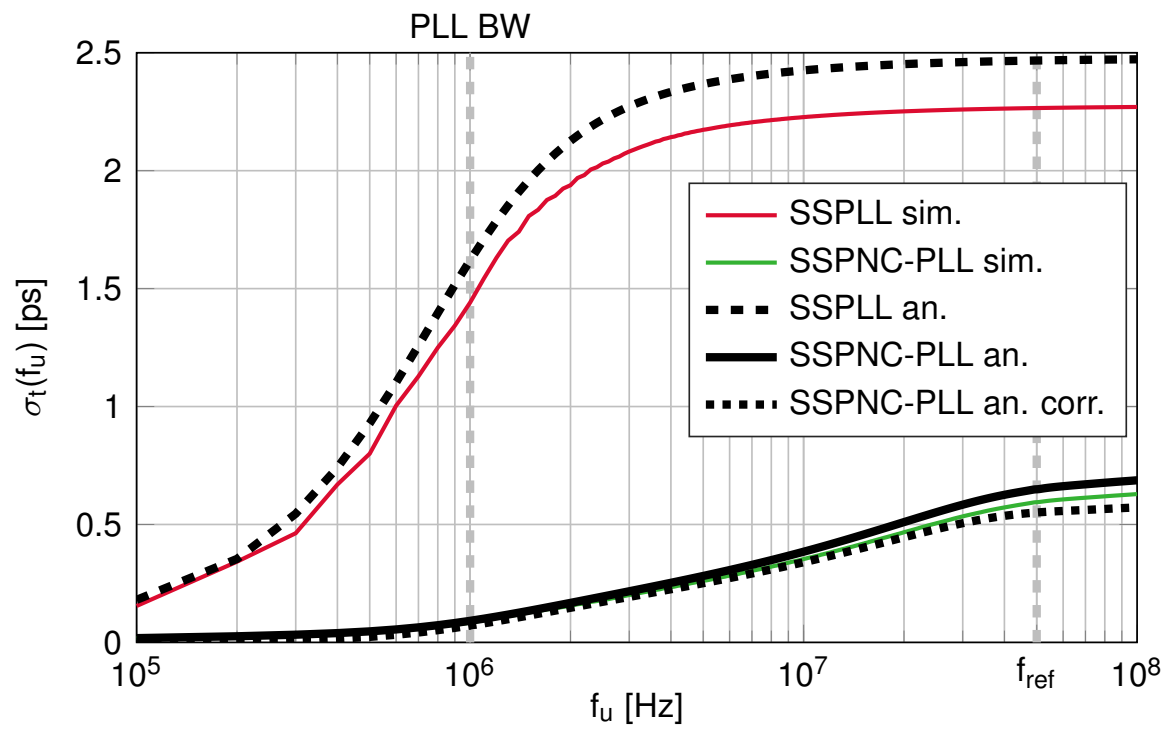

Figure 5.7: Simulated (sim.) and analytical (an.) cumulative rms jitter w/ (SSPNCPLL) and w/o (SSPLL) phase noise cancellation, the SSPLL bandwidth is $f_{\text {ref }} / 50$. 


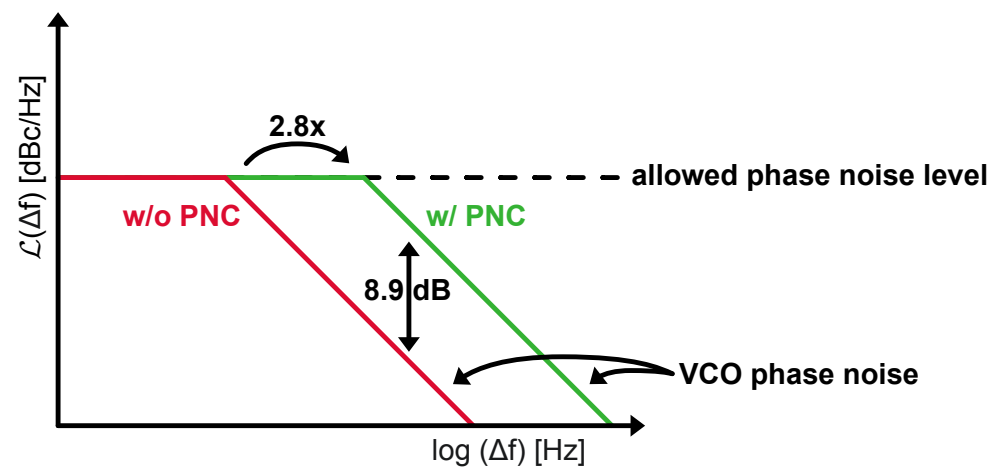

Figure 5.8: PLL phase noise $\mathrm{w} /$ and w/o sub-sampling phase noise cancellation for a receiver application.

dominant. The phase noise reduction bandwidth is $0.3 f_{\text {ref }} .9 \mathrm{~dB}$ phase noise reduction is achieved at a frequency offset of $f_{r e f} / 10$. The out-of-band phase noise is $4 \mathrm{~dB}$ lower than in the case of $f_{r e f} / 10$. The corresponding cumulative jitter is shown in Fig. 5.7. The jitter contribution is much more spread across frequencies than without phase noise cancellation. The aliased components have only a minor effect on the total rms jitter as illustrated by the jitter of the correlated part. The total rms jitter is significantly reduced: $11 \mathrm{~dB}$ and $7.2 \mathrm{~dB}$ compared with the SSPLL with bandwidth $f_{\text {ref }} / 50$ and $f_{\text {ref }} / 10$, respectively.

Our analysis shows that the state-of-the-art performance of [19] can still be enhanced. The phase noise reduction bandwidth can be improved from roughly $f_{r e f} / 10$ [19] to $f_{\text {ref }} / 3.6$ by increasing the auxiliary path bandwidth; significantly reducing the jitter.

\subsection{IoT Receiver Context}

The proposed phase noise cancellation architecture is developed as a general purpose technique to increase the effective PLL phase noise reduction bandwidth and to reduce the jitter of a PLL for a given power consumption. In the context of the highly selective IoT receiver, sub-sampling feedforward phase cancellation can allow for a reduced power consumption of the PLL as illustrated in Fig. 5.8. The baseband analog FIR filter has a flat stop-band at a very small frequency offset. This flat stopband requires a certain phase noise level to avoid corruption of the desired signal by reciprocal mixing of a nearby blocker: the allowed phase noise level. The increase of the effective PLL bandwidth allows for a higher VCO phase noise in the PLL, since this phase noise is reduced by cancellation. The phase noise reduction bandwidth is 
increased by $2.8 \times$. Hence, the VCO power consumption can be reduced by roughly $7.7 \times(8.9 \mathrm{~dB})$ for the same VCO FoM. The PLL power consumption will be reduced considerably as the $\mathrm{VCO}$ is a major contributor to its total power consumption, e.g., $39 \%$ in $[24]$.

\subsection{Conclusions}

Feedforward phase noise cancellation can reduce the phase noise and jitter of clocks without stability limitation. A sub-sampling phase detector is attractive, because of its linearity and high detection gain. The performance of this detector is fundamentally limited by aliasing, hold delay, in-band hold attenuation and limited out-of-band attenuation of the aliases. A sub-sampling phase noise cancellation PLL architecture that reuses the error signal of a sub-sampling PLL is discussed for feedforward phase noise cancellation. Moreover, it cancels spurs that are introduced in the PLL loop. Analytical expressions are derived that predict the output phase noise given an input phase noise spectrum to the cancellation technique. These expressions are verified by simulations for a given wideband sub-sampling PLL design. The phase noise reduction bandwidth is increased to $f_{r e f} / 3.6$ by the phase noise cancellation technique. The phase noise is improved by more than $9 \mathrm{~dB}$ at a frequency offset of $f_{r e f} / 10$. The total rms jitter of the PLL is improved by $7.2 \mathrm{~dB}$ compared with a sub-sampling PLL with maximal bandwidth.

The proposed phase noise cancellation technique increases the effective phase noise reduction bandwidth of the PLL. This allows for a higher VCO phase noise for the same reciprocal mixing products. The VCO power consumption could roughly be

reduced by $7.7 \times$. The proposed technique is simulated for an integer-N PLL but a DTC in the reference clock path can allow fractional-N operation $[1,2]$.

\section{References}

[1] X. Gao, O. Burg, H. Wang, W. Wu, C.-T. Tu, K. Manetakis, F. Zhang, L. Tee, M. Yayla, S. Xiang, R. Tsang, and L. Lin, "A 2.7-to-4.3GHz, 0.16ps rms $^{-}$-Jitter, -246.8dB-FOM, Digital Fractional-N Sampling PLL in 28nm CMOS," in IEEE Int. Solid-State Circuits Conf. Dig. Tech. Pap., vol. 59, Jan. 2016, pp. 174-175.

[2] N. Markulic, K. Raczkowski, E. Martens, P. E. Paro Filho, B. Hershberg, P. Wambacq, and J. Craninckx, "A DTC-Based Subsampling PLL Capable of Self-Calibrated Fractional Synthesis and Two-Point Modulation," IEEE J. SolidState Circuits, vol. 51, no. 12, pp. 3078-3092, Dec. 2016.

[3] B. J. Thijssen, E. A. M. Klumperink, P. Quinlan, and B. Nauta, "Feedforward 
Phase Noise Cancellation Exploiting a Sub-Sampling Phase Detector," IEEE Trans. Circuits Syst. II Express Briefs, vol. 65, no. 11, pp. 1574-1578, Nov. 2018.

[4] B. J. Thijssen, A Phase Noise Cancelling Technique for On-Chip Clock Generation, Jun. 2016, MSc. Thesis.

[5] B. J. Thijssen, E. A. M. Klumperink, B. Nauta, and P. E. Quinlan, "Feedforward Phase Noise Compensation," United States Patent US10291214 B2, May 14, 2019.

[6] X. Gao, E. A. M. Klumperink, M. Bohsali, and B. Nauta, "A Low Noise SubSampling PLL in Which Divider Noise is Eliminated and PD/CP Noise is Not Multiplied by N ${ }^{2}$," IEEE J. Solid-State Circuits, vol. 44, no. 12, pp. 3253-3263, Dec. 2009.

[7] K. Sogo, A. Toya, and T. Kikkawa, "A Ring-VCO-Based Sub-Sampling PLL CMOS Circuit With with $-119 \mathrm{dBc} / \mathrm{Hz}$ Phase Noise and 0.73ps Jitter," in IEEE Eur. Solid State Circuits Conf., vol. 2, no. 1, Sep. 2012, pp. 253-256.

[8] X. Gao, E. Klumperink, and B. Nauta, "Sub-Sampling PLL Techniques," in IEEE Cust. Integr. Circuits Conf., vol. 2015-Novem, no. 2, Sep. 2015, pp. 1-8.

[9] F. M. Gardner, Phaselock Techniques. Jonh Wiley \& Sons, 2005.

[10] F. Aflatouni, M. Bagheri, and H. Hashemi, "Design Methodology and Architectures to Reduce the Semiconductor Laser Phase Noise Using Electrical Feedforward Schemes," IEEE Trans. Microw. Theory Tech., vol. 58, no. 11, pp. 32903303, Nov. 2010.

[11] S. Min, T. Copani, S. Kiaei, and B. Bakkaloglu, "A 90-nm CMOS 5-GHz RingOscillator PLL With Delay-Discriminator-Based Active Phase-Noise Cancellation," IEEE J. Solid-State Circuits, vol. 48, no. 5, pp. 1151-1160, May 2013.

[12] A. Imani and H. Hashemi, "An FBAR/CMOS Frequency/Phase Discriminator and Phase Noise Reduction System," IEEE Trans. Microw. Theory Tech., vol. 63, no. 5, pp. 1658-1665, May 2015.

[13] H. Wu, M. Mikhemar, D. Murphy, H. Darabi, and M.-C. F. Chang, "A BlockerTolerant Inductor-Less Wideband Receiver With Phase and Thermal Noise Cancellation," IEEE J. Solid-State Circuits, vol. 50, no. 12, pp. 2948-2964, Dec. 2015. 
[14] Z.-Z. Chen, Y. Li, Y.-C. Kuan, B. Hu, C.-H. Wong, and M.-C. F. Chang, "Digital PLL for Phase Noise Cancellation in Ring Oscillator-Based I/Q Receivers," in IEEE Symp. VLSI Circuits, Jun. 2016, pp. 1-2.

[15] C.-F. Liang and K.-J. Hsiao, "An Injection-Locked Ring PLL with Self-Aligned Injection Window," in IEEE Int. Solid-State Circuits Conf. Dig. Tech. Pap., vol. 42, no. 7, Feb. 2011, pp. 90-92.

[16] S.-Y. Cho, S. Kim, M.-S. Choo, J. Lee, H.-G. Ko, S. Jang, S.-H. Chu, W. Bae, Y. Kim, and D.-K. Jeong, "A 5-GHz Subharmonically Injection-Locked AllDigital PLL with Complementary Switched Injection," in IEEE Eur. Solid State Circuits Conf., Sep. 2015, pp. 384-387.

[17] S. Kim, H.-G. Ko, S.-Y. Cho, J. Lee, S. Shin, M.-S. Choo, H. Chi, and D.-K. Jeong, "A 2.5GHz Injection-Locked ADPLL with $197 \mathrm{fs}_{\mathrm{rms}}$ Integrated Jitter and $-65 \mathrm{dBc}$ Reference Spur Using Time-Division Dual Calibration," in IEEE Int. Solid-State Circuits Conf. Dig. Tech. Pap., vol. 60, Feb. 2017, pp. 494-495.

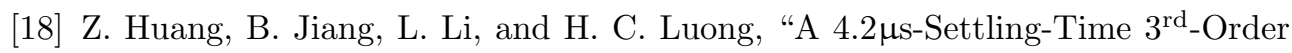
2.1GHz Phase-Noise-Rejection PLL Using a Cascaded Time-Amplified ClockSkew Sub-Sampling DLL," in IEEE Int. Solid-State Circuits Conf. Dig. Tech. Pap., Jan. 2016, pp. 40-41.

[19] S. S. Nagam and P. R. Kinget, "A -236.3dB FoM Sub-Sampling Low-Jitter Supply-Robust Ring-Oscillator PLL for Clocking Applications with FeedForward Noise-Cancellation," in IEEE Cust. Integr. Circuits Conf., vol. 2017April, Apr. 2017, pp. 1-4.

[20] S. Levantino, L. Collamati, C. Samori, and A. L. Lacaita, "Folding of Phase Noise Spectra in Charge-Pump Phase-Locked Loops Induced by Frequency Division," IEEE Trans. Circuits Syst. II Express Briefs, vol. 57, no. 9, pp. 671-675, Sep. 2010.

[21] A. A. Abidi, "Phase Noise and Jitter in CMOS Ring Oscillators," IEEE J. SolidState Circuits, vol. 41, no. 8, pp. 1803-1816, Aug. 2006.

[22] A. Hajimiri, S. Limotyrakis, and T. H. Lee, "Jitter and Phase Noise in Ring Oscillators," IEEE J. Solid-State Circuits, vol. 34, no. 6, pp. 790-804, Jun. 1999.

[23] C. S. Vaucher, Architectures for RF Frequency Synthesizers. Boston: Kluwer Academic Publishers, 2003. 
[24] Y. He, Y.-H. Liu, T. Kuramochi, J. van den Heuvel, B. Busze, N. Markulic, C. Bachmann, and K. Philips, "A $673 \mu \mathrm{W}$ 1.8-to-2.5GHz Dividerless FractionalN Digital PLL with an Inherent Frequency-Capture Capability and a PhaseDithering Spur Mitigation for IoT Applications," in IEEE Int. Solid-State Circuits Conf. Dig. Tech. Pap., Feb. 2017, pp. 420-421. 
One worthwhile task carried to a

successful conclusion is better than

50 half-finished tasks.

Bertie Charles Forbes

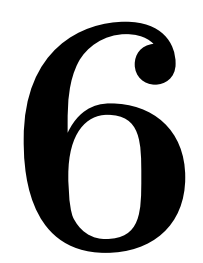

\section{Conclusions}

This chapter presents the conclusions of this dissertation. The main innovations of this work are listed in the Section Original Contributions. In addition, recommendations are given for future research.

\subsection{Conclusions}

Wireless connectivity is essential to enable the Internet-of-Things (IoT). The increasing number of devices challenges the requirements on the wireless specifications as well as the power consumption. This dissertation focuses on improving the wireless receiver selectivity and reducing the power consumption while maintaining low noise figure (NF) and good linearity. The target applications are $2.4 \mathrm{GHz}$ IoT standards as Bluetooth Low Energy (BLE) and IEEE802.15.4. Reducing the receiver power consumption will improve the battery lifetime, since it reduces the average and peak power consumption. This dissertation proposes analog finite impulse-response (FIR) filtering to improve the receiver selectivity and introduces several power optimizations across the receive chain - including a Windmill frequency divider architecture. Furthermore, a feedforward phase noise cancellation architecture is suggested to reduce phase-locked loop (PLL) phase noise at little additional power consumption.

Analog FIR filters can be implemented using a simple architecture. The output is sampled and can be at a low sample rate, because the analog FIR circuit filters the unwanted spectral components substantially. Analog FIR filters with symmetric 
coefficients introduce a pure time delay and have therefore a linear phase response, which does not phase distort the desired signal. The inherent sinc filtering of the filter aliases relaxes the requirements of a prefilter and allows a low FIR coefficient update rate. Analog FIR circuits have been investigated prior to this work, but not as channel selection filters for an IoT application, which requires low power consumption as well as steep and strong filtering. (Chapter 2).

An analog FIR filter architecture that uses two 10bit pseudo-differential transconductance digital-to-analog converters $\left(\mathrm{g}_{\mathrm{m}} \mathrm{DACs}\right)$ and four integration capacitors is proposed. It implements a 128tap FIR. Several performance impairments are analyzed, including the $g_{m} \mathrm{DAC}$ output impedance and mismatch. The parasitic $\mathrm{g}_{\mathrm{m}} \mathrm{DAC}$ output impedance is compensated in the filter coefficients. The effect of transconductor mismatch is reduced by partially thermometer coding the $\mathrm{g}_{\mathrm{m}} \mathrm{DAC}$. The filter is designed and fabricated in a $22 \mathrm{~nm}$ fully-depleted silicon-on-insulator (FD-SOI) process. Its bandwidth is accurately tunable from 0.06 to $3.4 \mathrm{MHz}$. The filter combines steep and strong filtering $\left(f_{-60 \mathrm{~dB}} / f_{-3 \mathrm{~dB}}=3.8\right)$ with low power consumption $(92 \mu \mathrm{W})$ and low input-referred noise (IRN) $(12 \mathrm{nV} / \sqrt{\mathrm{Hz}})$. The low power consumption is accomplished by: the single switchable transconductor design, a low filter update rate of $64 \mathrm{MHz}$ and $5 \mathrm{bit}$ thermometer coding of the $\mathrm{g}_{\mathrm{m}} \mathrm{DAC}$. The blocker $1 \mathrm{~dB}$ compression point $\left(\mathrm{B}_{1 \mathrm{~dB}}\right)$ is $-3.4 \mathrm{dBm}$ and a consistent attenuation of $>60 \mathrm{~dB}$ is obtained for unwanted signals up to $-4 \mathrm{dBm}$. (Chapter 3 ).

A zero-IF receiver architecture is proposed with power optimizations across the receive chain. It employs a push-pull inductive degenerated low-noise transconductance amplifier (LNTA) which was optimized using brute-force search on a simplified model. The LNTA combines a low NF with low power consumption. The LNTA output current is downconverted by a passive mixer and converted to voltage using a transimpedance amplifier (TIA). This TIA is used as prefilter to reduce the filter aliases of the subsequent analog FIR channel filter. The combined inherent attenuation of analog FIR filter and TIA prefilter result in $80 \mathrm{~dB}$ attenuation of the filter aliases, while allowing a reduction in the FIR coefficient update rate to $16 \mathrm{MHz}$ which further reduces the analog FIR filter power consumption. A Windmill 25\% duty-cycle frequency divider architecture is proposed. It reduces the power dissipation by almost $2 \times$ while reducing the phase noise by $2 \mathrm{~dB}$ or more compared with prior art designs as verified by simulations. The receiver front-end was designed and fabricated in a $22 \mathrm{~nm}$ FD-SOI process. It has more than $63 \mathrm{~dB}$ adjacent-channel rejection (ACR) at three channels offset or more, a competitive $5.5 \mathrm{~dB} \mathrm{NF}$ and $-7.5 \mathrm{dBm}$ inputreferred third-order intercept point (IIP3) at maximum gain — while consuming only $370 \mu \mathrm{W}$. (Chapter 4).

Improvements on the receiver filtering specifications bring more stringent demands on the local oscillator (LO) phase noise performance. A feedforward phase noise cancellation structure employing a sub-sampling phase detector (SSPD) is proposed to 
reduce the phase noise without a (significant) increase in the power consumption of the LO generation. This phase noise cancellation structure can be implemented in a sub-sampling phase-locked loop (SSPLL) and the inherent SSPD can be reused. Furthermore, spurs that are introduced in the PLL loop are reduced as well. Analytical expressions are derived and verified by simulations to qualify the performance improvement. The phase noise cancellation technique increases the phase noise reduction bandwidth to $f_{\text {ref }} / 3.6$. The phase noise at $f_{r e f} / 10$ is reduced by $10 \mathrm{~dB}$ and the total rms jitter of the PLL is improved by $7.2 \mathrm{~dB}$ using phase noise cancellation. (Chapter 5).

Several techniques are proposed and verified that allow to significantly improve the performance of IoT receivers while reducing their power consumption - granting improved selectivity along with increased battery life-time. These innovations help to pave the way to an all connected world. Not just connecting everyone, but connecting everything.

\subsection{Original Contributions}

Several original contributions are proposed in this dissertation:

- The inverter-transconductor capacitor analog FIR filter architecture to provide minimal input referred noise for a given power consumption.

- A transconductor analog FIR filter with dynamically switched coefficients in combination with a continuous time common-mode feedback, resulting in a stable transconductor output common mode voltage.

- Low-update rate in the analog FIR filter in combination with a simple prefilter to reduce power consumption.

- Partially thermometer bit analog FIR coefficients for;

- reduced power consumption of the analog FIR DAC;

- reduced coefficient mismatch effect on the filter transfer.

- The analysis of the following practical implementation impairments of analog FIR filters;

o the effect of the $g_{m} \mathrm{DAC}$ output conductance on the filter transfer and its compensation;

○ the effect of parasitic $g_{m}$ DAC output capacitance on the filter transfer;

○ the effect of analog FIR coefficient mismatch on the filter stopband attenuation for binary and (partially) thermometer coded designs. 
- A receiver architecture with analog FIR channel selection filter suitable for low power IoT applications.

- The Windmill 25\% duty-cycle frequency divider architecture that employs only a single gate between input clock and four $25 \%$ duty-cycle output phases.

- The feedforward phase noise cancellation architecture employing an SSPD and analytical analysis of its performance;

○ as a stand-alone technique;

$\circ$ when reusing the SSPD in an SSPLL.

\subsection{Recommendations}

After the considerable improvement in power consumption and ACR in the receive chain, new bottlenecks arise. The main recommendations for future research are shortly discussed.

Since the proposed receiver front-end's power consumption is $2 \times$ lower than a state-of-the-art $L C$-based PLL, the next challenge is to further reduce the power consumption of the PLL. However, it is important to note that this should not come at an increase of phase noise, because of the very strong ACR performance.

The proposed receiver front-end has very high linearity compared to other state-ofthe-art $2.4 \mathrm{GHz}$ IoT receivers. However, it is desirable to improve the linearity further — without increasing the power consumption - to fully benefit from the increased filtering performance.

The proposed analog FIR filter approach has shown its merits for IoT receivers. It is highly selective, low power, very flexible and is very suitable to implement in new technology nodes that have reduced digital power consumption and supply headroom. The concept has great potential and is not limited to low power receivers. It is therefore important to continue research on analog FIR implementations for other applications. Analog FIR circuits could shape the (analog) signal processing future. 


\section{List of Publications}

\section{Peer-Reviewed}

[1] B. J. Thijssen, E. A. M. Klumperink, P. Quinlan, and B. Nauta, " $2.4 \mathrm{GHz}$ Highly-Selective IoT Receiver Front-End with Power Optimized LNTA, Analog FIR Filter and Frequency Divider Architecture," IEEE J. Solid-State Circuits, 2020, (Early Access).

[2] B. J. Thijssen, E. A. M. Klumperink, P. Quinlan, and B. Nauta, "Low-Power Highly-Selective Channel Filtering Using a Transconductor-Capacitor Analog FIR," IEEE J. Solid-State Circuits, vol. 55, no. 7, pp. 1785-1795, 2020.

[3] B. J. Thijssen, E. A. M. Klumperink, P. Quinlan, and B. Nauta, "A $370 \mu W$ 5.5dB-NF BLE/BT5.0/IEEE 802.15.4-Compliant Receiver with >63dB Adjacent Channel Rejection at $>2$ Channels Offset in 22nm FDSOI," in IEEE Int. Solid-State Circuits Conf. Dig. Tech. Pap., vol. 63, Feb. 2020, pp. 467-468.

[4] B. J. Thijssen, E. A. M. Klumperink, P. Quinlan, and B. Nauta, "A 0.06-3.4MHz 92- $\mu \mathrm{W}$ Analog FIR Channel Selection Filter With Very Sharp Transition Band for IoT Receivers," IEEE Solid-State Circuits Lett., vol. 2, no. 9, pp. 171-174, 2019.

[5] B. J. Thijssen, E. A. M. Klumperink, P. Quinlan, and B. Nauta, "A 0.06-3.4$\mathrm{MHz}$ 92- $\mu \mathrm{W}$ Analog FIR Channel Selection Filter With Very Sharp Transition Band for IoT Receivers," in IEEE Eur. Solid-State Circuits Conf., vol. 45, Sep. 2019. Co-publication with [4].

[6] B. J. Thijssen, E. A. M. Klumperink, P. Quinlan, and B. Nauta, "Feedforward Phase Noise Cancellation Exploiting a Sub-Sampling Phase Detector," IEEE Trans. Circuits Syst. II Express Briefs, vol. 65, no. 11, pp. 1574-1578, Nov. 2018. 


\section{Patents}

[1] B. J. Thijssen, E. A. M. Klumperink, B. Nauta, and P. E. Quinlan, "Feedforward Phase Noise Compensation," United States Patent US10291214 B2, May $14,2019$.

[2] B. J. Thijssen, E. A. M. Klumperink, P. E. Quinlan, and B. Nauta, "Systems and Methods for Analog Finite Impulse Response Filters," United States Patent US20200321943 A1, October 8, 2020.

\section{Other}

[1] B. J. Thijssen, E. A. M. Klumperink, B. Nauta, and P. Quinlan, interviewed by Paul van Gerven, "An IoT design Don Quixote wouldn't be able to resist," as part of "ISSCC2020: what did the LowLands come up with this year", Bits\&Chips, May 1, 2020. 


\section{Acronyms}

ACR adjacent-channel rejection

ADC analog-to-digital converter

ADPLL all-digital phase-locked loop

AFIR analog finite-impulse-response

AWG arbitrary waveform generator

$\mathbf{B}_{\mathbf{1 d B}}$ blocker 1dB compression point

BBD bucket-brigade device

BCCD bulk channel charge coupled device

BER bit-error-rate

BLE Bluetooth Low Energy

BNF blocker noise figure

BPF bandpass filter

CCD charge coupled device

CID charge injection device

CMFB common-mode feedback

CMOS complementary metal-oxide-semiconductor

DAC digital-to-analog converter

DC direct current, but also used to refer to the zero-frequency of a signal

DDFS direct-digital frequency systhesis 
DFT discrete Fourier transform

DTC digital-to-time converter

ECG electrocardiogram

ESD electrostatic discharge

FD-SOI fully-depleted silicon-on-insulator

FET field-effect transistor

FIR finite impulse-response

FoM figure-of-merit

$\mathbf{g}_{\mathrm{m}} \mathrm{DAC}$ transconductance digital-to-analog converter

GFSK Gaussian frequency-shift-keying

HS-OQPSK half-sine shaped offset quadrature phase shift keying

I/Q in-phase/quadrature-phase

IDT interdigital transducer

IF intermediate frequency

IIP3 input-referred third-order intercept point

IIR infinite-impulse response

IM3 third-order modulation

IoE Internet-of-Everything

IoT Internet-of-Things

IRN input-referred noise

ISM industrial, scientific and medical

LNA low-noise amplifier

LNTA low-noise transconductance amplifier

LO local oscillator

LPF low-pass filter

LSB least-significant bit 
MSB most-significant bit

MSK minimum-shift keying

NF noise figure

NFET n-channel field-effect transistor

OIP3 output-referred third-order intercept point

OOB out-of-band

$\mathbf{O P}_{1 \mathrm{~dB}}$ output-referred $1 \mathrm{~dB}$ compression point

PCB printed circuit board

PCCD peristaltic charge coupled device

PFD phase-frequency detector

PFET p-channel field-effect transistor

PLL phase-locked loop

PRBS pseudo-random bit-stream

PVT process voltage temperature

QFN quad-flad no-leads

$\mathbf{R F}$ radio frequency

rms root mean square

RX receiver

SAR successive-approximation register

SAW surface acoustic wave

SCT surface charge transistor

SFDR spurious-free dynamic range

SNR signal-to-noise ratio

SSDLL sub-sampling delay-locked loop

SSPD sub-sampling phase detector

SSPLL sub-sampling phase-locked loop 
SSPNC-PLL sub-sampling phase noise cancellation phase-locked loop

TIA transimpedance amplifier

$\mathbf{V} \rightarrow \mathbf{I}$ voltage-to-current

$\mathbf{V} \rightarrow \mathbf{Q}$ voltage-to-charge

VCO voltage-controlled oscillator

ZIF zero insertion force 


\section{About the Author}

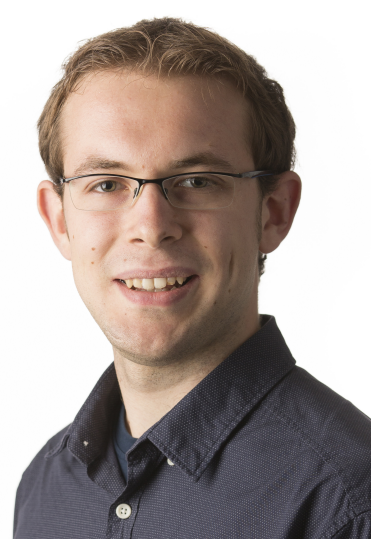

Bart J. Thijssen was born in Ede, The Netherlands, in 1992. He obtained the B.Sc. degree (cum laude) in advanced technology and M.Sc. degree (cum laude) in electrical engineering from the University of Twente, Enschede, The Netherlands, in 2014 and 2016, respectively.

From 2016 to 2020, he worked as a PhD candidate at the ICD-Group at the University of Twente, which was concluded with this dissertation.

Bart Thijssen has authored six technical journal and conference papers and holds two patents. He is recipient of the "Analog Devices Outstanding Student Designer Award". 
